R. L. Victoria Pöhls | Mariane Utudji (eds.)

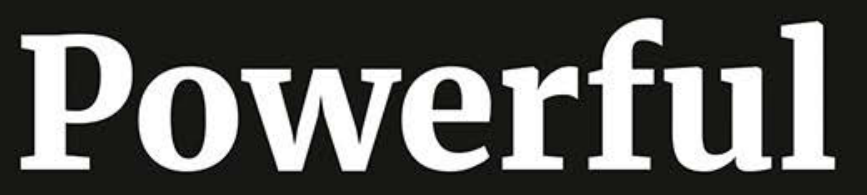

Drese How Textual Features Impact Readers

$\diamond$

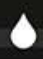

[transcript] Lettre 
R. L. Victoria Pöhls, Mariane Utudji (eds.)

Powerful Prose 
R. L. Victoria Pöhls works as a researcher at the Max Planck Institute for Empirical Aesthetics (Frankfurt). Her interest in studying literature with both hermeneutical and empirical methods evolved during graduate studies in cognitive science (University College Dublin) and literature, linguistics, and philosophy (Universität Hamburg). To foster interdisciplinary work at the frontiers of these disciplines, she cofounded the Powerful Literary Fiction Texts-Network in 2019. Her research focuses on comparative, empirical, and cognitive approaches to literature and is especially concerned with the portrayal of minorities.

Mariane Utudji has completed a PhD thesis in English studies and translatology at the Sorbonne Nouvelle University (Paris), a work which investigates Salman Rushdie's highly valued prose style and shows how the reading experience it provides can be retained or recreated in French. Her approach to literary texts thus combines stylistics, applied linguistics and translation studies, and she is getting more and more interested in cognitive linguistics. She cofounded the Powerful Literary Fiction Texts- Network in 2019. 
R. L. Victoria Pöhls, Mariane Utudji (eds.)

\section{Powerful Prose}

How Textual Features Impact Readers 
We are very grateful to the Max Planck Institute for Empirical Aesthetics, and to Co-Director Winfried Menninghaus in particular, for funding this open-access publication.

\section{Bibliographic information published by the Deutsche Nationalbibliothek}

The Deutsche Nationalbibliothek lists this publication in the Deutsche Nationalbibliografie; detailed bibliographic data are available in the Internet at http:// dnb.d-nb.de

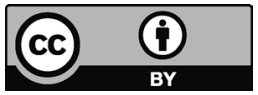

This work is licensed under the Creative Commons Attribution 4.0 (BY) license, which means that the text may be remixed, transformed and built upon and be copied and redistributed in any medium or format even commercially, provided credit is given to the author. For details go to http://creativecommons.org/licenses/by/4.o/

Creative Commons license terms for re-use do not apply to any content (such as graphs, figures, photos, excerpts, etc.) not original to the Open Access publication and further permission may be required from the rights holder. The obligation to research and clear permission lies solely with the party re-using the material.

\section{First published in 2021 by transcript Verlag, Bielefeld \\ () R. L. Victoria Pöhls, Mariane Utudji (eds.)}

Cover layout: Claudia Schille, R. L. Victoria Pöhls

Cover illustration: Claudia Schille

Printed by Majuskel Medienproduktion $\mathrm{GmbH}$, Wetzlar

Print-ISBN 978-3-8376-5880-4

PDF-ISBN 978-3-8394-5880-8

https://doi.org/10.14361/9783839458808

ISSN of series: $2703-013 \mathrm{X}$

eISSN of series: $2703-0148$

Printed on permanent acid-free text paper. 


\section{Contents}

Acknowledgments .............................................. 9

\section{Experiencing Powerful Prose}

R. L. Victoria Pöhls, Max Planck Institute for Empirical Aesthetics \& Goethe

Universität Frankfurt (Germany);

Mariane Utudji, Sorbonne Nouvelle University (France)........................ 11

\section{Part I}

Emotional Experiences: Textual Features Eliciting Positive, Negative or Mixed Emotions

A Psycho-Biological Approach to Suspense and Horror:

Triggers of Emotion in a Passage from Lewis's The Monk

Peter Wenzel, RWTH Aachen University (Germany) .............................. 25

Repeated Pleasure: Reading the Threesome Ménage Romance as Digital Literature

Elina Valovirta, University of Turku (Finland) .................................. 45

Negating the Human, Narrating a World Without Us

Mahlu Mertens, Ghent University (Belgium) .................................... 63

Refiguring Reader-Response:

Experience and Interpretation in J.G. Ballard's Crash

Ciarán Kavanagh, University College Cork (Ireland) 77 


\section{Part II}

Coming to the Fore: The Subtle Influence of Rhythm, Sounds, and Sensory Representations

Lives and Deaths of Gatsby:

A Semantic Reading of a Key Passage in a Powerful Text

Christine Chollier, University of Reims (France).

Introducing Jane: The Power of the Opening

Kimberley Pager-McClymont, University of Huddersfield (UK)

111

Performing Rhythm Through Enunciation: Prose Versus Poetry About Lighthouses

Maryvonne Boisseau, Université de Strasbourg (France)

The Pictorial Paradigm of La Vallée:

A Text-Image Reading of the Incipit of The Mysteries of Udolpho

Alice Labourg, Rennes-II University (France) 145

\section{Part III}

Readers, Characters, Authors:

Relations Formed by Textual Features

The Nature of the Agonistic in a Pragmatics of Fiction

Tahir Wood, University of the Western Cape (South Africa).

The Relevance of Turning a Page: Monotony and Complexity in §25 of David Foster Wallace's The Pale King

Sixta Quassdorf, University of St. Gallen (Switzerland)....

The Language of Engagement and the Projection of Storyworld Possible Selves in Roberto Bolaño's The Savage Detectives 
"Smuggling in Accidental Poetry":

Cognitive and Stylistic Strategies of a Stammering Teen

in David Mitchell's Black Swan Green

Constance Robert-Murail, Université Gustave Eiffel - Paris-Est (France)........... 231

Contributors ................................................... 249

Editors............................................................. 253

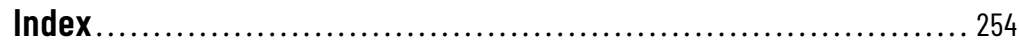





\section{Acknowledgments}

In July 2019, together with Craig Jordan-Baker, we organised an international conference at the University of Brighton entitled Powerful Literary Fiction Texts. This conference sought to promote the exploration of prose fiction texts via an approach that combined reading aloud, close reading and the study of a text's potential effects on readers; in other words, our focus was the reading experience provided by the text. Participants chose short passages to read aloud to the audience before explaining why and how these texts achieved such a powerful impression on the reader. Our aim was to situate such prose excerpts at the centre of attention and to use them as the concrete starting point of any subsequent literary commentary, thus enabling both the 'contributor-reader' and the audience to experience and comprehend them thoroughly.

As this approach proved quite fruitful, we decided not only to organise further Powerful Literary Fiction Texts conferences, with the second one to take place in 2020 in Paris, but also to collect and publish a selection of papers from the first event. First and foremost, then, we would like to thank everyone who made these conferences possible and took part in the convivial atmosphere and discussions. We are especially grateful not only to the four keynote speakers - Michael Toolan and Nigel McLoughlin in 2019, and Sandrine Sorlin and Raymond A. Mar in 2020 - but to all the presenters and guests who shared their thoughts, considerations and criticisms, thus contributing not only to the conversations, but also to the chapters of this book.

We are also thankful to the University of Brighton (UK), the Université Sorbonne Nouvelle (France), and the Poetics and Linguistics Association (PALA) for their substantial financial support of the two conferences, and to the Max Planck Institute for Empirical Aesthetics (Germany) for its organisational support, especially Felix Bernoully and Sarah Brendecke from the graphics department. 
We are very grateful to the Max Planck Institute for Empirical Aesthetics, and to Co-Director Winfried Menninghaus in particular, for funding this open-access publication. We should mention that in the course of preparing this volume, Daria Rashkina and Nico Imhof were of reliable und unfailing help with the nuts and bolts of the publishing process, as were Maja Fricke and Annette Dyck-Henning when launching it. The first impression of this anthology owes much to the compelling cover design by Claudia Schiller, who we also wish to thank.

Lastly, we would like to give our thanks to the editorial team at Transcript Verlag, for their support and confidence in this book. 


\section{Experiencing Powerful Prose}

R. L. Victoria Pöhls, Max Planck Institute for Empirical Aesthetics \& Goethe Universität Frankfurt (Germany); Mariane Utudji, Sorbonne Nouvelle University (France)

Storytelling has been described as "an act, an event, one that has the power to produce change, and first and foremost to produce change between narrator and narratee" (Chambers 1984: 74). While this may be true for all kinds of narratives, literary prose seems especially likely to provide both emotional and cognitive pleasure and thus to be perceived as 'powerful'. But what exactly makes readers describe a text with this still somehow mysterious descriptor, 'powerful'?

This volume collects answers to this question from literary scholars, linguists, and empirical reader-response researchers. By elucidating the effects on readers as well as their responses which convincingly describe such a reading experience, we interrogate the widely used term 'powerful', providing insight into the understudied potentialities of prose texts. We ask how an author's stylistic choices inform a text's embodiment and interpretation by a reader in the act of reading (aloud). And we attempt to sketch out how an analysis of a given text moves from introspection to the gathering of objective data to the generation of an interpretation on the basis of the accumulated data. While still subjective, such an interpretation is nevertheless informed enough to allow for hypotheses about other readers' experiences that are generalizable and can be tested empirically.

\section{Authorial Style}

The stylistic value and significance of any literary text are located in what linguist Michael Halliday calls "the ideational function of language", namely, the way the author's language organises and conveys the cognitive realities of real or fictitious experience (Leech/Short 2007: 26). According to the lin- 
guist's functional model of language, "all linguistic choices are meaningful, and all linguistic choices are stylistic" (ibid.: 27). As a consequence, only linguistic analysis "may prompt, direct, and shape [the reader's intuition] into an understanding" (ibid.: 4). To comprehend the stylistic value of a fiction text, one thus needs to focus on the author's "choices of language which do not involve changes in the fictional universe" (ibid.: 29). In other words, one ought to comprehend how the author has worked "in language", "as text-maker", rather than focus on the diegesis ${ }^{1}$ that he or she, "as a fiction-maker", has created "through language" (ibid.: 30). Roman Jakobson's theory of "[w] hat makes a verbal message a work of art" (Jakobson 1960: 350) serves as a useful guide. Stylistic value can be understood as inhering in "the poetic function of language", which Jakobson defined as the "dominant, determining function of verbal art." It is this function, which promotes "the palpability of signs" and deepens "the fundamental dichotomy of signs and objects" (ibid.: 356), that must be identifed and investigated, rather than the "referential" or "denotative" function (ibid.: 353) of language in a fiction text.

The interdependence between the impact created by a powerful text and the language it is made of can be demonstrated through stylistic and linguistic analysis. As French linguist Sandrine Sorlin puts it, stylistics aim to "figure out how a given utterance (written or oral) uses the potentialities of language to fulfil a given purpose in a specific context of production and reception" (Sorlin, 2014: 12, our translation). ${ }^{2}$ The reading experience provided by a given text is due mainly to the linguistic choices consciously or unconsciously made by its author. Sébastien Salbayre and Nathalie Vincent-Arnaud therefore maintain that any utterance should be comprehended as "an actual aggregate of signs, of clues" that proceeds from the utterer's own mental operations (Salbayre/Vincent-Arnaud 2006: 19, our translation) ${ }^{3}$ because as linguist Antoine Culioli has shown, any utterance is necessarily "modulated" by its utterer (Culioli $1999: 47){ }^{4}$

The word diegesis refers to the fictional setting, events, and characters that make up a work of fiction, the text world.

"[L]a stylistique vise à saisir la façon dont un discours (écrit ou oral) utilise les potentialités de la langue à des fins spécifiques dans un contexte particulier de production et de réception" (Sorlin 2014: 12).

"[L]e discours apparaît comme un véritable agrégat de signes, d'indices de ce qui se trame, se tisse dans l'intériorité du sujet parlant selon une stratégie mentale qui lui est propre" (Salbayre \& Vincent-Arnaud 2006: 19)

4 "[I]I n'existe pas d'énoncé qui ne soit modulé" (Culioli 1999: 47) 


\section{Oral Performance and Reading Aloud}

The manner in which a piece of writing will be orally performed is informed by the reader's interpretation and understanding of the text, which partly determines the effects the literary passage is likely to produce on that same reader. Although all of this depends to an extent on readers' subjectivity, it also results from the text itself, namely, the textual elements it is composed of and the way these are combined, that is to say, the stylistic value and significance of the text. Interestingly, this has already been proven empirically for poetry (see Menninghaus et al. 2018) - objective acoustic measurements of both professional and non-professional recordings showed that poems feature distinct and text-driven pitch and duration contours and that these are correlated with subjective perceptions of melodiousness by listeners - and it can be hypothesised that similar effects may also be found for prose.

Historically, oral storytelling has been a valuable means of expression and transmission of skills, knowledge, and culture from generation to generation, and this tradition is still alive today in western civilisation, where it has taken new forms, including the reading aloud of literary texts in various kinds of media, such as audiobooks and films. This may well contribute to a phenomenon we have all experienced while reading enjoyable literary texts that deeply move us: the urge to read such passages aloud, as if they were poems or songs meant to be embodied through the human voice - our voice being a potential vehicle of energy and emotion and the best means at our disposal to release the full power of a prose text by transforming into a sensuous material. Not only does such performance enable the reader, and possibly an audience, to revel in the physicality of the selected texts, it can actually be part of the stylistic analysis of a literary excerpt, being an effective way to highlight the specific linguistic components and workings of the text.

\section{From Subjective Interpretations to Hypotheses of Reader Response}

The commitment to "show precisely how texts produce meanings" (Bell et al. 2021) lies at the core of various linguistic theories (see Sorlin 2014: 12-13). One could add to it the commitment to explain accurately why texts stir emotional responses and how they generate other effects connected to the reading, e.g., effects on (strengths of) propositional beliefs, planned action, or changed self- 
understanding. These pragmatic methods strive for rigorous textual analysis and are the only way to avoid a haphazard approach that, because it is not anchored in the linguistic material of the text, is prone to lead to irrelevant interpretations (see Gardes Tamine 2010: 6).

While such an analysis relies on "objective data" that can be recreated by other researchers, it provides "a (necessarily subjective) interpretation" (Sorlin 2014: 13 , our translation $)^{5}$ as the effects attributed to the text are in most cases based on introspection and a subjective reading experience. There is no need, however, to stop at this point. Literary studies which take texts seriously as aesthetical and cultural objects implicitly or explicitly make claims beyond individual experience. Even when not working in an empirical manner, the work of linguists and literary scholars can be more than an entry in a personal reading diary. Taking introspection and the individual experience as a starting point, how can stylistic analyses and hermeneutic interpretations of literary texts advance informed hypotheses about the interaction between textual features and a readerly experience which is not the researcher's own?

Stylistic or hermeneutic practices regularly acknowledge the ambiguity specific to literary fiction and embrace the possibility of consequently varying interpretations, pointing to the ways different readers might construct differing text worlds (see Werth 1999; Gavins 2007) or favour one line of interpretation over another. Even if an analysis only highlights one particular reading or strand of interpretation, it is generally presented as one of many possible interpretations and reading experiences instead of as the only true description. Contemplating varying textual interpretations, it is possible to arrive at informed hypotheses regarding the connection between differing interpretations and the diversity of readers: the assumed 'model reader' multiplies when assumptions about the reading experience consider how experience, knowledge, psychological make-up, cultural background, or group affiliation might result in varied experiences. Still, the nature of these imagined readers remains idealised; when making hypotheses about the connection between readerly features and experiences, one of course has to extrapolate which features of one's own reader persona are responsible for the effects a given text

"[C]e que toutes les analyses stylistiques ont en commun, c'est la recherche d'une certaine rigueur dans l'analyse textuelle. En effet, en analysant les signes que fournit le texte, la stylistique s'appuie sur des données "objectives" pour proposer une interprétation (nécessairement subjective)" (Sorlin 2014: 13) 
has had on oneself, and such self-reflection always remains sensitive to error and bias.

A similar type of self-reflection may also pertain to the reading situation: (stylistic) analysis - which in most cases is a long process involving multiple re-readings, facilitated by (digitally enhanced or manual) tools for counting or contrasting certain features, one that draws upon earlier research and background literature - is all in all a reading and interpretation situation quite unlike most experiences with literary fiction. Employing such a self-reflective step in meticulous stylistic analyses or interpretations that draw heavily on non-obvious intertextual references is an advancement in scholarship. It allows us to hypothesise on the prominence and noticeability of stylistic features and determine which features are so foregrounded, prominent, or remarkable that they will not fail to have an effect on most readers who are sufficiently attentive, by contrast with other features that might escape notice on first reading, or will only be apparent to a trained eye, or require considerable background or genre knowledge.

We believe that literary linguists and literary scholars are ideally equipped for these kinds of self-reflective explorations (which does not mean they are infallible): for us, too, there is a first reading, we can reflect on interpretation skills only acquired through our studies and insights gained merely by using sources or tools after our first impression has already been made.

Although scholars and researchers cannot from their armchairs determine which interpretations and effects will be educed amongst a general readership, we can and do assume that certain understandings of texts rely on commonly held semantic interpretations or widespread genre knowledge, or that certain stylistic features ordinarily evoke certain feelings and can thus be hypothesised to be shared by many. Such triangulations which take insights from other disciplines into account can partly "mitigate the singularity of subjectivity by generalising it" (Stockwell 2021: 176).

A successful analysis thus clarifies the textual cues our own reading experiences are built upon, and can be understood as advancing informed hypotheses. These ideally communicate precisely which textual features are believed to elicit which response in which reader under which circumstances and do so in a falsifiable, testable way. 


\section{From Hypotheses to (Empirical) Testing}

But which quest for knowledge stops at the level of hypothesising? How can these hypotheses be evaluated or assessed? Stylisticians and literary scholars have traditionally 'tested' their findings on colleagues and peers, who are thus imagined as 'other readers'. Do these readers believe the hypotheses put forward to be sound, or do they challenge, e.g., the advanced understanding of the emotional effect a piece of writing most likely elicits in readers? Which part of the argumentation do they disagree with and why?

Such scholarly exchanges are not 'tests' in the scientific sense, of course, and while they have led to valuable findings, they are nonetheless limited. They do not investigate real-life contexts and real-life readers, apart from the few directly involved in the exchange. This is not necessarily a shortcoming. If we are interested in a literary work's possible meanings and impact, then it is worth taking account of any sound analysis by an individual reader that elucidates why the work is powerful for him or her, given that aspects so far hidden to us (or all other readers) might thus be revealed, enriching our understanding of the literary work in question. ${ }^{6}$

If on the other hand we are interested in speculating about readers' reactions and hypothesising about the way texts are processed and represented in their minds - which is not only at the heart of cognitive linguistics, stylistics, and poetics, but is also the centre of attention of empirical aesthetics and literary studies - then one can understand empirical methods as "a natural extension" of these perspectives on reading and the mind (Bell et al. 2021: 5). While most literary scholars have yet to engage with it, empirical research can be very fruitful: long-standing theories, including Roman Jakobson's theory of poetic parallelism, have been refined, verified, and sometimes even proved wrong as a result of empirical and experimental research (see Menninghaus 2021). This suggests that when followed by an empirical study, the stylistic analysis of and ensuing hypotheses about a text's appeal, emotional effects,

Often the scope or aim of an analysis is not made explicit because the steps of selfreflection are not taken or at least not reported on. If that is the case, researchers cannot be sure whether an interpretation aims to explain textual mechanisms most likely to influence a general or specific audience, or is solely putting forward one possible idiosyncratic interpretation, showing the text in a light so far unobserved, but uninterested in the minds of other beholders. As argued above, we believe it is important to make this explicit. 
or influence can address questions that lie beyond the reach of 'traditional' linguistics or literary studies, while making use of the vast knowledge accrued in the 'classic' fields of stylistics, linguistics, narratology, etc. While some of this volume's contributors are already doing empirical reader-response research, we expect that most such work will be carried out in "agenda- and expertisespecific cooperations" (Menninghaus 2021: 127) and interdisciplinary teams.

However, only if engaging with methodologies borrowed or adapted from psychology, sociology, and cognitive science achieves greater acceptance within research communities working non-empirically, will such results increasingly be of interest to a broader community apart from those working in the field of reader-response research or empirical literary studies. While the methodological divide has been pointed to as the main reason why results from empirical studies are not more broadly discussed within adjacent fields, another reason also seems plausible to us. We advance the hypothesis that the inclination to engage unfamiliar (empirical) methodologies and modes of research will increase if the research questions they address investigate and challenge concepts or theories more in line with traditional scholars' interests. While positive examples provided by interdisciplinary teams or researchers with a multidisciplinary background can already be found, stylisticians, cognitive linguists, and literary scholars could speed up the process of generating significant findings by offering rigorous, retrievable, and replicable analyses of their close readings (see Simpson 2014:3-4) which inform well-grounded hypotheses about the cognitive and emotional effects of (certain works of) literature on (certain) readers in (certain) reading situations. This approach allows us to treat individual works attentively, as the singular pieces of art they are most often experienced as, without having to consider them as either generic or exemplary of a certain genre or period, or by contrast, having to focus exclusively on reactions to very specific textual features. ${ }^{7}$ Empirical work starting off from those premises, based on hypotheses so derived, will, on the other hand, be guarded from the familiar criticism that they do not contribute to the scholarly debate or only investigate areas of minor interest. research methodologies dealing with literature as stimulus material, see Stockwell (2021) and Stockwell/Whiteley (2014). 
The thirteen articles gathered in this volume investigate a variety of textual, stylistic as well as readerly, psychological features responsible for the effects powerful prose texts may elicit in readers. Such close readings, as demonstrated by the articles collected here, can identify the textual features responsible for the text's impact on readers and ultimately tackle the underlying question: if all linguistic choices are potentially meaningful, which ones are powerful and thus responsible for the audience's reactions to a given text?

Part I, "Emotional Experiences", explores positive, negative, and mixed emotional reactions as significant contribution to an evaluation of 'powerfulness'. Special attention is paid in these chapters to the interconnection of style features with type, strength, and duration of emotional effects and the possibility that different (types of) readers might react very differently to the same literary text.

In "A Psycho-Biological Approach to Suspense and Horror: Triggers of Emotion in a Passage from Lewis's The Monk", Peter Wenzel emphasises the psycho- and neurobiological aspects of the named emotions, but also reflects on the historical and cultural causes of their effects. He provides preliminary empirical evidence supporting his analysis of powerful devices for triggering these suspense and horror in readers. At the same time, his investigation gives an insight into cultural circumstances and stylistic features of this classic Gothic novel that may well explain the difference in the experiences had by contemporary readers and the book's original readership.

Elina Valovirta's focus on an often-overlooked genre demonstrates that literature does not always have to rely on a build-up of suspense or engage its readers in acts of gap-filling to create a sense of excitement or involvement. In her chapter, "Repeated Pleasure: Reading the Threesome Ménage Romance as Digital Literature", she examines the effect mechanisms of paratextual information, textual strategies like realism, point of view, and repetition, as well as the affordances of digital reading itself, all of which creates a reading experience within the affective matrix of pleasure, fascination, titillation, and arousal.

Mahlu Mertens discusses the narrative possibilities of representing a "world without us" in Ontroerend Goed's play of the same name for an audience or reader who obviously still exists. In "Negating the Human, Narrating a World Without Us", she argues that part of the text manages to evoke, through its list-like form, tense, and accompanying rhythm, mixed feelings 
of sadness and comfort in the face of human extinction - instead of the feeling of 'activist melancholia' often elicited by ecological elegies.

In "Refiguring Reader-Response: Experience and Interpretation in J.G. Ballard's Crash", Ciarán Kavanagh seeks to establish a methodological basis for reader-response analysis and to give substance to theory through its deployment in his study of Ballard's novel, a text which combines and subverts multiple frameworks. His chapter thus focusses on the microcosmic, line-by-line reading experience provided by two excerpts that exemplify Ballard's clinical over-description of damaged and refigured bodies, as well as on macrocosmic interpretive frameworks relating to genre, embodiment, and aesthetics.

Part II, "Coming to the Fore", finds the answer to the question - which textual features contribute to a powerful reading experience? - in unexpected places that are usually unnoticed or ignored by readers themselves. Subtle stylistic features - such as metaphorical realms, vividness of described settings, rhythm, and layout - can be determining factors when one accounts for the powerful reading experience provided by some literary prose texts.

Christine Chollier provides a semantic reading of the passage of The Great Gatsby in which the protagonist's death is suggested. Her chapter, "Lives and Deaths of Gatsby: A Semantic Reading of a Key Passage in a Powerful Text", highlights the text's ambiguity, as well as its proleptic semantic features, its euphemising strategy, and its meaningful semantic clusters as textual elements that contribute to the text's powerfulness, because, she hypothesises, they succeed in impacting readers both emotionally and intellectually.

Kimberley Pager brings to light the stylistic features that make up the powerful opening of Jane Eyre. Her chapter "Introducing Jane: The Power of the Opening" demonstrates how the eponymous heroine is implicitly presented and constructed through the use of pathetic fallacy, iconicity, and features pertaining to discourse. As these three types of devices contribute to the protagonist's characterisation, they potentially influence the reader's perception of Jane at a very early point in the story.

In "Performing Rhythm Through Enunciation: Prose Versus Poetry", Maryvonne Boisseau proposes to investigate the rhythms of a prose excerpt and a short poem whose common topic is the description of a lighthouse. She assumes that whatever response a text elicits, its constitutive rhythm is a cardinal element that governs the way it is received when read aloud. Her study, which is based on the key notions of enunciation, rhythm, and points 
of prosodic condensation, shows how a prose extract from a book classified as non-fiction may induce a reader's response akin to that prompted by a poem.

Alice Labourg focusses on the opening of The Mysteries Of Udolpho, which has the effect of a metaphorical landscape painting as it emerges through what critics have called Ann Radcliffe's "word-painting". Her chapter, "The Pictorial Paradigm of La Vallée: A Text-Image Reading of the Incipit of The Mysteries of Udolpho", investigates the powerful visual effects of the passage on structural, thematic, symbolic, and semiotic levels. Labourg draws our attention to the structuring movement of the picturesque gaze, construing the evocation of the landscape as a pictorial matrix and delving into the text's semiotic pictoriality.

Part III, "Readers, Characters, Authors", analyses different forms of readerly engagement and meaning-making processes prompted by a felt connection between readers, (fictional) character(s) or (imagined) authors stimulated by textual features. While the terms sympathy, empathy, identification, and character engagement are often used interchangeably by scholars, the contributions focus on the role different textual devices might play in readers' constructions of characters, authors or themselves (as readers).

Tahir Wood argues that fictional communication necessarily involves three types of agents: character, author, and reader. "The Nature of the Agonistic in a Pragmatics of Fiction" examines why, in order to achieve overall coherence in the reader's eye, the assumption of authorial intention is necessary, whether readers know the author's identity or not.

In "The Relevance of Turning a Page: Monotony and Complexity in \$25 of David Foster Wallace's The Pale King", Sixta Quassdorf focusses on the text's power to elevate readers into a pleasurable state of discerning the relevant in a seemingly repetitive and thus presumably boring piece of text. Despite (or because of) the strong cognitive effort they demand, tiny stylistic features such as the text being laid out in columns, the use of inverted commas, or the use of short sentences - effectively address both readers' cognitive faculties and their sensory modalities, and thus allow readers to view themselves as a collaborator in the meaning-making process, grasping the text's critical political dimension as possibly intended by the author.

Maria-Angeles Martinez's chapter, "The Language of Engagement and the Projection of Storyworld Possible Selves in Roberto Bolaño's The Savage Detectives", explores stylistic possibilities hypothesised to draw readers into a sto- 
ryworld early on. Multiple textual markers which encourage readers to blend self-images with their mental constructs of the story's protagonists are identified at the beginning of Bolaño's' novel. The article examines the abundance and distribution of varying forms of personal deixis, i.e., markers indicating mental activities or contracted forms, and other textual features in both the Spanish original and the English translation. It then discusses whether readers of these two versions might be left with different impressions due to the translator's choices.

Constance Robert-Murail's chapter, 'Smuggling in Accidental Poetry': Cognitive and Stylistic Strategies of a Stammering Teen in David Mitchell's Black Swan Green", explores the passage that dramatises the onset of the 13-year-old protagonist's stammer. The close stylistic reading it provides highlights the juxtaposition of the teenager's pathological speech impairment and his bustling, bubbling inner monologue. The article points out diverse textual features that trigger a strong form of empathy in readers, who find themselves caught between frustration and delectation as the young protagonist's palliative strategies allow Mitchell to smuggle in moments of 'accidental' poetry and humour.

\section{References}

Bell, Alice/Browse, Sam/Gibbons, Alison/Peplow, David (2021): "Responding to style”, in: Alice Bell/Sam Browse/Alison Gibbons/David Peplow (eds.), Style and reader response, Amsterdam/Philadelphia: John Benjamins Publishing Company, 1-19.

Chambers, Ross (1984): Story and situation: Narrative seduction and the power of fiction, Minneapolis: Manchester and Minneapolis University Presses.

Culioli, Antoine (1999): Pour une linguistique de l'énonciation. Formalisation et opérations de repérage - Tome 2, Gap, Paris: Ophrys.

Gardes Tamine, Joëlle (2010): La stylistique, Paris: Armand Colin.

Gavins, Joanna (2007): Text World Theory: An Introduction, Edingburgh: Edingburgh University Press.

Jakobson, Roman (1960): "Closing statements: Linguistics and poetics", in: Thomas Albert Sebeok (ed.), Style in Language, Cambridge: Technology Press of Massachusetts Institute of Technology, 350-377.

Leech, Joeffrey N./Short, Michael H. (2007 [1981]): Style in Fiction. A Linguistic Introduction to English Fictional Prose, London \& New York: Longman. 
Menninghaus, Winfried (2021): "Empirical aesthetics of language and literature: its strengths and weaknesses compared to the humanist scholarship of literature", in: Letteratura e letterature, 15, 113-127.

Menninghaus, Winfried/Wagner, Valentin/Knoop, Christine A./Scharinger, Mathias (2018): "Poetic speech melody. A crucial link between music and language", in: PloS one, 13 (11), 1-21.

Salbayre, Sébastien/Vincent-Arnaud, Nathalie (2006): L'analyse stylistique Textes littéraires de langue anglaise, Toulouse: Presses Universitaires du Mirail.

Simpson, P (2014): Stylistics. A resource book for students, $2^{\text {nd }}$ edition, London: Routledge.

Sorlin, Sandrine (2014): La Stylistique anglaise. Théories et Pratiques, Rennes: Presses Universitaires de Rennes.

Stockwell, Peter (2021): "In defence of introspection", in: Alice Bell/Sam Browse/Alison Gibbons/David Peplow (eds.), Style and Reader Response, Amsterdam/Philadelphia: John Benjamins Publishing Company.

Stockwell, Peter/Whiteley, S. (eds.) (2014): The Cambridge Handbook of Stylistics, Cambridge: Cambridge University Press.

Werth, Paul (1999): Text Worlds. Representing Conceptual Space in Discourse, London: Longman. 


\section{Part I}

Emotional Experiences:

Textual Features Eliciting Positive, Negative or Mixed Emotions 



\section{A Psycho-Biological Approach to Suspense and Horror: Triggers of Emotion in a Passage from Lewis's The Monk}

Peter Wenzel, RWTH Aachen University (Germany)

That repose I wooed in vain. The agitation of my bosom chased away sleep. Restless in my mind, in spite of the fatigue of my body I continued to toss about from side to side, till the Clock in a neighbouring Steeple struck 'One.' As I listened to the mournful hollow sound, and heard it die away in the wind, I felt a sudden chillness spread itself over my body. I shuddered without knowing wherefore; Cold dews poured down my forehead, and my hair stood bristling with alarm. Suddenly I heard slow and heavy steps ascending the stair-case. By an involuntary movement I started up in my bed, and drew back the curtain. A single rush-light, which glimmered upon the hearth shed a faint gleam through the apartment, which was hung with tapestry. The door was thrown open with violence. A figure entered, and drew near my Bed with solemn measured steps. With trembling apprehension I examined this midnight Visitor. God Almighty! It was the Bleeding Nun! It was my lost Companion! Her face was still veiled, but She no longer held her Lamp and dagger. She lifted up her veil slowly. What a sight presented itself to my startled eyes! I beheld before me an animated Corse. Her countenance was long and haggard; Her cheeks and lips were bloodless; The paleness of death was spread over her features, and her eye-balls fixed stedfastly upon me were lustreless and hollow.

I gazed upon the Spectre with horror too great to be described. My blood was frozen in my veins. I would have called for aid, but the sound expired, ere it could pass my lips. My nerves were bound up in impotence, and I remained in the same attitude inanimate as a Statue.

The visionary Nun looked upon me for some minutes in silence: There was something petrifying in her regard. At length in a low sepulchral voice She pronounced the following words. 
"Raymond! Raymond! Thou art mine!

Raymond! Raymond! I am thine!

In thy veins while blood shall roll,

I am thine!

Thou art mine!

Mine thy body! Mine thy soul!

Breathless with fear, I listened while She repeated my own expressions. The Apparition seated herself opposite to me at the foot of the Bed, and was silent. Her eyes were fixed earnestly upon mine: They seemed endowed with the property of the Rattle-snake's, for I strove in vain to look off her. My eyes were fascinated, and I had not the power of withdrawing them from the Spectre's.

In this attitude She remained for a whole long hour without speaking or moving; nor was I able to do either. At length the Clock struck two. The Apparition rose from her seat, and approached the side of the bed. She grasped with her icy fingers my hand which hung lifeless upon the Coverture, and pressing her cold lips to mine, again repeated,

"Raymond! Raymond! Thou art mine!

Raymond! Raymond! I am thine! \&c.

(Lewis 1994 [1796]: 263-264) ${ }^{1}$

\section{Still Largely Downplayed in the Humanities: The Biological Foundations of Emotions}

Though emotions have become an increasingly important topic in the study of literary fiction texts in the past twenty years, attempts to explain their powerful potential from a psycho- or neurobiological perspective have remained comparatively rare. The reservations of many literary scholars about biological approaches are obviously a consequence of the humanities' long-standing belief in Cartesian dualism and in Dilthey's postulate of a categorical difference between 'scientific explanations' and 'historical understanding'. This fatal

1 In the following, all quotations without any reference specified are taken from this literary excerpt. 
schism has led to secret or even openly voiced fears of many traditional scholars that opening up the humanities to psycho- and neurobiological knowledge must result in reductionism, deterministic reasoning and a loss of the very principles on which philology has customarily been grounded, i.e. history, culture and the value of the individual text. ${ }^{2}$ Given the general shift from an a-modal to an embodied view of cognition (see Hufendiek 2016), however, it appears justified to overcome the traditional reservations ${ }^{3}$ and take the biological backgrounds of emotions much more seriously.

In what follows, I will pursue this endeavour by giving an analysis of a suspense-and-horror-passage from a classic Gothic novel, drawing on a multiplicity of biology- and nature-oriented paradigms such as evolutionary psychology (e.g. Griffiths 1997; Tooby/Cosmides 2008), neuropsychology (e.g. Damasio 1999, 2003), evolutionary cultural semiotics (Koch 1993), German 'Biopoetics' (Eibl 2004; Mellmann 2006, 2007) and various emotion-focussed literary approaches (e.g. Robinson 2005; Hogan 2003, 2011, 2018; Vernay 2016). ${ }^{4}$ My intention is to emphasise the psycho- and neurobiological aspects of suspense and horror without denying that there are also historical and cultural causes of their effects. This will make it necessary to specify the concept of 'emotion', which is an all too general and unitary notion from folk psychology. Thus, I will first draw a distinction between three levels' or 'types' of emotion (section 2). This preliminary step will be followed by

Blatant German examples of this position are Kelleter 2007 and Feige 2009. The title of Kelleter's article ("A Tale of Two Natures: Worried Reflections on the Study of Literature and Culture in an Age of Neuroscience and Neo-Darwinism") nicely shows to what a degree humanist reservations against science are often linked with pent-up frustration about a supposed loss of power and influence of the humanities. See for a witty ironic refutation of such lamentations Eibl 2007: "On the Redskins of Scientism and the Aesthetes in the Circled Wagons".

3 For a general plea for overcoming the Cartesian mind/body-dualism and for integrating scientific knowledge into the humanities, see Slingerland 2006; for an excellent short and balanced overview of the entire debate about the significance of the sciences for the humanities, see Dancygier 2012: 11-16.

4 I intentionally pass over the so-called "Literary Darwinists" here, because I think that the adherents of this school (such as Joseph Carroll and D.S. Wilson) tend to ascribe too specific, utilitarian functions to literature (so that for them, early oral storytelling, for instance, is just a device of male sexual display to attract female mates). I think that this position ignores the possibility that literature may serve more general needs (maybe that of providing some pleasant relaxation from stress in a tiring struggle for existence [see Eibl 2004: 302-319]). 
a contextualisation of the selected Gothic text (section 3) as well as a brief conventional stylistic analysis of it (section 4). In sections 5 and 6, I will then explicate my emotion-focussed, psycho-biological approach, exposing a preypredator confrontation (section 5) and a fatal confusion of bio-programmes (section 6) as the most powerful devices for triggering suspense and horror in the text. In my conclusion (section 7), I will finally provide some preliminary empirical evidence for the relevancy of my psycho-biological approach, but I will also show why it should still be supplemented with a cultural and historical analysis.

\section{From the Vernacular Concept of Emotion to a Structured Typological Analysis}

As has often been emphasised in both scientific and humanist research (see Griffiths 1997, Menninghaus et al. 2019), the term 'emotion' is far too broad and vague to be of any analytical value, unless it is specified. In the present article, I will therefore draw a distinction between three different levels or types of emotions: 1) emotion as an affect programme; 2) emotion as a subjective feeling; 3) aesthetic emotion.

ad 1) In its first and simplest sense, emotion is a mere affect programme - a stereotyped, involuntary response, steered by the limbic system, more specifically by two almond-like shaped nuclei, the amygdala. Such amygdala reflexes are called forth in a non-linear process that involves environmental stimulus, non-cognitive appraisal and physiological change (see Robinson 2005:3). These phenomena precede a more complex evaluation (see Mellmann 2006) that may then lead to a conscious realisation of fear. Affect programmes of this automatic nature are deeply grounded in evolution and of central significance to what one calls 'basic' or 'primary emotions', especially fear, anger

The concept of 'basic emotions' is still fiercely contested in psychological research. While only a few extreme social constructivists reject the notion entirely, the exact number of basic emotions has always remained unclear. Based on lists established by scholars such as Ekman and Plutchik, most frequently distinguished are fear, anger, sadness, joy, and disgust; further often accepted candidates are surprise, pride, shame, and contempt; to which one might add attachment, hunger, and lust (see Hogan 2018: 52-53). Of all these, fear must certainly be regarded as the most fundamental one, since it is most important for survival and thus, from an evolutionary perspective, least 
and disgust, i.e. those emotions that are most important for a species' survival in a perilous environment.

ad 2) While amygdala circuits trigger and control all the physiological responses elicited by threats, they are not directly responsible for feelings of "fear" (see LeDoux 2015). Rather emotion in this second sense is a higher cognitive phenomenon that is experienced subjectively and can be culturally influenced and remodelled (see Damasio 1999, 2003). But although it is therefore indispensable to keep emotion as a mere affect programme and emotion as a subjective feeling theoretically apart, nearly all researchers assume that there are many feedback loops between these two systems.

ad 3) Yet another level or type of emotion, least explored so far, is aesthetic emotion. According to the first comprehensive article on the subject, published only recently (Menninghaus et al. 2019), there are at least two features that set off this type against the two others: Aesthetic emotion is usually linked with positive appraisal, focusing on such positive values as pleasantness or novelty, and it always includes an element of conflict or incongruity, thus constituting what one may call a 'mixed' or 'multicomponent' emotion (e.g. sadness and joy, horror and pleasure, a feeling of separation and reunification, etc.).

The present article will direct its attention mainly to level 1 - emotion as a mere affect programme - and have occasional recourse also to level 2 - the characters' and readers' subjective feelings. Level 3 - the question of a possible aesthetic quality of emotion triggered by the text - will only be touched on briefly in the conclusion.

\section{The Text and Its Context: Lewis's The Monk as a Prototypical Gothic Novel}

Matthew Gregory Lewis's (1775-1818) The Monk (1796), from which the present text passage is taken, has rightly been regarded as probably the most powerful and effective British Gothic novel - "a romance of extraordinary fascination" (Varma 1966: 140), blood-curdling and taboo-breaking, "an orgy of sadistic and sexual fantasies" (Seeber et al. 1991: 262). While a public scandal to the critics - Coleridge, for instance, termed the book "a poison for youth" and a work

dispensable (see Stanley-Jones 1970: 34; Panksepp 2005: esp. 206-217; Öhman 2008: 710). 
"which if a parent saw in the hands of a son or daughter, he might reasonably turn pale" (Varma 1966: 147) -, Lewis's novel was yet a sensational success with its contemporary audience. ${ }^{6}$ The prototypicality of the novel as an exemplar of suspense and horror is also attested by its intertextuality. For Lewis, who was only nineteen when he composed the book, plagiarised many of its plot elements and even parts of the surface structure from various French and German sources (see Varma 1966: 149-153 for the details).

The present text passage, a scene from the sub-plot of the novel (Book II, Chapter I), is thus strongly grounded on a tale called "Die Entführung" (i.e. "The Abduction") in Johann Karl August Musäus's Volksmärchen der Deutschen (Popular Tales of the Germans) (see Guthke 1958: 176-183): When trying to free and elope with his mistress from a castle, the protagonist - named Fritz in the German, Don Raymond in the British text - unfortunately confuses her, who was supposed to disguise as a legendary ghost named the "Bleeding Nun", with the real spectre. As a welcome, he kisses the spectre, reciting a love poem, and is now haunted by her in return. She adopts the role of his mistress, kisses him and recites his welcoming love poem in a slightly modified version (see the text extract above). While the general course of the action in Musäus and Lewis and even some details are virtually the same, Lewis manages to increase the effectiveness of the scene considerably by giving a more realistic description of the ghost's accessories, emphasising the protagonist's passion (see Guthke 1958: 179) and employing both conventional stylistic and bio-psychological textual strategies to intensify the scene's suspense.

\section{Two General Strategies of Suspense: 'Narrative Urgency' and Experientiality}

Lewis's text passage owes some of its attraction to conventional suspenseproducing stylistic strategies: There is, first, what Paul Simpson (2014) has termed 'narrative urgency', i.e. a "constellation of stylistic tendencies" (ibid.: 7) that produce the impression of fast-moving action and motivate readers to identify with the protagonist's plight: More specifically, these devices are simple sentences with single clauses, a primacy of the text world over any 
modalised sub-worlds, a comparatively short duration of the scene (in Genettian terms, many lines of the text display an identity of story-time and discourse-time), and the use of free forms of thought or speech foregrounded by exclamation marks. Second, the readers' identification with the startled and horrified response of the protagonist to the intruding spectre is further heightened by the production of a fairly high degree of experientiality or 'embodied perception' (see Sanford/Emmott 2012: 132-160; Caracciolo 2014). Thus, there is (to use Dorrit Cohn's terminology) a consonant first-person narrative situation and much thought- and speech-representation, often in connection with the use of 'experience verbs' (namely, "listened", "heard", "examined", "beheld") and other references to sense impressions (see "sight", "lustreless", "silence", "silent"). All these suspense-producing factors are, however, not sufficient for explaining the enticing appeal of the passage. Only an emotion-focused psycho-biological analysis can accomplish this purpose.

\section{A Psycho-biological Analysis I: An "Emotion Episode" Based on a Prey-Predator Confrontation}

Beyond its suspenseful experience-focused presentation, the present passage can be classified as a prototypical "emotion episode" as it has been described by Patrick Colm Hogan in several of his publications (2003: 145-146 and 169-170, 2011: 2-3, 2018: 43-44 and 179). First, there are eliciting conditions. These are the circumstances that give rise to the emotion of fear - in this case "the Clock in a neighbouring Steeple" which strikes 'One", and various frightening noises such as "the mournful hollow sound" that the protagonist hears "die away in the wind" at the beginning of the scene and the "slow and heavy steps ascending the staircase" he perceives somewhat later. The next component of the emotion, following directly from the eliciting conditions, is what Hogan calls the feeling or phenomenological tone. As this is "the subjective quality of an emotion" that "cannot be shared" (Hogan 2018: 46), Lewis

7 Conventionally, the scary hour when the clock strikes is midnight, not one. But this deviation can easily be accounted for: In Lewis's source, Musäus's "The Abduction", the clock actually strikes at twelve ("Wie die Glocke Zwölfe schlug [...]", Musäus 1922 [1782-1786]: 250); thus, it is likely that Lewis, as in so many other cases, changed this detail in order to veil his plagiarism (see Guthke 1958: 178-181 for a detailed discussion of Lewis's borrowings from Musäus's version). 
typically has recourse to the topos of inexpressibility for its illustration: "I gazed upon the Spectre with horror too great to be described." While this emotional response is situated at the second of the above distinguished levels, much more basal are Hogan's physiological outcomes and actional outcomes, as these components are immediate manifestations of the embodied affect programme triggered in this scene. To understand these outcomes in more detail, it becomes necessary to cast a closer glance at what psycho-biologists have said about the 'biology of fear'.

Physiological manifestations of fear, as most blatantly visible in a prey's confrontation with its predator, include the following phenomena (see Marks 1987: 68-69; McNaughton/ Zangrossi 2008: 13; Tooby and Cosmides 2008: 135, note 1 ):

1) reduced temperature (produced by vasoconstriction, see Stanley-Jones 1970: 34), bringing about a sensation of coldness,

2) goose bumps as well as hair standing on end,

3) startle (like the other items an involuntary response),

4) shivers,

5) silence (in the sense of inability to call out or scream),

6) gazing at the predator in a reaction of "tonic immobility" (see Marks 1987: 61-62),

7) increased respiration,

8) the predator's gaze at the prey, hypnotising it.

Amazingly, each of these eight typical components of a prey-predator confrontation is also explicitly mentioned in Lewis's text:

ad 1) "I felt a sudden chillness", "I shuddered", "[c]old dews poured down my forehead",

ad 2) "my hair stood bristling with alarm",

ad 3) "[b]y an involuntary movement I started up",

ad 4) "[w]ith trembling apprehension",

ad 5) "I would have called for aid, but the sound expired",

ad 6) "my startled eyes", "I gazed", "bound up in impotence", "[m]y eyes were fascinated, and I had not the power of withdrawing them from the Spectre's",

ad 7) "[b]reathless with fear", 
ad 8) "[h]er eyes were fixed earnestly upon mine", "endowed with the property of the Rattle-snake's".

Even the numerous metaphors in the passage - with the exception of those in line I (" $t$ ] hat repose I wooed" and "chased away sleep") — have a direct link to the prey-predator programme determining the scene, because without any exceptions, they turn out to be offshoots of three conceptual metaphors that are closely interwoven with some of the above-outlined components of fear:

1) Fear is death (see "I heard it [i.e. the mournful sound] die away in the wind", "[t]he paleness of death was spread over her features", "the sound expired", "in a low sepulchral voice").

2) Fear is coldness (see "[m]y blood was frozen in my veins"; also: "her icy fingers").

3) Fear is immobility (see "I remained [...] inanimate as a Statue", "[t]here was something petrifying in her regard").

Of the various components that form part of the prey-predator confrontation, the most interesting ones are clearly items 6 and 8, i.e. the fact that prey and predator keep staring at each other, which seems to give the predator some hypnotic power and leads to a 'shock paralysis' on the part of the prey. This phenomenon is not only well known in biology, where it has been "documented in scores of vertebrate and invertebrate species ranging from arthropods and molluscs to fish, amphibians, reptiles, birds and mammals, including humans" and is known under "numerous names" such as "death feint", "terror paralysis", "animal hypnosis", "bewitchment" or "fascination" (Marks 1987: 61), but also in anthropology and the study of culture. ${ }^{8}$ In classical antiquity, for instance, the notion already manifested itself in the 'Medusa effect', i.e. the myth of the terrible sight of a monstrous goddess that would turn onlookers to stone; in the Early Modern period, such powers were strongly associated with sorcery and witchcraft; and in the time of Neoclassicism and Romanticism, they became a far-spread cliché in the form of the mesmerising, fiery eyes of the Gothic villains (see Baumbach 2015).

See Nöth 1990: 406: "Phylogenetically, staring eyes are a threat signal for many animal species. For several primate species, the glance has been shown to be a signal by which social dominance is established or strengthened [...]. In human culture, the motif of the evil eye [...] seems to be an archetypal pattern of a threat signal." 
Typically, "of all beings, serpents were attributed the greatest power of fascination: they were believed to petrify their prey by fixing it through their lethal gaze, holding it mute and frozen before its death" (Baumbach 2010:232). As early as 1796, as I found out, i.e. the very year in which Lewis's Monk appeared, Benjamin Smith Barton, a professor of natural history and Botany in the University of Pennsylvania, already published a disquisition on the subject, in which he ascribes "the fascinating faculty" "to the rattle-snake and other American serpents" in particular (see Barton 1796). What is interesting is that in our text passage, Lewis refers to the very same animal: "Her eyes [...] seemed endowed with the property of the Rattle-snake's". Nonetheless, it is likely that there is no direct connection between the two references, especially as Lewis wrote his novel two years before its publication. ${ }^{9}$

Finally, in addition to its particular prominence in Lewis's text, there is further evidence that the prey-predator confrontation provides an essential function for the production of suspense and horror in Gothic texts. For exactly the same physiological and actional outcomes of horror and fear appear in the key passages of other famous Gothic novels. Due to lack of space, the only example that I will adduce here is the well-known scene in Frankenstein in which Victor awakes from a troubled sleep to look at his self-made monster for the first time:

I started from my sleep with horror; a cold dew covered my forehead, my teeth chattered, and every limb became convulsed: when, by the dim and yellow light of the moon, as it forced its way through the window shutters, I beheld the wretch — the miserable monster whom I had created. He held up the curtain of the bed, and his eyes, if eyes they may be called, were fixed on me. His jaws opened [...] (Shelley 1994 [1818]: 490-491)

Just as in Lewis's horror scene, the protagonist is confronted with the 'spectre' while lying in his bed, similar to an animal that is attacked in the very core of its shelter, namely its resting place. Again, the situation is typically that of

Rather, the belief in the fascinating faculty of serpents appears to have been general knowledge. Thus Barton (1796: 20) refers to it as follows: "The belief in the fascinating faculty of serpents has spread through almost all the civilized parts of North America. Nor is it confined to America. It has made its way into Europe, and has there taken possession of the mind of scholars, of naturalists, and of philosophers." It does not come as a surprise that some three quarters of a century later, Darwin (1872: 108, note 28) in his famous study on The Expression of the Emotions in Men and Animals makes mention of the belief as well. 
semi-darkness, a state that is particularly dangerous for prey animals (more than complete darkness, in which most predators are not able to see, either). And again, the depiction of the scene is dominated by the typical physiological outcomes of fear - startle, a sensation of coldness, shivers, and most importantly, the predator's lethal gaze at the prey: "his eyes, if eyes they may be called, were fixed on me." What is interesting in addition to that is that in Shelley's text, the prey-predator pattern even becomes manifest in the use of a conspicuous animal metaphor: "His jaws opened".

\section{A Psycho-biological Analysis II: Confusion of Bio-programmes Highlighted by Charm-like Repetition}

In addition to the prey-predator confrontation climaxing in the prey's shock paralysis and the predator's lethal gaze, there are yet some other psycho-biological effects which may contribute to the thrilling emotional effect of the scene. Particularly noticeable here is a fatal confusion of two deep-seated biological programmes whose distinction is essential for all animal species as well as for humans. To understand the functioning of these programmes, it is necessary first to discuss them briefly in a wider scope.

According to the teachings of various socio-biologists, all animals must be able to handle three essential 'instincts', 'drives', or 'biocultural survival programmes', as the semiotician Walter A. Koch (1993: 45-46, 120-121, 154-156) has termed them. These bio-programmes are related to the three fundamental areas of behaviour:

1) "crimen", i.e. the aggressor-defender relationship, comprising activities of fight, flight, and pursuit,

2) "fructus", i.e. the parent-offspring relationship, comprising activities of feeding and parental care,

3) "sexus", i.e. the male-female relationship, comprising activities of mating and sexuality.

All species as well as humans must keep their behavioural programmes in the three areas strictly apart, especially because "there is so strong a temptation for transition and promiscuity" (Koch 1993: 159) since the same parts of the 
body (such as the mouth, for instance) are used for performing actions in each of the three areas. That is why in human culture, any behavioural transitions of the boundaries between the areas are strictly tabooed. In literary fiction texts, however, these boundaries are often transgressed with the help of a thrilling story the task of which is to confirm the taboo through its ending. Oedipus Rex, for instance, violates the taboo in a twofold manner, transgressing the boundary between "fructus" and "crimen" by killing his father, and that between "fructus" and "sexus" by having intercourse with his mother. Likewise, the famous vampire-myth can be related to this framework, since in many stories it implies thrill-providing transitions from "sexus" to "crimen".

Lewis's horror passage, when analysed in the larger context of its surrounding story, can also be assigned to this framework. For as was already mentioned, the protagonist, unaware of the fact that the refugee from the castle was not his mistress Agnes in ghostly disguise but the real spectre, gave her a welcome kiss and - pressing her to his bosom - recited the following love poem, thereby triggering the "sexus"-frame:

"Agnes! Agnes! Thou art mine!

Agnes! Agnes! I am thine!

In my veins while blood shall roll,

Thou art mine!

I am thine!

Thine my body! Thine my soul!" (Lewis 1994 [1796]: 261)

In the horror passage under discussion, the spectre repeats the protagonist's poem, exchanging its addressee and modifying the position of some of its pronouns in a mocking, parodying manner, thereby intermingling the "sexus"- with a "crimen"-frame:

"Raymond! Raymond! Thou art mine!

Raymond! Raymond! I am thine!

In thy veins while blood shall roll,

I am thine!

Thou art mine!

Mine thy body! Mine thy soul! --" (ibid.: 263)

When reciting the poem for the second time, the spectre even grasps the protagonist's hand, "pressing her cold lips to [his]" in an aggressive erotic gesture. What was first a love poem emphasising the protagonist's submission to his mistress (see the last two lines of version 1: "I am thine! / Thine my body! Thine 
my soul!") thus changes into an aggressive erotic onslaught foregrounding the spectre's possessiveness (see the last two lines of version 2: "Thou art mine! I Mine thy body! Mine thy soul!"). The outcome of this is a strange but thrilling blend ${ }^{10}$ - a mixture of the bio-programmes of "sexus" and "crimen".

It is also instructive to cast a closer glance at the poem's well-thought out linguistic structure. To an unusual degree, the poem is marked by obtrusive repetition. Thus, in addition to rhyme, there are numerous instances of sound repetition, verbal repetition and grammatical repetition (see the frequent assonances on ' $a i$ ' and ' $i$ ', the alliteration contained in thee, thine and thy, and the chiasmus of "Thou art mine! I am thine!" as well as "I am thine! Thou art mine!"). ${ }^{11}$ In an interesting article on the linguistic structure of charms and spells, no less a scholar than Northrop Frye (1976: 126) has uncovered the particular rhetorical purpose of such extreme manifestation of repetition: "it sets up a pattern of sound so complex and repetitive", Frye states, "that the ordinary processes of response are short-circuited. Refrain, rhyme, alliteration, assonance, [...], antithesis: every repetitive device known to rhetoric is called into play. Such repetitive formulas break down and confuse the conscious will, hypnotize and compel to certain courses of action." The poem, then, employs the principle of repetition for achieving a mesmerising effect. Quite in line with that, the charm-like quality of the poem is further enhanced by its metre, which is catalectic trochaic tetrameter throughout. ${ }^{12}$ In contrast to other metrical patterns, this metre sounds unnatural and mechanical similar to the trochaic tetrameter Shakespeare uses for the uncanny verses of his witches in Macbeth. In Lewis's text, the purpose of the charm-like poem is that of suggesting a mysterious, inescapable identity of mine and thine ${ }^{13}$,

10 On the concept of blending, see Fauconnier/ Turner 2002, and with particular regard to narrative: Schneider/ Hartner 2012.

11 That Lewis created the obtrusiveness of these repetitions with deliberate intention can be concluded from the fact that the original version of the poem in Musäus ([1782-1786] 1922: 251) is much less repetitive: "Friedel, Friedel, schick' dich drein, ich bin dein, du bist mein mit Leib und Seele" (in English: "Friedel, Friedel, give in to me, I am thine, thou art mine with body and soul").

12 Lines 4 and 5 of the poem can be interpreted as two half-lines whose catalectic trochaic dimeter adds up to another line in trochaic tetrameter. Interestingly, the parallelism "thine and mine" provides what the semiotician Koch (1991: 4-5) termed a "fit" or "zipper" structure, i.e. an eye-catching structural coincidence of a signifier with its signified, which - since the two areas normally function independent of each other - appears as something non-accidental, thus assuming 
thus overpowering and hypnotising the protagonist in a manner similar to the predator's lethal gaze. And again, the extremely repetitive structure of the poem can be regarded as being closely related to an embodied psycho-biological effect, for although reliable research results in the field are still scarce, there is some interesting neurobiological evidence that such extreme repetition in a text tends to go hand in hand with extreme neural activation in the brain of its recipient (see Ernst 2013: 129-131 and 154-156).

\section{Conclusion: Suspense and Horror - A Psycho-biological, but also a Cultural Phenomenon}

Carrying out what I have called a psycho-biological analysis, I have illustrated various deeply embodied biological patterns with the help of which the triggering of suspense and horror in Lewis's text can plausibly be explained. To produce further evidence that the strong emotional appeal of the text really hinges on these patterns, I also conducted an exploratory empirical experiment.

For this purpose, questionnaires were distributed to 15 students in a seminar on the gothic novel at RWTH Aachen University. ${ }^{14}$ I asked the participants to mark those three passages in Lewis's text that struck them as most suspenseful. As I had expected, the passages named were those that also played a major role in my emotion-focused psycho-biological analysis. Thus eight times, the paragraph describing the protagonist's coldness, silence and tonic immobility, climaxing in his shock paralysis was mentioned; six times, the passage in which the ghostly predator unveils her face; five times, the scene in which with her icy fingers she grasps the protagonist's hand and presses her cold lips to his; four times, the enchanting poem.

In spite of this empirical confirmation of the relevancy of my psycho-biological approach, the question must finally be raised whether the recommended new focus on the 'natural', biological aspects of suspense and horror demands a complete paradigm change in literary emotion research or whether it should rather only be employed as a complementary methodology.

the seeming quality an inherent logical proof. 'Nomen est omen' and 'traduttore - traditore' are other examples provided by Koch for this intriguing semiotic effect.

14 I am obliged to my colleague Jan Alber for allowing me to conduct the experiment in his class. 
In my opinion, the second option is preferable. For in spite of the immense significance of psycho-biological patterns for the triggering of emotions, an important influence of cultural and historical factors cannot be denied. Thus, two thirds of the students participating in the above-mentioned experiment were of the opinion that they were probably less thrilled by the response and horror of Lewis's text than its original reading public. They adduced cultural and historical factors as reasons for this judgment. While in Lewis's time, beneath a Christian and enlightened veneer superstition was still alive in many areas (see Stearns 2008: 209), no remnants of the belief in ghosts are left in modern times. Moreover, the strong presence of suspense and horror in the cinema is likely to have reduced the susceptibility of modern readers for the emotions in Lewis's text. Last but not least, as one of the participating students commenting on his personal response rightly remarked, the archaic language in Lewis's text ${ }^{15}$ produces a strongly distancing effect on the modern reader. In combination with Lewis's tendency towards overdoing his depiction of emotions in a grotesque and comical manner (see Schumacher 1990: 184), this factor might even lead to the experience of 'mixed' or 'multicomponent' emotions and thus open up the possibility of an aesthetic reading of the text. ${ }^{16}$ But whether that is really the case could only be explored in another, more sophisticated empirical reception study.

\section{References}

\section{Corpus}

Lewis, Matthew Gregory (1994 [1796]): “The Monk", in: Four Gothic Novels, Oxford: Oxford University Press, 159-444.

See the following examples: "[t]he agitation of my bosom", "[a] single rush-light", "Corse" (for: "corpse"), "sepulchral", "endowed with", "fascinated" (for: "bewitched"), "Coverture" (for: "covering").

16 See Jerrald E. Hogle's opinion that in the Cothic novel, there is quite generally an "intermixture of the sublime with what Burke calls the unthreatening 'beautiful' and with the comically bathetic and other incongruous elements", adding to the "deliberately forced unreality" and "insistent artificiality" of the genre (Hogle 2002: 15). I find it difficult to believe, however, that the majority of the common readers in Lewis's time really approached the novel from such a complex, aesthetic perspective. 


\section{Other Works}

Barton, Benjamin Smith (1796): A memoir concerning the fascinating faculty which has been ascribed to the rattle-snake, and other American serpents, Philadelphia, Pa.: Henry Schweitzer.

Baumbach, Sibylle (2010): "Medusa's gaze and the aesthetics of fascination", in: Anglia, 128 (2), 225-245.

- (2015): Literature and fascination, Houndmills, Basingstoke, Hampshire: Palgrave Macmillan.

Caracciolo, Marco (2014): The Experientiality of narrative: An enactivist approach, (Narratologia 43), Berlin and Boston: De Gruyter.

Damasio, Antonio (1999): The feeling of what happens: Body and emotion in the making of consciousness, New York: Harcourt Brace \& Company.

- (2003): Looking for Spinoza: Joy, sorrow, and the feeling brain, Orlando, Fla.: Houghton.

Dancygier, Barbara (2012): The language of stories: A cognitive approach, Cambridge: Cambridge University Press.

Darwin, Charles R. (1872): The expression of the emotions in men and animals, London: John Murray, http://darwin-online.org.uk/content/frameset?itemID $=$ F1142\&viewtype=text\&pageseq=1 (Last accessed: 23.04 .2021 ).

Eibl, Karl (2004): Animal poeta: Bausteine der biologischen Kultur- und Literaturtheorie, Paderborn: Mentis.

- (2007): "On the redskins of scientism and the aesthetes in the circled wagons", in: Journal of Literary Theory, 1 (2), 421-441.

Ernst, Wolfgang (2013): Gehirn und Zauberspruch: Archaische und mittelalterliche psychoperformative Heilspruchtexte und ihre natürlichen Wirkkomponenten. Eine interdisziplinäre Studie, Frankfurt am Main: Lang.

Fauconnier, Gilles/Turner, Mark (2002): The way we think: Conceptual blending and the mind's hidden complexities, New York: Basic Books.

Feige, Daniel Martin (2009): "Biologische Evolution und Kunst: Eine Kritik", in: Martin Huber/Simone Winko (eds.), Literatur und Kognition: Bestandsaufnahmen und Perspektiven eines Arbeitsfeldes, (Poetogenesis: Studien und Texte zur empirischen Anthropologie der Literatur 6), Paderborn: Mentis, 165-181.

Frye, Northrop (1976): Spiritus mundi: Essays on literature, myth, and society, Bloomington and London: Indiana University Press.

Griffiths, Paul E. (1997): What emotions really are: The problem of psychological categories, Chicago and London: University of Chicago Press. 
Guthke, Karl S. (1958): Englische Vorromantik und deutscher Sturm und Drang: M.G. Lewis'Stellung in der Geschichte der deutsch-englischen Literaturbeziehungen, (Palaestra: Untersuchungen aus der deutschen und englischen Philologie und Literaturgeschichte 223), Göttingen: Vandenhoeck \& Ruprecht. Hogan, Patrick Colm (2003): Cognitive science, literature and the arts: A guide for humanists, New York and London: Routledge.

- (2011): Affective narratology: The emotional structure of stories, Lincoln and London: University of Nebraska Press.

- (2018): Literature and emotion, (Literature and Contemporary Thought), New York and London: Routledge.

Hogle, Jerrald E. (ed.) (2002): The Cambridge companion to Gothic fiction, Cambridge: Cambridge University Press.

Hufendiek, Rebekka (2016): Embodied emotions: A naturalist approach to a normative phenomenon, (Routledge Studies in Contemporary Philosophy 76), Milton Park, Abingdon, Oxfordshire: Routledge.

Kelleter, Frank (2007): "A tale of two natures: Worried reflections on the study of literature and culture in an age of neuroscience and Neo-Darwinism", in: Journal of Literary Theory, I (1), 153-189.

Koch, Walter A. (1991): Gott und die Welt: Semiogenese und Theogenese, (Bochumer Beiträge zur Semiotik 32), Bochum: Brockmeyer.

-(1993): The biology ofliterature, (Bochum Publications in Evolutionary Cultural Semiotics 14), Bochum: Brockmeyer.

LeDoux, Joseph E. (2015): The amygdala is NOT the brain's fear center, https://ww w.psychologytoday.com/us/blog/i-got-mind-tell-you/201508/The-amygd ala-is-not-the-brains-fear-center (Last accessed 29.01.2016).

Lewis, Michael/Haviland-Jones, Jeannette M./Barrett, Lisa Feldman (eds.) (2008): Handbook of Emotions, $3^{\text {rd }}$ edition, New York, London: Guilford Press.

McNaughton, Neil/Zangrossi, Helio Jr. (2008): “Theoretical approaches to the modeling of anxiety in animals", in: Robert J. Blanchard/ Caroline D. Blanchard/Guy Griebel/David Nutt (eds.), Handbook of anxiety and fear, (Handbook of Behavioral Neuroscience 17), Amsterdam: Academic Press, 11-27.

Marks, Isaac M. (1987): Fears, phobias, and rituals: Panic, anxiety and their disorders, Oxford: Oxford University Press.

Mellmann, Katja (2006): "Literatur als emotionale Attrappe: Eine evolutionspsychologische Lösung des 'paradox of fiction”, in: Uta Klein/Katja Mellmann/Steffanie Metzger (eds.), Heuristiken der Literaturwissenschaft: Diszi- 
plinexterne Perspektiven auf Literatur (Poetogenesis: Studien und Texte zur empirischen Anthropologie der Literatur 3), Paderborn: Mentis, 145-166.

- (2007): "Biologische Ansätze zum Verhältnis von Literatur und Emotion", in: Journal of Literary Theory, I (2), 357 -375.

Menninghaus, Winfried, et al. (2019): “What are aesthetic emotions?", in: Psychological Review, 126 (2), 171-195.

Musäus, Johann Karl August (1922 [1782-1786]): "Die Entführung", in: Die Volksmärchen der Deutschen, Vol. 5, 229-256.

Nöth, Winfried (1990): Handbook of semiotics, Bloomington, Indianapolis: Indiana University Press.

Öhman, Arne (2008): "Fear and anxiety", in: Michael Lewis/Jeannette M. Haviland-Jones/Lisa Feldman Barrett (eds.) (2008): Handbook of emotions, $3^{\text {rd }}$ edition, New York, London: Guilford Press, 709-729.

Panksepp, Jaak (2005): Affective neuroscience: The foundations of human and animal emotions, Oxford: Oxford University Press.

Robinson, Jenefer (2005): Deeper than reason: Emotion and its role in literature, music, and art, Oxford: Oxford University Press.

Sanford, Anthony J./Emmott, Catherine (2012): Mind, brain and narrative, Cambridge: Cambridge University Press.

Schneider, Ralf/Hartner, Marcus (eds.) (2012): Blending and the study of narrative: Approaches and applications, (Narratologia 34), Berlin and Boston: De Gruyter.

Schumacher, Manfred (1990): Das Groteske und seine Gestaltung in der Gothic Novel, (Aspekte der englischen Geistes- und Kulturgeschichte 21), Frankfurt am Main: Lang.

Seeber, Hans Ulrich, et al. (1991): Englische Literaturgeschichte, Stuttgart: Metzler.

Shelley, Mary ([1818] 1994): "Frankenstein", in: Four Gothic novels, Oxford: Oxford University Press, 449-606.

Simpson, Paul (2014): "Just what is narrative urgency?", in: Language and Literature, $23(1), 3-22$.

Slingerland, Edward (2006): What science offers the humanities: Integrating body and culture, Cambridge and New York: Cambridge University Press.

Stanley-Jones, D. (1970): "The biological origin of love and hate", in: Magda B. Arnold (ed.), Feelings and emotions: The Loyola Symposium, New York and London: Academic Press, 25-37.

Stearns, Peter N. (2008): "History of emotions: Issues of change and impact", in: Michael Lewis/Jeannette M. Haviland-Jones/Lisa Feldman Bar- 
rett (eds.) (2008): Handbook of emotions, $3^{\text {rd }}$ edition, New York, London: Guilford Press, 17-31.

Tooby, John/Cosmides, Leda (2008): "The evolutionary psychology of the emotions and their relationship to internal regulatory variables", in: Michael Lewis/Jeannette M. Haviland-Jones/Lisa Feldman Barrett (eds.) (2008): Handbook of emotions, $3^{\text {rd }}$ edition, New York, London: Guilford Press, 114-135.

Varma, P. Devendra (1966 [1957]): The Gothic flame, New York: Russell \& Russell. Vernay, Jean-Francois (2016): The seduction of fiction: A plea for putting emotions back into literary interpretation, Hampshire: Palgrave Macmillan. 



\section{Repeated Pleasure: Reading the Threesome Ménage Romance as Digital Literature}

Elina Valovirta, University of Turku (Finland)

Clayton and I had run into this situation before. "We could share her," I proffered. [...] "Dude, this is crazy enough, that we both want to fuck our new hire," Clayton said. "Don't get me wrong, I'm willing to share if she is but-" "Well, what's your read on her?" "I mean, she seems pretty sexual. Right before you walked in, I was describing what I'd do to her and she was pretty into it."[...] "Okay, so we explain to her. She'll either be into it or not, right? Besides, doing two brothers. That has a certain mystique, right?" "Some women might think so, yes." "But we have to play our cards right. We don't want it to come off as creepy." [...]

"Hey, Mandy," I started. "I hope I didn't scare you by barging in like that before." "No-no, it's fine," she assured. "I'm just so happy to have this opportunity." "Well, we're happy to have you," I assured. "And the Plemmons brothers-we can't help ourselves when it comes to a damsel in distress, so we found you a place." "Oh, my God, seriously? Already?" she said, her big beautiful eyes going wide. "Yeah," explained Clayton. "Carl reminded me: We have this summer rental near the beach. This time of year, no one's using it. You'd actually be doing us a favor by staying in it and keeping an eye out on the place." "Wow, I don't know how to thank you guys," she gushed. "I insist you charge me something." "Honestly, we were paying to have the place cleaned. You clean it, you can stay there until you find some place better," assured Carl. "As for thanking us..." "Carl!" interrupted Clayton. "What? I gotta come clean," said Clayton. "About what?" she asked. "You are very qualified for this position, the most qualified in fact. But when I saw your picture on LinkedIn, I was smitten. Seriously. Just like my brother here. We have similar tastes in women. I hope you don't find that weird," said Carl smoothly. "No, it's very flattering," she blushed. "I find you both very attractive." "Well, the thing is-and this is completely separate from our offer to let you stay at our beach house, 
mind you-Clayton and I might like to share you, if you get my meaning. Is that something that interests you?"

(Sparks/Conners 2017: loc. 643 to 687 of 24 822, Kindle) ${ }^{1}$

Sex with multiple partners is cited as the most common sexual fantasy in Justin Lehmiller's 2018 survey of a sample of over four thousand adult Americans. As Lehmiller observes, "sex with multiple partners is a staple of Americans' fantasies" and eighty-nine per cent of the sample "reported fantasizing about threesomes". Women's fantasies about multipartner sex were particularly elaborate (Lehmiller 2018: 16) and threesomes with the surveyed individual at "the centre of attention" (ibid.: 17) were the most common type of threesome fantasy. The survey's results highlight the centrality of multipartner sex as sexual fantasy material, and thus begs the phenomenon to be taken seriously when considering people's erotic desires from a scholarly view. If sexual fantasy is a type of fiction, in Lehmiller's context reported in written form, then it makes sense to examine the kinds of elaborations of this fantasy emerging in erotic fiction outside pornography, disseminated through electronic platforms such as the Amazon Kindle and currently booming in the literary marketplace.

This paper examines a corpus of English-language threesome or ménage romances in the subgenre of erotic romance in a digital format targeted to adult audiences. The most striking feature of these powerful literary texts aimed at titillating and pleasuring readers is their reliance on repetition as the ground rule of romance. The titles studied here all recycle certain well-known elements of e-romance, such as alternating first-person narration (or, alternatively, internally focalised third-person), wealthy love partner, and heightened erotic tension, but they also bring in the added element of multi-partner romance instead of pornography's focus on the act of sex alone. While these threesome romances highlight strongly erotic scenarios and explicit sex scenes, they do not satisfy themselves with merely sex, but also feature a deeply romantic, consensual and committed relationship forming between the female protagonist and her two male suitors. Despite the erotic make- 
up familiar from pornography, the stories are monogamous and conservative at heart and as such, fairly traditional popular romance narratives operating within the heterosexual matrix. ${ }^{2}$

This dimension of the happily-ever-after romance as a mandatory part of these stories clearly differentiates them from sexual act-oriented pornography, and as such represents an interesting amalgam of sex and romantic love removed from the time-honoured equation of two people at the centre of the romance. For the purposes of this collection, my question concerns the power of these literary texts. How does their power emerge and how does it operate on the level of the text and on the level of reading as can be gleaned from their textual construction? The novels' power as literary texts designed for the express purpose of providing pleasure and satisfaction in the reader, as mentioned above, lies in their use of repetition in multiple ways. Lynne Pearce has aptly remarked, that repetition is "the life-blood of romance" (Pearce 2011: 1). The way these novels perform their function of eliciting pleasure in readers is through repetition of various elements within the text, which pertain to linguistic choices, narration, characters, and themes such as safe sex. The first part of my discussion focuses on the basic trappings of threesome stories as a subgenre of the New Adult romance, after which I move on to discussing a close reading of one of the novels in an effort to highlight the typical mechanics of this form of digital literature, where the format is crucial to its make-up. My final remarks draw together my discussion and consider what this might mean overall for the act of reading, which, based on my analysis, emerges as both sexual in its own right as well as regulated by the digital format.

\section{Between Pornography and Literature: The Threesome Ménage Erotic Romance}

New Adult (NA) literature is a genre geared towards audiences above the target age of Young Adult (YA) literature meant for teens and preteens. This adult form of literature is the perfect playground of sexual fantasy. To name but a

2 Only one of the titles examined in this paper includes non-heterosexual activity between the partners, and only two of the titles explicitly refer to the word polyamory or polyamorous to characterise the relationship. The corpus is detailed in the following section and summarised in the Appendix. 
few, the highly explicit topic content of these books can range from stepsiblings in blended families falling in love (see Valovirta 2019), or a royal prince falling in love with a commoner (see Valovirta 2020), or threesome romance as examined here. E.L. James' bestselling Fifty Shades of Grey (2012) is a landmark of the genre, temporally coinciding with women's growing consumption of pornography (Illouz 2014: 33). The sexually explicit romance is a natural extension of how "sexual freedom, for women, is complexly entangled with the longing for intimacy" (ibid.: 34), which partly helps explain the success of the NA erotic romance. Readers today want sexual content, but within the frame of romance and intimate relationships.

The new type of romantic love explored in recent NA literature, the threesome ménage romance, is a curious mixture of multiple partner sexual fantasy as seen in pornography, yet following the very formulaic conventions of monogamy and happily ever after -driven romance writing. The six titles in my corpus include novels, novellas or stories with explicit reference to the desired relationship constellation from the very outset, as their titles usually refer to two love partners. The titles are: Two Close for Comfort (2014), In Two Deep (2015), and Two for One Special (2015) by Marie Carnay; Not Safe for Work (2017) by Charlotte Stein; Two Billionaires for Christmas (2017) by Sierra Sparks and Juliana Conners; and Twice the Fun: A Bad Boy MFM Menage (2017) by Juliana Conners. All are examples of the 'reverse harem' or 'MFM ménage' (mostly, and therefore henceforth, spelt without the accent) e-romance category, which capitalises on the erotic and exotic obstacle of two male friends or brothers falling in love with - and, ultimately, sharing - the same woman. The table attached as an appendix charts my corpus in more detail, and allows some general remarks to be made by their shared features summarised. All novels were published in the past five years and purchased from the Amazon Kindle Store for not more than a few US dollars apiece. One title, Twice the Fun, came with the purchase of another one in a so-called bundle, a typical selling strategy to acquaint the reader with further titles by the same author at no extra cost.

At a first glance, already the covers of the novels in my corpus communicate their power through repetition: they are almost interchangeable by title and cover image, which makes them instantly recognisable. The cover image of all e-books features two, mostly shirtless, men and one woman in a passionate embrace. In two cases, the men are wearing suits and ties to accentuate the corporate setting of the novels; in both cases the men are the heroine's bosses. The word two appears in all but one title, and the word menage ap- 
pears in them all as a subtitle. These factors communicate, that the novels need to be instantly recognisable to the reader looking for their desired story type.

Naturally, as dictated by the genre, all the novels end in full closure and happily ever after. On one hand, the subgenre capitalises on the eroticism of the multiple partner fantasy, but at the same time, is clearly marked romantic literature by not advocating open relationships. As such, they differ from the cultural phenomenon of consensual polyamory, such as the one promoted by Janet Hardy and Dossie Easton's landmark book, The Ethical Slut (2017), where the idea is to foster multiple relationships in a consensual, committed and ethical way. The menage romance, in contrast, stays firmly within the confines of monogamous, heterosexual romantic love, but its hook, the romance between two men and one woman, provides a sufficiently exotic scenario for those readers looking for a titillating new romantic scene. As Lehmiller's study suggests, the proliferation of threesome fantasies may help explain the emergence of this subgenre: readers interested in threesomes perhaps seek to broaden their horizons by venturing to explore the fantasy, but from the safety of reading fiction.

The contemporary e-romance constantly needs new fuel for its formula varying relatively little yet needing a gimmick on which to capitalise. Threesome romance is therefore a prime example of a key ingredient in "the winning formula" (Valovirta 2019: 172): it offers the traditional obstacle to love always required by romance, but is completely new in that there are two prince charmings instead of one. This threesome scenario offers heightened tension creating thrill and suspense in the reader. The utopian element of the threesome romance frees the romance script from societal norms, while at the same time stays confined to those norms, as the end result is without fail a loving, consensual and committed relationship between the three romantic partners.

A romance narrative always needs of an obstacle challenging the budding love between prospective partners, as without hardship, there would hardly be a great love story (see Belsey 1994: 22). At the same time, this obstacle needs to be overcome in an effort to satisfy the requirement of happily ever after, the selling point of the romance narrative. In the case of the MFM menage, the obstacle complicating the plot is the social taboo of multipartner romance and romantic relationship, as the monogamy-driven social order becomes fundamentally undone in the prospect of a heroine romancing two suitors. At the same time, for the sake of achieving the mandatory happy ending, the obstacle 
needs to be overcome fairly effortlessly so as not to disturb the narrative with too much unwanted drama, which would stir feelings outside of the affective matrix of pleasure, fascination, titillation and arousal. The love obstacle in NA romance is therefore more of a minor speed bump than a genuine dealbreaker seen in tragic romances like Romeo and Juliet and its multiple retellings. The technique is quite utilitarian: take a social taboo, create a love story around the issue rendering prospective relationship precarious, but in the end, resolve the conundrum in one fell swoop. The threesome romance is a prime example of how this formula works in practice, as will be demonstrated in the following.

\section{Close Reading with Feeling: Repetition and Specificity}

A representative passage selected for close reading in this section is from the novel Two Billionaires for Christmas: An MFM Menage Romance (2017) by Sierra Sparks and Juliana Conners. While all the novels in my selection feature explicit sexual acts in abundance, the excerpt here portrays developing sexual tension between the female protagonist, Mandy, and the men fancying her, Clayton and Carl. The acts of sex themselves are portrayed as deeply erotic and mutually consensual, but do not necessarily offer interesting material for close reading in terms of the strategies by which the novels aim to impact their readers. The argument put forth by way of this close reading exercise clarifies, how the novels work to establish a mutual value base and carefully negotiates consent before entering a sexual stage in the relationship. All novels in the corpus contain a similar development, where the interested parties come to terms with and negotiate the potential relationship. Such a scene serves the purpose of speeding up the plot and clearing out obstacles leading to the main action, sex. The two brothers at the centre of Sparks and Conners' narrative, Clayton and Carl, run a successful airplane engine parts company and have hired Mandy as an assistant. At the same time, they decide to offer her a place to stay in their beach house as she has just broken up with her meth-dealing boyfriend and is at the risk of being homeless.

The two gentlemen coming to the aid of a "damsel in distress" is explicitly referred to in the narrative, when Carl speaks on behalf of the two brothers: "We Plemmons brothers-we can't help ourselves when it comes to a damsel in distress, so we found you a place [to live]" (emphasis added). This nod to con- 
vention shows how self-aware this type of romance is in recycling romances of the past.

Further details about Mandy and the two brothers desiring her are dropped throughout the story in order to establish an air of authenticity and relatability between the reader and the text's characters. Mandy characterises herself as 5'6" tall, curvy, and she looks "a little like Rebel Wilson, but with auburn hair and a prettier face" (Two Billionaires, loc. 138 of 24822, Kindle). In more than one case, in fact, the heroine is described as plus-sized, like in In Two Deep, which is by its subtitle referred to as a BBW (Big Beautiful Woman) romance. In the story, Julie refers to "her plump backside" (In Two Deep, loc. 38 of 703, Kindle) and in Two For One Special, Macy is aware she "might not be razor thin", but that "men liked a round butt and ample boobs" (Two For One, loc. 31 of 552, Kindle). This deviation from the body norm is needed to accentuate the female protagonist's voluptuous sensuality and, perhaps, also to interpellate the expected target demographic of 'ordinary women'. Mandy's suitors, the Plemmons brothers, in turn, golf, wear tailored suits, but have tattoos, and are obviously billionaires.

Naturally, as it becomes clear, despite their muscular, tattooed bad boy outlook and street credibility, all the men in the novels always make sure to practice safe sex and wear condoms when having sex with the heroine. The only case in the corpus, where condom use is not explicated, is in Carnay's In Two Deep, where the woman, Julie, lets her friends-turned-lovers, Jake and Conner, know that she is on the pill and thence further contraception is not needed. In all other novels, the lovers eventually discard condoms after having "the Talk" securing exclusivity. Such an attention to detail means credibility, anchoring the narrative into specific little minutiae like tailored suits and what cars they drive (Mandy, for example, has a 2002 Hyundai) in order to make it appear authentic. Readers are clearly not satisfied with just sex, as in visual or textual pornography, which usually only offer vague pretexts that fly out of the window the moment when sex begins. Here the prelude to sex is the long build-up needed before the narrative's climax.

The passage in a chapter narrated by Carl in Two Billionaires begins with Clayton and Carl's one on one discussion probing the possibility of both of them pursuing Mandy instead of having to decide which one of the two gets her:

Clayton and I had run into this situation before. "We could share her," I proffered. [...] "Dude, this is crazy enough, that we both want to fuck our new 
hire," Clayton said. "Don't get me wrong, I'm willing to share if she is but-" "Well, what's your read on her?" "I mean, she seems pretty sexual. Right before you walked in, I was describing what l'd do to her and she was pretty into it." [...]

"Okay, so we explain to her. She'll either be into it or not, right? Besides, doing two brothers. That has a certain mystique, right?" "Some women might think so, yes." "But we have to play our cards right. We don't want it to come off as creepy." [...]

"Hey, Mandy," I started. "I hope I didn't scare you by barging in like that before." "No-no, it's fine," she assured. "I'm just so happy to have this opportunity." "Well, we're happy to have you," I assured. "And the Plemmons brothers-we can't help ourselves when it comes to a damsel in distress, so we found you a place." "Oh, my Cod, seriously? Already?" she said, her big beautiful eyes going wide. "Yeah," explained Clayton. "Carl reminded me: We have this summer rental near the beach. This time of year, no one's using it. You'd actually be doing us a favor by staying in it and keeping an eye out on the place." "Wow, I don't know how to thank you guys," she gushed. "I insist you charge me something." "Honestly, we were paying to have the place cleaned. You clean it, you can stay there until you find some place better," assured Carl. "As for thanking us..." "Carl!" interrupted Clayton. "What? I gotta come clean," said Clayton. "About what?" she asked. "You are very qualified for this position, the most qualified in fact. But when I saw your picture on LinkedIn, I was smitten. Seriously. Just like my brother here. We have similar tastes in women. I hope you don't find that weird," said Carl smoothly. "No, it's very flattering," she blushed. "I find you both very attractive." "Well, the thing is-and this is completely separate from our offer to let you stay at our beach house, mind you —Clayton and I might like to share you, if you get my meaning. Is that something that interests you?" (Two Billionaires, loc. 643 to 687 of 24822 , Kindle)

Recurrent features in this passage, which best exemplify typical forms in this genre, are the plain, conversational style and first person plural dialogue, where the brothers profess a shared mindset as a sign of unity and consent. "We" and "us" are mentioned some twenty times during the scene from which the above passage is abridged. This is a common scene in the novels, where the initiative comes from the men; it is explicitly what they want. Furthermore, it is not just a threesome that they desire, but a relationship thus tying the novels into the romance genre and its maxim of happy ending. The func- 
tion of this negotiation is also to add a dimension of the real to the narrative; you do not just jump into a threesome without establishing common ground. In pornography, such a move would be possible, but not in erotic romance fiction.

The rules of the genre, in other words, require this back and forth told in alternating first person narrative perspective (or alternatively, third person omniscient), which ascertains that each party relates their thoughts straight to the reader without leaving out any of the relevant angles out of the figuration. When the reader gets access to all three main characters' thoughtprocesses, the narrative is able to establish a relationship of intimacy with the reader, who in a sense is the fourth wheel in this carriage proceeding at a steady pace towards its climax, threesome sex.

In the chapter following the brothers Clayton and Carl's deliberation, Mandy's inner monologue reveals to the reader her decision-making process, serving the reader with Mandy's musings on the intriguing proposal and thus advancing the plot:

I couldn't believe the day I was having. Cod, I get so down sometimes and then the whole day just turns around. Not one, but two amazing bosses. So nice (so attractive), and so willing to go out of their way just for me. [...] I had a proposal to think about: two billionaire, boss brothers at once. [...] [T]he brothers had made it clear that they both wanted me. How could I choose between those two? I mean, they were both amazing looking. Clayton was young, taut and dreamy. Carl was rugged, wild and manly. Just thinking about them got me wet.

[...]

I thought I would choose, but it was inevitable that I was going to be with both of them at the same time. The three of us had to do it. (Two Billionaires, loc. 713 to 786 of 24822 , Kindle)

After this meditation, Mandy is saved the trouble of verbalising her consent, as when she has settled into her new beach house given to her to live in for free by the brothers, they walk in on her masturbating to the thought of sex with the two brothers. Threesome sex proceeds followed by establishment of a threeway relationship. There is one further complication of plot by the reappearing ex-boyfriend, when heroes fight the villain and the threesome has sex again to celebrate. Afterwards, the brothers propose with two diamond engagement rings and the narrative closes with plans of a future together. 
As we can expect readers to, generally speaking, consume erotic romance literature for its affective and sexual quality, these conventions detailed above (such as the brothers' first person plural propositioning and Mandy's inner monologue) have a function in driving the plot and the story. Questions like "opacity" or "gap-filling" which Leech \& Short mentioned as factors of the writer and reader's creativity alike (Leech/Short 2007: 24), actually seem to have little function in contemporary popular romance writing. Readers are not expected to be creative, but rather, the texts are transparent in revealing what they need to communicate for the reader to be safe to enjoy themselves. Readers are served by the text and nothing is hidden. As Eva Illouz remarks, romance is full of "insistent meanings" (Illouz 2014: 40) and she calls for reading strategies pointing out those meanings which are "explicitly and consciously intended to cater to the readers' expectations" (ibid.). This way, we get access to those mechanisms, which lend these texts their power.

Another important factor in serving the reader with transparency, are the paratexts revealing major plot points about the novels before the reader has even purchased their copy. I have previously remarked on the paratexts surrounding the books on their Amazon pages and in text samples, such as no cheating and HEA (happily ever after) as a warranty establishing shared value base with the consumer (Valovirta 2019). The reader is then free to 'go' with the text when not having to doubt its design. The text's mechanisms thus enable a very safe seduction, when the reader gets access to all motives, thoughtprocesses and decision-making surrounding the budding romantic and sexual relationship, and does not need to be kept on their toes regarding whether the resolution is what they want: full closure and a happy ending.

An important point in the passage from Two Billionaires advancing the plot is Mandy's decision: "I was going to do it". This is her decision and moment of consent, which further reassures the reader that the juicy material (sex) will soon materialise. Such rationalising helps alleviate the concerns that would surround a real-life corporate HR nightmare thanks to the power imbalance involved in the scenario of two bosses sleeping with an underling. These types of obstacles quickly disappear, when love conquers all takes over as the ultimate rationale. Mandy's explicit voicing of her consent to the reader finds its counterpart in the excerpt at the beginning of this section, where the brothers essentially perform a very quick and efficient SWOT (strengths-weaknessesopportunities-threats) analysis of the prospect of sex with Mandy and decide to move ahead with the plan. 
Another aspect smoothing the way to a safe reading experience besides these negotiations under my close reading is the fact mentioned earlier, that all novels in this genre practice safe sex. Sex scenes in contemporary erotic romance very conspicuously mention faithful condom use when practicing intercourse (see Valovirta 2019: 170). For example, in the seminal book of the genre, Fifty Shades of Grey, condoms are mentioned nineteen times, whereas in the author's latest novel, The Mister, published in 2019, there are a total of thirty-three mentions. The same strategy applies to the novels in my corpus: condom use is dutifully mentioned at each onset of intercourse (save for one novel, In Two Deep, where the lovers already know one another as friends). The readers of contemporary erotica need not just any old romance for pleasure and leisure: the text also needs to cater to their values. Such a relationship of trust between the text and the reader facilitates the act of reading and thus increases pleasure, which then means that the novels work for the intended purpose.

In its persistent tendency to repeat itself, the threesome romance narrative relies heavily on the power of repetition to satisfy readers. Pearce notes that the romance genre in general owes a huge debt to repetition, to the point of compulsion, as the Western civilisation has been preoccupied with retelling the same story and "romance has become synonymous with the promise of 'happy endings"' (Pearce 2011: 7). In this case, the repeated elements, such as the negotiation between the two men in the above passage, including their use of the first person plural, and repetition of the personal pronoun we, are about confirming to the reader, that the novel's content will adhere to the expected romance script. This promises to the reader, that both pleasure and happiness will be repeated in due course and not by only one, but two lovers.

\section{The Act of Reading: Digital Reading Requires Repetition}

Empirical studies of digital reading help explain the connection between these repetitive features such as the negotiation, voicing of consent and condomuse and the way they are supposed to affect the reader. On-screen reading is perceived to be "less emotionally involving" and there is a shared cultural belief that digital reading provides less pleasure (Benedetto et al. 2013). Repetition is therefore needed to drive the point home. Furthermore, readers tested reading on screens are poorer at predicting their performance in comprehension as well as regulating their metacognition (Ackerman/Goldsmith 2011). There 
are also studies that indicate that transportation (the feeling of being 'transported' into the storyworld) is less common when texts are read on digital screens (Mangen/Kuiken 2014). Spelling out and explicating the plot's turning points is thus needed in order to make up for the reduced capacities of retaining information and forming predictions and to facilitate transportation. At the same time, these "impairments" on readers reading digitally may serve to increase their excitement levels as they are not as concerned with reading analytically when reading for leisure. Studies also show that readers are more detached from the text when reading on screen (Mangen 2013: 95), which means that more help in immersion (and therefore, potentially, arousal) is needed by repeated, familiar conventions such as condom-use. Lack of safe sex might lead to a pause in the flow of reading, when the reader might stop to think whether potential sexually transmitted diseases are at stake.

Therefore, ensuring that the literary content is belief-consistent with the reader is part and parcel of customer satisfaction, as the reading process must flow uninterrupted by unwanted complications challenging the capacity of the reading experience to elicit pleasure. Eye-tracking studies charting readers' cognitive processes establish, that readers are likely to have less lookbacks and take less time to read a text which is in line with their own prior beliefs (Maier et al. 2018). ${ }^{3}$ The reading process is likely to be faster than when encountering conflicting beliefs. Fixating less on those elements of a text that are consistent with one's own beliefs also means that the texts fit a contemporary, busy everyday life, where moments for reading may be few and far between. For example, the Amazon sales page for one of the stories, In Two Deep, explicitly mentions the time required to finish the reading effort: the story promises to be one of "a series of sexy romances made to heat up your eReader one hour at a time". Here potential readers are provided with information on the time investment required to consume a title, and one hour here is deemed suitable a time to be mentioned. fully ascertain such results in this context, as most eye-movement tests in general are more interested in cognitive processes like reading skills (see Hyönä/Kaakinen 2019: 242) instead of other processes, such as affective responses like pleasure. Furthermore, it is questionable, whether eye-movement research would yield sufficient evidence on the matter (let alone whether scholars might be able to find test subjects willing to test their arousal levels). 
As genre fiction is designed for consumption, the book needs to be an easy read and to be finished in one sitting. An easy narrative keeps the reader swiping pages forwards, while not having to refer back in an effort to secure comprehension, which they are more likely to do in case of cognitively difficult texts (Hyönä/ Kaakinen 2019: 259). The market needs the reader to finish the book and purchase another one. We would need more empirical studies examining how digital vs. paper media impact on readers' affects and sensations (such as arousal) in reading the romance, but the results of the studies mentioned above apply to the overall scenario of digital reading and readers' values. Encountering belief-inconsistent material slows down the reading process (Maier et al. 2018: 182) and is hence likely to hinder pleasure, whereas popular romance as leisure reading needs to be sufficiently unchallenging in order for the reader to not be disturbed by unnecessary complications. Such a freedom from everyday strife with its complications, in fact, is a factor behind reading the romance in the first place, as established by Janice Radway's classic study on how and why women read romance novels (Radway 1984).

Then how does the literary text operate through power affecting the reader, who is engaged in their seemingly harmless, uncomplicated enjoyment of literature - literature, which at the same time is consciously designed to manipulate their desires? Rita Felski (2008) writes, how we might engage with literature through enchantment, a way to become seduced or enchanted by texts. She contends that "Women are often seen as especially prone to such acts of covert manipulation. Susceptible and suggestible, lacking intellectual distance and mastery over their emotions, they are all too easily swept up in a world of intoxicating illusions" (Felski 2008: 53). She also points out, however, that no cultural critic worth her salt would view woman consumers of popular cultural products - like romance - as uncritically yielding to the lure of the text (ibid.: 60). I share this view of attributing more intellect and critical attitude to the readers than the limits of the genre they consume may suggest. While Felski hardly mentions works of popular romance in her meditations on the uses of literature, she nevertheless is an ardent defender of the "ordinary reader". She writes that "literary theory would do well to reflect on - rather than condescend to - the uses of literature in everyday life: uses that we have hardly begun to understand" (Felski 2015: 191).

One way to understand the uses of erotic romance literature, as suggested in this paper, is through the Felskian lens of enchantment when viewed in connection with Lehmiller's study on sexual fantasy; these stories, simply put, 
provide readers with masturbation material. Curiously, there is no mention at all in Radway's early study on masturbation as one of the uses of romance. This has changed conspicuously as, at the risk of stating the obvious, the erotic romance is designed with the express intent of stimulating and exciting readers - that is, ordering their desires for enjoyment. If readers' needs are met in providing arousal through reading, the texts have quite simply fulfilled their purpose; they work.

If the novels' sexual acts correspond with the act of reading as a sexual act, as claimed by Elin Abrahamsson (2018), we need to further consider the masturbatory function of such novels as their primary pleasure point. Eve Kosofsky Sedgwick's seminal essay, "Jane Austen and the Masturbating Girl" (1991) posits auto-eroticism as a prototype of modern sexual identity, something subject to prohibitions and pathologising, especially for women. Thomas Lacquer remarks in his cultural history of masturbation, how it is a persistent taboo, hovering "between abjection and fulfilment" (2002: 13). At the same time, feminist and health studies like the tellingly titled Masturbation as a Means of Achieving Sexual Health (Coleman/Bockting 2013) reiterate the fact that masturbation reinforces sexual empowerment and healthy self-image, and is beneficial to well-being, but these results come foregrounded by the taboo history.

Abrahamsson's view of romance reading as primarily a sexual act for the Sedgwickian "female onanist" helps us infer, how it is the act of reading itself which rises as significant in the consumption of digital literature. Reading in its own right is the act, which provides arousal, titillation, seduction, and pleasure - perhaps even orgasmically speaking. Textual strategies dissected in this paper are not only needed in order to establish a relationship of trust between the text and the reader, but also in order to facilitate the act of reading and thus increase pleasure. The requirements placed on the text to fulfil certain criteria help us see them as results of readers negotiating their dealbreakers when looking for the perfect match, just like a successful romance is a contract negotiated before and during the act of reading. The repetitive loop of textual nods and gestures as explored in this paper, offers the reader pleasures and enjoyments in a highly formulaic and seemingly banal form of literature, which in the end reveals itself to be very consciously constructed and disciplined - something to be taken seriously. 


\section{References}

\section{Corpus}

Conners, Juliana (2017): Twice the Fun: A Bad Boy MFM Menage, Self-published Kindle ebook.

Carnay, Mary (2014): Two Close for Comfort, Self-published Kindle ebook.

- (2015): Two for One Special, Self-publised Kindle ebook.

- (2015): In Two Deep, Self-published Kindle ebook.

Sparks, Sierra/Conners, Juliana (2017): Two Billionaires for Christmas: An MFM Menage Romance, Juliana Conners' Sizzling Hot Press, Kindle.

Stein, Charlotte (2017): Not Safe for Work. A Billionaire Ménage Novella, New York: Swerve by St. Martin's Press, Kindle.

\section{Other Works}

Abrahamsson, Elin (2018): Enahanda Läsningar. En Queer Tolkning av Romancegenren (One-handed readings. A queer interpretation of the romance genre), Stockholm: Eureka, Ellerströms Akademiska 67.

Ackerman, Rakefel/Goldsmith, Morris (2011): "Metacognitive regulation of text learning: On screen versus on paper", in: Journal of Experimental Psychology: Applied, 17 (1), 18-32.

Belsey, Catherine (1994): Desire. Love stories in western culture, Oxford: Blackwell. Benedetto, Simone/Drai-Zerbib, Véronique/Pedrotti, Marco/Tissier, Geoffrey/Baccino, Thierry (2013): "E-readers and visual fatigue", in: PLOS ONE 8 (12): e83676.

Coleman, Edmond J./Bockting, Walter O. (2013 [2003]): Masturbation as a means of achieving sexual health, New York: Routledge.

Felski, Rita (2008): Uses of literature, Oxford: Blackwell.

- (2015): The limits of critique, Chicago \& London: The University of Chicago Press.

Hardy, Janet W./Easton, Dossie (2017 [1997]): The ethical slut: A practical guide to polyamory, open relationships, and other freedoms in sex and love, $3^{\text {rd }}$ edition, Berkeley: Ten Speed Press.

Hyönä, Jukka/Kaakinen, Johanna K. (2019): "Eye-movements during reading", in: Christopher Klein/Ulrich Ettinger (eds.), Eye movement research. An introduction to its scientific foundations and applications, Cham: Springer, 239-274. 
Illouz, Eva (2014): Hard-core romance. Fifty Shades of Grey, best-sellers, and society, Chicago: The University of Chicago Press.

James, E.L. (2012): Fifty Shades of Grey, London: Arrow Books.

- (2019): The Mister, London: Arrow Books.

Lacquer, Thomas W. (2003): Solitary sex. A cultural history of masturbation, New York: Zone Books.

Leech, Geoffrey/Short, Mick (2007 [1981]): Style in fiction. A linguistic introduction to English fictional prose, Harlow: Pearson.

Lehmiller, Justin (2018): Tell me what you want. The science of sexual desire and how it can help you improve your sex life, New York: Robinson.

Maier, Johanna/Richter, Tobias/Britt, M. Anne (2018): "Cognitive processes underlying the text-belief consistency effect: An eye-movement study", in: Applied Cognitive Psychology, 32 (2), 171-185.

Mangen, Anne (2013): "The digitisation of narrative reading: Theoretical considerations and empirical evidence", in: Joost Kirsch/Adriaan Van der Weel (eds.), The unbound book, Amsterdam: Amsterdam University Press, 91-106.

Mangen, Anne/Kuiken, Don (2014): "Lost in an iPad. Narrative engagement on paper and tablet", in: Scientific Study of Literature, 4 (2), 150-177.

Pearce, Lynne (2011): "Romance and repetition: Testing the limits of love", in: Journal of Popular Romance Studies 2 (1), 1-14, http://www.jprstudie s.org/2011/10/"romance-and-repetition-testing-the-limits-of-love"-bylynne-pearce/ (Last accessed: 25.02.2020).

Radway, Janice A (1984): Reading the romance: Women, patriarchy, and popular literature, Chapel Hill: University of North Carolina Press.

Sedgwick, Eve Kosofsky (1991): "Jane Austen and the masturbating girl", in: Critical Inquiry, 17 (4, Summer), 818-837.

Valovirta, Elina (2019): "No ordinary love: The romantic formula of stepsibling erotica", in: Joel Kuortti/Kaisa Ilmonen/Elina Valovirta/Janne Korkka (eds.), Thinking with the familiar in contemporary literature and culture 'Out of the Ordinary', Amsterdam: Brill, 160-179.

- (2021): "The stuff of which fairy tales are made: Royal romance, ordinariness and affectivity in the literary market", in: Irene Pérez-Fernández/Carmen Pérez Ríu (eds.), Romantic escapes: Post-millennial trends in contemporary popular romance fiction, Frankfurt am Main: Peter Lang, 75-94. 


\section{Appendix: List of Ménage Romance Texts}

List of ménage romance texts

\begin{tabular}{|c|c|c|c|c|c|c|}
\hline Title & $\begin{array}{l}\text { Au- } \\
\text { thor(s) }\end{array}$ & $\begin{array}{l}\text { Year } \\
\text { of } \\
\text { Pub- } \\
\text { lica- } \\
\text { tion }\end{array}$ & $\begin{array}{l}\text { Price } \\
\text { (USD) }\end{array}$ & Publisher & Safe sex & POV \\
\hline $\begin{array}{l}\text { Two Billion- } \\
\text { aires for } \\
\text { Christmas: } \\
\text { An MFM } \\
\text { Menage } \\
\text { Romance }\end{array}$ & $\begin{array}{l}\text { Sierra } \\
\text { Sparks, } \\
\text { Juliana } \\
\text { Conners }\end{array}$ & 2017 & 1.23 & $\begin{array}{l}\text { Cosmic } \\
\text { Letterz }\end{array}$ & $\begin{array}{l}\text { con- } \\
\text { doms }\end{array}$ & $\begin{array}{l}1^{\text {st }} \text { person } \\
\text { alternates }\end{array}$ \\
\hline $\begin{array}{l}\text { Twice the } \\
\text { Fun: } \\
\text { A Bad Boy } \\
\text { MFM Menage }\end{array}$ & $\begin{array}{l}\text { Juliana } \\
\text { Conners }\end{array}$ & 2017 & $\begin{array}{l}\text { gift } \\
\text { with } \\
\text { pur- } \\
\text { chase }\end{array}$ & $\begin{array}{l}\text { self- } \\
\text { published }\end{array}$ & $\begin{array}{l}\text { con- } \\
\text { doms }\end{array}$ & $\begin{array}{l}1^{\text {st }} \text { person } \\
\text { alternates }\end{array}$ \\
\hline $\begin{array}{l}\text { Not Safe } \\
\text { for Work: } \\
\text { A Billionaire } \\
\text { Menage } \\
\text { Novella } \\
\end{array}$ & $\begin{array}{l}\text { Char- } \\
\text { lotte } \\
\text { Stein }\end{array}$ & 2017 & 2.10 & $\begin{array}{l}\text { New York, } \\
\text { St Mar- } \\
\text { tin's } \\
\text { Press }\end{array}$ & $\begin{array}{l}\text { con- } \\
\text { doms }\end{array}$ & $\begin{array}{l}3^{\text {rd }} \text { person } \\
\text { omniscient, } \\
\text { internal } \\
\text { focalisation } \\
\text { on her }\end{array}$ \\
\hline $\begin{array}{l}\text { In Two Deep: } \\
\text { BBW Menage } \\
\text { Romance } \\
\text { (Mill Creek } \\
\text { Menage } \\
\text { Book 3) }\end{array}$ & $\begin{array}{l}\text { Marie } \\
\text { Carnay }\end{array}$ & 2015 & 1.23 & $\begin{array}{l}\text { self- } \\
\text { published }\end{array}$ & pill & $\begin{array}{l}3^{\text {rd }} \text { person } \\
\text { omniscient, } \\
\text { internal } \\
\text { focalisation } \\
\text { on her }\end{array}$ \\
\hline $\begin{array}{l}\text { Two For } \\
\text { One Special } \\
\text { (Menage } \\
\text { Romance) }\end{array}$ & $\begin{array}{l}\text { Marie } \\
\text { Carnay }\end{array}$ & 2015 & 1.23 & $\begin{array}{l}\text { self- } \\
\text { published }\end{array}$ & $\begin{array}{l}\text { con- } \\
\text { doms }\end{array}$ & $\begin{array}{l}3^{\text {rd }} \text { person } \\
\text { omniscient, } \\
\text { mostly } \\
\text { internal } \\
\text { focalisation } \\
\text { on her }\end{array}$ \\
\hline $\begin{array}{l}\text { Two Close } \\
\text { For Comfort } \\
\text { (Menage } \\
\text { Romance) }\end{array}$ & $\begin{array}{l}\text { Marie } \\
\text { Carnay }\end{array}$ & 2014 & 1.23 & $\begin{array}{l}\text { self- } \\
\text { published }\end{array}$ & $\begin{array}{l}\text { con- } \\
\text { doms }\end{array}$ & $\begin{array}{l}3^{r d} \text { person } \\
\text { omniscient }\end{array}$ \\
\hline
\end{tabular}





\section{Negating the Human, Narrating a World Without Us}

Mahlu Mertens, Ghent University (Belgium)

\section{"No Milkshake"}

no more drinks are served, no last call, no phone numbers exchanged, no tips, no taxi waiting anymore, no bicycle stolen, nobody pulls an all-nighter anymore, nobody sleeps, no hangover in the morning, no regret, no coffee, no breakfast, no soft-boiled egg, nobody staring at the water until it boils, no smile about something that's been said, nobody thinking about the other night,

no new encounters, no connection, no sweaty hands, no hands that don't know what to do, no feeling put into words, no words for it, no more words, no word for nothing.

no word for the feeling that everything comes to an end, no milkshake, no horror movie, no Casablanca, no black and white, no black, no white, no beggars, no arguments about them,

Nobody is afraid of what's coming next, nobody demonstrates, nobody keeps their photos in a box,

no future is imagined, no honey kept in jars,

nothing is given a name anymore, no celebration,

no Simon

no Hazel

nobody has to read a story before bedtime, no dragons, no good, no evil, no faith, nobody hopes that something won't happen, no bombs are thrown anymore, no bad news, no pain, nothing is ironic

no ending, nobody dies anymore, nobody digs a grave, no flowers, no coffin, no hands are folded, no eyes closed, no make-up, no last salute 
nobody misses anything anymore, the world doesn't miss anything nobody remembers what missing is, nobody can explain how it feels, nobody can talk about what's no longer there, nobody lives on in memory, nobody to tell it to, no room full of people, nobody gathers to listen in silence nobody hears the words to imagine a world of their own, no seven billion different worlds, not a single world anymore.

(Ontroerend Goed 2016: 24-25) ${ }^{1}$

The Anthropocene constitutes dramatic challenges to customary literary and artistic forms of expression. One such challenge is how to narrate humanity as a geological agent that is inscribing its existence on the Earth, leaving traces that will outlive the human species, or, as Margaret Ronda phrases it: how to narrate this "scaled-up' human culpability" (Ronda 2013: n. p.). The anticipatory melancholic grief that accompanies this realisation is often expressed through the form of a proleptic ecological elegy, a mourning for "events that have not yet (fully) happened" (Morton 2010: 254). Typically, such elegies are characterised by the future perfect tense: they weep for "that which will have passed given a continuation of the current state of affairs" (ibid.: 254), and this often goes together with the trope of the future reader. This is a "narrativeenabling device [that] provides a perspective from which the tale of ongoing human error can be narrated with the benefit of hypothetical hindsight" (Vermeulen 2017: 872). Such Anthropocene fiction, however, also contradicts literary excerpt. In another article on the same play, I write about the relationship between the geological archive and human archiving practices (World Without Us: "Staging the Geological Archive: Ontroerend Goed's World Without Us and Anthropocene Theater", in: Lit: Literature Interpretation Theory 31,1, 60-74). It can be read in companion with this article, which focuses on the narratological and formal characteristics of one specific scene in this play. 
the idea of total destruction: it warns against "total death, or the death of us" by using a future vantage point that implies that "consciousness goes on" (Morton 2010: 254). Most ecological elegies thus provide a consolation in the form of an imagined future "vision or referring eye" that will be there to interpret the traces that remain (Colebrook 2014: 28). In this paper I will do a close reading of the scene "No Milkshake" quoted above from the Flemish theatre play World Without Us by Ontroerend Goed to show how a proleptic ecological elegy can avoid such a future vantage point or referring eye beyond extinction. I will argue that this scene simultaneously engages in and problematises the ecological elegy, because its formal features highlight the contradiction in mourning the end of human existence, or the impossibility of mourning total destruction. I will first contextualise the scene "No Milkshake" by providing more information about the play and its staging, before I move on to analysing the actual excerpt. After that I will look at the formal features of the scene at two levels: the stylistic features at the sentence and word level and the form of the literary list on the level of the scene as a whole.

\section{Staging a World Without Us}

World Without Us imagines what geological and cultural archival traces of humanity would remain on Earth after our extinction. The performance is an artistic reworking of Alan Weisman's speculative non-fiction work The World Without Us (2007). In this book, Weisman describes among others how human infrastructure would collapse and eventually vanish, how concrete jungles would slowly turn into, or revert to, real jungles, how birds, cockroaches and other species would flourish, and which man-made products would be "our most lasting gifts to the universe" ("About the Book"). For the theatre adaptation Ontroerend Goed chose to take the physical setting of the theatre space as the starting point: World Without Us is a monologue for one actor who functions as a narrator, and who describes in a rather distant and factual tone what would happen to the theatre space if the human species suddenly disappeared. How long will the music in the theatre café continue? When will the small animals start to feel the absence of humans and come out of their hiding places? How long until the last remaining light, the emergency exit sign, will die out? And when the roof finally collapses, what will the world outside, and by extension the Earth, look like by then? 
The form of the play is stripped down and minimalistic: the cast consists of one actor-narrator whose only prop is their voice, and the stage is empty except for a dimly lit pillar. The presence of this narrator is minimised through the performer's costume of black clothes and the reduction of lighting (for a considerable time it is even pitch-dark). From the audience's perspective, the actor is often hardly more than a hint of hands and eyes. In fact, the identity of the narrator matters so little that the play is alternatingly performed by a male and a female actor. These formal choices help to direct attention away from the human presence in a play that largely depends on language - that is to say, one of the most human inventions - to represent a world without our species.

The performance explicitly takes the present, the here and now of the theatre space where the actor and audience are gathered together, as a starting point for a proleptic remembering of the geological archive. The opening words of the actor draw attention to the auditory stimuli that they are experiencing while listening to the audience that is settling in:

There's rustling, whispering here and there...

A chair creaks...

A body still looking for the right position...

The quick folding of a leaflet...

A sleeve softly brushes a jacket...

A handbag opens... (Ontroerend Goed 2016: 1)

The actor has their eyes closed and is standing with their back toward the audience, and it is only at the end of the opening monologue, when the narrator "deletes" the audience - and by extension humanity - from the narrative, that they turn around and look at the audience:

There's the rising and falling rustling of lungs filling up and letting go

[...] Almost inaudible: this concert of breathing in different tempos.

This is the sound of an audience being quiet while it's watching.

This sound vanishes now.

performer opens eyes. (ibid.)

The stage direction "performer opens eyes" marks the moment the narrator takes an imaginative leap into a non-human future. From then on, viewers oscillate between the here in the now and the here in the future, and they are simultaneously presently absent and absently present. This paradoxical double bind is also made explicit in the text, when the narrator says: "But then you can hear 
what's left. If everyone's gone, you can hear it" (Ontroerend Goed 2016: 2). For most of the play, the actor then imagines what would happen to a world devoid of humans and which evidence of our existence would remain, ever faster moving into the future by steadily accelerating the narrative speed from the human time of the opening scene to a geological time of centuries per second. The scene "No Milkshake", roughly three quarters into the play, by contrast, is a list and seems to be set outside time. The form of this scene stresses the ephemerality of social memory, by which I mean, drawing on Richard Klein, all the systems of cataloguing and retrieval in organised existence that make the transfer and interpretation of memories and knowledge - be it oral or written - possible (see Klein 2013: 83).

\section{Reading the Scene as a List}

On a macrolevel, the one characteristic that sets the scene quoted in the beginning of the article apart from the rest of the play, is its form: because it is a list, the temporal progression of the narrative is halted. Drawing on Werner Wolf's way of defining description and narrative (Wolf 2007: 33-34), von Contzen proposes to think of list and narrative as two poles on a continuum on which the former is concerned with "existential" phenomena and the latter focuses on "actantional representation" and in this scene the focus indeed shifts from action to existence (von Contzen 2016: 246). The term "list" can cover a wide range of concepts that includes special forms like calendars and catalogues as well as rhetorical figures such as the enumeration (ibid.: 244), but for my argument Robert Belknap's rather broad definition of the list suffices. He defines the list as "a formally organized block of information that is composed of a set of members. It is a plastic, flexible structure in which an array of constituent units coheres with specific relations generated by specific forces of attraction" (Belknap 2000: 35). The concept of the list can thus be regarded as a subcategory of description that is characterised by a formal framework "that holds separate and disparate items together" (ibid.: 35) and as such "implies a strong formal focus" (von Contzen 2016: 243).

In Imagining Extinction literary scholar Ursula Heise notes that, when trying to "convey a more panoramic view of mass extinction, artists and writers often resort to lists or catalogs" (Heise 2016: 55). She is mainly referring to the Sixth Extinction and for now, the human species is not a species that is endangered. Quite the contrary: as the IUCN Red List almost mockingly points out, 
we are listed as "Least Concern as the species is very widely distributed, adaptable, currently increasing, and there are no major threats" (Global Mammal Assessment Team 2008). However, the concept of the Anthropocene has created a heightened awareness of our potential future vulnerability as a species and considering the idea that the form of the list is well-suited to deal with existential phenomena, it seems not too surprising that Ontroerend Goed turns to the form of the list as a way to grasp the possibility of the end of human life. Fictional and non-fictional texts about endangered species often use catalogues to "accompany and complement the narrative [and to] evoke a numerical sublime of sorts, numbers too large to be contained by conventional storytelling procedures that focus on a discrete set of events, scenes, and characters" (Heise 2016: 56). In World Without Us, by contrast, the list is not used to evoke a numerical sublime, but to overcome another obstacle that the Anthropocene poses to conventional storytelling: how to represent humanity as a whole as a protagonist? More precisely, the assemblage in "No Milkshake" can be read as an effort to represent the abstract concept of, in this case, the finitude of human life.

As a literary form, the list holds a special position: even though we are used to "encountering and decoding lists in our everyday lives", a list that is part of a narrative text requires a lot of work from the reader, because it "break[s] open the sequential flow of the narrative" and draws attention to the text as form (von Contzen 2018: 323, 316). Because they "resist the immersive impetus and challenge readers on a cognitive level, requiring, to varying degrees, strategies of familiarization and narrativization in order to make sense of their meaning," lists have the potential to disrupt the narrative (von Contzen 2016: 246). In order to make sense of both the list as a whole and the items that are on the list, the list has to be integrated into the surrounding narrative (von Contzen 2018: 316). Due to the link to the everyday experience and practice of list-making, a literary list cuts "across the textual level and the level of content" and it is exactly this feature that allows the reader to 'read' the list (ibid.: 320 ). In short: as a form, or, more precisely, exactly because of its form, a list is immediately recognisable in a text and requires specific gapfilling processes for which readers can draw on real-life experience. As von Contzen explains: "The practice of list-making becomes the anchor by means of which we can read and decode the list successfully" (ibid.: 323). 


\section{Mourning the Loss of the Repertoire}

In order to successfully decode the list in "No Milkshake" - with members ranging from objects (coffee, milkshake, soft-boiled eggs, photos, flowers, coffins), over activities and abstract concepts (digging a grave, new encounters, connections), to feelings (the hope that something won't happen, the feeling that everything comes to an end) - the spectators need to activate certain schemata that allow them to fill in the gaps. The items in the first paragraph, for example, match the actions and images that fit within a flirting and bar schema, followed by a dating schema in the second paragraph and a cinema schema in the third paragraph. The fourth paragraph evokes family life, and the items in the fifth paragraph fit in a funeral schema. As "cognitive structures representing generic knowledge" these schemata provide "default background information" that helps to "compensate for any gaps in the text", or - in this case - the list, and together these five sub-lists evoke a life-cycle narrative from adolescence over parenthood to death (Emmott/Alexander 2014: n. p.). The last paragraph lacks a situational schema, but here the theme of (the absence of) remembrance binds the items together. In addition to the schemata, the larger narrative in which the list-like scene of "No Milkshake" is embedded and, most importantly, the stylistic features of the scene itself provide essential cues to decode and integrate the list. The repetitive use of negations, which annihilate every image that the narrator sketches beforehand, helps to signal that the shared characteristic of the items on the list is that they no longer exist. In other words, they foreground the "specific force of attraction" that holds the separate items in the list as a whole together: their absence (Belknap 2000: 35).

Up until the scene "No Milkshake" the play is mainly concerned with describing the traces humanity will leave on the earth, with the material memories our species will inscribe in the geological archive, but in this scene, the focus shifts from the archive to the repertoire, and, consequently, from what will be left to what will be lost, a shift that is marked by the repetitive use of negations. The repertoire, performance studies scholar Diana Taylor explains, is "a nonarchival system of transfer" (Taylor 2003: xvii). Whereas the archive consists of recorded memories that exceed the live and separates - in time or space - the knowledge from the knower, the repertoire enacts ephemeral, embodied memories and as such requires presence (ibid.: 19-20). Regarding the repertoire "people participate in the production and reproduction of knowledge by 'being there,' by being part of the transmission" (ibid.). The ex- 
tinction of the human species thus by definition implies the annihilation of the repertoire, of social memory. "No Milkshake" can be read as an elegy for all the aspects of human life that cannot survive in a world without us, from the very small act of "staring at the water until it boils" to the act of mourning itself. The chosen aspects stress that even if the material thing can outlive humanity, the social, personal and/or cultural meaning that we attach to it cannot, as for example the reason someone does not stay for breakfast after a one-night stand, or the emotional meaning attached to photos kept in a box.

Varied though the categories of items that are included on the list may be, as enumeration they can thus be read as an attempt to imagine the end of modern society by listing (aspects of) human forms of life that are gone. Anthropologist Stefan Helmreich defines forms of life as the "social, symbolic, and pragmatic ways of thinking and acting that organize human communities," whereas life form refers to the biological species (Helmreich 2011: 673). The list is, in other words, not so much concerned with the finitude of human life as a biological species, but rather focuses on the finitude of human life as "an assemblage of cultural forms" (Vermeulen 2017: 870). The short sentences, often mere phrases, help to create a tension between the list-like form on the one hand and the topic of this list on the other: they create a staccato rhythm that suggests a detached enumeration of facts, and that highlights the straightforward act of listing things, which contrasts with the content of the list, that can be seen as an attempt to grasp the totality of being human. Because the schemata allow the listener to fill in the gaps easily and almost immediately, the rhythm of the text could be said to evoke a flipbook effect: even though the images are not connected with clauses, the connections can be made so quickly that it seems as if the scene is playing out smoothly. The first sentences of the scene "No Milkshake" might still seem to refer to a typical human scene, an expression of human culture on an individual scale: a date that did not end as planned, because "no phone numbers [were] exchanged, [...] no coffee, no breakfast, [...] no smile about something that's been said". Or, alternatively, that did end as planned, because there are "no regrets". Soon, however, the narrator zooms out from this situation on the personal scale to the socio-historical scale - "Nobody is afraid of what's coming next, nobody demonstrates, nobody keeps their photos in a box, no future is imagined" to end at the geological scale at which "nobody misses anything anymore, the world doesn't miss anything" and it becomes evident that this is not a personal memory of a first date, but an imagining of the extinction of human life as we know it. With this in mind, the flipbook feeling created by the staccato 
rhythm can also be linked to the idea of one's life flashing before one's eyes right before one dies.

The stylistic features of "No Milkshake" underline the ephemerality of the repertoire. The most pertinent feature in this scene is of course the repetitive use of negations - starting with "no" and ending with the more specific "nobody" - which stress the theme of total annihilation. This is further emphasised by the physical action of the actor when they say (or actually do not say) the words: "no word for nothing." At this point, the actor stops moving their mouth, and it becomes clear that this elegy is actually recorded, thus highlighting the contradictory nature of the word "nothing", that, in its uttering, destroys what it signifies. They linger a little longer before disappearing from the stage on which their now disembodied voice continues the narrative. After that the text reminds the audience that they too should delete themselves from the act of mourning, both through the repetition of the word nobody, as well as through the sentence "nobody misses anything anymore". In combination with the absence of visual stimuli, these words create a heightened awareness of the essential role of human brains and bodies for the transmission of embodied memories.

The scene thus implicitly points out the pointlessness of what Jacques Derrida called "archive fever" (Derrida 2008: 92) which is, as Mark Currie explains, "the frenzied archiving and recording of contemporary social life which transforms the present into the past by anticipating its memory", by stressing the ephemerality of embodied memory and by wondering to what extent an archive that would outlive humanity - be it geological or cultural - would hold meaning without humans to interpret it (Currie 2007: 11). The choice for the form of the list further stresses that trying to narrate (the end of) human existence is an always already failed attempt. Firstly, because the list is an archival form par excellence and, as Taylor notes, there is a tension between the archive and the repertoire: even though, or exactly because "the archive endures beyond the limits of the live, [...] the live can never be contained in the archive" (Taylor 2003: 173). Secondly, because defining human life by enumerating aspects of it leads to a list that can, quite literally, go on forever, yet as a form, the list has by definition a clear-cut beginning and a precise end. As historian of science Geoffrey Bowker notes: by including "all and only a certain set of facts/discoveries/observations, [an archive or list] consistently and actively engages in the forgetting of other sets" (Bowker 2005: 12). Sometimes, however, lists "foreground their own incompletion as a way of pointing towards these things that exceed them, that cannot be listed or enu- 
merated (Eco 2009: 15-17, paraphrased in Heise 2016: 65). Ontroerend Goed is well-aware that as long as there is someone to enumerate, the enumeration of the end of human life is incomplete and this paradox is foregrounded in "No Milkshake" when the narrator stops moving their mouth and disappears from the stage on which their now disembodied voice continues the narrative. But even then, there is still an audience to hear the enumeration and as a consequence, the imagined total extinction is still out of reach. Sentences like "nobody hears the words," "nobody to tell it to," or "no room full of people" make the audience aware of this paradox by transporting them back and forth between the theatre space where they hear the words and the imagined nonhuman future.

In addition to mourning what will be lost, this scene also points out the upside of human extinction by including negative and destructive aspects of human behaviour. The sentences "nobody hopes that something won't happen, no bombs are thrown anymore, no bad news, no pain" have a universal ring to it, but in the context of the premiere of the play in 2016, right after the terrorist attacks in Brussels, Belgian spectators would probably immediately link this phrase to the emotions they felt at the $22^{\text {nd }}$ of March. The idea that such attacks could never happen again, provides some sort of comfort alongside the sadness for all the good things that would be lost.

The stylistic features of "No Milkshake", and in particular the use of negations as a structural element, convey a sense of nihilism as defined by Ray Brassier: the realisation "that there is a mind-independent reality, which, despite the presumptions of human narcissism, is indifferent to our existence" (Brassier 2007: xi). Each "no" negates part of the social memory of humanity and the long list of negations creates the sense of an enumeration that does not inventory what is left, but that annihilates everything it recites. The list is a negating catalogue of human forms of life, a black hole into which everything disappears: because the items are all preceded by a negation, every image that the narrator sketches is annihilated beforehand. This sentence structure has a similar effect to the instruction: "do not think of a pink elephant in a skirt." The negations paradoxically require the audience to imagine something, only to imagine its absence, as well as their own absence as the ones imagining this absence to begin with. This nihilism is further stressed by the use of the present tense: the directionality of time is from the present into the future. The present tense emphasises that "No Milkshake" imagines a prospective rather than a retrospective viewpoint: the scene works its way towards an imagined total destruction, rather than looking back from beyond 
the death of memory. It projects the audience into the imagined non-human future, but without providing the escape of a future reader.

\section{The Impossibility of Imagining Nothing}

"No Milkshake" simultaneously engages in and problematises the ecological elegy as a form, because it conveys the contradiction that lies at the base of a true ecological elegy: if the destruction is total, there is no one left to mourn. The sentences "no ending, nobody dies anymore, nobody digs a grave, no flowers, no coffin, no hands are folded, no eyes closed, no make-up, no last salute" explicitly reference the rituals surrounding death, thus providing the context in which an elegy has a place. However, the next sentence shows how futile the narrator's elegy would be in a posthuman world, because: "nobody misses anything anymore, the world doesn't miss anything". An elegy laments the dead, but in a posthuman world "nobody can explain how it feels, nobody can talk about what's no longer there, nobody lives on in memory". The simple negation "no" is replaced by "nobody" which specifically references the absence of bodies, and thus the impossibility of embodied memory. The last sentences of the scene annihilate the function of the elegy, by highlighting that the end of the repertoire also deletes the need for mourning: "nobody gathers to listen in silence, nobody hears the words to imagine a world of their own, no seven billion different worlds, not a single world anymore". In other words, even though it "maintains the importance of elegiac retrospection and its language of necessity and loss," "No Milkshake" highlights that "these conventions are finally inadequate to their current task," because the "elegiac language [...] speaks its own constitutive failures" (Ronda 2013: n. p.). The short sentences in combination with the use of ellipsis formally underline this falling short of language in describing the imagined extinction of our species. The scene thus "underlines the radical finitude of both the human life form and our forms of life" (Vermeulen 2017: 870).

To conclude, the form of the scene "No Milkshake" - a literary list — in combination with the stylistic features of the items enumerated on the list are crucial in emphasising the impossibility of mourning of the end of human existence and to undermine the scene's elegiac function by annihilating not only everything that can be lamented, but also everyone that could lament. The ultimate effect of the stylistic features - the present tense, the anaphoric use of negations, the staccato rhythm, the ellipsis and the repetition - is that the 
audience engages in a work of proleptic mourning that, by imagining total annihilation, provides a strange form of consolation. Alongside the sadness for what will be lost, there is the comfort that if humanity goes extinct, sadness as a concept has no meaning anymore, and the planet and the non-human world will not care about the archival traces - geological or cultural - that will be left.

At the same time, this elegy, I argue, comes closer to imagining total destruction than the typical proleptic ecological elegy, since, by using the present tense, it does not provide the consolation of a consciousness that will be there to remember. "No Milkshake" oscillates between lamentation and annihilation, between mourning and nihilism, and as such, it is simultaneously more fatalistic and less cautionary than the typical ecological elegy. Whereas most ecological elegies engage in "ethical mourning and melancholia in an ultimately hopeful attempt to create a better future" (Barr 2017: 191) or what Patricia Rae calls "activist melancholia", World Without Us is thus less a call to action than a critical examination of humanity's hubris and anthropocentric thinking, and, closely related, a call to ponder the inevitable and ultimate death (Rae 2007: 19).

\section{References}

\section{Corpus}

Ontroerend Goed (2016): World Without Us, TS, Theatre company's private collection.

- (2016): World Without Us, Video recording, Theatre company's private collection.

\section{Other Works}

"About the Book." Worldwithoutus, http://worldwithoutus.com/index2.html (Last accessed: 19.04.2021).

Barr, Jessica Marion (2017): "Auguries of Elegy: The Art and Ethics of Ecological Grieving”, in: Ashley Cunsolo/Landman Karen (eds.), Mourning nature: Hope at the heart of ecological loss and grief, Montreal \& Kingston: McGillQueen's University Press, 190-226. 
Belknap, Robert (2000): "The literary list: A survey of its uses and deployments", in: Imagination, 2 (1), 35-54.

Bowker, Geoffrey C. (2005): Memory practices in the sciences, Cambridge: MIT Press.

Brassier, Ray (2007): Nihil unbound: Enlightenment and extinction, Basingstoke: Palgrave Macmillan.

Colebrook, Claire (2014): Death of the posthuman: Essays on extinction, Vol. 1, Michigan: Open Humanities Press, http://www.oapen.org/search?identi fier=502353 (Last accessed: 19.04.2021).

Currie, Mark (2007): About time: Narrative, fiction and the philosophy of time, Edinburgh: Edinburgh University Press.

Derrida, Jacques (2008): Archive fever: A Freudian impression, Paperback ed., [Reprint], Chicago: University of Chicago Press.

Emmott, Catherine/Alexander, Marc (2014): "Schemata", in: Peter Hühn/Jan Christoph Meister/John Pier/Wolf Schmid (eds.), The living handbook of narratology, Berlin, München, Boston: De Gruyter, https:/www.lhn.uni-ham burg.de/index.html (Last accessed: 19.04.2021).

Global Mammal Assessment Team (2008): Homo sapiens. The IUCN red list of threatened species, https://dx.doi.org/10.2305/IUCN.UK.2008.RLTS.T13658 4A4313662.en (Last accessed: 19.04.2021).

Heise, Ursula K (2016): Imagining extinction: The cultural meanings of endangered species, Chicago: The University of Chicago Press.

Helmreich, Stefan (2011): "What was life? Answers from three limit biologies", in: Critical Inquiry, 37 (4), 671-696.

Klein, Richard (2013): "Climate change through the lens of nuclear criticism", in: Diacritics, 41 (3), 82-87.

Morton, Timothy (2010): "The dark ecology of elegy", in: Karen A. Weisman (ed.), The Oxford handbook of the elegy, Oxford: Oxford University Press, 251-271.

Rae, Patricia (2007): "Introduction: Modernist mourning", in: Patricia Rae (ed.), Modernism and mourning, Bucknell University Press, 13-49.

Ronda, Margaret (2013): "Mourning and melancholia in the Anthropocene", in: Post45 Peer Reviewed, June 2013, http://post45.research.yale.edu/20 13/06/mourning-and-melancholia-in-the-anthropocene/ (Last accessed: 19.04.2021).

Taylor, Diana (2003): The archive and the repertoire: Cultural memory and performance in the Americas, Durham: Duke University Press. 
Vermeulen, Pieter (2017): "Future readers: Narrating the human in the Anthropocene", in: Textual Practice, 31 (5), 867-885.

von Contzen, Eva (2016): "The limits of narration: Lists and literary history", in: Style, 50 (3), 241-260.

- (2018): "Experience, affect, and literary lists", in: Partial Answers: Journal of Literature and the History of Ideas, 16 (2), 315-327.

Weisman, Alan (2007): The world without us, New York: St. Martin's Press.

Wolf, Werner (2007): "Description as a transmedial mode of representation: General features and possibilities of realization in painting, fiction, and music", in: Werner Wolf/ Walter Bernhart (eds.), Description in literature and other media, Amsterdam: Rodopi, 1-86. 


\section{Refiguring Reader-Response: Experience and Interpretation in J.G. Ballard's Crash}

Ciarán Kavanagh, University College Cork (Ireland)

\section{Extract 1}

I remember my first minor collision in a deserted hotel car-park. Disturbed by a police patrol, we had forced ourselves through a hurried sex-act. Reversing out of the park, I struck an unmarked tree. Catherine vomited over my seat. This pool of vomit with its clots of blood like liquid rubies, as viscous and discreet as everything produced by Catherine, still contains for me the essence of the erotic delirium of the car-crash, more exciting than her own rectal and vaginal mucus, as refined as the excrement of a fairy queen, or the minuscule globes of liquid that formed beside the bubbles of her contact lenses. In this magic pool, lifting from her throat like a rare discharge of fluid from the mouth of a remote and mysterious shrine, I saw my own reflection, a mirror of blood, semen and vomit, distilled from a mouth whose contours only a few minutes before had drawn steadily against my penis.

(Ballard 2014: 8-9)

\section{Extract 2}

Gabrielle placed a drop of spit on my right nipple and stroked it mechanically, keeping up the small pretence of this nominal sexual link. In return, I stroked her pubis, feeling for the inert nub of her clitoris. Around us the silver controls of the car seemed a tour de force of technology and kinaesthetic systems. Gabrielle's hand moved across my chest. Her fingers found the small scars below my left collar bone, the imprint of the outer quadrant of the instrument binnacle. As she began to explore this circular crevice with 
her lips I for the first time felt my penis thickening. She took it from my trousers, then began to explore the other wound-scars on my chest and abdomen, running the tip of her tongue into each one. [. . . ] My first orgasm, within the deep wound in her thigh, jolted my semen along this channel, irrigating its corrugated ditch. Holding the semen in her hand, she wiped it against the silver controls of the clutch treadle. My mouth was fastened on the scar below her left breast, exploring its sickle-shaped trough. Gabrielle turned in her seat, revolving her body around me, so that I could explore the wounds of her right hip. For the first time I felt no trace of pity for this crippled woman, but celebrated with her the excitements of these abstract vents let into her body by sections of her own automobile.

(Ballard 2014: 147-148)

\section{Introduction: Reconsidering Reader-Response}

Reader-oriented criticism can take a multitude of diverse forms. Common to its focus, however, is a defining ideology which underscores the text as an experience: an event partaken in by individuals. Reader-oriented criticism thereby highlights the variability of this textual experience, shifting attention away from a unifying or 'correct' reading of a text to one which explores the text as a used, lived object, and the reader as the principal agent of interpretation. The analysing of these interpretive experiences sends critics to different theoretical and methodological corners, seeking answers to questions around the shape of such experiences, where and how they diverge or converge, or how these experiences affect their experiencer. Recent years have seen a renaissance in reader studies powered by developments in fields such as psychology and the cognitive sciences, which have provided invaluable new perspectives on old problems. As such, there has been a distinct, and distinctly new, quantitative turn in reader-oriented criticism. Stylisticians, in particular, have blazed promising new trails by exploring the wider claims of stylistics through quantitative, reader-focused methodologies (for a survey of these efforts, see Whiteley and Canning 2017).

However, the current renaissance of reader-oriented criticism owes much to the largely qualitative, literary focus of the reader-response founded by 
scholars such as Louise Rosenblatt, ${ }^{2}$ Judith Fetterley, Stanley Fish, Wolfgang Iser and Norman Holland. This iteration of reader-response waxed in influence in the late 1960 s and throughout the 1970s, and eventually waned in the early 1980s. The waning influence of reader-response has been interpreted in several ways. In retrospect, scholars have generally understood this not as the death of the field, but rather as the wide scale assimilation of reader-response's philosophies. In Jennifer Riddle Harding's words, reader-response was "folded into so many disparate and interesting approaches that now the emphasis on readers' interpretation is no longer a defining feature of a unified theoretical school, but a common praxis among many schools of criticism" (Harding 2014: 74). Patricia Harkin, however, while similarly seeing apotheosis, rather than death, in reader-response's disappearance, warns that its assimilation into wider theory has been at the expense of its affect, "the productive emotions that attended the notion that readers make meaning" (Harkin 2005: 413, emphasis in original). More controversially, Harkin further opines that reader-response lost academic cachet due to the fact that it wasn't "difficult" enough, and did not, therefore, serve as so arcane an intellectual currency that it distinguished its holder (ibid.: 415).

In this increasingly specialised age of reader-oriented criticism, whose various and varied explorations are well represented in this edited collection, it is thus important to underscore the theoretical and philosophical foundations laid by these early reader-response critics, and the legacy of their assimilation into wider literary analysis. While new reader-oriented projects have taken on the name of reader-response, it should be noted, with some few exceptions, that the original iteration of reader-response rarely stepped into quantitative or quantitatively informed analysis. ${ }^{3}$ The new quantitative

Louise Rosenblatt first outlined her 'transactional theory' in 1938, decades before the reader-response movement. When reader-response formalised into a movement, she returned to her transactional theory in The Reader, The Text, The Poem: The Transactional Theory of the Literary Work (1978), and other texts.

Norman Holland is the major exception here. Holland's work, however, while claiming a certain psychological rigour in its analysis of real readers, has not aged particularly well. His Five Readers Reading, for example, wherein he investigates the variety of response through prolonged interviews with the titular five readers, characterises these same readers through baffling descriptions ("a lapsed Catholic with aspirations toward aristocracy") and wildly inappropriate stereotypes (the single female reader as "a tall, very attractive woman, gentle and subdued in her manner") (Holland 1975: 3-4). Its worth to current response theorists is, therefore, limited. 
studies now being conducted under the name of reader-response would, in reader-response's original era, probably have been under the aegis of reception studies. Of course, the work taking place in one field informs that taking place in the other field, a movement of ideas that can only be of benefit to both. However, because the competencies required to conduct reader studies through quantitative methodologies (taken from psychology, cognitive linguistics, cognitive poetics, and so on) are becoming increasingly specialised, and the training necessary to do so increasingly arduous, engagement with the theoretical and philosophical foundations of reader-response has become increasingly rare.

This chapter is a small link in my wider project of revitalising the readerresponse built by the aforementioned theorists. This revitalisation is a critical one, underscoring both the weaknesses and strengths of reader-response's original embarkation, and refiguring it to specifically deliver on its philosophy of the reader as the locus of interpretation. Response theorists such as Fish and Iser, for example, attempted to centre the reading experience on a monolithic conceptual reader, who reads the text in a critically approved way, and has critically approved textual experiences. In this way, they sought to remove the reader variable from their analytical equation, or at least constrain it to a few approved differentials. However, this is contrary to the philosophy which they themselves espouse, whose focus is in the lived reality of the text, a reality neither limited to specially trained readers, nor circumscribed by their approval. True analysis of the reader as the supplier and experiencer of textual meaning requires extending critical attention to the reader as a variable, whose variances may conceivably determine the path to meaning more meaningfully than either the author's intention or the text's structure. The focus of this chapter is, therefore, twofold: firstly, to establish a methodological base for this type of analysis; secondly, to give substance to theory through its deployment in an analysis of J.G. Ballard's Crash (1973), specifically the unusual embodied experience of that novel, and the challenge of interpreting it.

\section{Situating Reader-Response}

While reader-response has always claimed to account for the experience of readers plural, its past deployments have generally relied on some form of conceptual reader: implied reader (see Booth 1961, Fish 1980), superreader (see Riffaterre 1966), informed reader (see Fish 1980), and so on. The concep- 
tualisation of a reader or readers, compared to gathering data on or from real readers, is largely what separates reader-response from reception theory. This differentiation, however, has rarely been complete: the reader conceptualisations of response theorists are generally informed by a knowledge of readers and reading groups, often from the courses taught by the theorists; ${ }^{4}$ while the framing and analysing of data in reception theory requires, itself, a form of reader conceptualisation. Moreover with the new means of incorporating the reader learned from the cognitive sciences, this differentiation appears to have, in recent years, more fully dissipated. Nevertheless, a conceptual reader (or readers) roughly serves to differentiate reader-focused literary analysis from reception theory, and other data-driven modes of reader and reading analysis. Of course, neither quantitative nor qualitative approaches claim to represent the experience of every reader: just as the response theorist chooses a conceptual reader in the knowledge of the types of readers thereby excluded, so does the reception theorist choose their methodology, demographic, scope, and so on.

The principal difficulty of reader-response, then, and the means by which its practitioners have been largely distinguished, is in the construction of this conceptual reader. This represents not only the methodology of the analysis, but the scope of the study. It may also be a magnet for the critic's own biases and experiences: in reader-response's founding era, response theorists typically imagined how academic or 'informed' readers might experience a text. In such a study, other potential reading experiences are then coded, variously, as tangential, marginal or simply wrong. Louise Rosenblatt and Judith Fetterley, however, buck this trend and truly give thought to the divergence of reading experiences and interpretations as fascinations to be studied rather than as anomalies to be constrained. Rosenblatt, for example, stresses how much the reader brings of themselves to the text, and underscores, without judgement, the reader's ability to read a text against cultural norms or the author's intention (see Rosenblatt 1938). Fetterley, meanwhile, says it is not only possible to read 'against the grain', but that, for most readers, it is necessary to do so to resist the process of self-marginalisation, a claim she contextualises against the white, straight, male domination of the American canon (Fetterley 1981: viii).

4 Stanley Fish, in particular, frequently draws on classroom discussions in his writing. For an example, see Fish (1980), 322. 
The conceptual reader of reader-response serves as a mechanism to limit the near infinitely possible lived experiences of the text. Despite this, it is yet the aim of the reader-response theorist to illustrate how real readers navigate, experience and use texts. However, by foregrounding the reader as the primary agent in the interpretive process, and the great differences which individual readers bring to their reading, the response critic likewise foregrounds the vastness of the territory which their analysis begs to explore. Emphasising the vastness of readers' responses serves, also, to emphasise the limited area which the response critic can explore. Of course, this is true of all criticism; however, part of the discovery of reader-response is the impossible extent of the unexplored. The limitations assigned by earlier response theorists to the reader figure were not, therefore, solely to delimit what they assumed to be the major, correct, or intended textual experiences: these limitations also arose from necessity. It is not, therefore, the idea of these limitations that particularised the studies of these early response critics, but rather the contours of those limitations, being the conceptual reader through which the text was 'read'.

\section{Redefining Limitations: Interpretive Frameworks}

The philosophy of reader-response propels the critic to read and analyse contrary to their usual methods or inclinations in order to reveal some aspect of the multitude of ways in which a text can be experienced. In essence, to understand the reader that does not read like they do, the reader-response critic must learn to read plurally. In practice, however, the foundation of reader-response analysis has typically been a restrictive conceptualisation of the reader, deployed to make navigable the infinitude of possible readings and experiences that texts, through explication by different readers in different cultures, eras and so on, contain. Nevertheless, the restrictions which defined past conceptualisations have typically been defined by an elitism, or have, at least, been principally concerned with academically informed readers. This leads to expressions of what the reader should do, must do, will do, won't do: predictions which cannot hope to accurately forecast the reality of how readers will read.

The refiguration of reader-response theory that I suggest is a refiguration of this limitation: analysing the experience of the text not through another conceptual reader, but rather a conceptualisation of the mental strategies, contexts and predeterminations with which readers create readings. I 
call these conceptualised knowledge systems 'interpretive frameworks'. Interpretive frameworks are the mental blueprints which provide readers with the contexts and cues necessary for interpretation. On the macro level, a formal interpretive framework may provide a reader with the context needed to know that we interpret a headline differently to a haiku. On the micro level, a generic interpretive framework may enable a reader to understand that a dilating door typically signifies that a text is science fictional. I specify 'may' here because a reader may not have the knowledge to navigate that particular interpretive quandary, but they still have an interpretive framework for science fiction. Even if this framework does not provide appropriate context in this instance, the reader may afterwards add dilating doors to their interpretive framework. Each text, therefore, provides new context for the next text. Thus, interpretive frameworks are elastic: composed of a gestalt of past experiences and capable of change through new experience. More simply, a framework is one's understanding of how things are and how things should or might be, ranging from grammar to genre to psychology.

Interpretive frameworks are, of course, metaphorical. The means by which we understand an individual's motives and the means by which we understand genre are not necessarily discrete processes; but, the idea of the framework is a useful discursive tool to denote the networks of knowledge which we utilise to understand not only new texts, but any new experiences. Thus, while we can sensibly discuss a reader's generic knowledge of science fiction and memoir as separate interpretive frameworks, this separation should be understood as discursive: a means of identifying the types of knowledge which a reader might bring to bear against a text, and the insights or interpretations that such context would provide. This analysis is not concerned with establishing a 'correct' or 'informed' interpretive framework, but rather analyses a number of the building blocks available for such frameworks, and what type of interpretations which might come from utilising the same.

Interpretive frameworks are essentially conservative mental processes in that they serve to familiarise the strange. Texts which subvert expectations, which defamiliarise, may be difficult to incorporate into one's pre-existing interpretive frameworks. Defamiliarisation, itself, is a challenge to the interpretive framework, potentially requiring a reassessment of how we have constructed them. Thus, if such subversions are to be incorporated into an interpretive framework, they may require a significant change to that framework. Genres, for example, can be seen as prototypical interpretive frameworks: a megatext of which individual texts are part, and against which the individual 
text will be contextualised. Texts which challenge the boundaries of a genre may require us to rethink how we define the category itself. However, such experiences are then added to the individual's interpretive framework (their understanding or knowledge of the wider genre), making future subversions easier to navigate, even expected.

Thus, texts which muddle the interpretive codes of customary interpretive frameworks, or which combine and subvert multiple frameworks (as in slipstream genres or avant-garde art) can be of particular interest to the readerresponse critic due to the fact that these subversions may serve to reveal the automatised expectations which they flout. J.G. Ballard's Crash is one such text.

\section{Crash}

Following a car accident in which another man is killed, Crash's protagonist, James Ballard, becomes deeply and obsessively involved with a group of highway-haunting fetishists who are aroused by the watching and staging of carcrashes. The novel is predominantly focused on detailing the minutiae of Ballard's new sex life, and minutiae is worth emphasising as Crash's descriptive focus is microscopic. Ballard's clinical overdescription of damaged and refigured bodies, as both author and character, turns the anatomist's gaze microphilic, descriptively dissecting the victims of car crashes, both human and mechanical. Their wounds, scars and disfigurements are thus elevated to "units in a new currency of pain and desire" (Ballard 2014: 109). ${ }^{5}$ This eroticised explication of wounds and wounding has led to Crash being described by many of its readers in a strongly visceral vocabulary: repulsive, disgusting, nauseating, sickening, etc. ${ }^{6}$

5 On usage of the word 'disfigurement', see page 2 of Disfigurement in the U.K by Changing Faces.

6 Critical analysis of Crash is noticeably lacking in discussions of wounded or disabled bodies as real bodies, rather than as aesthetic categories. The danger of this abstractification, and its potential offense, is captured in the pages of Science Fiction Studies, wherein Vivian Sobchak, recovering at the time from serious surgery, took deep offense to Baudrillard's celebration of Crash's world (see Baudrillard 1991; Sobchak 1991). Sobchak reminds us that the ability to consider these bodies as purely aesthetic categories is not the experience of every reader, and is a distinct privilege of non-disabled people. 
Crash is not simply an account of a fetish but is, itself, focalised through that fetish. Blood, mucous and semen are not described as they are, but are poetically distilled, eroticised, and apotheosised. The act of reading Crash is thereby fetishistically performative: it is in the reader's mind that these images may be given life. It is through the reader's creative efforts, not just Ballard's, that the transformation of bodily fluid to erotic manna occurs. It is, therefore, particularly suited to a reader-response analysis, as the imaginative and interpretive demands on the reader are both visceral and unusual.

I have elsewhere analysed Crash in relation to the grotesque, which, I argue, is a category defined by an affective profile: an irresolvable tension between humour, awe (both its positively and negatively valenced aspect) and disgust (see Kavanagh 2019). In this chapter, I will focus, first, on some of the reading experiences which Crash offers, principally the embodied experiences. With an understanding of how Crash might catalyse such experiences, ${ }^{7}$ this chapter then moves on to how these experiences might be interpreted. In the service of this analysis, I introduce pornography as an interpretive framework, examining why a reader might look to this framework for interpretive cues, explicating a number of the cues therein found, and illustrating the ensuing difficulties of trying to categorise Crash solely against this framework. This analysis focuses on the interpretive 'nodes' in two excerpts, for which a reader may require recourse to these wider frameworks.

\section{Close Readings}

The following two excerpts describe incidents in which the protagonist, James Ballard, has sex in a car. Neither of these excerpts are unusual in Crash, and the language is relatively similar to that of the rest of the novel. The first excerpt occurs prior to the narrator's own collision and ensuing involvement with the fetishist group, and the latter after. The excerpts are chosen for the means by which the contained language muddles contradictory interpretive codes, in particular, the means by which catalysts which reliably arouse embodied feelings of both sensory and moral disgust are played with, even aestheticized, through language and metaphor associated with awe and the sublime. inert, requiring an active agent to spark change. I refer to textual features as catalysts to emphasise the reader as the agent of interpretation. 
I remember my first minor collision in a deserted hotel car-park. Disturbed by a police patrol, we had forced ourselves through a hurried sex-act. Reversing out of the park, I struck an unmarked tree. Catherine vomited over my seat. This pool of vomit with its clots of blood like liquid rubies, as viscous and discreet as everything produced by Catherine, still contains for me the essence of the erotic delirium of the car-crash, more exciting than her own rectal and vaginal mucus, as refined as the excrement of a fairy queen, or the minuscule globes of liquid that formed beside the bubbles of her contact lenses. In this magic pool, lifting from her throat like a rare discharge of fluid from the mouth of a remote and mysterious shrine, I saw my own reflection, a mirror of blood, semen and vomit, distilled from a mouth whose contours only a few minutes before had drawn steadily against my penis. (Ballard 2014: 8-9)

Noël Carroll describes disgust as the "emotion that has been adapted to guard the intimate borders of the human body - mouths, nasal passages, genitals, and so forth" (Carroll 2013: 98). This forms an easy comparison to Bakhtin's seminal description of the grotesque as that which is concerned with the limits and violations of the body's physical seal, which "ignores the impenetrable surface that closes and limits the body as a separate and completed phenomenon" (Bakhtin 1984: 318). Disgust, therefore, arises from core grotesque features, being the impure, the breached, the contradictory and the crosscontaminated. ${ }^{8}$ This first extract is directed by the progressive breaching of the bodily seals: mouth, rectum, vagina, penis, and even the point where the eye meets the contact lens. Moreover, these seals are not only breached, but their porousness, their openness to the world, is emphasised by the passage of bodily fluids through them: vomit, blood, mucous, excrement, tears, semen. In their combined pool, Ballard looks and sees a reflection of himself: a fascinated, aroused and unashamed Dorian Gray, whose lesson is not the ugliness of debauchery, but its sublime beauty.

It is not only, therefore, catalysts for disgust which are worked into Crash. In this first extract, strong disgust catalysts are specifically combined with those typically used to convey feelings of awe and beauty. Through the narrator's fetishising gaze, the disgusting is literally (and literarily) distilled into the awesome. Clots of blood in vomit are as red as rubies, while the vomit itself 
emerges as the miraculous discharge from a rare shrine and is distilled (purified) by the contours of a mouth previously engaged in oral sex. Excrement is sanitised through its production by a fairy queen. The miniscule, a reliable catalyst for awe (Keltner and Haidt 2003: 310), is likewise invoked through the fine detailing of Catherine's contact lenses, and the globes of liquid which form alongside them. This dialectic is not unique to this extract, but is the defining trend of Crash: the aestheticization and abstractification of the horrific and the disgusting. In the first extract, this is attempted through tying each disgust vector to a sanitised mystical or divine image. Catherine's vomit is thereby presented on a silver platter to be perused and enjoyed.

Gabrielle placed a drop of spit on my right nipple and stroked it mechanically, keeping up the small pretence of this nominal sexual link. In return, I stroked her pubis, feeling for the inert nub of her clitoris. Around us the silver controls of the car seemed a tour de force of technology and kinaesthetic systems. Gabrielle's hand moved across my chest. Her fingers found the small scars below my left collar bone, the imprint of the outer quadrant of the instrument binnacle. As she began to explore this circular crevice with her lips I for the first time felt my penis thickening. She took it from my trousers, then began to explore the other wound-scars on my chest and abdomen, running the tip of her tongue into each one. [. . .]

My first orgasm, within the deep wound in her thigh, jolted my semen along this channel, irrigating its corrugated ditch. Holding the semen in her hand, she wiped it against the silver controls of the clutch treadle. My mouth was fastened on the scar below her left breast, exploring its sickle-shaped trough. Gabrielle turned in her seat, revolving her body around me, so that I could explore the wounds of her right hip. For the first time I felt no trace of pity for this crippled woman, but celebrated with her the excitements of these abstract vents let into her body by sections of her own automobile. (Ballard 2014: 147-148)

In the second extract, Ballard, in his descriptions as author and ministrations as character, fulfils the entirety of Bakhtin's grotesque conventions: that which is rooted in "exaggeration, hyperbolism, [and] excessiveness" (Bakhtin 1984: 303), and "orientated around the limits of the body, the violation of the body's physical seal, its interaction with the outside world" (ibid.: 317). Gabrielle's scars and wounds are here treated as new orifices and protuberances, and become the focus of Ballard's attention. Moreover, these wounds are not treated neutrally, but are laden with disgust-arousing imagery. Bal- 
lard's first orgasm (leaking, flowing) is spent not only in a scar, but one described as a "corrugated ditch," connoting both a jaggedness and dirtiness. This semen, a potential disease vector, is lifted from this scar and smeared around the car. Another wound of Gabrielle's is described as a "sickle-shaped trough," invoking the dining table of the animal, and is explored by Ballard's tongue. Gabrielle is progressively mechanised: her clitoris an inert nub, her body revolving, and her wounds imagined as "abstract vents," thereby associating her body with the mechanical exhalation of hot (foul) air.

However, while Ballard's descriptions render these wounds in disgustladen language, it likewise imbues them with a type of beauty which falls between an eroticisation and an aestheticization. While to even attempt such an aestheticization has the potential to inculcate a certain sociomoral horror and disgust, it also gives readers the 'safer' option to invest their creative energy in an appreciation for Ballard's artistry. Keltner and Haidt posit that "art can produce awe by rendering exceptional moments in time that are signs of vast, powerful forces," adding that "works that challenge and that involve obscurity are more likely to induce awe" (Keltner/Haidt 2003: 310). Ballard's style of writing combines a specificity of detail with an ideological and aesthetic vastness, visible in both the scope and constancy of Crash's project and in its alternatingly apocalyptic and divine meditations on the postmodern world. According to Keltner and Haidt, this manner of awe is likewise fertile for a sublime experience as it involves a fear or danger that is distanced and partially neutralised (ibid.: 304), allowing prolonged meditation on Ballard's artistry.

Florian Cord, for example, contextualising Crash against Kristeva, Foucault and others, understands Ballard's characters as having lost their horror of the abject, a condition which he describes as liberating, figuring their acts through sublime and divine language (see Cord 2017: 44). Considered against particular scenes where Crash's characters break a number of sexual taboos - such as Ballard's amorous encounter with Vaughan wherein he notes the "faint odour of a woman's excrement clinging to the shaft of his penis," before taking it into his mouth (Ballard 2014: 166) - Cord argues that these actions are those of men liberated from the paternal laws of guilt, shame and embarrassment (see Cord 2017: 45). Cord thereby transfigures, through complex philosophical and aesthetic interpretive frameworks, scenes with intense disgust vectors into images of sublimity, of men rising above deeply embedded cultural taboos. While the catalysts for a sublime experience are, as explicated, latent in Crash, Cord's transformation of the novel's negatively valenced em- 
bodied effects figures these interpretive frameworks as liberatory, and their exercising in Crash as a means of defamiliarising ourselves from such taboos.

\section{Interpreting Crash}

The core challenge of Crash, and the reason why it is chosen for this casestudy, is its disruption of the signs which point readers toward relevant interpretive frameworks. In short, it is difficult to find explanatory contexts to make Crash's dangerous strangeness familiar, to answer the basic question of 'why'. Nonetheless, interpretation is the prerogative of the reader, not the text. And, even when the text makes this process more difficult, or even troubles the idea of interpretation itself, the text itself is never entirely alien, only alien to. Thus, even by their strangenesses are such texts contextualised, and, through such context, interpreted.

What frameworks, then, do readers have at their disposal when decisions, both microcosmic and macrocosmic, need to be made about Crash? Firstly, Crash clearly has some of the codes to suggest it can be contextualised against a specific genre of play, wherein play is part of the text's ontology: pornography. In both extracts, though more clearly in the second, we have clearly pornographic scenes, structured in relatively generically familiar ways: seduction, leading to foreplay, climaxing with the male orgasm, and told through a descriptive focus on the body which allows for the reader to more fully imagine, or imagine themselves into, the scene. As an interpretive framework, therefore, pornography may provide necessary interpretive context.

Contextualising Crash solely against one's knowledge of pornography can, of course, be complicated by a concurrent imagistic focus on car parts, wounds, and a fetishisation of said wounds, along with the various things that leak from cars and bodies. Crash's potential to arouse may, therefore, appear overwhelmed by its proclivity to disgust; however, the erotic is yet present in those same disgust catalysts and, as seen in Cord's interpretation, disgust may be overcome or sidestepped by the reader. The mixing of the potentially disgusting and arousing may also serve to underscore their near paradoxical relationship. Sex, while complicated by an unusual fetish, is still the focus of the narrative. Moreover, while the embodied experience of disgust can surely deflate those of arousal, arousal and disgust are also interlinked. To return to Bakhtin's language, both sex and the grotesque are orientated around protuberances, orifices, leaking, flowing and the piercing of bodily 
seals. By this definition, all sex acts are grotesque acts. Interpreting Crash as pornographic, as intended to arouse, certainly remains problematic, but it remains possible, with this possibility, itself, revelatory of the grotesqueness of even non-automotive themed pornography. And, of course, the reader may share Crash's symphorophilia, and have interpretive frameworks, and erotic preferences, readily made for the novel's strangenesses.

Ballard's portrayal of the body is grotesque in itself; however, the fact Crash's many imaginitively wounded bodies are eroticised, treated as desirable, amplifies this grotesqueness. Ballard's treatment of the damaged body breaks from conventional representations of such bodies because it does not ask the reader to gag at, gape at or fear it, nor to sympathise with it, but to be aroused by it. This eroticisation may trigger the generic codes of pornography in an arena where acting upon them would be highly troubling. A reader finding themselves titillated by Crash could find such an experience distressing. It may, specifically, set a reader in a conflict with their own body if they disapprove of the arousal due, for example, to cultural taboos around the fetishisation of disability. Applying a pornographic interpretive framework to Crash can, therefore, make sense of certain aspects of it, but may fail to provide appropriate context to others, or even provide a context whose inappropriateness is disturbing.

Further complicating this dialectic is the particular language in which these acts are described, which not only emphasise the disgusting potential of sex acts, but concurrently resist the potential to abstractify the sex acts into pornography through clinical overdescription. Though the content is pornographic, the telling of it is not only disgust-laden, but clinical, to the point that the novel's outlandishness can become repetitious and boring. This clinicality, so obviously unsuited to the scenes it describes, feels polluted and polluting in its incongruity: a category mistake if we attempt to contextualise the novel solely against pornography. Baudrillard, in his controversial "Ballard's Crash", opines that there is a discordance produced by the functional nature of Crash's erotic vocabulary: "not ass, prick, or cunt, but anus, rectum, penis, vulva. No slang, no intimacy in the sexual violence, only functional language" (Baudrillard 1991: 316).

In Crash, contradictory interpretive and experiential codes are, therefore, combined: pornographic, yet clinical; disgusting, yet arousing; horrific, yet sublime. The combination of unlikes, of near mutually exclusive contextual codes (although, their combination reveals their overlaps), drastically complicates the ability of any reader to neuter, via explanatory interpretive frame- 
works, what may seem as a wildly dangerous book. Even the reader who shares the fetishes which the novel explores or, like Cord, figures these fetishes as liberatory, and therefore has amenable interpretive frameworks for contextualising the novel, may not find Crash to be easily interpreted as solely pornographic.

It is also worth underscoring that, like pornography, interpretation, too, is a realm of play. The process of interpretation - of teasing meaning out of something, stamping it with our own take, exercising control over a wild object - is one of abstractification. Just as Ballard aestheticizes Catherine's vomit, with its clots of blood like liquid rubies, so too does the process of interpretation bind the text for our perusal and gratification. This is not, necessarily, an immunising process: it does not remove the potential of Crash's discomforting embodied effects. We can preface and postface these excerpts with reams of contextualising, abstracting and academically neutering information and opinions, but it does not necessarily remove the potential embodied effects of, say, the image of semen jolting into a scar's corrugated ditch.

\section{By Way of a Conclusion: Interpretation and Meaning}

The embodied effects of the novel heretofore discussed, combined with the connected contextual, authorial and generic ambiguities, and a sparsity of plot and character development, does not result in a 'traditionally' enjoyable novel. Likewise, in relation to Ballard's use of clinical language, the flattening of effect therein achieved, though it may be regarded as an artistic achievement, does not lend to the novel's readability. For most readers, Crash will be, either at points or in its totality, uncomfortable, distressing, boring or a healthy combination of each. However, its particularity and singularity of vision, combined with its cultural cachet and the mere fact that it has been published, suggests that it may have been written for reasons other than simple enjoyment. The crossroads that a reader might thereby find themselves at requires them to answer a few questions: why would J.G. Ballard write this, why would it be published and why do people praise it so much? The novel's paratexts, and its cultural life and cachet, must also, therefore, be considered as interpretive frameworks. If the reader does not simply decide that the novel is a mistake, prank or scam, then it necessitates that these questions be answered by the simple assumption that the novel does something, that it has some manner of meaning or purpose, or at least that others have found such 
in the novel. Meaning, then, is not simply something extracted from a text. A belief in meaning, which can be variously informed by different critical cultures, alters how we read, and how we process the text. The idea of meaning can therefore be considered an interpretive framework.

The search for meaning in Crash situates the reader at an interpretive crossroads that offers many potential routes; however, there are a variety of cultural signposts which readers might turn to for guidance. One of these is the simple fact that if one finds a work boring or otherwise unenjoyable, yet it has received high praise from others, then we feel pressure to find and partake in that appreciation. Such a work may, for example, be accomplishing something 'greater than' entertainment, or require specific cultural competencies to be entertaining: the presiding assumption of which is that a text can do something that makes it worth a difficult or slow read, that is, that the text has a significance due to a purpose, meaning or message. Whether this drive can propel a reader through the entirety of Crash is a different story, likewise as to whether the reader can find this vaunted meaning; however, it is certainly an effect of Crash, one upon which it will be more dependent than a traditionally 'enjoyable' text would.

Crash near necessitates that the reader who does not enjoy the novel, in a traditional sense, will continue reading and, during that reading, look for a justifying meaning or intention. A novel that appears to be purposefully unenjoyable or difficult sparks an unusual interpretive dilemma. Even stories of tragedy or loss, stories which cannot quite be said to be 'enjoyable', are nevertheless some variation of enjoyable. When the cathartic power of a text is in its ability to catalyse sorrow or spur tears, we consider its distressing effects worthy, even necessary. A novel such as Crash, even when readers acknowledge its message as worthy or important and therefore justify the embodied effects which aid and abet this message, does not get as easy a pass as the tragic novel.

Crash, of course, is also very different from tragedy. Crash may require the reader to supress the corporeal effects of the novel in order to progress and to appreciate it for its cultural and psychological commentary. Reading Crash can be an active struggle to proceed - to justify, to not feel, to avoid constructing images, to steal a glance rather than openly gape. It thereby calls for a justification, a belief in an underlying meaning. Without the belief in an intention higher than that to disgust or arouse, you either have pointless shock-lit or off-taste pornography. And, of course, this is not a necessity particular to Crash. Tragedy too requires some belief in a higher or greater worth 
to justify the sorrow that it arouses. This worth, however, is far more culturally accessible due to the different social purposes of sorrow and disgust. Sorrow is communal and communicative, and begs understanding and sharing. Disgust serves to warn and reject, directing its emotional intensity not at the individual feeling disgusted but the offending item or behaviour. In this sense, these embodied effects, and their social purposes, can also be fruitfully considered as interpretive frameworks.

Crash, nevertheless, does find itself recommended, and its readers, even its detractors, have been largely successful in finding a message in it (though whether they felt that this 'justified' the text varies). Crash, in its typical physical and digital forms, eases the passage to such meanings and messages in the same manner that almost all texts do: paratexts. In Crash's case, the publisher's peritexts establish shortcuts to semi-sanitised interpretations by asserting its originality, cultural importance, and giving hints as to where the reader should spend their creative and interpretive efforts. In the cited edition, the front cover features a quotation from Will Self, labelling Ballard as "the last great English avatar of the avant-garde." It also informs of an introduction by Zadie Smith. The back cover quotes Anthony Burgess, "a work of very powerful originality," and Martin Amis, "Crash sensationally and scintillatingly succeeds." Its blurb describes Crash as "the definitive cult, postmodern novel - a shocking blend of violence, transgression and eroticism."

Of course, the effect of this, on a cultural level, may find itself somewhat blunted over time, as the newness of Crash ages and domesticating codes become easier to access. Readers of Crash's first edition, for example, did not have the cautionary tale introduction, the preface from Zadie Smith, nor the other disambiguating paratexts which ease modern readers into the text through sanitising pre-interpretations. Tellingly, however, we do have a reader's report on Crash, solicited by Ballard's publisher on an earlier and much longer draft of the novel. Without the benefit of these sanitising interpretive frameworks, without even the knowledge that the novel would be published, this reader states: "This author is beyond psychiatric help. Do not publish" (qtd. in Elborough 2014: 188). 


\section{References}

\section{Corpus}

Ballard, J.G (2014): Crash, London: Fourth Estate.

\section{Other Works}

Bakhtin, Mikhail (1984): Rabelais and his world, Bloomington: Indiana University Press.

Baudrillard, Jean (1991): "Ballard's 'Crash' ('Crash' de Ballard)”, in: Science Fiction Studies, 18 (3), 313-320.

Booth, Wayne C. (1961): The rhetoric of fiction, Chicago: University of Chicago Press.

Carroll, Noël (2013): Minerva's night out: Philosophy, pop culture and moving pictures, Chichester: Wiley-Blackwell.

Cord, Florian (2017): J.G. Ballard's politics: Late capitalism, power, and the pataphysics of resistance, Berlin: De Gruyter.

Changing Faces charity (2017): Disfigurement in the UK, London: Changing Faces, https:/www.changingfaces.org.uk/wp-content/uploads/202 1/03/disfigurement-in-the-uk-changing-faces-2017.pdf (Last accessed: 19.04.2021).

Elborough, Travis (2014): "The road to Crash", in: J.G. Ballard: Crash, London: Fourth Estate.

Fetterley, Judith (1981): The resisting reader: A feminist approach to American fiction, Bloomington: University of Indiana Press.

Fish, Stanley (1980): Is there a text in this class? The authority of interpretive communities, Cambridge, MA: Harvard University Press.

Haidt, Jonathan (2003): "The moral emotions", in: Richard Davidson/Klaus Scherer/H. Hill Goldsmith (eds.), Handbook of affective sciences, Oxford: Oxford University Press, 852-870.

Harding, Jennifer R. (2014): "Reader response criticism and stylistics", in: Michael Burke (ed.), The Routledge handbook of stylistics, Oxon: Routledge, 68-84.

Harkin, Patricia (2005): "The reception of reader-response theory", in: College Composition and Communication, 56 (3), 410-425.

Holland, Norman (1975): Five readers reading, London: Yale University Press. 
Iser, Wolfgang (1978): The act of reading: A theory of aesthetic response, Baltimore: John Hopkins University Press, 1978.

- (1989): Prospecting: From reader response to literary anthropology, Baltimore: John Hopkins University Press.

Kavanagh, Ciarán (2019): "Categorically grotesque: Ballard, bodies and genre in Crash", in: Open Cultural Studies, 3 (1), 456-468.

Keltner, Dacher/Haidt, Jonathan (2003): "Approaching awe, a moral, spiritual, and aesthetic emotion", in: Cognition and Emotion, 17 (2), 297-314.

Riffaterre, Michael (1966): "Describing poetic structures: Two approaches to Baudelaire's les Chats", in: Yale French Studies 36/37, 200-242.

Rosenblatt, Louise (1938): Literature as exploration, New York/London: DAppleton Century Company, https://openlibrary.org/books/OL6370042M /Literature_as_exploration (Last accessed: 19.04.2021).

- (1978): The reader, the text, the poem: The transactional theory of the literary work, Carbondale: Southern Illinois University Press.

Sobchak, Vivian (1991): "Baudrillard's obscenity", in: Science Fiction Studies, 18 (3), 327-329.

Whiteley, Sarah/Canning, Patricia (2017): "Reader response research in stylistics”, in: Language and Literature, 26 (2), 71-87. 



\section{Part II \\ Coming to the Fore: \\ The Subtle Influence of Rhythm, Sounds, and Sensory Representations}





\section{Lives and Deaths of Gatsby: A Semantic Reading of a Key Passage in a Powerful Text}

Christine Chollier, University of Reims (France)

At two o'clock Gatsby put on his bathing-suit and left word with the butler that if anyone phoned word was to be brought to him at the pool. He stopped at the garage for a pneumatic mattress that had amused his guests during the summer, and the chauffeur helped him pump it up. Then he gave instructions that the open car wasn't to be taken out under any circumstances - and this was strange, because the front right fender needed repair.

Gatsby shouldered the mattress and started for the pool. Once he stopped and shifted it a little, and the chauffeur asked him if he needed help, but he shook his head and, in a moment, disappeared among the yellowing trees.

No telephone message arrived, but the butler went without his sleep and waited for it until four o'clock until long after there was anyone to give it to if it came. I have an idea that Gatsby himself didn't believe it would come, and perhaps he no longer cared. If that was true he must have felt that he had lost the old warm world, paid a high price for living too long with a single dream. He must have looked up at an unfamiliar sky through frightening leaves and shivered as he found what a grotesque thing a rose is and how raw the sunlight was upon the scarcely created grass. A new world, material without being real, where poor ghosts, breathing dreams like air, drifted fortuitously about ... like that ashen, fantastic figure gliding toward him through the amorphous trees.

The chauffeur - he was one of Wolfshiem's protégés - heard the shots - afterwards he could only say that he hadn't thought anything much about them. I drove from the station directly to Gatsby's house and my rushing anxiously up the front steps was the first thing that alarmed anyone. But they knew then, I firmly believe. With scarcely a word said, four of us, the chauffeur, butler, gardener, and I, hurried down to the pool. 
There was a faint, barely perceptible movement of the water as the fresh flow from one end urged its way toward the drain at the other. With little ripples that were hardly the shadows of waves, the laden mattress moved irregularly down the pool. A small gust of wind that scarcely corrugated the surface was enough to disturb its accidental course with its accidental burden. The touch of a cluster of leaves revolved it slowly, tracing, like the leg of transit, a thin red circle in the water.

It was after we started with Gatsby toward the house that the gardener saw Wilson's body a little way off in the grass, and the holocaust was complete."

(Fitzgerald 1990 [1925]: 153-154) ${ }^{1}$

What is a powerful literary fiction text? The question seems to first imply that some literary texts are fictional while others are not. Does it mean that non-fictional literary texts - for example, autobiographies or authentic testimonies - are intrinsically powerful and that fictional literary texts are not? Or the other way round: that fiction texts are potentially powerful, as opposed to non-fictional ones? Or else does it mean that they exert their power differently? These questions raised by the issue at stake concern the engagement of the reader: does such a text address only one component of the reader's mental faculties (either the emotional one or the intellectual one) or more than just one (for example, both the emotional one and the intellectual one)? Does it address them throughout the reading process or just temporarily - for instance, in the reading of a powerful passage? Studies in text semantics have shown that not all literary excerpts are equally powerful; in other words, that some passages a more powerful than others (see Riemer 2016: 491-506). The subsequent hypothesis about The Great Gatsby relies on the idea that Gatsby's death in Chapter VIII is such a passage because it is an important stage in the building of the global meaning in the novel. Studies on real readers ${ }^{2}$ have ventured that each reader's reading experience is shaped by more than the two capacities mentioned above. Michel Picard theorised a three-part reader divided into an unconscious component, a physical/bodily presence, and a rational self (see Picard 1986). Vincent Jouve stepped in to suggest that the

In the following, all quotations without any reference specified are taken from this literary excerpt.

2 I understand these as opposed to W. Iser's implied reader, J. Linvelt's abstract reader, U. Eco's ideal reader, and M. Riffaterre's archreader. 
second instance did not play any role in the reader's interaction with the text, maintaining that the description needed revising (see Jouve 1992). He came up with the same unconscious part (the passively hallucinated lu which is dominated by the unconscious) and the rational interpreter at each end (lectantinterprétant) of the spectrum but added in between the consciously identifying reader (lisant) and the playing/gaming reader (lectant-jouant) who does a lot of anticipating guess-work, relying on encyclopedic knowledge (see Jouve 1992). Jouve insists on distinguishing the part totally immersed in the unconscious from the consciously identifying self, on the one hand, and the anticipating reader from the interpreting reader ${ }^{3}$ (the rational interpreter), on the other, while researchers studying literary reading differ in opinion regarding the way the various parts co-exist. For example, Picard suggests that they co-exist within a balance which may be disrupted when one part takes control, until the delicate equilibrium is resumed (see Picard 1986: 214). Belgian researcher Jean-Louis Dufays does not mention swinging movements but sees a continuum between those components: a text perused from beginning to end may thus engage those various parts simultaneously or successively (see Dufays 2019: 183-191). In other words, although readers may be split into novice vs. expert groups, each reader can himself be divided into different roles and various types of engagement, which are not mutually exclusive.

What I propose to do in the following development is a semantic reading of a crucial passage which can be construed as a local transformation of the global meaning of Fitzgerald's novel, The Great Gatsby. While a protagonist's death most certainly engages the reader's emotional part, like any life/death issue, I will submit an interpretation relating global and local levels based on semantic building. ${ }^{4}$

When the narrator in The Great Gatsby starts relating what happened during the summer of 1922 (in Chapter I), for most readers a tension between mixed feelings of fascination and disgust towards the eponymous protagonist builds up right away. This tension then goes back and forth between various he has read and whom he quotes to support his own arguments, and his intellectual constructs rely on ethically explicit tools and procedures.

4 'Semantic building' implies that meaning is not always already found in the text but needs an interpreter interacting with the text and using it both as the object of interpretation and the parameter of the interpretation (e.g. using the context to neutralise traits or actualise others). 
peaks until the murder of the ironically "great" Gatsby, the scapegoat, in the penultimate chapter. Nick Carraway, the narrator, is Gatsby's neighbour and they first have a reserved and cordial relationship. After Gatsby finds out that Nick is his former sweetheart's cousin, they begin spending more time together. Being instrumental in helping facilitate Gatsby's mad dream to rekindle his love affair, Nick eventually appears more or less as the only one who cares about Gatsby after his death. This death is given in the extract under scrutiny ${ }^{5}$, in chapter VIII, occurring after Myrtle Wilson has been knocked down by Gatsby's speeding yellow car driven by Daisy, his eternal princess. The runaway driver's shirking of responsibility gives Daisy's husband — Tom Buchanan, incidentally Myrtle's lover - an opportunity to get rid of his own wife's wooer by giving away his rival's name to the bereaved Wilson ${ }^{6}$. The created quid pro quo with the ultimate goal of vengeance prepares either a tragic scene or a crime scene, resting on the conspiracy of two offended husbands. And indeed, the story seems to unfold as both a tragedy and a piece of crime fiction; yet, the codes of tragedy and crime fiction are simultaneously undercut, as we are going to 'see'.

In the chosen extract from Chapter VIII, the codes of the detective story are both established and undermined. Established by precise chronological facts and the revelation of the criminal's name at the end; and undermined by blurring proleptic announcements such as "until long after there was anyone to give it to" ( $\$ 3)$ or "afterwards he could only say that he hadn't thought anything much about them" ( $\$ 4)$. Not only is time logic disturbed but causal logic is also disrupted by contradictions ("but he shook his head" [\$2], "but the butler went without his sleep" [\$3]); and so are the characters' identities.

Part of the ambiguity found in the passage can be attributed to narrator Nick Carraway, who - being the retrospective enunciator - is supposed to know, whereas as a character, he could not predict all the developments. This duality is echoed in two different sorts of paragraphs: narrative, empirical paragraphs, based on facts and experience $(\$ 1,2,4,6$, sentence 1 in $\$ 3$ ) vs. descriptive, lyrical paragraphs ('transcendent realism' $\$ 3,5$ ). Paragraph 4

The passage is signalled in most editions as framed by blanks or typographical signs. The previous segments deal with Wilson's preparations and movements. The chosen piece ends on movement as well. Moving is often a convenient way to separate sequences, as in drama.

6 "'What if I did tell him? That fellow had it coming to him. He threw dust into your eyes just like he did in Daisy's"' (Fitzgerald 1990 [1925]: 169). 
thus appears as a pivotal moment in the reading experience because in the second series, enunciation markers ${ }^{7}$ which are first conspicuous (" $I$ have an idea" [\$3]) next become invisible (\$5). In other words, some kind of change must have taken place in between.

What is related in paragraph 4 is obviously a focal point reshuffling the previous elements, however crisis-marked they may have been already. Indeed paragraph 4 is the place of Gatsby's empirical death, which is both suggested by facts ("heard the shots") but left off stage by that conspicuous synecdoche. However, paragraph 3 has prepared us for Gatsby's death in more ways than just one:

No telephone message arrived, but the butler went without his sleep and waited for it until four o'clock until long after there was anyone to give it to if it came. I have an idea that Gatsby himself didn't believe it would come, and perhaps he no longer cared. If that was true he must have felt that he had lost the old warm world, paid a high price for living too long with a single dream. He must have looked up at an unfamiliar sky through frightening leaves and shivered as he found what a grotesque thing a rose is and how raw the sunlight was upon the scarcely created grass. A new world, material without being real, where poor ghosts, breathing dreams like air, drifted fortuitously about ... like that ashen, fantastic figure gliding toward him through the amorphous trees (§ 3$)$.

In this part Wilson has become a ghost, a puppet manipulated by Tom Buchanan and he dies to avenge Myrtle, and - unwittingly - Daisy's husband, by proxy, just as Gatsby pays "a high price" (\$ 3) instead of Daisy. The swapping of roles and identities contributes to the general confusion. Notably, identities seem to melt and merge: they dissolve when Gatsby becomes "anyone to give it to" (in the proleptic announcement "until long after there was..." [\$ 3]) just as Daisy had previously become anyone (in "anyone phoned" in $\S 1$ ); Wilson is not immune to the dissolution of identity as he grows into someone is speaking" (the situation of uttering) plays a key role as it "provid[es] one with a central anchoring point around which all locations ('repérages') evolve" (GirardGillet/Chauvin 2015: §2). The notion of enunciation can thus be used to refer to the enunciative markers in a text, that is to say, the linguistic components which determine the situation of uttering. 
"that ashen, fantastic figure gliding toward him through the amorphous trees"; identities even appear to merge, as narrator Nick resorts to epistemic modality to identify with Gatsby: "I have an idea that Gatsby himself didn't believe..., and perhaps he no longer cared. If that was true he must have felt that... He must have looked up..." ( $\$ 3$, emphasis added). This identification process contributes to portraying Gatsby as a dweller from "the old warm world" completely at odds with "[a] new world" (\$ 3). The defamiliarisation of the world is conveyed by $\emptyset$ determiner, as in "frightening leaves" or "poor ghosts", and by the indefinite article "A", as in "[a] new world" (vs. the definite article THE, as in "the old warm world"), as well as by such adjectives as "unfamiliar", "frightening." and "grotesque" (\$ 3$).$

In other words, Gatsby's death seems to have happened before he was even shot down, when he left the romantic world for a dysphoric, modern world: "he knew that he had lost that part of it, the freshest and the best, forever" (Chapter 8: 146). And this, too, contributes to the attenuation of the violent shooting. Moreover, cessative semantic traits have been scattered over the text, starting with "yellowing" (\$2), which suggests autumn, a season poetically associated with the beginning of the end, and reminding us that summer is connected with life ("life was beginning over again with the summer" [Chapter I: 10]). ${ }^{8}$

This emphasis on the "new world", which ushers in the murderer, can be used as an instruction to examine the similarities between the human actor and the transcendent ones. Indeed, the "new world" (\$3), 'Wilson' and 'Death' seem to share the same cluster of semantic traits: all three are material, unreal and amorphous, as summarized in table 1.

As evidenced in this table, unlike the new world and the murderer, death is neither described, nor mentioned. The euphemising strategy concerning death is continued and amplified in paragraph 5:

There was a faint, barely perceptible movement of the water as the fresh flow from one end urged its way toward the drain at the other. With little ripples that were hardly the shadows of waves, the laden mattress moved irregularly down the pool. A small gust of wind that scarcely corrugated the surface was enough to disturb its accidental course with its accidental burden. The touch of seasons, Buchanan met Daisy in spring 1919 and married her in June, while Gatsby first kissed Daisy in autumn (Chapter VI), which does not bode well, symbolically. 
of a cluster of leaves revolved it slowly, tracing, like the leg of transit, a thin red circle in the water. $(\S 5)$

Table 1:

\begin{tabular}{|l|l|l|l|}
\hline & /material/ & /unreal/ & /amorphous/ \\
\hline $\begin{array}{l}\text { new world, on the } \\
\text { //cosmic//isotopy }\end{array}$ & $\begin{array}{l}\text { sky, leaves, rose, } \\
\text { sunlight, grass, } \\
\text { trees... }\end{array}$ & $\begin{array}{l}\text { unfamiliar, without } \\
\text { being real, ghosts, } \\
\text { dreams, }\end{array}$ & amorphous (trees) \\
\hline $\begin{array}{l}\text { Wilson, on the } \\
\text { //human// isotopy }\end{array}$ & ashen & fantastic & figure \\
\hline $\begin{array}{l}\text { Death, on the } \\
\text { //metaphysical// } \\
\text { isotopy }\end{array}$ & shots & $?$ & $?$ \\
\hline
\end{tabular}

Significantly, shapes, weight and movements are reduced, played down, erased by modifiers, namely the adjectives and adverbs listed in table 2 :

Table 2:

\begin{tabular}{|l|l|}
\hline modifier & modified term \\
\hline faint & movement \\
\hline barely & perceptible \\
\hline little & ripples \\
\hline shadows & waves \\
\hline irregularly & moved \\
\hline small & gust \\
\hline scarcely & corrugated \\
\hline enough & disturb \\
\hline accidental & course \\
\hline accidental & burden \\
\hline slowly & revolved \\
\hline
\end{tabular}

'Death', the metaphysical actor, is thus made as unreal and as amorphous as the murderer. Causal logic is deleted; only consequences ("tracing" [ $\$$ ]) are left, but minimally so. Gatsby's body and blood vanish in metonymy or 
synecdoche ("the laden mattress", "a thin red circle", [\$ 5, emphasis added]). The murder - resulting in the burden of the corpse - becomes a mere accident, which is itself eclipsed by minimum morphemic change ("accidental", [\$ 5, emphasis added]). Moreover, "accidental" resumes "fortuitously" (at the end of $\$ 3$ ), converting tragedy - that which concerns essence - into accident - that which does not threaten essence. More than ever, the word euphemism takes on its meaning from its Greek etymology - euphemein: to adore in silence.

So, what is it which is euphemised? Gatsby's life, which slowly dies down? Or Gatsby's death, which is denied? Both, of course. Indeed, this powerful passage shifts the protagonist from life-in-death (a non-life, without Daisy) to death, and finally to his non-death. The semantic features /vertical/ and /dynamic/ first attributed to Gatsby in paragraph 1 (when seen standing and moving) have been implicitly transferred to the fantastic figure gliding through in paragraph 3 and implicitly replaced with /horizontal/ and /static/ by the "laden mattress" in paragraph 5 . However, in paragraph 6, Wilson's body - even for him, the term 'corpse' is carefully avoided and replaced by 'body' - is found in the grass, which owes him to inherit /horizontal/ and /static/. By contrast, the beginning of paragraph 6 induces some kind of hallucination as one reads "It was after we started with Gatsby toward the house that [...]" (\$ 6) and we almost hear or see Gatsby walking to the house with the others (a collective WE in which Nick merges). The protagonist is raised from the dead.

Besides this exchange of semantic features, the two characters are connected with different cosmic elements: the "grass" and the "holocaust" link Wilson to chthonian elements (earth and fire, $\$ 6$ ); while the uranic water and wind are ascribed to Gatsby, with the "small gust of wind [...] scarcely corrugat[ing] the surface" (\$ 5) suggesting a dying soul animating the surface of the water. ${ }^{9}$ This integration to a higher transcendent realm, the cosmic one, is a denial of death preparing readers for the final metamorphosis of Gatsby. The ending of the novel actually promotes Gatsby as the embodiment of the American Dream through the mythological figure of the Dutch sailor who first set foot on the green island: "as the moon rose higher the inessential houses

9 As early as Chapter I Daisy's husband kills the wind, and all the rest collapses: "Then there was a boom as Tom Buchanan shut the rear windows and the caught wind died out about the room, and the curtains and the rugs and the two young women ballooned slowly to the floor" (Fitzgerald 1990 [1925]: 13). 
began to melt away until gradually I became aware of the old island here that flowered once for Dutch sailors' eyes [...]" (Fitzgerald 1990 [1925]: 171).

The speaker's identification with the deceased and the latter's integration to a transcendent realm in Chapter VIII have paved the way for Gatsby's final passage to the land of mythology.

Text semantics has described interpretation as reader-perception of semantic clusters which lose or drop traits as the reading process develops. Reading has been compared indeed to the building of forms standing out against backgrounds, the way cognitive psychology depicted perception of mental images. However helpful this comparison may be, it does not go as far as to assimilate perception of images to perception of semantic traits, or the other way round, since one semiotic system cannot be reduced to another. Yet, I managed to build a cluster of (semantic) traits including /material//, /unreal/, and /amorphous/ that corresponds to the "new world", as well as to Wilson and to death. After characterising the treatment given to the predators, the next step was to follow the victim's changing fate. The cluster attached to Gatsby first includes /vertical/ and/dynamic/, which are then swapped with their antonyms /horizontal/ and /static/, and which finally reverts to the protagonist through the reading hallucination mentioned above. This led me to gather a number of elements in my reading of the chosen excerpt. First, the speaker identifies with the deceased, as he will again below ("I began to have a feeling of defiance, of scornful solidarity between Gatsby and me against them all" (Fitzgerald (1925) 1990: 157), declares the narrator after all close relations retreat into diffident shyness. Secondly, he refers to Providence. Thirdly, he blames close relations for their negligence ("The chauffeur - he was one of Wolfshiem's protégés - heard the shots - afterwards he could only say that he hadn't thought anything much about them." [\$ 4]).These features are not unlike some of the norms found in elegies. Yet in the excerpt under study, I have emphasised the specific transformation applied to these generic norms which is added to the general linguistic use and to the author's stylistic tour de force. My final hypothesis thus concerns the whole novel as an elegy - or an elegiac mode, to use Alastair Fowler's terminology (see Fowler 1981) — and leads me to reconsider this passage as powerful because it is a local transformation of the global meaning. One of the principles of hermeneutics, taken up by Schleiermacher, is the determination of local nodes by the global textual project. So, I searched the broader context of the novel for what may have determined this crucial passage, and I found the following: a deploration of 
$\operatorname{loss}{ }^{10}$, a eulogy ${ }^{11}$; the blaming of everything and everyone that harms Gatsby ${ }^{12}$ and of close relations ${ }^{13}$ : Wolfsheim is dishonest ${ }^{14}$; Klipspringer is a parasite; Jordan Baker is a liar; the servants are negligent; the Buchanans are "careless people" (ibid.: 170) ${ }^{15}$; some kind of consoling access to transcendence (see the closing chapter). This cannot fail to remind us of the elegies written by Donne $^{16}$, Tennyson, Auden and Rilke (see Abrams 1981: 46-48).

To conclude on the question as to which linguistic phenomena are potentially responsible for readers' reactions, it turns out that a powerful reading of a powerful text combines thematic components, narrative elements (for example, the function 'kill', or the process 'die'), linguistic modalities (especially those markers revealing the enunciative origin of utterances), and semantic linear arrangements (for example, the semantic process through which the

10 "After Gatsby's death the East was haunted for me" (Fitzgerald (1925) 1990: 167), "the party was over" (ibid.: 171)

11 "No - Gatsby turned out all right at the end" (ibid.: 8)

12 "it is what preyed on Catsby, what foul dust floated in the wake of his dreams that temporarily closed out my interest in the abortive sorrows and short-winded elations of men" (ibid.). The opposition between the earth and the wind is already found in the contrast between 'dust'/'(short)-winded'.

"They're a rotten crowd" (ibid.: 146). In older elegies nymphs and protecting chaperons were blamed for their negligence.

14 "When a man gets killed I never like to get mixed up in it in any way. I keep out." says Wolfshiem (ibid.: 163).

15 "It was all very careless and confused. They were careless people, Tom and Daisy--they smashed up things and creatures and then retreated back into their money or their vast carelessness or whatever it was that kept them together, and let other people clean up the mess they had made...." (ibid.: 170).

16 Thanks to Michael Toolan for asking about "the leg of transit" and suggesting that the compass image was once used by John Donne in "A Valediction: Forbidding Mourning" (1611) to "denote the lovers, unbreachably linked even if one of the pair travelled far away." In March 1925, Maxwell Perkins, who was working with Charles Scribners' Sons and doing proof-reading of Fitzgerald, Hemingway and Wolfe, wrote to Fitzgerald: "The other change was where in describing the dead Catsby in the swimming pool, you speak of the "leg of transept." I ought to have caught this on the galleys. The transept is the cross formation in a church and surely you could not figuratively have referred to this. I think you must have been thinking of a transit, which is an engineer's instrument. It is really not like compasses, for it rests upon a tripod, but I think the use of the word transit would be psychologically correct in giving the impression of the circle being drawn." Fitzgerald's answer came too late and reveals some kind of awkward misunderstanding: "Transit will do fine though of course I really meant compass" (Bruccoli 1991: 40-59). 
transcendent state reached by Gatsby allows for the narrator's, and perhaps the reader's, consolation). I hypothesise that each reader's unconscious part is engaged by Gatsby's unfair death. However, while the playing/gaming reader can elaborate on what is going to happen next - to Daisy, the reckless driver, to Nick, the divided friend, to Tom, Daisy's manipulating husband, etc. the intellectual part in the reader is faced with a complex passage, where the mourning narrator transforms Gatsby's former image through euphemising strategies and his access to another realm. It can thus be ventured that cruel, brutal death is denied, diluted, and done away with while Gatsby's soul is blown in the wind. The specific, powerful configuration found in the passage under scrutiny has, hopefully, been described as a local transformation of the global elegiac meaning of the novel.

\section{References}

\section{Corpus}

Fitzgerald, Francis Scott (1990 [1925]): The Great Gatsby, Harmondsworth \& New York: Penguin Books.

\section{Other works}

Abrams, M. H./Harpham, Joeffrey (1981): A glossary ofliterary terms, $4^{\text {th }}$ edition, New York: Holt Rhinehart \& Winston.

Bruccoli, Matthew J. (1991): "Getting it right. The publishing process and the correction of factual errors - with reference to The Great Gatsby", in: Dave Oliphant (ed.), Essays in honor of William B. Todd, comp. Warner Barnes and Larry Carver, Austin: Harry Ransom Humanities Research Center, University of Texas, 40-59, http://www.science.edu/fitzgerald/essays/right.htm 1 (Last accessed: 17.04.2021).

Canon-Roger, Françoise/Chollier, Christine (2009): "A comparison of several interpretations of 'Snow' by Louis MacNeice”, in: Imaginaires, 13 (Linterprétation au pluriel), Reims: Presses Universitaires de Reims, 155-175.

Chollier, Christine (2016): "Lire/lier sens global et sens local dans une œuvre littéraire. The Heart is a Lonely Hunter de Carson McCullers", in: Daniel 
Thomières (ed.), Des Mots à la pensée. Onze variations sur l'interprétation, Reims: EPURE, 113-131.

Fowler, Alastair (1982): Kinds of literature, Oxford: Oxford University Press.

Girard-Gillet, Geneviève/Chauvin, Catherine (2015): "Introduction", in: Lexis 9 (Utterer-Centered Studies on Lexical Issues), http://journals.openedition .org/lexis/992 (Last accessed: 17.04.2021)

Hirsch, E. D. (1967): Validity in interpretation, New Haven and London: Yale University Press.

Rastier, François (1997): Meaning and textuality, Toronto: Toronto University Press.

- (2016): "Interpretative semantics", in: Nick Riemer (ed.), The Routledge handbook of semantics, London: Routledge, 491-506.

Rastier, François/Abeille, Anne/Cavazza, Marc (2002): Semantics for descriptions, Chicago: CSLI Publications.

Schleiermacher, Friedrich et al. (2008 [1959]): Hermeneutics and criticism: And other writings, Cambridge: Cambridge University Press.

Szondi, Peter (1995): Introduction to literary hermeneutics, Cambridge: Cambridge University Press. 


\section{Introducing Jane: The Power of the Opening}

Kimberley Pager-McClymont, University of Huddersfield (UK)

There was no possibility of taking a walk that day. We had been wandering, indeed, in the leafless shrubbery an hour in the morning; but since dinner (Mrs. Reed, when there was no company, dined early) the cold winter wind had brought with it clouds so sombre, and a rain so penetrating, that further out-door exercise was now out of the question.

I was glad of it: I never liked long walks, especially on chilly afternoons: dreadful to me was the coming home in the raw twilight, with nipped fingers and toes, and a heart saddened by the chidings of Bessie, the nurse, and humbled by the consciousness of my physical inferiority to Eliza, John, and Georgiana Reed.

The said Eliza, John, and Georgiana were now clustered round their mama in the drawing-room: she lay reclined on a sofa by the fireside, and with her darlings about her (for the time neither quarrelling nor crying) looked perfectly happy. Me, she had dispensed from joining the group; saying, 'She regretted to be under the necessity of keeping me at a distance; but that until she heard from Bessie, and could discover by her own observation, that I was endeavouring in good earnest to acquire a more sociable and childlike disposition, a more attractive and sprightly manner - something lighter, franker, more natural, as it were - she really must exclude me from privileges intended only for contented, happy, little children.'

(Brontë 2014 [1847]: 1) ${ }^{1}$

1 In the following, all quotations without any reference specified are taken from this literary excerpt. 


\section{Introduction}

"Emotions are the core of Literature": every character and story have for purpose to trigger a reaction (Brown 1962: 122). Emotions are used to engage readers and potentially produce an empathetic reaction from them towards characters. Yet the character's emotions are not always easy to convey to all readers as their perception will depend on the reader's personal and cultural experience. This article is concerned with the elements of language used in texts to convey emotions, using the opening of Jane Eyre as an example.

Jane Eyre is a well-known piece of literary fiction by Charlotte Brontë, published in 1847 at the peak of Romanticism. The novel follows the specific features of the artistic movement: virtue, omnipresence of Nature and free expression of emotions (see Jeffries 1993: 6; Siddall 2009: 36-37). The opening of the novel introduces the reader to the eponymous heroine who is to become a strong and independent woman.

Here, figurative language and discourse presentation are used in multiple ways, offering a wide range of information about Jane's situation and feelings for the reader to interpret. This article therefore aims to assess the impact of imagery and speech presentation on readers' perceptions of characters and their emotions, as well as on readers' understanding of the plot, using Brontë's novel as a textual example. Firstly, I focus on the notion of characterisation before presenting the stylistic framework I use to analyse the first paragraphs of the novel. Secondly, I discuss the key linguistic features which make the opening a powerful one and how it might impact the way readers picture the famous heroine. Finally, I explore the potential contribution 'Conceptual Metaphor Theory' can bring to the analysis and perception of Jane's emotions.

\section{Analytical framework}

\subsection{Building characters}

Characterisation is "the representation of persons in narrative and dramatic works" and "the creation or construction of a fictional character" (Baldick 2008: n. p.). A lot of research on this topic has been conducted to categorise characters, such as 'flat' (humorous, caricature-like) and 'round' (complex) characters (see Forster 1985); or 'humanising' (considering characters as real people) (see Harvey 1965), 'dehumanising' (see Knight 1963) or mixed 
approaches to characters (see Margolin 1983, 2007). Although this is useful, I argue that a crucial stage, which precedes this categorising process and aims to make it more relevant, consists in understanding how characters are built in the course of a narrative.

Jonathan Culpeper not only considers characters in terms of categories and their functions, but also focuses on the "process of characterisation' and specifically wonders "what are the textual cues in characterisation?" (Culpeper 2001: 1). A key aspect of Culpeper's stylistic approach to characterisation is 'bottom-up' processing, as it reflects how readers gather information during the reading process to form an impression of characters. As George puts it, "instead of focusing on the 'finished product' of characterisation [...] [Culpeper analyses] how, as readers, we construct our own impressions of this character" (George 2002: 374). Recognition of the features that constitute a character's appearance enables us to understand the role the latter may play in a story or the effect they have on the reader. Geoffrey Leech and Mick Short explain that such a 'bottom-up' approach is rather common in stylistic analysis and has for objective to concentrate "particular textual detail and how character and characterisation can be inferred from that textual detail" (Leech/Short 2007: 297). Culpeper explores varied theories of Linguistics and Psychology to list the elements that contribute to building a character, although I agree with George that "one may be left with the impression that Culpeper has not gone far enough in his enumeration of textual cues" (George 2002: 375): Although he discusses explicit, implicit and authorial cues, as well as speech acts and politeness, he omits to mention the crucial role played by figurative language. Imagery facilitates the expression of emotions and conveys them to the reader, and this in turn might shape the readers' view on particular characters. H. Porter Abbott, on the other hand, states that "verbal narration [...] draws on figurative language, particularly metaphors. Often on the page what is internal to a character comes out in metaphorical language" (Abbott 2008: 118). While providing useful examples of analysis, he does not offer a systematic way to interpret figurative language with regards to the character-building process or their perception. Thus, such an approach to character building needs further developing.

Despite the mentioned gap, Culpeper's approach to characterisation is thorough and can be considered to be one of "the most highly articulated stylistic account of character in fiction to date" (Leech/Short 2007: 297), which is why I develop it in my analysis, using input from other stylistic frameworks as discussed below. Following Abbott's example, I aim to evidence how figu- 
rative language and discourse presentation can contribute to the building of characters and by studying the opening of Jane Eyre. Not only is this passage the first impression readers get of the novel, it is also the first time the heroine is introduced to the reader and, most of all, it is an emotionally engaging piece of literary fiction.

\subsection{A stylistic approach to text analysis}

Stylistics is a branch of Linguistics that aims to explore language and style in literary and non-literary contexts (see Wales 2001: 372-373). To analyse language, stylisticians follow specific principles to ensure their methods are systematic and objective (see Jeffries/ McIntyre 2010: 22-23). A rigorous analysis thus allows for findings to be thoroughly researched and falsifiable. Such results should be retrievable and clearly explained with the use of explicit terms through a replicable method that "should be sufficiently transparent as to allow other stylisticians to verify [the obtained results]" (Simpson 2004: 4).

A key stylistic theory is the theory of foregrounding (see Mukařovský 1964: 44-49), which claims that certain linguistic features are foregrounded against the rest of the text, either by parallelism (repeated features) or by deviation from the rest of the text (see Simpson 2004: 49). Deviations can occur internally (contained within the text itself), or externally (the language deviates against the norm of the language under study). My analysis of the extract aims to study how foregrounded elements contribute to the reader's perception of Jane's character.

Goeffrey Leech and Mick Short have developed a complete checklist of linguistic and stylistic categories divided into four main headings: lexical categories, grammatical categories, figures of speech, and context and cohesion (see Leech/Short 2007: 61-64). Although it is not exhaustive - each text being unique, it is impossible to predict all the language features used for this effect (see ibid.: 60-61) - the checklist can be used as a starting point to systematically collect data of foregrounded elements in any fiction text. However, it primarily considers features that can be easily identified, as for instance word categories, clause types or tropes, thus omitting implicit types of stylistic tools, such as pathetic fallacy, which nevertheless crucially contribute to the characterisation process. As Michael Toolan points out, "whenever confronted by such checklists [...] one is drawn to question how - and why these particular features have been listed, and whether there is - or can be a hierarchy of importance of language features in texts" (Toolan 1983: 136). 
Culpeper also uses foregrounding theory to inform his model of characterisation, particularly to discuss readers' interpretation of text (see Culpeper 2001: 132). He states: "one of the main reasons for the success of the notion of foregrounding lies in its relevance to the study of the process of textual interpretation" (ibid.). This is relevant to characterisation, as readers build a representation of characters based on textual cues throughout the reading process. Using Culpeper's bottom-up approach and the stylistic tools put forth by Leech and Short, my analysis' focus is on the character-building language features of the extract, specifically imagery and discourse presentation.

\section{Imagery in Jane Eyre}

\subsection{Pathetic fallacy}

The opening of Jane Eyre engages the reader to read further. Although the novel is eponymous and consists in a first-person narrative, Jane is not named here, and as opposed to the Reed children, she is not paid much attention and blends into the background. Yet, I hypothesise, the reader understands her emotions and sympathises with her situation (see Rubik/MettingerSchartmann 2007: 49) because her state of mind is depicted through pathetic fallacy, a literary technique and metaphorical expression best defined as "a projection of human emotions onto phenomena in the natural world" (Lodge 1992: 85). For this definition to be fulfilled, three key aspects of the texts need to be analysed: Jane, her emotions, and her surroundings. In the extract, lexical fields, personification and syntax are used to convey how Jane feels, thus enhancing the pathetic fallacy present.

Two main lexical fields are foregrounded by parallelism as they provide running themes throughout the text: emotions and weather elements. First, negative emotions are explicitly stated throughout the text by phrases such as "dreadful", or "humbled by the consciousness of my physical inferiority", combined with negative forms such as "no possibility", "never", or "out of the question". The metonymy "heart saddened" is foregrounded by external deviation as it also contributes to the portrayal of Jane's emotion: it refers to Jane by mentioning a smaller part of her (her heart) and personifying it. Overall, this lexical field conveys how sad and isolated Jane feels. Secondly, the lexical field of elements pertaining to a harsh weather are omnipresent and foregrounded by parallelism: "leafless shrubbery", "cold winter wind", "clouds so 
sombre" or "chilly afternoons". Negative connotation is also associated with this lexical field with terms such as "leafless", "cold", "sombre" resulting in an overall negative representation of the mentioned surroundings. Due to the overall entanglement of those two lexical fields, Jane's physical and emotional states are mirrored in the harsh surroundings. This instance of pathetic fallacy conveys Jane's personal and therefore subjective experience and emotions in a concrete and universally understood manner: the weather. Her melancholia is here materialised in each drop of rain or gust of wind.

The effect of pathetic fallacy is further enriched by the effects of syntactic and phonetic iconicity, which I will focus on below.

\subsection{Iconicity}

An icon is a type of image or sign "which resembles in its form the object to which it refers" (Wales 2001: 193). In literature especially, iconicity is used for 'imitation' (see ibid.). Wales maintains that "variations in clause structure, and rhythm, can suggest (to the reader) auditory or kinetic phenomena; and the (word) order of elements in a sentence can reflect the order of real-world events or actions" (ibid.: 194), and she comes to the conclusion that "sentence complexity is frequently a sign of mental complexity" (ibid.), meaning that the complex structure of sentences mirrors characters' (or narrators') mental complexity. Iconicity can to that extent be seen as a type of imagery: it provides a concrete and physical representation of the situation described in the text and of the characters' complexity through a mimicking effect. Leech and Short explain that "literature follows the 'principle of imitation': in other words, literary expression tends to have not only a presentational function ( $\mathrm{di}$ rected towards the reader's role as decoder) but a representational function (miming the meaning that it expresses)" (Leech/ Short 2007: 188, emphasis in original). In this extract from Jane Eyre, iconicity is both syntactic and phonetic.

Jeffries explains that grammar can be used in literature symbolically, as is the case for syntactic iconicity, which can be defined as the symbolic use of syntactic features to emphasise meaning (see Jeffries 1993: 110-112). In this extract, the example of syntactic iconicity is very representative of Jane's daily living condition with the Reeds. The clause "Me, she had dispensed from joining the group; [...]" is introduced by the direct object personal pronoun "me" referring to Jane. This pronoun is isolated from the rest of the clause by a comma, thus reflecting the meaning of the sentence: Mrs Reed is isolating 
Jane by forbidding her to join the group, as the "me" subject is isolated from the rest of the clause. The syntax physically represents Jane's alienation, embodied by the comma, and thus foregrounding this clause by parallelism as the syntax and meaning mirror each other. Furthermore, in this scene, Jane is not an actor: she remains passive, as opposed to Mrs Reed (referred to as "she") who is the subject of the sentence and the one who performs the action. This is significant as it illustrates Jane's daily life: Mrs Reed controls the situation and the action, whereas Jane has no choice but to passively comply.

Another instance of Jane's passivity in the extract can be noticed in the clause "dreadful to me was the coming home in the raw twilight". In their framework, Leech and Short discuss the system of 'transitivity' based on Halliday's functional grammar (see Leech/ Short 2007; Halliday 1967, 1968, 2004). Transitivity allows us to "comprehend[s] relations between verbs, noun phrases, and adverbials in the clause" and it "locates stylistic significance in the ideational function of language; that is, in the cognitive meaning or sense which for the dualist is the invariant factor of content rather than the variable factor of style" (Leech/Short 2007: 26-27). Using transitivity in the analysis of this particular clause from Jane Eyre's opening is interesting as it highlights how Jane positions herself in her own narration: the process is relational circumstantial as she indicates how her circumstances make her feel. The structure of the clause provides two circumstances ("dreadful" and "in the raw twilight"), there are two participants: "the coming home" is the carrier and subject of the process "was", whereas the passive "me" is the attribute, thus showing how side-lined Jane is in her own story. Brontë chose to portray Jane as passive as opposed to being prominent as an experiencer in a mental process such as "I felt that coming home in the raw twilight was dreadful". The state auxiliary to be is followed by a gerund, "the coming home", which is the subject of the clause, while Jane (referred to as "me"), is entirely subjected to the event, which she can only undergo. This again illustrates Jane's lack of control over her own daily life, and the fact that she can only accept her submissive position amongst the Reeds. These instances of syntactic iconicity contribute to Jane's characterisation, as it indicates her felt lack of control upon her own life, and her feeling of isolation, as well as illustrate her mental complexity.

Additionally, this extract also includes phonetic iconicity, which Körtvélyessy describes as "sound symbolism [that] has been successfully exploited in poetry and fiction" (Körtvélyessy 2016: 29). Such iconicity is often achieved through stylistic features like consonance, alliteration, or onomatopoeia. In 
this extract, the first sentence's last clause offers phonetic iconicity in the form of consonance, the repetition of a consonant sound: "[...] the cold winter wind had brought with it clouds so sombre, and a rain so penetrating, that further out-door exercise was now out of the question". Three different sounds are repeated here: the bilabial approximant sound /w/ ("the cold winter wind"); the palato-alveolar approximant sound /r/ ("brought", "rain" and "penetrating"); and the fricative sounds /f/ ("further"), / $\theta /$ ("with"), /ठ/ ("the", "that", "further"), /z/ ("clouds", "exercise", "was"), and /s/ ("so", "sombre", "exercise", "question"). These repeated sounds illustrate the setting of the scene as they mimic the noises of the elements that make it up: the whistle of the wind (/w/), the noise of the rain falling in showers (fricative sounds), or the $/ \mathrm{r} /$ sound similar to the onomatopoeia associated with cold 'brrr'. Leech and Short argue that phonetic iconicity is "only suggestive of meaning in the presence of a suitable semantic stimulus: the sound evokes, rather than directly represents, its meaning" (Leech/Short 2007: 188), which I suggest is the case here. Indeed, these consonances provide the reader with a well-rounded experience of the surroundings of the scene: not only is the lexical field of weather provided, but the sound effect it generates is also featured. Therefore, this phonetic iconicity is foregrounded by parallelism as sound effects mirror the elements described. This reinforces the effects produced by the pathetic fallacy discussed above, and therefore can potentially contribute to the reader's mental representation of the scene.

The imagery analysed is key in the introduction of the heroine's character and her emotions. In the extract, there are also other elements of language such as discourse presentation that build on the effect of imagery to introduce Jane.

\section{Perceiving Jane through discourse presentation}

In this extract of the novel, Jane can be viewed in two different ways: she can be perceived as a difficult and stubborn child, or as a rejected and lonely being. These possibilities stem from the narrator's interaction with other characters, as well as from Brontë's subtle use of 'represented speech' (Leech/Short 2007: 233). In this section, I employ Leech and Short's model of discourse presentation and analyse the foregrounded features in Jane's speech which allow the reader to perceive Jane through multiple facets. 


\subsection{A Difficult Child?}

In the opening of Jane Eyre, the narrator and eponymous heroine is not named immediately, as opposed to Mrs Reed who is the first character to be introduced to the reader. The information provided about Mrs Reed is neutral, in other words it does not have any connotation ('Mrs. Reed, when there was no company, dined early'). However, as the narration progresses, she is more and more described through Jane's eyes. The last sentence, which consists of Jane recounting a conversation she had with Mrs. Reed, is foregrounded by external deviation due to its unusual structure:

Me, she had dispensed from joining the group; saying, 'She regretted to be under the necessity of keeping me at a distance; but that until she heard from Bessie, and could discover by her own observation, that I was endeavouring in good earnest to acquire a more sociable and childlike disposition, a more attractive and sprightly manner — something lighter, franker, more natural, as it were - she really must exclude me from privileges intended only for contented, happy, little children'.

Although the use of inverted commas and the reporting verb 'saying' suggest that it could be direct speech, the third person pronoun 'she' (instead of ' $\mathrm{I}$ ) and the verbs in the past tense (instead of the present tense) immediately reveal that it is an instance of free indirect speech. Free indirect speech "has a rather odd status in terms of truth claims and faithfulness. It is in a sort of halfway house position, not claiming to be a reproduction of the original speech, but at the same time being more than a mere indirect rendering of that original" (Leech/Short 2007: 261). This speech presentation impacts the level of faithfulness of the meaning conveyed here: Jane's voice is interposed between the reader and what Mrs Reed says, which creates distance and puts Jane in control of the reported speech (see ibid.: 268), while signalling Jane's attempt of a truthful reproduction to the reader.

In this piece of free indirect speech, Mrs. Reed explains why she does not want Jane to join the rest of the family, her sole argument being that the little girl is an unpleasant child. The overuse of punctuation (one semi-colon, eight commas, and two dashes), together with the inverted commas, suggest that Jane-narrator is attempting to mimic Mrs. Reed's tone and mannerism. The confusion between indirect and direct speech aims to evidence the narrator's mockery of Mrs. Reed. Jane actually disagrees with Mrs. Reed's comments about her, and does not believe that she deserves to be excluded: she is being 
ironic. Leech and Short define irony in literature as "a double significance which arises from the contrast in values associated with two different points of view" (Leech/Short 2007: 223), as is the case here: Jane-narrator conveys Mrs Reed's conversation with Jane-character but keeps her own point of view as opposed to also providing Mrs Reed's directly.

The reader can view Jane as a troublesome child who does not want to take part in any activity, as suggested by the negative forms to be found in the first two paragraphs: "no possibility of taking a walk", "I never liked long walks" or "dreadful to me was coming home in the raw twilight". The narration then moves on to portraying Jane not getting along with Bessie and the three Reed children. To this extent, Jane can be considered a rude and negative child, thus fitting Mrs. Reed's description. Since readers do not know Mrs Reed's character extensively, they have no reason to doubt her words. Yet, on the other hand, the reader is more likely to appreciate Jane's viewpoint because the first-person narration creates a bond (see Leech/Short 2007: 221) that permits them to realise that Mrs. Reed is just trying to justify her cruelty and injustice towards a child. The use of the free indirect speech "allows us to infer different characters' attitudes towards the information presented" (ibid.: 269), which has for effect "to channel our sympathies towards one character [Jane]" (ibid.: 269), and away from Mrs Reed. While Jane can thus be perceived as a difficult child who refuses to do as she is told and who criticizes the woman who looks after her, she will more likely appear to be a neglected child who happens to be ill-treated by the Reed family as shown by the section below.

\subsection{A "sullen Cinderella, an angry Ugly Duckling" (Gilbert 1977: 783)}

What is noticeable in the opening of Jane Eyre is how isolated and lonely Jane is. Gilbert links Jane's situation to the Ugly Duckling tale since Jane is "the smallest, weakest, and plainest child in the house, she embarks on her pilgrim's progress as a sullen Cinderella, an angry Ugly Duckling" (Gilbert 1977: 783). Gilbert references the famous tale Cinderella, highlighting the similarities it has with Jane's story: both involve "a foolish and wicked 'stepmother" (ibid.), as well as difficult step-siblings, and a daily life of rejection. He explains that "the child Jane cannot, as she well knows, be 'sanguine and brilliant'. Cinderella never is; nor is the Ugly Duckling, who, for all her swan'sdown potential, has no great expectations. 'Poor, plain, and little', Jane Eyre her name is of course suggestive - is invisible as air, the heir to nothing” (Ibid.). 
This impression of Jane is semantically constructed in the first paragraphs of the novel. The reader is first introduced to the Reed family: Mrs. Reed, then Bessie the nurse, and finally the Reed children. The still unnamed narrator depicts the family's daily activities and routine. In the first paragraph, daily activities such as walks or dinner are associated with moments of the day ("in the morning", "chilly afternoons"). These depictions allow the reader to get an overall impression of the family's daily routine which Jane is "dispensed from joining", thus appearing as the "Ugly Duckling' of the family.

Along with portraying the family's daily life, the Reed children are introduced with a triplet that echoes throughout the opening: "Elisa, John and Georgiana", whose ternary rhythm is echoed in other triplets, such as "nipped fingers and toes and a heart saddened" and "contented, happy, little children", pointing out everything that they are according to their mother, that is to say, everything that Jane supposedly is not. In fact, in the last paragraph, a doublet and a triplet, both composed of comparative adjectives, underline Mrs Reed's comparison between Jane and her own children ("more sociable and childlike disposition, a more attractive and sprightly manner" and "lighter, franker, more natural"), thus confirming the fact that the Reeds children are considered as "darlings" and "perfectly happy", whereas Jane is perceived as the opposite, which bolsters the idea that she is a sullen, troublesome outcast. The rule of three is an ideal rhetorical device to convey ideas and convince others of the point being made, and in this instance, it is likely to encourage the reader sympathise with Jane because of Mrs Reed's cruelty.

The contrast thus established between Jane and her cousins suggests the heroine's negative feelings about them, which are not expressed explicitly and therefore have to be inferred by the reader. The noun phrase "their mama" (instead of 'our mama') and the distinction between the pronouns "me" (Jane) and "them" (the Reed children), show that Jane is not part of the family, but also that she does not fit at all into the family routine. The noun "mama" is foregrounded by internal deviation insofar as it is colloquial language compared to the rest of the text, highlighting Jane's disdain towards the family. Jane views the Reed children negatively and highlights this to the reader in her description by adding "for the time neither quarrelling nor crying". This implies that the Reeds children behave in such a way frequently, which contradicts the way Mrs Reed describes them. Additionally, the use of the phrase "the said" before the triplet "Elisa, John and Georgiana" is commonly found in legal language to refer to defendants or victims: "used in legal writing, the word said is a Middle-English sibling of aforesaid, having the sense 'above-stated'. Orig- 
inally legal writers would write the said defendant [...] The use of the phrase 'the said' is particularly ludicrous when used to modify a proper name." (Garner 2001: 779) As a result, through her ironical use of the phrase, Jane portrays the three Reed children as defendants and herself as their victim, namely the one who has to endure their "quarrelling".

As explained above, Jane-narrator is reporting Mrs Reed's speech with irony. The level of modality characterising Mrs Reed's words shows how isolated and passive Jane is amongst the Reeds. Indeed, the use of auxiliaries such as "must" and the verbal phrase "regretted to be under the necessity" display the scene through deontic modality, which focuses on the speaker's norms, expectations and obligation, that is to say Mrs Reed's ground rules in this opening of Jane Eyre (see Portner 2009: 2). Deontic modality is expressed through auxiliaries, other verbs (here "regretted", "exclude") and adverbs ("really"), all of which picture the speaker's expectations of a situation (ibid.: 3). According to Mrs Reed, if Jane follows the "system of rules" laid out for her in this particular deontic frame and becomes a more pleasant child, she will be allowed to enjoy privileges reserved for happy children (ibid.: 23-24). This modality implies that Mrs Reed has no other choice but to deal with Jane the way she does, when in reality she consciously chooses to treat the little girl as a despised and unwanted child: Jane must abide by her "system of rules" to fulfil the "deontic frame" (ibid.: 23). She is forced to accept this isolation and her passivity ("dreadful to me") because she cannot escape her miserable fate, which reinforces the idea that she is the Reeds's 'Ugly Duckling'.

All of this contributes to the characterisation process: while the narrator and eponymous heroine has not yet been named, her daily life and living conditions can be inferred and pictured by the reader thanks to all the textual cues mentioned above, particularly through imagery and discourse presentation. Both aspects of her personality work together for the reader to perceive how complex Jane's character is: she is stubborn and knows what she wants, and yet she has very little control over her own life. Both sides of Jane's character are essential for the rest of the storyline to make sense and impact readers emotionally.

\section{The potential contribution of Conceptual Metaphor Theory}

Throughout this text analysis, I evidenced that figurative language, particularly pathetic fallacy, contributes to the development of Jane's character. 
Figurative language is mostly used in literature to allow readers to have a richer mental representation of elements of the plot, or characters' feelings. The process of perception of emotions can be explained through Conceptual Metaphor Theory (hereafter CMT), which states that one conceptual domain is understood in terms of another (see Lakoff/Johnson 1980: 5; Diaz-Vera 2014: 226; Kövecses 2002: 6). This theory maintains that metaphors typically associate a more abstract concept (referred to as a target domain) to a more concrete or physical concept (referred to as a source domain). Argument, love, ideas, social organisation are all more abstract concepts than war, journey, food, and plants (see Kövecses 2002: 6). The target domain is understood through the source domain, and metaphors achieve in this way a cross-domain mapping (see Lakoff/Johnson 1980).

I argue that CMT can be applied to standard metaphors and specific extended metaphors (such as pathetic fallacy or symbolism) alike, as in most figures of speech, an image is generated to give a concrete and physical alternative to an otherwise abstract concept. Just like metaphors, other figures of speech and iconic language (icons) perform cross-domain mapping, a fact which may deepen our understanding of the language used and its effect on the text overall. Being aware of this may thus streamline our understanding of how such textual features contribute to the characterisation process. By considering all imagery through the prism of CMT, cross-domain mappings could be identified and help us to better assess the impact such stylistic features have on readers.

In the case of the opening of Jane Eyre, multiple figurative language techniques were used, as I have analysed above. Pathetic fallacy projects Jane's feelings of sadness onto her surrounding: the dark clouds, the cold wind, the rain, and the falling leaves. Lakoff and Johnson (1980: 10-11) established a list of conceptual metaphors, amongst which what they call 'orientational metaphors' such as 'BAD Is DowN' (see Lakoff/Johnson 1980: 10-11). As mentioned in section 2.1, the downward motion of the leaves ("leafless shrubbery"), and the falling rain ("rain so penetrating") can be considered to be the source domain Down of the metaphor. Jane's sadness and sense of isolation is the target domain $\mathrm{BAD}$, thus providing the cross-domain mapping $\mathrm{BAD}$ Is DOWN. The mapping hereby performed concretely illustrates Jane's emotions: her spirit is low. In accordance with the main premise of CMT, the heroine's implicit immaterial feelings are understood in terms of a material domain: the weather. As for the instance of phonetic iconicity discussed in section 2.2, the consonances mimic the sound of the elements. The phonetic iconicity in 
this extract reinforces the effect produced by the technique of pathetic fallacy, as the weather is experienced through these sounds. If CMT can be used to explain the effects provided by figurative language generally, it may shed further light on the process of representation of emotions in the case of pathetic fallacy.

\section{Conclusion}

Figurative language greatly impacts the process of characterisation, particularly in the opening of Jane Eyre, where linguistic devices such as connected lexical fields, pathetic fallacy, and iconicity contribute to the building up of the protagonist in the reader's mind. Overall, most of the information provided about Jane in this opening is communicated implicitly, through imagery and clever use of discourse presentation which enable readers to gain an accurate idea of the narrator-protagonist's personality. This validates Culpeper's idea that characterisation is a 'process' of building characters: the reader infers information from the text and does not rely solely on what is explicitly said in the narration (see Culpeper 2001: 4). Textual cues, such as discourse presentation can implicitly contribute to the character-building process, as it is the case here: readers learn that Jane uses irony to deal with her sadness and alienation, and Mrs Reed is a cruel woman. Figurative language, as a further type of implicit textual cue within Culpeper's model, can also significantly contribute to characterisation as it allows readers to build a mental representation of characters (here the protagonist Jane) and their emotions through cross-domain mapping processes, as evidenced by an approach drawing from Conceptual Metaphor Theory.

From the very first lines of the novel, the reader learns that Jane can be self-aware and moody at times, but also that she has a sense of humour, being able to ridicule her guardian's malice. She feels estranged, lonely and out of place with the Reeds, and the reader is made to sympathise with her. The bond hereby created is crucial as it will encourage the reader to keep turning the pages. The opening thus sets the tone for the rest of the story, which makes these first paragraphs so powerful. 


\section{References}

\section{Corpus}

Brontë, C. ([1847] 2014): Jane Eyre: An autobiography. Minneapolis, MN: Lerner Publishing Group.

\section{Other works}

Abbott, H. Porter (2008): The Cambridge introduction to narrative, $2^{\text {nd }}$ edition, Cambridge: Cambridge University Press.

Brown, Calvin S. (1962): "Towards a definition of Romanticism", in: Stanley Burnshaw (ed.), Varieties of Literary Experience, New York: New York University Press, 115-36.

Chris Baldick (ed.) (2008): 'characterisation', in: The Oxford Dictionary of Literary Terms (2008), Chris Baldick (ed.), Oxford: Oxford University Press, http s://www.oxfordreference.com/view/10.1093/acref/9780199208272.001.0 001/acref-9780199208272-e-188?rskey=6CBo9x\&result=1 (Last accessed: 17.04.2021).

Culpeper, Jonathan (2001): Language and characterisation: People in plays and other texts, Harlow: Longman.

Díaz-Vera, Javier E. (ed.) (2014): Metaphor and metonymy across time and cultures: Perspectives on the sociohistorical linguistics of figurative language, Berlin/Munich/Boston: De Gruyter Mouton.

Eder, Jens et al. (2010): Characters in fictional worlds: Understanding imaginary beings in literature, film, and other media, New York: De Gruyter.

Forster, Edward M. (1985): Aspects of the novel, Vol. 19, Boston: Houghton Mifflin Harcourt.

Garner, Bryan A. (2001): A dictionary of modern legal usage, Oxford University Press, USA.

George, Anne (2002): "Book review: Language and characterisation: People in plays and other texts", in: Language and Literature, 11 (4), 373-375.

Gilbert, Sandra M. (1977): "Plain Jane's progress", in: Signs, 2 (4), 779-804, htt p://www.jstor.org/stable/3173210 (Last accessed: 12.11.2019).

Halliday, Michael A.K. (1967): "Notes on transitivity and theme in English: Part i”, in: Journal of Linguistics, 3 (1), 37-81 
- (1968): "Notes on transitivity and theme in English: Part ii", in: Journal of Linguistics, 3 (2), 199-244.

Halliday, Michael A.K./Matthiessen, Christian (2004): An introduction to functional grammar, London: Arnold.

Harvey, William J. (1965): Character and the novel, Vol. 67, Ithaca, NY: Cornell University Press.

Herman, David (2007): The Cambridge companion to narrative, Cambridge: Cambridge University Press.

Jeffries, Lesley (1993): The language of twentieth-century poetry, Basingstoke: Macmillan.

Jeffries, Lesley/McIntyre, Dan (2010): Stylistics, Cambridge: Cambridge University Press.

Katz, Albert et al. (1998): Figurative language and thought, Oxford: Oxford University Press.

Knight, Lionel C. (1963): Explorations: Essays in criticism mainly on the literature of the seventeenth century, London: Chatto \& Windus.

Körtvélyessy, Livia (2016): "A cross-linguistic research into phonetic iconicity", in: Lexis, 6 (6), https://journals.openedition.org/lexis/409 (Last accessed 12.11.2019).

Kövecses, Zoltan (2002): Metaphor: A practical introduction, New York: Oxford University Press.

Lakoff, George/Johnson, Mark M. (1980): Metaphors we live by, Chicago: University of Chicago Press.

Leech, Geoffrey. N./Short, Mick (2007): Style in fiction: A linguistic introduction to English fictional prose, Harlow: Pearson Longman.

Lodge, David (1992): The art of fiction: Illustrated from classic and modern texts, London: Penguin.

Margolin, Uri (1983): "Characterisation in narrative: Some theoretical prolegomena”, in: Neophilologus, 67 (1), 1-14.

- (2007): "Character", in: David Herman (ed.), The Cambridge companion to narrative, Cambridge: Cambridge University Press, 66-79.

Mukařovský, Jan (1964 [1932]): "Standard language and poetic language", in: Paul L. Garvin (ed.), A Prague school reader on esthetics, literary structure, and style, Washington DC: Georgetown University Press, 17-30.

Oxford Dictionary of English (2010), Angus Stevenson (ed.), Oxford: Oxford University Press.

Portner, Paul (2009): Modality, New York, Oxford: Oxford University Press. 
Roberts, Richard M./Kreuz, Roger J. (1994): "Why do people use figurative language?", in: Psychological Science, 5 (3), 159-163.

Rubik, Margarete/Mettinger-Schartmann, Elke (2007): A breath of fresh Eyre: Intertextual and intermedial reworkings of Jane Eyre, New York, Amsterdam: Rodopi.

Ruskin, John (2012 [1843]): Modern painters, Vol. III, The Project Gutenberg, ht tp://www.gutenberg.org/ebooks/38923 (Last accessed: 19.04.2021).

Siddall, Stephen (2009): Landscape and literature, Cambridge: Cambridge University Press.

Simpson, Paul (2004): Stylistics: A resource book for students, London: Routledge. Toolan, Michael (1983): "Style in fiction: A linguistic introduction to English fictional prose by Geoffrey N. Leech, Michael N. Short" (Review), in: Poetics Today, 4 (1), 135-137.

Wales, Katie (2001): A dictionary of stylistics, $2^{\text {nd }}$ edition, Harlow: Longman. 



\section{Performing Rhythm Through Enunciation: Prose Versus Poetry About Lighthouses}

Maryvonne Boisseau, Université de Strasbourg (France)

\section{Introduction}

Reader-response theories have changed the way literary texts can be studied by introducing the reader as a crucial parameter in the overall appreciation of the power of a text. As a result, it is now commonly acknowledged that a text, whatever its genre, has an influence on the readers it is in theory intended for. However, this rather vague and consensual assumption probably needs probing through an examination of its implications. This entails considering two aspects, the thematic content and make-up of the text on the one hand, its readers on the other hand, but also, and more importantly, understanding how the two sides articulate in the very act of reading. There are many ways of reading, from silently absorbing the words on the page to flipping through a book, to reading aloud. The practice of loud reading was customary in the Middle Ages but it gradually waned and nowadays tends to be confined to reading to children at bedtime or to public readings in the context of commercial or cultural events. Concerning reading itself, whether slow or fast, scholarly or ordinary, all readers are performers ${ }^{1}$ in so far as reading, whether private or public, is an interpretative gesture as Virginia Woolf so brilliantly demonstrated in The Common Reader (see Woolf 1957). As such, it "presupposes an interplay between textual clues and the reader's attribution of meaning" (Nünning 2017:30). In the case of reading aloud and public reading, the question of the text's potential effects, the pleasure it may provide, and the response it may elicit is further complicated since these aspects are

1 For lack of a better word, since readers do not usually think of themselves as artists. 
filtered by a reader-performer whose voice conveys his or her interpretation to a listener's ear. This hearer is dependent on the pondered interpretation of a text as reflected and mediated by the reader who stands between the printed words and his or her attention. Nonetheless, while it may seem uncertain to foresee and gauge a listener's reactions to an oral performance, it is plausible to anticipate its effects by analysing the reading experience in the first place. In other words, how does a text capture a reader's interest? How does a reader let himself or herself be captivated by a text? What does a listener hear and understand ${ }^{2}$ Part of the answer lies in the emotional potential of a text, "its relation to empathy, perspective taking and persuasion" (Nünning 2017: 39). This is completed by the reader's ability to cultivate his or her inner ear so as to listen to what the text communicates through itself as "a form of words"3 whose meaning is entrusted to this very reader.

Given this, I posit that, whatever response a text elicits and independently of its genre, its constitutive rhythm is a cardinal element that governs the way it is received. In order to probe this general hypothesis, I propose to investigate the rhythms of a prose excerpt and a short poem whose common topic is the description of a lighthouse, an immobile beacon approached from the shore in both cases and described by a tourist-narrator. My perspective is based on the findings of enunciation and language theorists, such as linguists Émile Benveniste and Antoine Culioli, language theorist and poet Henri Meschonnic for whom rhythm is language, and translation expert Clive Scott, starting from the premise that a creative piece of writing does something to both writer and reader who share in the process of assigning meaning to a text. After defining key notions (enunciation, rhythm, points of prosodic condensation) and introducing the texts themselves, I propose to concentrate on the comparison between some passages in the texts that present some affinities as well as syntactic similarities to try and determine whether, and to what extent, prose and verse are identified as fundamentally different, or not, by a hearer when texts are performed.

2 Put into French, the question is: Qu'entend le public? entendre meaning "hear" and "understand" at once.

3 I borrow the expression from a poem by Derek Mahon: "This [the poem itself] is a circling of itself and you - / A form of words, compact and compromise, / Prepared in the false dawn of the half-true / Beyond which the shapes of truth materialize." (Mahon 2011: 20). 


\section{Enunciation, rhythm, points of prosodic condensation}

The theoretical notions of enunciation and rhythm are closely related in so far as they refer to the speech activity and functioning of language positing a subject as "enunciator", at the same time source and product of the enunciative act performed in a specific situation, in and through which an intersubjective space is framed. ${ }^{4}$ According to Antoine Culioli, language is grounded in enunciative situations (or 'uttering Situation') coinciding with "real" or fictitious situations. Situations, text and meaning are constructed through the located interaction of enunciators shifting into a necessary presence (co-enunciators actualized as speakers, and co-speakers/addressees, in other words, poets, writers, narrators, characters, readers and so on ${ }^{5}$ ). The "text" (or 'utterance') resulting from this intersubjective interaction bears the traces of its enunciation, that is to say of the cognitive operations (called 'predicative' and 'enunciative' operations) through which it is processed, as well as of the impulse that triggered the movement of its enunciation. ${ }^{6}$ Hence rhythm, as a primary force, is by necessity congruent with the act of enunciation, and if, as suggested by Meschonnic, it is to be understood as the very organisation of discourse, operating the simultaneous and comprehensive functioning of syntax, prosody and enunciation, it is also, and at the same time, an energy, a "performative event" (Scott 2014: 219). Discourse, or text (poem, fiction, drama, nonfiction), comes alive when enacted through reading, acting, performing. Therefore, rhythm is re-enacted at each performance and actualized as a singular enunciative event, the result of an encounter between text and reader.

The metalinguistic terms used here are the concepts elaborated by Antoine Culioli (1924-2018). His interdisciplinary approach to language and languages including syntax, semantics, lexicon and culture has influenced a whole generation of linguists in France and far beyond. For a faithful and reliable description of the theory and of its conceptual framework and vocabulary, see Groussier 2000.

5 Other frequent terms to denote these are 'locutors' and 'interlocutors', depending on the linguist's cultural background.

6 To put it in other words and account for the choice of the word movement in this context, it can be said that enunciation is an active process originating in some desire or need to express something in relation to a situation that is being constructed at the same time through and by the very process of enunciation. This central point allows a connection with Henri Meschonnic's general Theory of Language whose fundamental axis is rhythm viewed as representing the continuous (and sometimes discontinuous) flow of language (see Meschonnic 1982). 
And so, paradoxically, although we look for its imprints in the materiality of the text itself, rhythm may be perceived not as a property of the text but as an experience including physiological and paralinguistic features such as the quality of the reader's voice and body involvement. The printed word becomes a spoken word and the linear arrangement of the words on the page turns into an embodied utterance. It would probably be misguided to equate the hearer's experience to that of the reader even though the hearer's understanding and his or her appreciation of the text very much depend on the aspects of the text the reader has focused on. These elements may be single words stressed by the reader, clusters of words, text segments, phrases, rhymes, pauses, all of those marked by a specific and striking tone of voice, timbre, pitch and intonational contour. Following David Nowell Smith (2014), I suggest calling them 'points of prosodic condensation'. ${ }^{7}$ As signals, they accumulate syntactic and semantic information, either erasing, or pointing to, the (aural) discontinuities in the flow of words, thus imparting rhythm to the very enunciation of the text.

By surrendering to the pleasure of literature, readers and hearers jointly acknowledge the power of the texts to trigger emotions but also, and probably most importantly, to stir the imagination and seduce the ear. It is usually understood that only literature of the highest order - like poetry, and to most readers poetry belongs to this category - can rouse emotions but one can also derive pleasure from reading a good piece of fiction or journalism, a biography or a memoir, provided that the "crocus" should fill "precisely the space allotted to it", and "radiate a golden glow", to borrow a metaphor from Virginia Woolf (Woolf 1957: 263). ${ }^{8}$ On the surface, the prose excerpt and the short poem selected for this contrastive study engage their readers and hearers in quite a different manner. A comparison based on their respective points of prosodic condensation will nonetheless seek to highlight their affinities.

To David Nowell Smith, a 'point of prosodic condensation' can be a word or a phrase whose "prosodic density results not simply from phonic patterning, but also from the demands it makes on our interpretive activity as those reading, and voicing, the poem" (Nowell Smith 2014: 34).

8 In a penetrating essay, Woolf gives advice to writers who should be careful to choose their "patrons" wisely since "To know whom to write for is to know how to write" (Woolf 1957: 264). Therefore the fortune of a good piece of writing (a "crocus") also depends on the integrity and good judgement of the "patron" (or, in our modern times, publisher): "[...] the fate of literature depends upon their happy alliance [...]" (ibid.: 266). 


\section{Texts, contextualisation and postulations}

The prose text is a short extract from The Rule of the Land: Walking Ireland's Border by Garrett Carr. Published to wide acclaim in 2017, the book is an account of his journey on foot and by canoe along the entire length of the border that separates Northern Ireland from the Republic. From east to west, Carr's threehundred-mile journey takes him from the entrance to Carlingford Lough to Donegal and Derry. As a travel essay, it belongs to nonfiction but the book is not so easily classified and is undoubtedly more than a travel essay. Some of the border people encountered on the way could well figure as characters in a novel or in short stories while the border itself is endowed with a life of its own, so much so that it becomes the island's "third state", "a unique realm of its own". ${ }^{9}$ Besides, reviewers have praised the literary quality of the writing, admiring a "poet's facility with words" 10 as well as the way the complexity of the subject - including history and geography, political sociology, psychology - is treated at a time when the border takes on a new significance (on account of the Brexit negotiations). As Patricia Craig writes, "He has written a great book about a compelling subject" (Craig 2017), an assertion which can be interpreted as summing up the idea of an effective style impacting readers and hearers alike through the rhythms of walking and discovery. The selected passage can be found at the beginning of the narrative and describes the starting point of the journey, Haulbowline Lighthouse which marks the entrance to Carlingford Lough and seems to look inland towards the west rather than out to sea.

The poem to be contrasted with the prose extract is "A Lighthouse in Maine" by Irish poet Derek Mahon, ${ }^{11}$ with a dedication to the American painter Edward Hopper (1882-1967). Originally published in 1982 (see The Hudson Review 1982), it was republished in various collections of Selected Poems in 1990, 1991 and 1993. It then disappeared from later collections until it reappeared in an altogether different format in Art Notes (Mahon 2006) and

9 Blurb on the back cover of the book.

10 The Irish Independent, endorsement on the back cover of the book.

11 The quotations from The Rule of the Land. Walking Ireland's Border are used here as examples for the sake of the analysis. Thanks are due to Peter Fallon and The Gallery Press for kindly permitting to quote the poem "A Lighthouse in Maine" (๔ Derek Mahon 2011; www.gallerypress.com). The poem can be found online following this link: $<$ http $\mathrm{s}$ ///www.griffinpoetryprize.com/from-art-notes/>. See the reference section at the end of this paper for full bibliographical references. 
eventually in New Collected Poems (Mahon 2011). The original poem contains seventeen tercets and no dedication while the last version is a drastically reduced two-stanza poem, each of eight lines of verse. The dedication to Edward Hopper not only makes explicit the painting ${ }^{12}$ that influenced the writing of this poem but points to some masked "purifying" process that led to its re-invention or metamorphosis. ${ }^{13}$ The event that may have prompted the writing of the poem in the first place (a casual trip and walk to the lighthouse) seems to have receded to the background and a romanticized linguistic and poetic representation of the lighthouse is now foregrounded, turning the seventeen-stanza poem into a two-stanza ekphrasis, perceived as it were in a single take in an intersemiotic attempt to match painting and poem. With these notions in mind and considering the reading performance and the audience, three postulates can be examined:

I. the rhythms that contribute to the significance of the texts are inscribed in a similar geopoetical background and a shared apprehension of what a lighthouse represents;

II. the lighthouse's acknowledged significance is construed through and by the enunciation itself including enunciator and coenunciator;

III. orality/'aurality'14 tends to obliterate the traditional distinction between prose and poetry since rhythm and meaning are at one.

12 "In The Lighthouse at Two Lights Hopper isolated the dramatic silhouette of the 120foot-high lighthouse tower and adjoining Coast Guard station against the open expanse of blue sky. Set on a rocky promontory in Cape Elizabeth, Maine - though no water is visible in the painting, the architecture is bathed in bright sunlight offset by dark shadows; [...] To Hopper the lighthouse at Two Lights symbolized the solitary individual stoically facing the onslaught of change in an industrial society." (Anonymous undated)

13 Derek Mahon is well-known for constantly revising his poems, trimming unnecessary parts, smoothing what he probably considered imperfect, endlessly polishing his verse.

14 The homophonous technical term aurality refers to the aspect of the oral performance pertaining to hearing and listening. 


\section{Rhythm and geopoetical context}

Unsurprisingly, in both texts ${ }^{15}$, the topic of the lighthouse, is introduced via its location in space:

\begin{tabular}{|l|l|}
\hline Prose text & Poem \\
\hline $\begin{array}{l}\text { Ahead, tall and grey in the sodden at- } \\
\text { mosphere, is the border's first monument. } \\
\text { Haulbowline Lighthouse stands off shore. } \\
\text { Waves crash at it from all sides. }\end{array}$ & $\begin{array}{l}\text { It might be anywhere, that ivory tower } \\
\text { reached by a country road. } \\
\text { (Carr: } 8, \text { emphasis added) }\end{array}$ \\
\hline
\end{tabular}

The rhythms of the first two sentences in the prose text and that of the first sentence in the poem creates a space apprehended from a distance that enables the mind to gradually focus on the lighthouse. The distance is materialised by the order of the words and indirect mention of the topic ${ }^{16}$ whose designation is delayed in the poem through the choice of a cataphoric pronoun, "it", while its referent, "that ivory tower" (Mahon: I, 1), is placed at the end of the line. The same strategy operates in the prose text with the qualifications "tall and grey" foregrounded and a locative inversion at the end of the first sentence together with the indirect designation of the topic, "the border's first monument", named in the next sentence with, this time, a direct designation, "Haulbowline Lighthouse" (Carr: 8). The movement of the syntax seems to govern the pace of the diction: slow at the beginning ("Ahead, tall and grey in the sodden atmosphere, is the border's first monument" [Carr: 8] // "It might be anywhere, that ivory tower" [Mahon: I, I]), then faster with the succession of two short declarative statements adjacent to the previous sentence in the prose text and with the enjambement in the poem ("that ivory tower / reached by a country road" [Mahon: I, 1-2]). The space is defined as

For convenience's sake, the prose examples from Carr's book will be referred to as Carr, followed by the number of the page in the book, and Mahon's poem as Mahon, followed by the number of the stanza and the number of the line of verse (I, 1-2 stands for stanza I, lines of verse 1 and 2).

16 The topic is actually explicitly named in the title of the poem, "A Lighthouse in Maine". The title acts as a frame for the ekphrasis as suggested here and is part and parcel of the poem. 
at once unspecified or indefinite ("It might be anywhere" [Mahon: I, 1]) and fixed or definite (the border [see Carr: 8]).

In geopoetic terms, this space is an in-between, an edge - land's edge or water's edge - expanding both ways inland and out to sea but the point of view from which it can be observed remains the land ("off shore" [Carr: 8]; "reached by a country road / above a bay" [Mahon: I, 2 and II, 15]). The lighthouse (in Maine) at the tip of the land, "shines [...] above a bay" (Mahon: II, 15). Haulbowline Lighthouse, in Northern Ireland, although surrounded by the sea, is the beginning of a journey inland along the line that separates Northern Ireland and the Republic ("I think of it as the beginning because this lighthouse [...] is a fine spool from which to unwind the border" [Carr: 8]). This location at the end of the road confers to these two lighthouses, and by extension to any lighthouse in the world, an aura which appeals, fascinates and draws people to them. In both texts, those first lines concentrate enough information to be considered as "points of prosodic condensation" in so far as their rather slow diction, following the syntactic arrangement of words, conveys a sense of movement and opening from a fixed point of departure at the edge of the world towards some undisclosed reality. From there a powerful narrative can be unfolded. In other words, a story and a landscape will be gradually revealed extending horizontally - the border as a (story-)line - and vertically — the lighthouse standing as a towering beacon - which is exactly what a text also does, combining the syntagmatic development of sentences and the latent undisclosed possibilities on the paradigmatic axis since the words chosen not only denote but connote impressions and feelings. Moreover, these introductory lines open onto another space, that of the significance of the lighthouse. In both texts, the reader is led into a pragmatic situation on the one hand (how to access the lighthouse), a cognitive and conceptual world on the other hand (what the lighthouse looks like and what it represents) combining movement and fixity. The question here is to try and understand how these two planes are articulated when the text is performed.

\section{Enunciation and significance}

The first move in the texts is to create an intersubjective situation by directly addressing a co-enunciator-reader. Pragmatically, the reader is given directions while conceptually he or she is communicated a poetic description of 
the building as if he or she were the origin ${ }^{17}$ of the perception, particularly so in the poem. Narrator and reader's points of view are superimposed. This is linguistically materialised by the use of the personal pronouns, I and you, as grammatical subjects of the clauses concerned (as shown in the extracts below), with an ambivalent second-person pronoun, both generic (anybody) and specific (you, as reader):

\begin{tabular}{|l|l|}
\hline Prose text & Poem \\
\hline I think of it as the beginning [...] I imagine & $\begin{array}{l}\text { You make a left beyond the town, a right, } \\
\text { You turn a corner and there, ivory-white, } \\
\text { the line as [...] }\end{array}$ You can't stroll around Haulbowline, you \\
It shines in modest glory over a bay. \\
can barely take a step. The tower com- \\
pletely smothers the rock it stands on. \\
Paddy and I slip into the lighthouse's orbit. \\
(Mahon: II, 13-16, emphasis added)
\end{tabular}

In the prose text, the eyes of the reader follow the men paddling towards Haulbowline Lighthouse ${ }^{18}$. It is as if the lighthouse itself were beckoning, attracting the men in spite of the crashing waves. Two short juxtaposed clauses

17 The metaphorical term origin combines the idea of the perceiver as agent and source and, at a theoretical level, as a "locator" in relation to which other elements are "located". This operation of location is "the basic operation at the root of all enunciative operations" (Groussier 2000: 161). About this operation, Groussier stresses the fact that "the word location refers to an abstract operation, location in space being only one among several kinds of location" (ibid.: 167).

18 At the start of his journey, and wherever the border travels open water, the narrator will be accompanied by Paddy (Bloomer), a canoeist, to help him through these stretches. See the opening sentence of the narrative: "We pick up the border from the open sea, approaching it in a twelve-foot canoe" (Carr 2017: 8). 
showcase the occurrences of the pronoun you at a strategic initial position introducing the careful approach to the lighthouse in the prose text and swift access in lines 13 and 14 of the poem, and initiating a shifting movement from the viewer to the object viewed. Mentally, in the poem, the reader follows the direction as if he or she were in the car (see Mahon: II, 13-14), then the lighthouse literally appears, facing him or her (see Mahon: II, 14-15). The end of the approach is briskly ${ }^{19}$ made on foot (see Mahon: II, 16). In the prose text, the movement centres on the enunciator-narrator, including the two 'actants' ("Paddy and I" [Carr: 9]). As expected in a situation when one is given directions, the words that convey the directions and movement are ordinary words, prosaic in both texts, and meant to reflect the exact situation and location. However, in both cases, a comment interrupts the flow of the directions ("[...] and there, ivory white / It shines in modest glory over a bay" [Mahon: II, 14-15] and "The tower completely smothers the rock it stands on" [Carr: 9]). In the prose text, the enunciator-narrator continues: "[...] There is something comforting about the lighthouse, something paternal about the way it dominates our small craft. There is elegance here too, Haulbowline's body tapers out smoothly, granite made graceful" (Carr: 9) as if the explicit intention to reach the lighthouse needed the help of perceived evidence that it is indeed worth walking or paddling as close to it as possible. These comments ensure the junction between the two planes already mentioned, the pragmatic situation and the mental representation or image of the lighthouse. Their effect is to contain the diction of the reader-performer in an attempt to slow down the physical approach to the lighthouse so as to reassert its strong presence as well as the gradual awareness of its significance.

These passages, which combine conversational and descriptive features, establish the performer in a position empowering him or her to highlight the various enunciative, stylistic and prosodic choices made by the authors. In the two texts, the pragmatic and conceptual planes are intertwined at a discursive level so that a representation with both unique and universal features materialises.

Among enunciative choices, to the dialogic dimension and explicit construction of a fictitious co-speaker can be added an amount of indeterminacy marked by the modal auxiliary 'might' in the poem ("It might be anywhere" [Mahon: I, I]) - the "Lighthouse in Maine" is representative of any lighthouse

19 As hinted at by the pace of the line characteristically made up of monosyllables. From a poetic point of view, this last line also suggests something of an anticlimax. 
- compared, in the prose text, to an accumulation of descriptive and technical details that make Haulbowline Lighthouse unique in Ireland. Among stylistic choices contributing to a specific representation of either monument is a process of acknowledgment of the strength and solidity of the towering protective figure in the prose text, in spite of the waves that "crash at it from all sides" (Carr: 8), and identification through comparison with a paternal figure, Buddha, in the poem ("It faces every which way with an air / of squat omniscience, intensely mild, / a polished Buddha figure warm and dry [...];" [Mahon: I, 3-5]). As a result, the lighthouse is endowed with the qualities of the character it is identified with ("omniscient", "mild" [Mahon: I, 4], "comforting", "paternal" [Carr: 9]), not without a touch of femininity made of beauty, elegance and grace ("it sits there dozing in the afternoon / above the ocean like a ghostly moon / patiently waiting to illuminate" [Mahon: II, 10-12]). Haulbowline Lighthouse too is a reassuring figure, in spite of its grey colour, immensity and awe-inspiring structure. Here, in the prose text, the rhythm is marked by an alternation between the noun "lighthouse" and its name "Haulbowline Lighthouse" (Carr: 9) and, in the poem by the repetition of the anaphoric pronoun "it" (Mahon: I, 2-6 and II, 9-12, 15-16).

\begin{tabular}{|c|c|}
\hline Prose text & Poem \\
\hline $\begin{array}{l}\text { There is something comforting about the } \\
\text { lighthouse, [...] Haulbowline's body tapers out } \\
\text { smoothly [...] it is easy to imagine the light- } \\
\text { house's body continuing to curve [...] Above } \\
\text { the water, the structure is nothing but [...] } \\
\text { a mighty stump giving the lighthouse a low } \\
\text { centre of gravity. [...] Haulbowline was de- } \\
\text { signed to deny the sea any bite because } \\
\text { even a tiny space between blocks would } \\
\text { have been eaten at and widened, weak- } \\
\text { ening the structure, eventually pulling the } \\
\text { lighthouse down. Without a nook or cranny } \\
\text { for waves to pick at, Haulbowline has been } \\
\text { standing since } 1824 \text {. (Carr: } 9 \text {, emphasis } \\
\text { added) }\end{array}$ & $\begin{array}{l}\text { [...] Granite and sky, } \\
\text { It faces every which way with an air } \\
\text { of squat omniscience, intensely mild, } \\
\text { a polished Buddha figure warm and dry } \\
\text { beyond vegetation; [...] (Mahon: I, 2-6) } \\
\text { Built to shed light but also hoarding light, } \\
\text { it sits there dozing in the afternoon } \\
\text { above the ocean like a ghostly moon } \\
\text { patiently waiting to illuminate. } \\
\text { [...] (Mahon: II, 9-12) } \\
\text { it shines out in modest glory above a bay. } \\
\text { Out you get and walk the rest of the way. } \\
\text { (Mahon: II, 15-16, emphasis added) }\end{array}$ \\
\hline
\end{tabular}

This repetitive music together with the repetition of structural patterns ("there is something comforting [...] something paternal [...] There is elegance 
[...]" [Carr: 9]), the kind of wedge-shaped structuring of the prose, each sentence being solidly fastened to the previous one, each phrase made necessary by the movement of the words, rock against one's ears. As a result, it is impossible not to visualize - and perhaps admire - the two towers, one with its squat appearance, the other one with its tall graceful silhouette solidly anchored to the sea-floor. They have gradually been imparted with durable qualities as if they were invested with a sort of mysterious unalterable existence. They stand there with a mission to fulfil: shedding light but also hoarding it.

\section{Orality/"aurality": rendition and voice}

So far, I have tried to isolate points of prosodic condensation where enunciative choices operate the synthesis of components to form a connected whole provoking interest, curiosity and admiration. This is rhythm as the very organisation of discourse, involving syntax, semantics and prosody. The question of their recognition as prominent markers when the texts are performed before an audience remains. Indeed, rhythm as an experience of what language does depends on other factors belonging to the non-lexical components of communication ('the paralinguistic'). Is an oral performance helpful in identifying what this partial observation of the texts has so far revealed? Which of the two texts lends itself best to aural reception? There are arguments to decide that it is the poem. Firstly it is much shorter than the prose excerpt since it is made up of two octaves with a total of five sentences, each of them linguistically representing a step in the recognition of the lighthouse. Therefore, it is probably easier to take in, an attentive listener can recognise rhymes and half-rhymes ("sky"|"dry"; "afternoon"/"moon"; "right"/"white"; "bay"/"way"; "tower"/"air"; "glare"/"more" [Mahon: I and II]), and recurring sounds - /ai/ in particular — and, guided by the comparison with the Buddha figure, he or she can form a precise visual representation of the lighthouse. However, if there is movement in the smoothly graceful and fluent rhythm of the lines (owing to the run-on lines) and briskness in the approach to the lighthouse (owing to the monosyllabic line of verse closing the poem), the image formed is fixed and passive, a reminder of the painting by Hopper.

There is movement too in the prose extract, which gives Haulbowline Lighthouse an impressive aura. Whether the response to it is emotional is hard to decide but the fluctuations of the text (see the alternation of narrative 
and comment in the first example, table 1) convey a sense of restless landscape. The lighthouse seems to be constantly at war with the surrounding sea. Built to resist the crashing waves, it nevertheless keeps an eye inland, in the direction of the westerly extremity of the border, the promised end of the journey. It is as if its destiny were part and parcel of the history of the island in its temporal and spatial dimensions. The mixture of observation, information, action, feelings, and imagination evokes a live commentary on television or radio. Unlike the poem, the picture conjured up by the text is not so much a painting as a short documentary film with a descriptive account entirely focused on the monument. In short, in the poem, the lighthouse could be the aim of a short touristic outing; in the prose text, it is the starting point of a journey whose narrative is yet to come. This sole fact contributes to an impression of textual closure in the poem - and this does not imply that the interpretation is bounded - and to the feeling of an opening statement in the prose text. In both cases, the lighthouses have been established as landmarks by and through the act of enunciation and perceived as poetic and emotional boundaries through the vocalised experience of rhythm.

\section{Conclusion}

What makes a literary fiction text powerful? And what is meant by "powerful"? Raising the questions presupposes that the category a text belongs to makes a difference and that there is no certainty as to what combination of ingredients might warrant recognition of the effective influence of a text on an intended reader. This study has approached the question indirectly by attempting to show that a prose extract from a book classified as non-fiction, thus not claiming to stand as a "work of art", could elicit a reader's response akin to that prompted by a poem. In this particular instance, the same topic and scene (lighthouse and edge of the world), a description from a similar point of view (the monument seen at a distance then approached), and a deliberate significance imparted to the lighthouse through its linguistic representation (a paternal Buddha-like figure) are striking features fostering an active interpretation of the texts. In spite of this, the "common reader" resists too straightforward an assimilation of prose to poetry (or poetry to prose), and deep inside most likely clings to the idea that some texts are more pow- 
erful than others. So "how can we know the dancer from the dance"? ${ }^{20}$ The answer may well be found in the phonation of the texts, their externalisation enabling the reader to focus on and call attention to both the overall rhythm of the texts (in Meschonnic's sense of a "pattern of enunciation" ${ }^{21}$ ) and the specific changeable individual rendering of the rhythms that depend on his or her perceptions of the "multi-dimensional field of rhythm as a whole" as Clive Scott suggests (Scott 2014: 219). This is rhythm as an experience that conditions the rendition of the text: "performance ensures the reader's reinhabitation of polyrhythmy and defines the reader's task not as the identification of the rhythmic possibilities of a text, but the rhythmic possibilities offered by the embodiment of the text." (Scott 2014: 220, emphasis in original) ${ }^{22}$

When read and performed one after the other, the opening pages of Carr's travelogue, and specifically this short excerpt with its description of the narrator's approach to Haulbowline Lighthouse and Mahon's poem, "A Lighthouse in Maine" release energies beyond the printed page to reach a listener. Through the voice that carries their words, both texts lend themselves to the invention of their respective rhythms as enunciation, questioning - if not erasing - perhaps, too definite a distinction between the prosaic and the poetic.

\section{References}

\section{Corpus}

Carr, Garrett (2017): The Rule of the Land, London: Faber \& Faber, 8-9. Mahon, Derek ${ }^{23}$ (2006): "A Lighthouse in Maine", in: Art Notes, Oldcastle: The Gallery Press, "Gallery Books", unpaginated.

\footnotetext{
20 Last line of verse of the famous poem "Among School-Children" by W. B. Yeats.

21 "Rhythm in meaning, in the subject, and the subject, the meaning, in rhythm establish rhythm as a pattern of enunciation as much as a pattern of speech." "'Le rythme dans le sens, dans le sujet, et le sujet, le sens, dans le rythme font du rythme une configuration de l'énonciation autant que de l'énoncé", Meschonnic 1982: 72, my translation).

22 The term polyrhythmy used by Scott is borrowed from Pierre Boulez and refers to "the multiple activity of rhythm across timbre, duration, attack, dynamics, tempo, silence and so on" (ibid.).

23 Derek Mahon, born in Belfast in 1941, died on October 2nd, 2020 at his home in Kinsale, Co Cork.
} 
- (2011): "A Lighthouse in Maine", in: New Collected Poems, Oldcastle: The Gallery Press, 299.

\section{Other works}

Anonymous (undated): "The Lighthouse at Two Lights", in: Edward Hopper, Paintings, Biography, and Quotes, https://www.edwardhopper.net/the-ligh thouse-at-two-lights.jsp (Last accessed:16.06.2019).

Benveniste, Émile (1974): Problèmes de linguistique générale, Tome 2, Paris: Gallimard, coll. "TEL".

Bouvet, Rachel/Olivieri-Godet, Rita (eds.) (2018): Géopoétique des confins, Rennes: Presses Universitaires de Rennes.

Craig, Patricia (2017): "The Rule of the Land review: A compelling take on the border", in: The Irish Times, 28.01.2017, https:/www.irishtimes.com/cultu re/books/the-rule-of-the-land-review-a-compelling-take-on-the-border -1.2921282 (Last accessed: 17.02.2020).

Culioli, Antoine (1995): Cognition and representation in linguistic theory, Amsterdam/Philadelphia: John Benjamins Publishing Company.

Dessons, Gérard (1997): textes réunis et présentés par, La Licorne (Penser la voix), Poitiers: UFR Langues Littératures Poitiers.

Dessons, Gérard/Meschonnic, Henri (1998): Traité du rythme. Des vers et des proses, Paris: Dunod.

Goux, Jean-Paul (2003): "De l'allure", in: Semen 16, http://semen.revues.org/d ocument2664.html (Last accessed: 01.06.2019).

Groussier, Marie-Line (2000): "On Antoine Culioli's theory of enunciative operations”, in: Lingua 110, 157-182.

Mahon, Derek (1982): "A Lighthouse in Maine", in: The Hudson Review, 35 (2), 251-253.

Meschonnic, Henri (1982): Critique du rythme, Lagrasse: Verdier.

Nowell Smith, David (2014): "Distending the rhythmic knot”, in: Palimpsestes 27, 29-45.

Nünning, Vera (2017): "The affective value of fiction. Presenting and evoking emotions", in: Ingeborg Janall/Susanne Knaller/Sabine Schönfellner/Gudrun Tockner (eds), Writing emotions. Theoretical concepts and selected case studies in literature, Bielefeld: Transcript, 29-54.

Scott, Clive (2014): "Translation and the expansion of the rhythmic sense", in: Palimpsestes 27, 219-237. 
144 Maryvonne Boisseau

Woolf, Virginia (1957) [1925]: "The Patron and the Crocus", in: The Common Reader, London: The Hogarth Press, 261-266.

Wunenburger, Jean-Jacques/Lamy, Julien (eds.) (2018): Rythmanalyse(s). Theories et pratiques du rythme, ontologie, définitions, variations, Paris: Jacques André éditeur, coll. "Theriaka, remèdes et rationalités". 


\section{The Pictorial Paradigm of La Vallée: A Text-Image Reading of the Incipit of The Mysteries of Udolpho}

Alice Labourg, Rennes-II University (France)

On the pleasant banks of the Garonne, in the province of Gascony, stood, in the year 1584, the chateau [sic.] of Monsieur St. Aubert. From its windows were seen the pastoral landscapes of Guienne and Gascony stretching along the river, gay with luxuriant woods and vine, and plantations of olives. To the south, the view was bounded by the majestic Pyrenées, whose summits, veiled in clouds, or exhibiting awful forms, seen, and lost again, as the partial vapours rolled along, were sometimes barren, and gleamed through the blue tinge of air, and sometimes frowned with forests of gloomy pine, that swept downward to their base. These tremendous precipices were contrasted by the soft green of the pastures and woods that hung upon their skirts; among whose flocks, and herds, and simple cottages, the eye, after having scaled the cliffs above, delighted to repose. To the north, and to the east, the plains of Guienne and Languedoc were lost in the mist of distance; on the west, Gascony was bounded by the waters of Biscay.

(Radcliffe 1794: 1) $)^{1}$

A liminal space between reality and representation, the incipit is the narrative threshold that immerses the reader into the imaginary world of fiction (see Del Lungo 2003). The Mysteries of Udolpho opens onto the seminal landscape of La Vallée, the heroine's idyllic birthplace. The scenery is evoked through a pictorial description which provides an emblematic example of what critics 
have called Ann Radcliffe's "word-painting” (see Flaxman 1987: 9). ${ }^{2}$ Going beyond mere paragon-esque comparisons by redefining that notion from a textimage perspective based on a close formal reading of the text, ${ }^{3}$ this paper will examine how the very first paragraph of the novel registers like a "painting in words", in other words an iconotextual landscape, that is to say a metaphorical landscape painting which emerges through the use of a pictorial writing. ${ }^{4}$ From the structuring movement of the gaze to the evocation of the landscape as a pictorial matrix generating iconic and plastic forms, painting imbues the text on a structural, thematic, symbolic and semiotic level. Fulfilling its function as a strategic locus, the incipit on La Vallée establishes the foundations of a pictorial paradigm which sustains the whole novel, furnishing the reader with the essential tools to apprehend the narrative as a picturesque composition which melts the beautiful and the sublime.

\section{1. "The Eye" or The Picturesque Gaze: From Point of View to Pictorial Composition}

The visual dimension of Ann Radcliffe's writing has prompted such critics as Adriano Elia to read the incipit of The Mysteries of Udolpho in cinematographic terms (see Elia 2005: 65-67). ${ }^{5}$ Painting, even more than an anachronistic filmic model, actually proves the aesthetical framework which defines the Radcliffean Gothic (see Lévy 1968: 292-295). The incipit indeed operates a mise en abyme which aims at generating a "picture" for the readers to "look at"

2 For the use of the expression as applied to Radcliffe, see Rogers 1994: 189, and Elia 2002: 78.

3 The paragone is the traditional comparison between the arts, especially between painting and poetry, and painting and sculpture.

4 The pictorial is "the inclusion of a reference to the visual arts in a literary text, a reference which can be more or less explicit, and whose citational value produces an effect of textual metapictoriality" (Louvel, 2011: 73). By “iconotext", Louvel designates the merging of text and image in pictorial descriptions according to their various degrees of "pictorial saturation" (ibid.: 15, 89).

5 Elia reads the passage as an example of "dynamic cinematic word-painting" which involves a tracking shot from a bird's eye view followed by zooming. See also Elia 2002: 76-84. 
and imaginatively step into. ${ }^{6}$ Such an opening fits within the author's general conception of 'the novel as picture' (see Durant 1980), ${ }^{7}$ or rather, as a series of pictures, turning the reader into a spectator led from one picture to the next in a picture gallery (see Louvel 2011: 172) .

The passage is carefully built around the dynamics of the gaze which merges the thematic and narrative point of view with pictorial composition through focalisation. The reader is led to follow the movement of an omniscient "eye" - which could be assigned to the omniscient narrator - that surveys the landscape ("were seen", "the view", "seen and lost", "the eye", "lost"). For the cultured eighteenth-century reader, the expression "the eye", associated with the description of a natural scenery, would bring to mind William Gilpin's writings on the picturesque, "that peculiar kind of beauty, which is agreeable in a picture" or "capable of being illustrated by painting" (Gilpin 1768: 2, 1792: 1). ${ }^{8}$ The picturesque "eye" happens to be proleptic as its circular, expansive progress visually traces a metatextual shortcut which anticipates the future peregrinations of the heroine. Emily will indeed be literally confronted with those "awful forms" perceived in the distance, during her terrifying stay in the Apennines, before coming back "to repose" in the pastoral landscape of La Vallée, where the novel concludes its happy end. ${ }^{9}$ The incipit thus institutes the aesthetics of the picturesque as a programmatic reading grid, with painting and landscape as central interpretative keys of the novel.

There is a picture (the view from the windows) within the picture (the larger view on Cascony) framed by the overall "picture" of the paragraph; hence the idea of the mise en abyme.

"The novel as picture" is the title of the chapter on The Mysteries of Udolpho.

8 The picturesque may be understood as a sort of mediating aesthetical category between the beautiful and the sublime. In his books relating his tours of the English countryside, Gilpin popularised various ideas about "picturesque beauty", instructing the reader on how to look at nature from a pictorial point of view. Those writings established a certain rhetoric, echoes of which can be found in Radcliffe's descriptions. Disregarding the picturesque aesthetics and its discourse, Elia assimilates "the eye" to the camera eye (see Elia 2005: 67).

9 This overall structure is revisited on a micro level throughout the various sections of the novel. Those sections involve initiation crossings of mountains (the Pyrenees, the Alps, the Apennines, and again the Pyrenees) and alternative periods of "repose" in different plains and valleys (return to La Vallée after St. Aubert's death, Toulouse, Venice, Tuscan interlude in the Udolpho section, Chateau-le-Blanc). All the sections contain appropriate landscape descriptions. 
Painting in effect pervades the text formally. On a structural level, the reader enters the text through a series of embedded frames which delineate various pictures operating at different levels of representation. The description is first of all contained within the semantic unit of a paragraph, which helps frame the view as a picture (see Louvel 1998: 99-100). Placed as an epigraph, a quote from James Thomson emphasises the framing effect by acting as a parergon. ${ }^{10}$ The picture thus delineated is actually double. The prospects seen from the "chateau" at the heart of La Vallée are inserted within a larger panorama on Gascony, evoked in the first and last sentences:

On the pleasant banks of the Garonne, in the province of Gascony, stood, in the year 1584, the chateau of Monsieur St. Aubert / To the north, and to the east, the plains of Guienne and Languedoc were lost in the mist of distance; on the west, Gascony was bounded by the waters of Biscay. ${ }^{11}$

The picturesque view is thus literally framed within the paragraph by its larger geographical context. That framing picture roots the landscape within a known and culturally-determined reality through the use of actual toponyms ("Gascony", "Guienne", "Languedoc", "Biscay"). The first sentence, thereby, takes the reader from extradiegetical to diegetical "reality". ${ }^{12}$ It factually establishes the Bakthinean chronotope, namely the place (Southwest of France) and time (1584) of the story. The systematic use of the anaphoric operator THE before noun phrases referring to both actual and imaginary places ("the pleasant banks of the Garonne", "the province of Gascony", "the chateau of Monsieur St. Aubert") creates a network of memorial exophoras which imposes La Vallée as a "reality" within Gascony. ${ }^{13}$ The use of French words ("chateau", "Monsieur St. Aubert", "Pyrenées") enhances the effect.

10 On the notion of parergon, see Derrida 1978: 71-72.

11 Gascony, Guienne and Languedoc were former provinces in the southwest of France.

12 In poetics, the diegesis is the universe designated by the narrative (see Cenette 1972).

13 In enunciative linguistics, $\mathrm{TH}$ - is an operator indicating that something is "already known" because already mentioned in the context (anaphora). In a "situational anaphora" or "memorial exophora", the reference is not textual but extra-linguistic (see Lapaire 1991: 122-23). Although a new element in the narrative, the chateau is introduced by THE, as opposed to the presentative operator $\mathrm{A}$, which creates the illusion that the mansion does exist and that its existence is part of common knowledge, just as it is the case with the Garonne and Cascony. It is "already there" as an intrinsic part of the landscape, which helps define La Vallée as a microcosm. 
The thematisation of "the chateau of Monsieur St. Aubert" at the end of the opening sentence make readers expect a subsequent description of the mansion, or some particulars regarding its owner. Instead, the second sentence operates a shift of point of view. From a position outside the picture, readers are brought within. They virtually come to occupy the place of a spectator who contemplates the prospect from one of the windows of the mansion. A second picture then emerges, thematically framed by the casements, and semantically designated as the true protagonist of the story. The passive form "were seen", by suppressing the origin of perception, plays on focalisation and on the eye/I analogy to ensure the imaginary substitution of the omniscient narrator's eye with the reader's eye. The view from the windows is then constructed like a painted picture. The "chateau", topicalised at the end of the sentence, is placed at the fixed point assigned in classical linear perspective to the viewer facing the picture ("stood"). It is the equivalent of the monofocal eye at the summit of the cone of vision, as the synecdoque which substitutes the windows for the eyes suggests ("From its windows were seen"). The progress of the gaze then metaphorically follows the projection of the spectator's eye onto the canvas as constructed by linear perspective, with the veiled summits at the central vanishing point (ill.1). ${ }^{14}$ The use of the verb "scaled" backs up the idea by evoking a geometrical construction of space. Following the progress of "the eye", the reader is thus mentally projected into the landscape as if it were a picture.

Since Alberti, the window has been a conceptual metaphor for the delineation of a pictorial space of representation (see Alberti 2011). In landscape theory, the framing of the window is also a device of artialisation which turns the land into a landscape. ${ }^{15}$ It has likewise been identified as a literary topos in descriptions, conjuring up the analogy with a picture, and, more generally speaking, as a metaphorical space of creation. ${ }^{16}$ The windows-eyes thus mark the opening of a scopic field that envisions the prospect as a landscape painting. The idea is reinforced by the syntactic inversion ("From its windows were

14 In linear perspective drawing, the vanishing point is the spot on the horizon towards which all the receding parallel lines in the composition converge. In classical painting the pictorial space is constructed through linear perspective with the vanishing point as the projection of the viewer's eye onto the canvas. See Roger 1997, Cauquelin 2000, and Stoichita 1999. On the window as a scopic device, see Charbonnier 2007: 86, 94. See, among others, Barthes 1970: 56, Hamon 1993: 165, 172-175, and Del Lungo 2014: 65-66. 
Ill. I View From The Windows As A Landscape Painting

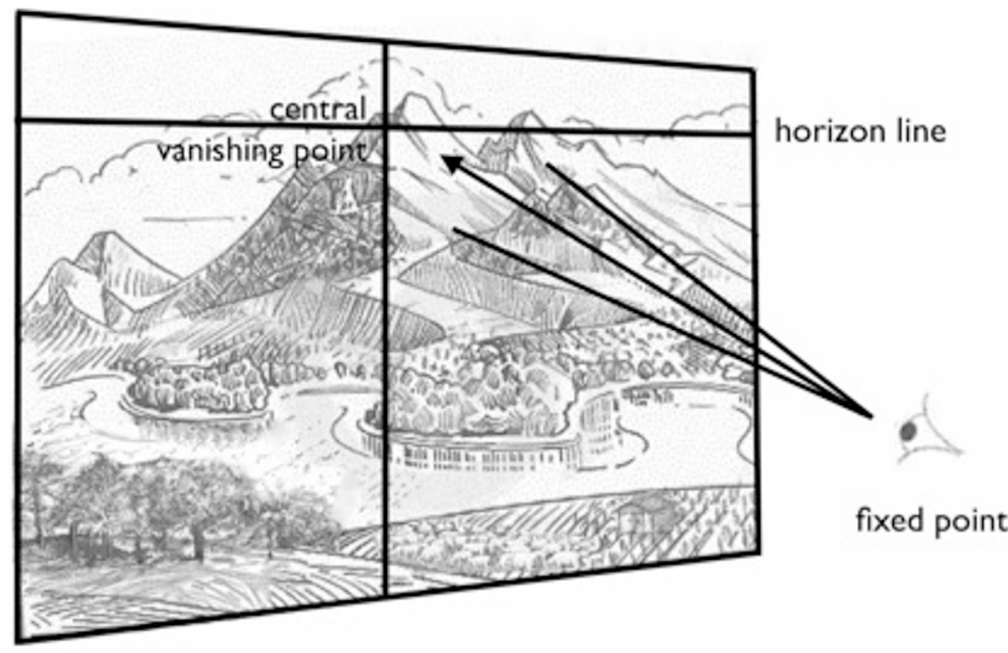

Adapted from ID 114522781@ Microvone/dreamstime.com @ Alice Labourg.

seen") which enables the long grammatical subject ("the pastoral landscapes of Guienne and Gascony stretching along the river, gay with luxuriant woods and vine, and plantations of olives") to unfold after the verb of perception. This produces an iconicity effect: form mirrors meaning as the reading of the long syntagm is evocative of the seminal act of perception which turns a stretch of land into a landscape. The references to vision describe a truly picturesque process that transforms natural scenery into a picture, from mere physical vision ("were seen"), to artialisation ("the view"), and final aesthetical appreciation ("the eye delighted to repose", emphasis added). The prepositions also help to sustain the progress of the gaze. "On" ("On the pleasant banks of Gascony") initially asserts the fixity of the viewpoint, "from" ("From its windows, were seen") establishes the origin of perception, while "to" ("To the south", "to the north and to the east") describes its panoramic expansion, and lastly "on" sets its final limits ("on the west, Gascony was bounded by the waters of Biscay."). Incidentally, the overall composition, with the Garonne meandering through the plains in the middle-ground and the mountains in the distance, 
recalls the tripartite organisation of classical seventeenth-century landscape paintings.

Besides, the embedded structure of the paragraph mirrors the zooming in and zooming out of the gaze. The eye focuses on the summits of the Pyrenees symbolically placed at the vanishing point of the perspective, as they are at the heart of the paragraph. A picture within the picture, the evocation of the mountains is framed by two sentences referring to the pastoral landscape at their skirts. A system of symmetrical echoes help move from one sentence, or frame, to the next, as elements belonging to one frame are taken up and expanded upon in the next (ill.2). The evocation of the veiled summits at the core of the description, reflects the very structure of the novel which places the Gothic section at Udolpho at its centre: in the castle in the Apennines, Emily will indeed face "awful forms", of which the veiled picture is the most notorious. The blurring of vision ("seen, and lost again") also recalls what spectators experience when they move too close to a canvas to see its details. The last two sentences open the scopic field again as if the reader were "stepping back" to take an overview of the whole canvas. The oscillation of the gaze, inherent to the experience of contemplating a painting, is thus instituted as the structuring principle of the novel. The reader will indeed progress through the narrative from one pictorial scene to the next, each one being first seen from a distance and then experienced from within.

\section{The Landscape as Pictorial Matrix}

The gaze, Philippe Hamon explains, is often used to open or close a description (see Hamon 1993). More importantly, it enables to organise its internal structure by introducing a distribution, a taxonomy, an order in the lexical nomenclature. A window stands as a "frame" but also as a "casement", prompting a vision that is also a division. The landscape perceived through the window is divided, surveyed and registered according to a grid which organises its different parts (ibid.: 180). That grid is here manifold: from geography to cartography to painting. The mention of the cardinal points provides the basic layer for the mapping of the geographical space ("the province of Gascony"). Out of this imaginary cartography, emerges a pictorial landscape through an aesthetical reading based on the recognition of predetermined visual and cultural elements. On a thematical level, the view on La Vallée indeed stands as a pictorial matrix, introducing a repertoire of motifs which will recur through- 
Ill. 2 Embedded Structure Of The Paragraph.

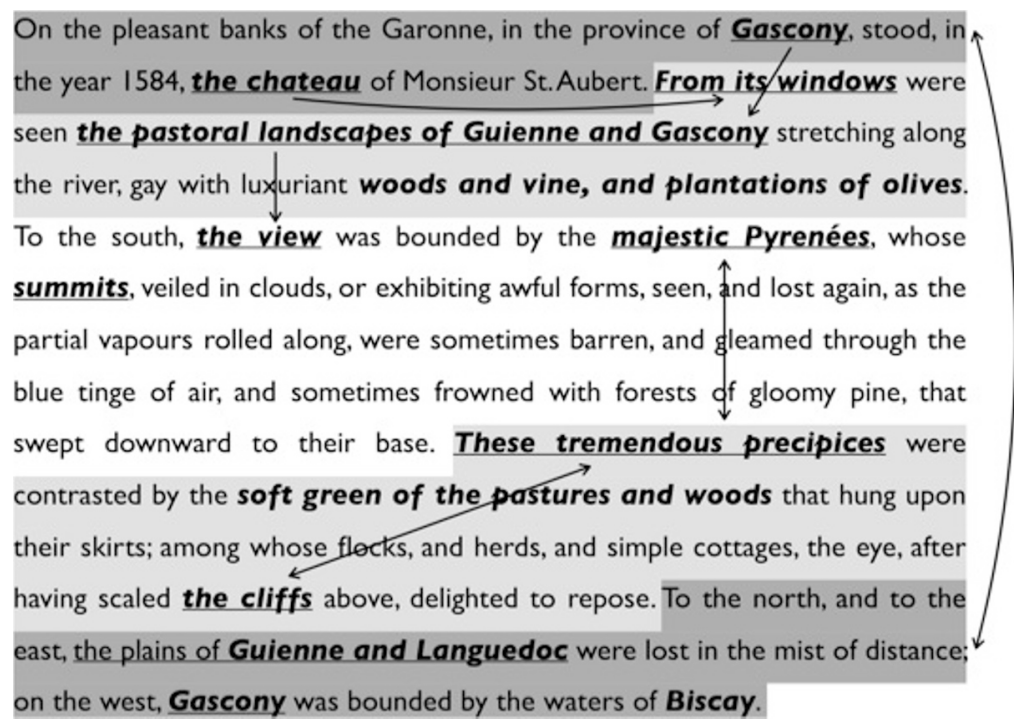

(c) Alice Labourg.

out the novel. Radcliffe's landscapes are the combination of a set of emblematic elements of which the picturesque view offers a literal and metaphorical overview. The description not only isolates the particulars of a singular landscape but it draws a list of the distinctive features of an ideal landscape model, making the Edenic valley of the well-named La Vallée ("The Valley") a symbolic crucible, a generative matrix from which all other landscapes will derive.

Two isotopies define two types of landscapes: the beautiful pastoral landscape, after Claude Lorrain (c.1600-1682), and the sublime rocky landscape, after Salvator Rosa (1615-1673). Very popular among the elite of eighteenthcentury Britain, Claude's and Rosa's paintings were regarded as the visual illustrations of the new aesthetical categories of the beautiful and the sublime as defined by Edmund Burke (ill.3 and 4) (see Burke 1998). Following the ut pictura poesis tradition, early critics, and after them later commentators, mentioned the seventeenth-century landscape masters in relation to Radcliffe's natural scenery, arguing that her evocations created verbal equivalents 
Ill. 3 Claude Lorrain, Pastoral Landscape: The Roman Campagna, c. 1639, oil on canvas, $101.6 \times 135.9 \mathrm{~cm}$, Metropolitan Museum of Art, New York.

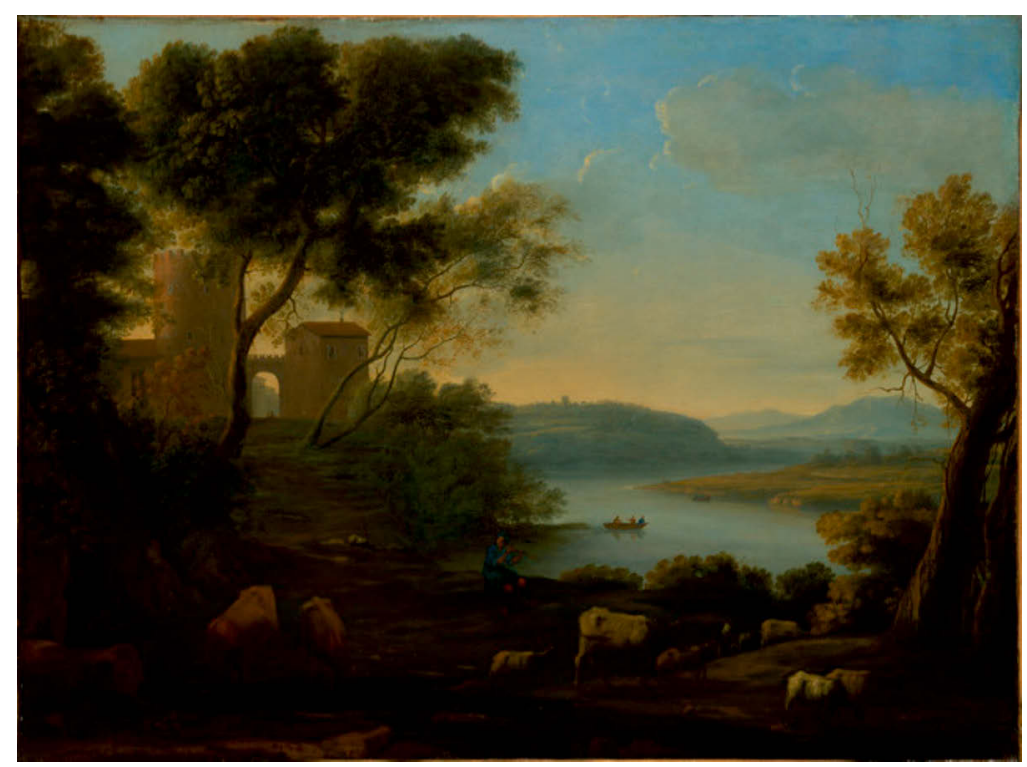

(c) Creative Commons Zero.

of their paintings. ${ }^{17}$ Dubbed "the sister of Salvator Rosa", the Gothic novelist was particularly praised for having added to "the wild landscape of Salvator Rosa [...] the softer graces of a Claude" (Rogers 1994: 129, 57). The explicit mention of "Salvator" during the crossing of the Pyrenees (Radcliffe 1794: 30), by acknowledging the extradiegetical pictorial model, seems to support such analogies, although this needs to be evidenced through a linguistic and stylistic text-image approach (see Labourg 2014: 21-51).

The contrast between "Claude" and "Salvator", taken as operative concepts, is examplified through a series of structural oppositions ("were contrasted"). To the horizontality of the plains ("stretching along the river"), associated with

17 See Rogers 1994 and Epstein Heller 1980. Horace's formula, Ut pictura poesis, "poetry is like painting", has been variously interpreted in literature and the visual arts, within the context of the paragone, to compare poetry and painting, often to the detriment of their intrinsic specificities. 
Ill. 4 Salvator Rosa, Bandits On A Rocky Coast, 1655-1660, oil on canvas, 74.9 100 $\mathrm{cm}$, Metropolitan Museum of Art, New York

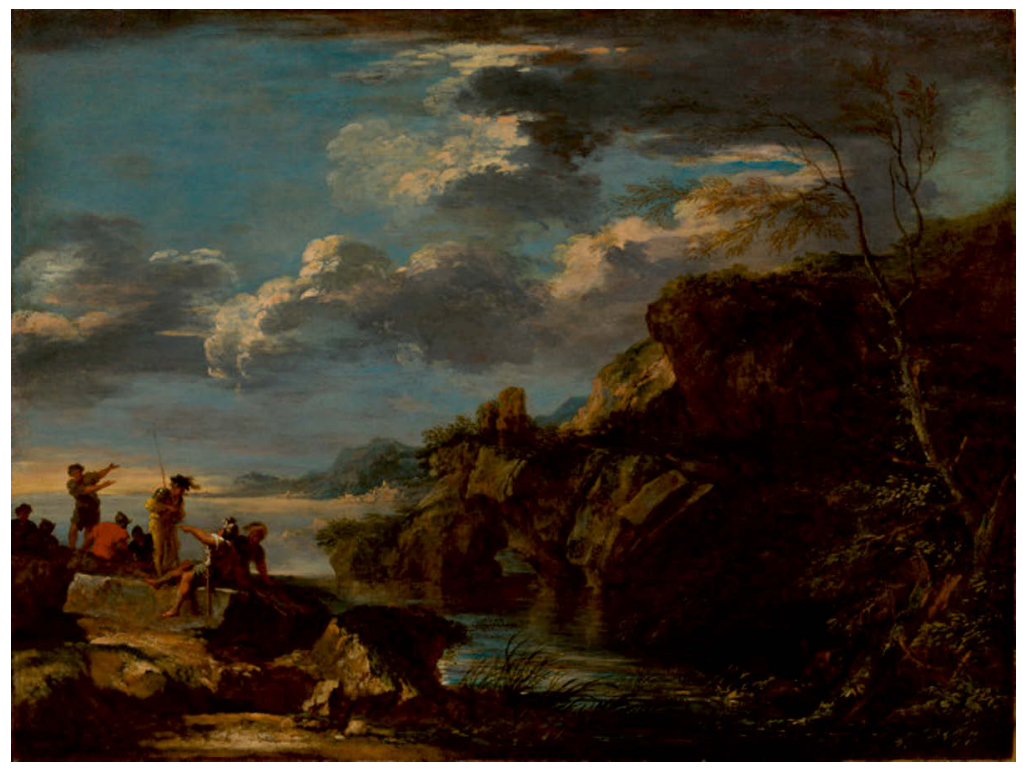

(c) Creative Commons Zero.

beautiful Claudean pastoral scenery, is opposed the verticality of the sublime Salvatoresque mountains ("swept downwards"/ "the cliffs above"). The opening of the plains ("lost in the mist of distance") contrasts with the closeness of the mountains which "bound" the view like walls. The ancient opposition between the locus amoenus, the "pleasant place", and the locus horridus, the "horrible place" is reactivated. Nature is either bounteous, sustaining cultivation and pastoral life ("luxuriant woods", "vines", "plantations of olives", "pastures", "flocks", "herds", "simple cottages") as befits the beautiful, or a sterile wilderness ("barren", "forests of gloomy pine") as suits the sublime.

The emotional response to the landscape is codified within the description through the use of adjectives with psychological connotations, either referring to the pleasing experience of the beautiful "pleasant banks", "gay with", "soft green") or the awe and fear inherent to the sublime ("majestic", "awful", "tremendous"). "Feeling through the eye", as Christopher Hussey puts it, is a 
distinctive feature of the picturesque (Hussey 1967: 4). Those adjectives, associated with the natural elements, personify the landscape, turning the object of the gaze into a feeling subject thus facilitating the reader's psychological involvement. Such a process culminates in the image of the pines frowning back at the viewer ("frowned with forests of gloomy pine"). The polysemy of the word "gloomy" turns the trees, evoked as a singular, generic entity, into a colour expressive of a mood, fusing the idea of a pictorialised landscape with the psychological idea of "feeling through the eye". The alliteration of /f/ (" $f$ rowned with forest"), combined with the doubling of the $/ r /$, heightens the subjective emotional effect as the harsh physicality of the sound adds to the sinister undertone while suggesting the shiver of pleasurable dread induced by the sublime. The reader's psychological involvement is reinforced by the suggestion that the progress of the gaze is a physical experience. It entails exhaustion ("the eye delighted to repose") as if the crossing of the mountains has actually been performed ("having scaled the cliff above"). This dialectics between distance and imaginary involvement, along the model of the walk or the hike, which the progress of the gaze suggests, is precisely at the heart of the pleasurable embodied experience of gazing at a landscape painting (see Arasse 2005: 249).

By playing on well-known visual codes associated with the Claudean and the Salvatoresque landscapes, the opening view provides readers with the aesthetical clues to read and "see" the Gothic novel as a picturesque composition which melts the beautiful and the sublime. By its very nature as a description, the incipit helps the reader identify those clues visually. For Hamon, a description, or rather a "descriptive system", is a hierarchical series of syntactic and semantic equivalences between a word, or common denominator (the object of the description), and an expansion, or the list of all the elements used to characterise it (see Hamon 1993: 127). Radcliffe makes this system a series of iconic equivalences, as the landscape components are turned into emblematic pictorial motifs. To borrow from visual semiotics, the linguistic syntagms which connote them acquire the status of "iconemes", units of iconic significance (see Cosette 2006: 135). Linguistic determination plays an essential role in their visualisation. The use of the anaphoric operator $\mathrm{TH}-$ points to known cultural models which contemporary readers would identify as either Claudean ("the pastoral landscapes", "the pasture and woods") or Salvatoresque ("the majestic Pyrenées", "these tremendous precipices", "the cliffs above"). On the other hand, the zero-article, referring to the notion beyond the noun, establishes the emblematic elements which compose them as 
archetypes. The pastoral landscape is made up of " $\varnothing$ luxuriant woods and $\varnothing$ vines and $\varnothing$ plantations of $\varnothing$ olives", " $\varnothing$ flocks and $\varnothing$ herds, and $\varnothing$ simple cottages". The repetition of an accumulative conjunction "and" conveys the idea of a bountiful nature. Similarly, " $\varnothing$ clouds", " $\varnothing$ awful forms", and " $\varnothing$ forests of $\emptyset$ gloomy pine" characterise the mountainous landscape and become archetypal throughout the novel as they are used to evoke the same kind of sublime Salvatoresque landscapes.

Throughout the novel, every time these, or similar elements, reappear in the description of a natural scenery, they act as linguistic and visual stimuli to help generate a picture. The coordinative "or" ("veiled in clouds, or exhibiting awful forms"), at the core of the description in the zooming in on the summits, an essential pictorial element, proves metatextual as the principle of linguistic permutation and variation is at the crux of the landscape matrix. The description unfolds along internal substitutions, from generic nominal phrases ("the majestic Pyrenées") to their metonymic components ("whose summits", "these tremendous precipices", "the cliffs") (ill.2). Throughout the novel, the mountains - the Pyrenees, the Alps or the Apennines are synecdotically described through the same images of "rocks", "precipices", and "cliffs", coupled with various adjectives connoting the sublime ("tremendous", "terrible," "awful" etc.). These semantic (pictorial) units are variations of the same conceptual idea and ideal picture of a Salvatoresque mountainous landscape. Likewise, pastoral scenery is conjured up through recurring images of "flocks, and herds", or alternative "herds and cattle" (Radcliffe 1794: 32), "simple cottages", or similar "shepherd's cabin" (ibid.: 51), and variations around "vine", "plantations of olives", and other "groves of orange and lemon" (ibid.: 55). The description of La Vallée thus entails a programmatic reading pact in which landscape, as a pictorial genre and a literary topos, becomes central for the novel's overall picture-like effect, all the more so as landscape description proves the emblematic iconotext by combining an iconic and figurative form of pictoriality, as previously described, to a more plastic form of pictoriality. 


\section{From Iconic Figurality to Semiotic Pictoriality}

For Groupe $\mu$, an image is an "icono-plastic utterance", the combination of an iconic sign and a plastic sign (see Groupe $\mu$ 1992: 269). ${ }^{18}$ Radcliffe's "pictures" seem to function along similar terms. From a semiotic point of view, the relationship to painting is indeed inscribed within the very fabric of the text through a pictorial writing which operates on two complementary modes. First, it works on an iconic and figurative level, presenting the reader with various picture-like scenes, such as La Vallée. The relationship to painting also functions on a more diffused, semiotic dimension which translates painting as a plastic signifier within the linguistic "materiality" of the text. This is symbolised by the detail of the veiled summits. The summits are both a particolare, the particular element of a pictorial composition as a whole, and a detaglio, an element singled out by the gaze of the viewer. The image of the veiled summits marks the shift between what art historian Daniel Arasse calls "iconic details", that is to say items significant for their mimetic resemblance to the referent they represent, to "pictorial details", details which enable us to see the plasticity of painting as a pictorial material on the surface of the canvas - or the text (see Arasse 2005: 11-12, 268). The landscape of La Vallée thus proves to be the linguistic equivalent of what Thomas W. J. Mitchell calls a "metapicture", a picture "used to show what a picture is" (Mitchell 1994: 35). Its reflexive character points at the crucial importance of landscape description for the inscription of the pictorial in the novel, as the evocation of natural scenery turns out to be the quintessential Radcliffean iconotext in its coupling of what I shall call iconic figurality (the metaphorical description of La Vallée as a landscape painting), with semiotic pictoriality (the metaphorical expression of painting as a plastic signifier within the text).

A text-image reading enables to complement the idea of the iconotext as an "icono-plastic utterance" and explore the idea of semiotic pictoriality from a linguistic point of view. Liliane Louvel details the various modalities for the pictorial to permeate the text, from explicit to more allusive references to

18 Borrowing from the linguistic and semantic triangle signifier-signified-referent, Groupe $\mu$ defines the iconic sign as the relationship between an iconic signifier, a type and a referent. Besides, Groupe $\mu$ aims at defining the specificity of the plastic sign through the system of colour, texture and form. Both iconic and plastic dimensions are interrelated to form the visual sign. 
painting (see Louvel 2002: 33). ${ }^{19}$ Here, such references include the perspective of the gaze, the use of the word "landscapes", and the allusion to colours, light and aerial perspective ("soft green", "gleamed", "blue tinge of air", "lost in the mist of distance"). Painting also pervades the text through what the intermedial critic calls "pictorial substitutes", such as the map, suggested with the mention of the cardinal points (see Louvel 2002: 45 \& 2011: 155). A pictorial paradigm is indeed superimposed onto a topographical grid as we move from the realm of geography ("the province of Gascony") to the realm of painting ("the pastoral landscapes of Guienne and Gascony"). ${ }^{20}$

Two other substitutes are introduced which will prove essential to the pictorialisation of nature throughout the novel: the veil, evoked through the image of the clouds, and the mirror, conjured up through the reflection of the sunlight on the barren surface of the mountain-peaks (see Labourg 2006). ${ }^{21}$ The summits of the Pyrenees are the domain of the uncanny as suggested by their metamorphosis under the veil of clouds into terrifying spectral forms. They introduce a mysterious, threatening element into the idyllic landscape of La Vallée. They proleptically hint at the "veiled picture" of Udolpho. Their veiling and unveiling ("veiled", "or exhibiting") symbolically anticipates Emily's lifting of the veil. This dialectics sustains what Maurice Lévy calls "the poetics of the hidden" (see Lévy 1996: 19-34). The veil also emblematises the theme of the supernatural animation of the canvas which gives the impression that the novelist "brought 'the landscape with figures' to life" (Hussey 1967: 231-232). ${ }^{22}$ Both notions are central to define the Radcliffean Gothic.

Moreover, the veiled mountains mark the space of another reality which is also that of another pictoriality. They no longer partake of the reassuring realm of figuration, but depict a terrifying disfiguration ("awful forms"). They represent the dissolution of forms under the gaze. They symbolise constant change, the instability of signs and meaning ("seen and lost again"). They are

\footnotetext{
19 See also Louvel 2011: 89-90.

20 The word "landscape" originally designated a landscape painting. Landscape theory explains that, historically and culturally, the very notion of "landscape" implies the mediation of painting. In western culture, "real" landscapes started to be seen in the natural world because they were first represented in art.

21 For the mirror as a pictorial substitute, see Louvel 2011: 147 and 2002: 45-46. The veil and the mirror are potent "metapictorial" symbols as they are at the mythological origins of painting through the story of the competition between Parrhasius and Zeuxis and through the myth of Narcissus.

22 See also Lévy 1995: 293-294.
} 
the place of the unknown, of the undecipherable, of alterity, the very place of the ontological experience of the Gothic. From an object gazed at, the mountains are turned into a subject gazing back at the reader-spectator ("exhibiting", "frowned"). Placed at the vanishing point, at the projection of the viewer's eye onto the canvas, they metaphorically stand where the gaze is reversed and the painting, as a symbolic structure of vision and representation, "looks back" at the viewer, destabilising him or her with a feeling of the uncanny (see Lacan 1973: 111-123). The veiled summits thus appear to be the symbol of an impenetrable sublimity which sets the limits for any transgression associated with the gaze, which the novel then develops in relationship to knowledge, sexuality, identity, gender, and death.

The peaks are introduced in the longest and most complex sentence of the paragraph. This inflation of language allows for the creation of a picture within the picture, a landscape within the landscape, in which the pictorial becomes associated with the poetic. Although they occupy a marginal position in the view and are introduced as an additional agent ("bounded by the majestic Pyrenées"), the summits then become the active subject of a long subordinate which introduces the central metaphor of the veil: "whose summits, veiled in clouds, or exhibiting awful forms, seen, and lost again, as the partial vapours rolled along." Parataxis enables the unfolding of the clause in an ample movement which translates their animation under the clouds. It is sustained by two syntactic parallelisms, the first one articulated by the conjunction "or", and the second one by the repetition of "sometimes". A succession of embedded phrases marking oppositions creates an uneven balance which suggests constant motion. The first appositive clause ("veiled in clouds, or exhibiting awful forms,") alternates passive ("veiled") and active forms ("exhibiting"). The second appositive ("seen, and lost again,") plays on the contrast between syntactic similarity, with the repetition of two monosyllabic past participles, and semantic opposition. The commas detach "seen", creating a " 1 ", suspension, " $2,3,4$ " acceleration which suggests the evanescence of perception. The time subordinate reintroduces a more regular tempo with its four successive strong stresses ("as the partial / vapours / rolled / along"), which may evoke the steady passing of the clouds. The alliteration of $/ \mathrm{p} /$ and $/ \mathrm{l} /$ heightens the effect by contrasting the explosion of the plosives with the fluidity of the liquids mixing with the vowels ("as the partial vapours rolled along").

Likewise, the repetition of "sometimes", draws a parallelism which underlines opposition and change ("sometimes barren, and gleamed through the blue tinge of air, and sometimes frowned with forests of gloomy pine, 
that swept downward to their base"). The summits and the forests become subjects of action verbs ("rolled along", "gleamed through", "frowned with", "swept downward") while more static verbs and passive forms dominate in the framing sentences evoking the pastoral scenery ("stood", "were seen", "was bounded", "were contrasted", "were lost", "was bounded"). Those follow a more regular and mainly ternary pattern which suggests classical order and harmony. The first sentence repeats the same basic structure of the + noun + of + noun ("On the pleasant banks of the Garonne", "in the province of Gascony", "the chateau of Saint-Aubert"). In the second and fourth sentences, the pastoral components unfold in a similar succession of three nouns, with a slightly expanded third syntagm, around the coordinative "and": "woods and vine, and plantations of olives"/"flocks, and herds, and simple cottages". On the contrary, the instability at the summits disrupts this regular rhythm as a somewhat trochaic pattern emerges: "[veiled in clouds], [or exhibiting awful forms], [seen, and lost again], [as the partial / vapours / rolled / along]". The phrase "frowned with / forests of / gloomy / pine" almost registers like a trochaic tetrameter. Besides, echoes in sonorities add to the majesty and mystery, with the /f/ alliteration in "awf ul forms" being repeated in " $f$ rowned with forests", complemented with the vowels.

Modulations in sounds also sustain the metaphor of the veil and the image of the mirror. Alliterative and assonant repetitions bring "veiled" and "vapours" together, facilitating the visualisation of the image. In "gleamed through the blue tinge of air", the modulations in the succession of the vowels create variations in sound suggestive of the variations of light on a reflective surface. The tense front vowel /i:/ ("gleamed") is made longer with the initial $/ \mathrm{g} /+/ \mathrm{l} /$. Two rounded back vowels $/ \mathrm{u}: /$, mellowed with $/ \mathrm{r} /$ and $/ \mathrm{bl} /$, then create a softer, more muffled sound continuum, which makes the following lax /I/ of "tinge", with the support of the dental consonant / $/$ / and the stress, tinkle, evoking a sparkle of light. The final monosyllabic "air", and its "suspended" diphthong, adds to the impression by suggesting a form of dissolution.

As the poetic thus emerges at the core of the description to evoke pictorial effects, the paragone is revived. Hearing converges with seeing as visual images are translated through sounds and the materiality of language perceived as a plastic form. This reflects on the whole passage, supporting the reader's impression that Radcliffe literally "paints" with words. 


\section{Conclusion}

Close formal analysis enables to circumscribe the very nature of Radcliffe's "word-painting". The pictorial impression many readers have felt is created through language and the use of a pictorial writing which generates powerful iconotexts. The opening of The Mysteries of Udolpho fulfils its strategic function as an incipit by providing a metatextual — or rather "metapictorial" illustration of such phenomena. The view on La Vallee subsequently transforms into a palimpsest as Emily takes away the landscape of her childhood in her memory - as well as in her drawings - and projects it onto the new places she is brought to throughout her initiatory journey, revisiting them as utopian and dystopian versions of this original composition (see Besson 1999: 66). The description of La Vallée is but contained within one, yet skilfully constructed, paragraph. Longer descriptions, such as the famous arrival at Udolpho, provide ampler textual space for the linguistic expression of Radcliffe's "pictorial" skills, justifying Walter Scott's assertion that she combined "the eye of a painter, with the spirit of a poet" (Rogers 1994: 114).

\section{References}

\section{Corpus}

Radcliffe, Ann (2008): The Mysteries of Udolpho, Oxford: Oxford University Press.

\section{Other Works}

Alberti, Leon Battista (2011): On painting, Cambridge: Cambridge University Press.

Arasse, Daniel (2005): Le Détail, Pour une histoire rapprochée de la peinture, Paris: Flammarion.

Barthes, Roland (1970): S/Z, Paris: Seuil.

Besson, Françoise (1999): "Les Pyrénées dans The Mysteries of Udolpho ou les mystères du paysage déplacé", in: Max Duperray (ed.), Les Mystères de Mrs Radcliffe, Nouveaux essais sur les Mystères d'Udolphe d'Ann Radcliffe (1794), Aixen-Provence: Publications de l'Université de Provence, 63-81. 
Burke, Edmund (1998): A philosophical enquiry into the origin of our ideas of the sublime and the beautiful, Oxford: Oxford University Press.

Charbonnier, Louise (2007): Cadre et regard, généalogie d'un dispositif, Paris: L'Harmattan.

Cauquelin, Anne (2000): L'invention du paysage, Paris: Presses Universitaires de France.

Cosette, Claude (2006): La publicité de $A$ à $Z$ dictionnaire technique français anglais, Quebec: Presses de l'Université Laval.

Del Lungo, Andrea (2003): L'incipit romanesque, Paris: Seuil.

- (2014): La fenêtre, sémiologie et histoire de la représentation littéraire, Paris: Seuil.

Derrida, Jacques (1978): La vérité en peinture, Paris: Flammarion.

Durant, David (1980): Ann Radcliffe's novels: Experiments in setting, New York: Arno Press.

Elia, Adriano (2005): "Sublime and word-painting in Ann Radcliffe's The Mysteries of Udolpho", in: Textus, English Studies in Italy, 18 (1), 61-76.

Elia, Adriano (2002): Ut pictura poesis: Word-image interrelationships and the wordpainting technique, Pescara: Libreria dell'Università Editrice.

Epstein Heller, Lynne (1980): Ann Radcliffe's Gothic landscape of fiction and the various influences upon it, New York: Arno Press.

Flaxman, Rhoda (1987): Victorian word-painting and narrative: Towards the blending of genres, Ann Arbor: University of Michigan Research Press.

Genette, Gérard (1972): Figure III, Paris: Seuil.

Gilpin, William (1768): An essay on prints, London: R. Balmire.

- (1972): Three essays, Farnborough: Gregg International Publishers Limited.

Groupe $\mu$ (1992): Traité du signe visuel, Pour une rhétorique de l'image, Paris: Seuil. Hamon, Philippe (1993): Du descriptif, Paris: Hachette.

Hussey Christopher (1967): The picturesque: Studies in a point of view, London: Frank Cass \& Co. Ltd.

Labourg, Alice (2006): “(Dé-)peindre la nature: 'peinture de mots' et paysages iconotextuels dans les romans gothiques d'Ann Radcliffe", in: Textimage, Revue d'études du dialogue texte-image, "Varia 5", http://revue-textimag e.com/12_varia_5/labourg1.html (Last accessed: 23.04.2021).

- (2014): "Such a scene as Salvator would have chosen': Metapictorial naming in The Mysteries of Udolpho and The Italian", in: Jakub Lipski/Jacek Mydla (eds.), Ann Radcliffe, The enchantress of words, sounds and images, Palo Alto: Academia Press, 21-51.

Lacan, Jacques (1973): Les quatre concepts fondamentaux de la psychanalyse, Paris: Seuil. 
Lapaire, Jean-Rémi/Rotgé, Wilfried (1991): Linguistique et grammaire de l'anglais, Toulouse: Presses Universitaires du Mirail.

Lévy, Maurice (1995): Le roman "gothique" anglais, 1764-1824, Paris: Alban Michel.

- (1996): "À propos des Mystères d'Udolphe: Ann Radcliffe et la poétique du caché”, in: Max Duperray (ed.), Les Mystères de Mrs Radcliffe, Nouveaux essais sur les Mystères d'Udolphe d'Ann Radcliffe (1794), Paris: CNED, DidierÉrudition, 19-34.

Louvel, Liliane (1998): L'œil du texte, Texte et image dans la littérature de langue anglaise, Toulouse: Presses Universitaires du Mirail.

- (2002): Texte/Image, Images à lire, textes à voir, Rennes: Presses Universitaires de Rennes.

- (2011): Poetics of The Iconotext, Farnham: Ashgate.

Mitchell, Thomas W. J. (1994): Picture theory: Essays on verbal and visual representation, Chicago: Chicago University Press.

Roger, Alain (1997): Court traité du paysage, Paris: Gallimard.

Rogers, Deborah (1994): The critical response to Ann Radcliffe, Westport: Greenwood Press.

Stoichita, Victor (1999): L'instauration du tableau: métapeinture à l'aube des temps modernes, Genève: Droz. 

Part III

Readers, Characters, Authors:

Relations Formed by Textual Features 



\section{The Nature of the Agonistic in a Pragmatics of Fiction}

Tahir Wood, University of the Western Cape (South Africa)

They sent him to Dallas to kill a nigger pimp named Wendell Durfee. He wasn't sure he could do it.

The Casino Operators Council flew him. They supplied first-class fare. They tapped their slush fund. They greased him. They fed him six cold.

Nobody said it:

Kill that coon. Do it good. Take our hit fee.

The flight ran smooth. A stew served drinks. She saw his gun. She played up. She asked dumb questions.

He said he worked Vegas PD. He ran the intel squad. He built files and logged information.

She loved it. She swooned.

"Hon, what you doin' in Dallas?"

He told her.

A Negro shived a twenty-one dealer. The dealer lost an eye. The Negro booked to big D. She loved it. She brought him highballs. He omitted details.

The dealer provoked the attack. The council issued the contract - death for ADW Two.

The preflight pep talk. Lieutenant Buddy Fritsch:

"I don't have to tell you what we expect, son. And I don't have to add that your father expects it too."

The stew played geisha girl. The stew fluffed her beehive.

"What's your name?"

"Wayne Tedrow."

She whooped. "You just have to be Junior!"

He looked through her. He doodled. He yawned. 
She fawned. She just looooved his daddy. He flew with her oodles. She knew he was a Mormon wheel. She'd loooove to know more.

(Ellroy 2010: 1-2) ${ }^{1}$

\section{The challenge of fiction}

Fiction presents unique challenges for pragmatics, the science of the verbal act, as announced by Charles Morris (see Morris 1938). Depending on one's methodological orientation, it may be approached in very different ways. The English philosopher Gillian Rose has written about the "agon of authorship" - how to consider texts, not as mere texts, but as works or struggles (see Rose 1992). This is as relevant for literary examples as it is for philosophical ones. It is from the point of view of authorship, its forms of work and struggle, and the responses of readers to its artifacts, that I approach the pragmatics of fiction.

In fiction, the difference between the character, on the one hand, and author and reader on the other, is that they belong to different ontological domains. However, it is important to mention that the difference is not always clear-cut. Napoleon, for example, can appear as an actual historical agent, but also as a fictional character, as in Scarlet and Black or War and Peace. So, if some novelist were to present us with Napoleon's inner, silent musings, this would be a blending of ontological levels. We might imagine the actual historical Napoleon and imagine also that we were being admitted into his inner subjective being. Such privileged access belongs only to literary fiction (see Gallagher 2006, 2011) and it is suggested here that this has become one of the most important sources of interest in the reading of fiction.

The cognitive blending of ontological levels (actual world and fictional world) applies not only to characters but also to places and historical events, so that actual ones are blended with fictional ones. But the representation of character thoughts in linguistic form is unique to fiction, whether the character is entirely fictional or not. The results of this blending on the part of a given reader cannot be predetermined from a consideration of the text itself, but one presumes that this can be empirically investigated.

1 In the following, all quotations without any reference specified are taken from this literary excerpt. 
To take one example in passing: where the crime novelist James Ellroy presents former FBI boss J. Edgar Hoover in such a relentlessly negative light (see Ellroy 2010), it may well condition one's impression of the actual historical Hoover. But regardless of the individual reader's response, this is an example of what I am calling the agon of authorship in fiction, an essentially ethical component of authorship, i.e. resulting from the ethical stance taken by the author in regard to the content of the work.

However, any attempt to bring the question of fictional communication down to essential constitutive elements faces difficult problems and even within pragmatics these have been approached in a number of different ways. Often differences within pragmatics arise from schools of thought in neighbouring disciplines such as philosophy or literary criticism, since pragmatics is by its nature an interdisciplinary field. Nevertheless, I am suggesting in the present contribution that two constitutive elements are: revelations of hidden or secret things (such as inner thoughts), and an agonistic stance of authors towards characters and social milieu, and also perhaps towards other authors.

\section{Some approaches to fiction in pragmatics}

\subsection{Speech act theory and logicism}

Speech act theory would not at first sight seem to offer much to the study of fiction, given that Austin regarded literature as being "not serious" and "not full normal" use of language (Austin 1975: 104). No doubt speech acts performed by characters in a novel are seen as non-serious because the characters do not exist as actual people. The way in which one might apply speech act theory to fiction then is to pretend that the characters are actual people in communication and to ask questions concerning their speech, such as "What speech act is character X performing here?" or "Is X's speech act felicitous or not?" and so on. But this alone cannot be the pragmatics of fiction, even though it may be pragmatics within fiction.

However, to dismiss the contribution of speech act theory altogether would be to overlook the important notion of the intentional act, discussed most influentially by John Searle (see Searle 1969, 1975). This intentionality can itself be split into two. Any communicator has intentions of a generic nature, in other words to perform socially recognised acts. But intention 
may also have another sense, to perform an act with certain intended consequences. Speech act theory has prioritised the first aspect over the second, the conventional and generic over the singular and unique.

Searle writes at the end of his 1975 article: "Literary critics have explained on an ad hoc and particularistic basis how the author conveys a serious speech act through the performance of the pretended speech acts which constitute the work of fiction, but there is as yet no general theory of the mechanisms by which such serious illocutionary intentions are conveyed by pretended illocutions" (Searle 1975: 332).

"Serious speech act" is, from an agentive perspective, a highly attenuated notion of authorial intentionality. Searle may have defended the intentional nature of an author's act, especially its conventional-generic nature, and also conceded, contra Austin, the possibility of its "seriousness", but this is not sufficient. The notion of illocutionary act is reductionist because it does not have any bearing on questions of style or intended effect, and therefore no bearing on aesthetics or ethics. The best that this approach can be expected to yield is the intention of an author to produce a work of a certain genre or sub-genre of fiction, defined for us by "constitutive rules". This would tell us nothing about why a reader might find one work more compelling or satisfying than another, let alone the agon of authorship.

Let us illustrate the difficulties that arise with such reductionist approaches when dealing with phenomena that have been familiar to literary scholars over the last century or more. What might speech act theory bring to the narrator question?

In an early contribution on this question, Ryan arrives at the conclusion that speech must in all cases of fiction be attributable to a narrator rather than to the author, even if this is an "impersonal" narrator - i.e. the third-person omniscient narrator of literary criticism (see Ryan 1981). If the narrator is of this impersonal kind, then this means that the text entails, logically, a speaker devoid of properties. This relieves the reader of any need to seek an answer to the question of who it is that speaks. The truism is offered that a linguistic meaning implies a speaker as origin of that meaning, but the postulate of an "impersonal" being that speaks is difficult. Such a being could not be a subject. Yet an act of narrating necessarily has subjective elements, for example in the selection of one thing to be narrated rather than another. Furthermore, the empirical question is at least as important as the logical question. Do actual readers muse upon the nature of the impersonal narrator as they do with characters? - for example wondering how it is that this narrator can 
be omniscient, why he/she/it would decide to tell us these hidden things (but not others), etc. If this seems an unlikely possibility, let us rather consider the proposal that the communicating person in fiction is never not the author. A 'no-narrator position' could then be defended on the grounds that 'voice' or 'speaker' is better understood as a matter of alternative masks or personae donned by the author.

As Bakhtin put it: "The novelist stands in need of some essential formal and generic mask that could serve to define the position from which he views life, as well as the position from which he makes that life public" (Bakhtin 1988: 161). In one case the mask is such that the author speaks through character's speech and in another case the author speaks in such a way as to transcend character speech. The author's discourse is thus 'refracted'. When speaking transcendently authors have traditionally resorted to an upper register of standard language in contrast to the low or idiosyncratic speech of characters. This tendency, to separate registers for this purpose, has grown greatly in importance since the mid-nineteenth century. But, by the same token the use of character storytellers in place of the transcendent narrator has increased apace since the nineteenth century. A parallel development, and more subtle, has been the gradual incorporation of character speech into that of the thirdperson transcendent narrator (TTN), through the development of such techniques as free indirect discourse (FID), which will be discussed further below with a detailed analysis of the extract above. More recently there has been the phenomenon of the author presenting certain utterances as being himor herself, as in examples by John Fowles, such as A Maggot and The French Lieutenant's Woman. For example in the latter work he addresses the reader, as his contemporary, directly concerning certain aspects of Victorian society. This self-representation by the author and his own general knowledge is to be taken as another, essentially non-fictional, insertion within the fictional test. This is still a relatively rare phenomenon of 'voice' in fiction.

The "impersonal" voice (i.e. The TTN) that Ryan imagines is not truly impersonal. Rather it is a literary practice that allows the author to speak in a transcendent manner at one moment while retaining the option of speaking through characters at others. The practice, it is suggested, is such that the reader grants the author the licence to speak in this transcendent manner so as to report on the speech of characters, their thoughts and their action, a stylistic convention that enables the enjoyment of a certain imaginative experience. It is a veritable social contract of fiction. But note that innovative techniques in narrative may be aimed at subversion of readers' expectations 
of generic form and style. Such innovations may or may not themselves become generic and expected over time, as has happened with scene shifting and with FID. In this view then there arises the question of the limits of the appetites of various empirical readers to stomach the innovative techniques, a point which will be illustrated further below.

An author 'speaks' in the persona of a transcendent storyteller or in the personae of character storytellers. The notion of persona or mask is an ancient one, and Bakhtin's formulation emphasises that these are generic conventions of fiction. Readers of fiction - and not everybody who can read a little is a competent reader of fiction - are just as much accustomed to having an author donning the mask of transcendent storyteller as they are accustomed to the author performing a more ventriloquistic sort of act through a character.

However, the development of the novel has long reached the point where expectations of a consistent narrating agency across the length of the novel, distinct from the empirical author, are regularly thwarted. This can be demonstrated with reference to the work of many a recent author. In much of his novel A Maggot Fowles has made it quite impossible for us to postulate a technical narrator at all. There are passages where there are explicit indicators of direct authorial comment; there are insertions of authentic period documents into the text, even with the original typography ostensibly intact; there are very extensive passages of dramatic courtroom dialogue, sans external narrative comment. What we have in the courtroom passages is a series of characters that are all narrators, in the ordinary non-technical sense. Such permutations have become quite acceptable to current readerships.

What has perhaps made the figure of a 'third-person omniscient narrator' so compelling historically is that it seems to stand for something like a Lacanian "big Other", a voice that comes from a place of authority, the abode of pure language in its transcendent impersonality (see Žižek 2006, 2013). The big Other, or a similar explanatory concept, would seem to be needed for us to understand the historical ubiquity of the transcendent third-person narrative. It suggests an inverse relationship to actual subjectivity that may be a source of special satisfaction. The third-person narrative seems to put the reader in the place of the big Other, in the fascinating position of occupying precisely the perspective where direct access to someone else's inner world seems possible. What if the 'omniscient narrator' reflects nothing other than our desire for this power, a desire that authors have, over time, mastered techniques of fulfilling? 
How to explain why third-person transcendent narrative (TTN) has been so ubiquitous historically (see Morreall 1994, Culler 2004, Sternberg 2007)? Instead of continuing with the fanciful notion of 'omniscience', it is better from the point of view of scientific pragmatics to enquire into function: what it is that TTN has facilitated or made possible. It has undoubtedly enabled a reader to have the enjoyment of discovering secret things, with the security of discovering these things in the language of authority, hence the traditional use of standard language in its upper registers for this purpose. In return readers license authors to continue with the practice as long as it is found satisfying. Notice, for example, how important a device such as the scene shift is. The author, in big Other mode, has the authority to say: "While that was happening, let us look at what was meantime happening somewhere else." This accords with a reader's wish, to know what has been happening simultaneously in two places, and what I have called the revelatory function of literary fiction. It is like the daydream of being able to fly before the invention of flying machines. The fit-for-purpose transcendent 'voice' has historically been able to provide such enjoyable illusions.

Thus, stories have been increasingly liberated from the ways in which nonfiction is written. It is only through these (generic) ways of revealing what is normally unknowable that fiction has been able to advance to the heights of sophistication that it has. Other narrative genres, such as an eyewitness's oral testimony in court, a factual news report, a biography, and even non-factual examples, such as traditional folktales, legends or myths, all differ from the writing of fiction in one key respect. All of them are performances of telling a sequence of events that is somehow already in place prior to the telling. By contrast, a novel involves the creation of a fictional world, rather than a 'telling about' in any strict sense. The telling in a novel is a simulated telling. However, this fictional world must be unfolded in time and in a linear manner by reliance on certain linguistic mechanisms drawn from the true genres of telling: deictic references to persons and things; action descriptions; sequences of past tense reportage. These are harnessed to the fictional project from other everyday genres, the "primary genres" of which Bakhtin speaks (see Bakhtin 1986). The novel is irreducibly a "secondary genre"; it depends for many of its stylistic possibilities on the primary genres of telling.

So while one may agree with logicists and speech act theorists that there must be one who speaks (or writes), and even that there may somehow be 'pretence' involved in the masks that the author dons in doing so, e.g. transcen- 
dent storyteller, character-observer, character-participant, and so on, there is, in actuality, only the author.

The logicists have rightly emphasised authorial intention, but their apparent wariness of the domains of ethics and aesthetics makes it unlikely that they would help us with the question of intended effect upon a readership, and the technical innovations that drive this historically.

\subsection{Post-structuralism and denialism of human agency}

Narrator-denial can be logically sound if it proceeds along lines already suggested above. However, the denial of authorship is of another order altogether, one that is untenable from the standpoint of pragmatics. In literary studies there have long been attempts to diminish the importance of authorship in the reading of literature, from the arguments of Wimsatt and Beardsley against the "intentional fallacy" (see Wimsatt \& Beardsley 1972), to the more radical claims of post-structuralism. Among the most influential of the latter have been those of Barthes (see Barthes 1977) and Foucault (see Foucault 1980). Barthes' essay, in which it is claimed that readers are liberated in their reading only at the expense of the author's "death", has been particularly influential in literary studies. This is how Barthes concludes his famous essay:

The reader is the space on which all the quotations that make up a writing are inscribed without any of them being lost; a text's unity lies not in its origin but in its destination. Yet this destination cannot any longer be personal: the reader is without history, biography, psychology; he is simply that someone who holds together in a single field all the traces by which the written text is constituted. Which is why it is derisory to condemn the new writing in the name of a humanism hypocritically turned champion of the reader's rights. Classic criticism has never paid any attention to the reader; for it, the writer is the only person in literature. We are now beginning to let ourselves be fooled no longer by the arrogant antiphrastical recriminations of good society in favour of the very thing it sets aside, ignores, smothers, or destroys; we know that to give writing its future, it is necessary to overthrow the myth: the birth of the reader must be at the cost of the death of the Author. (Barthes 1977: 148)

What sort of agent or subject is found to be lacking in "history, biography or psychology" (and yet described as a "someone")? We are told that "classic criticism has never paid any attention to the reader,", but what sort of atten- 
tion to the reader, if any, is being proposed? Compare Bakhtin's comment: “... each epoch, each literary trend and literary-artistic style, each literary genre within an epoch or trend, is typified by its own special concepts of the addressee of the literary work, a special sense and understanding of its reader, listener, public, or people." (Bakhtin 1986: 98) What is important here is the relation between author and reader, not the championing of one over the other. The liberationist aims that are said to underlie Barthes' call for the author's demise are proclaimed and not substantiated. And the argument for the empowerment of the reader rings hollow when this reader is defined as a "space" (Barthes 1977: 148), which would seem instead to de-emphasise agency on the part of a reader.

In a similar manner, Foucault discusses critically a construct that he calls "the author-function" (see Foucault 1980). The author-function is said to be linked to modernity as a "system of ownership for texts". Without wanting to engage further with this notion, which would take us too far from the objectives of this essay, let me make wo points here that I oppose to these notions, and which are more aligned to the pragmatics of fiction that I espouse.

The first is the answerability of authors for what they have done. This is an appropriate notion within "the philosophy of the act", a term which I have adopted from Bakhtin as a definition for pragmatics (see Bakhtin 1993). Answerability may be thought of in an ethical and in a legal way, so that, for example, there is a public acceptance and acknowledgment that individual $\mathrm{x}$ is the source of the particular text $y$. This is notion is not entirely at variance with speech act theory: e.g. one makes a promise or commitment of some kind as a form of answerability and one is identified as having been the one to do so. One might have reason to object if the commitment had actually been made by another individual rather than by oneself. This notion of individual intentionality and answerability we can retain from speech act theory. What if it were otherwise? Without being too speculative about this - neither Barthes nor Foucault trouble themselves much with this question - one would need at least to postulate a radically different form of ethical life in which texts were not associated with the labour of individuals, and also to imagine what the advantages would be of being prevented, as a reader, from cognitively realising such associations. This brings me to the second point.

A legitimate focus for pragmatics here is how fiction (and indeed authors of fiction) have been found interesting to readers, and why it is that these readers' interests are consequential in the study of fiction. If, for example, works were published with titles but not with authors' names, one would be 
hindered from seeking out other works by the same author. One would not have interviews with authors nor would one read authors' journals because authors would not exist. Notice too, that if texts were not associated with authors' names there would in all likelihood be no way of distinguishing different texts with the same titles. Let us not stare too far into this needless abyss here and confine ourselves rather to the actuality of culture and what it is that readers do find interesting. Many of them find authors interesting to the extent that they are prepared to read their biographies, and to compare these accounts with their literary outputs (and again, to blend the two), while others are merely interested in finding another book to read by an author that they have previously enjoyed. In all of these matters there is much to be understood in the way of agency.

\subsection{Literary pragmatics as interdisciplinarity}

If the logicist reductionism of speech act theory and the opacity of some of the denialist positions are not adequate, there are other ways that have been more productive for pragmatics.

There have been researchers who have instead drawn on a plurality of relevant neighbouring disciplines. Among the practitioners of such an interdisciplinary approach one might mention Jacob Mey (see Mey 1998) and Monika Fludernik (see Fludernik 1995, 2001, 2003). Rather than being dogmatically faithful to analytical philosophy or post-structuralism, such writers have sought to enrich pragmatics with a range of conceptual resources.

Let us try to keep in mind how it is that the evolving technical and stylistic expertise of authors brings new layers of functionality to the reader, whose appreciation has been prepared by centuries of literary evolution and education. On the importance of a diachronic approach to such innovation and functionality, consider the observations below from Fludernik. In her paper dealing with the evolution of scene shifting in English narrative literature, she concludes:

We have looked at what initially appeared to be a very minor example of historical change. Its significance became apparent in relation to the more general development of narrative structure between the late Middle Ages and the nineteenth century. In addition, the scene shift was ideally suited to demonstrate that formal analysis needs to be complemented by a functional approach. In this way I was able to demonstrate how a function can be super- 
seded and its former expressions still used for new purposes. The example of the scene shift was chosen for its very mundaneness. If even such basic features of narrative have so far remained unanalyzed from a diachronic perspective, it becomes self-evident how many questions there still are to be answered, how much there is still to be done in narrative studies, particularly from a diachronic perspective. (Fludernik 2003: 344)

Let us turn, in similar manner, to the case of free indirect discourse (FID). It is more recent than the scene shift, mainly a development of the nineteenth century. To illustrate I will use a recent example from a popular genre, the crime novel, one which does require the reader to absorb innovative devices, or the innovative use of existing devices. FID is an interesting case because in a relatively short historical timespan it has become an almost indispensable stylistic feature in third-person narrative, across subgenres of fiction. Why?

While there is potentially no limit to any inventory of possible fictional techniques, there may well be limits to the reading public's rate of absorption of them and thus, if hitherto seldomly-used devices like scene shifting or FID enjoy an increased popularity among authors, we can hypothesise that these techniques fulfil a certain kind of readerly interest. We must look in all such cases at the question of readers' interests and how these have evolved, an empirical question.

The following is an example showing the kind of virtuoso use of techniques, including FID, that readers have come to expect from popular authors, the opening paragraphs of James Ellroy's novel, The Cold Six Thousand:

They sent him to Dallas to kill a nigger pimp named Wendell Durfee. He wasn't sure he could do it.

The Casino Operators Council flew him. They supplied first-class fare. They tapped their slush fund. They greased him. They fed him six cold.

Nobody said it:

Kill that coon. Do it good. Take our hit fee.

The flight ran smooth. A stew served drinks. She saw his gun. She played up. She asked dumb questions.

He said he worked Vegas PD. He ran the intel squad. He built files and logged information.

She loved it. She swooned.

"Hon, what you doin' in Dallas?"

He told her. 
A Negro shivved a twenty-one dealer. The dealer lost an eye. The Negro booked to big D. She loved it. She brought him highballs. He omitted details.

The dealer provoked the attack. The council issued the contract — death for ADW Two.

The preflight pep talk. Lieutenant Buddy Fritsch:

"I don't have to tell you what we expect, son. And I don't have to add that your father expects it too."

The stew played geisha girl. The stew fluffed her beehive.

"What's your name?"

"Wayne Tedrow."

She whooped. "You just have to be Junior!"

He looked through her. He doodled. He yawned.

She fawned. She just looooved his daddy. He flew with her oodles. She knew he was a Mormon wheel. She'd loooove to know more. (Ellroy 2010: 1-2)

The most remarkable feature of the style of this passage is that the thirdperson narrative nowhere adopts a transcendent tone. It retains the register of colloquial character-speech throughout. The first sentence is third-person narrative. Yet the use of "nigger" is startlingly far from transcendent style, indicative rather of speech and/or thought within the character's own milieu. Thus the sentence has an aspect associated with FID (incorporation of character's perspective into third-person narrative) and an affinity with direct discourse (DD) speech style. This becomes more apparent in the second paragraph and continues throughout much of the extract: "tapped, greased, six cold". The doubled effect of these opening sentences is one of being taken into the private musings of the character during his flight, while simultaneously being supplied with the relevant background information.

The next two very short paragraphs build on the character's recollections, thinking back on what had been said and not said. And at the same time Ellroy begins to suggest for the alert reader's benefit one of his own abiding themes, the corrupt connections between organised crime and law enforcement.

When the dialogue with the stewardess begins, we are told that "She loved it" and "She swooned". This is by no means transcendent narrator-speak, but rather an evaluative description from the perspective of the character to whom she is speaking. The same applies to "The stew played geisha girl". The perspective remains Tedrow's; we see her from his perspective. 
In the sequence "A Negro shivved [...] booked to big D" there is nothing of the usual "he said ..." followed by DD or "he said that ..." followed by indirect discourse (ID) constructions. But the shift from "nigger" earlier to "Negro" nevertheless suggests a shift from private thoughts to audible speech, suggesting that "nigger" would be inappropriate in this conversation, while the slang "shivved" would be readily understood by the stewardess (and the reader) to refer to a stabbing. Note how such a construction needs to be apprehended by both the interlocutor-character and the reader for its multiple functions to be operational: (a) character replying to his interlocutor; (b) author providing more background information to the reader; (c) author creating character type and milieu.

The next paragraph supplies omitted details. We find out, but the stewardess does not, that "The dealer provoked the attack" and "The council issued the contract - death for ADW Two". The reason for this information being withheld from the stewardess, while it represents what is on Tedrow's mind, is that it conveys all too clearly (to us) the illicit link between police work and organised crime. The "council" can be taken to be mafia controlled, and its deadly modus operandi being the issuing of a "contract". But note the style of language used here: "death for ADW Two". Assault with a Deadly Weapon is the form of a charge associated with police. In other words, Tedrow does not reveal to the stewardess that his principals are both the police and the mob, but Ellroy reveals it to us.

This is clarified in the next two paragraphs concerning the police commission: "The preflight pep talk [...] your father expects it too". The way this is inserted, however, is not just for our clarification, but it also gives the impression of Tedrow recalling his briefing, even while in conversation with the stewardess.

The sequence of "She fawned [...] She'd loooove to know more" is a case of FID that includes elements of DD, which, on a general level, is characteristic of the extract as a whole. Verbatim character expressions are blended into third-person narration.

Let us assess this example against this account of the syntactic constraints for an FID reading:

What therefore are the minimal syntactic conditions for an FID reading to become operative? There are only two: the deictic (that is, anaphoric) alignment of "personal" referential expressions to the deictic center of the reporting discourse, and the ex negativo syntactic condition that contenders for FID 
must not be phrased in a verb-plus-complement clause structure. (Fludernik 1995: 95)

In the Ellroy passage, pronouns outside of quotation marks remain in the third person despite the character language found there. The "ex negativo condition" also holds throughout most of the extract. There is only one instance of the verb-plus-complement clause structure ("He said he worked [...]") and thus FID provides for the general form of the extract as a whole.

For a public to have absorbed this technique, means that such syntactic features have become functionally relevant, rather than merely being features of an author's singular style. They have become generic, and they are available to an author for serving his or her purposes (while possibly also shaping those purposes). It is in regard to the evocation of another's consciousness that FID has been such an important development. As we have seen, the third-person narrative need not be disrupted at all by direct character speech in order for a character's thoughts or mentality to be evoked.

A second functional aspect is also the fact that this technique enables a certain harmonious stylistic flow of language to be maintained. In the Ellroy extract the language of social milieu is maintained rather than interrupted by transcendent narrator speech. This particular aesthetic function will be discussed further below.

\section{Technique and agonistic forms}

\subsection{Character, milieu and social perspective}

We have different modes in which the word of the author may be discerned within the word of the character. What is the substance of this authorial voice as it manifests itself in the creation of characters? The following may help in understanding it.

From a literary critical perspective fictional worlds theories need to do more than address philosophical and linguistic concerns about reference: they must also offer an alternative account of the rhetorical use of fiction. Readers cannot be content merely to construct fictional worlds, as if this in itself were endlessly satisfying; they must also be concerned to evaluate them, to bring them into relation with the larger context of their own experience and understanding. (Walsh 2003: 114 [emphasis added]) 
One common way for a reader to be prompted into this sort of evaluation is for the voice of the author to be identified with certain characters, or character types, contra others, as we shall see. This is the way of realism wherein social types are exposed to authorial criticism through linking those types to (actual social milieux) and exposing them to such techniques as irony and satire. This is one way, perhaps so far the most pervasive, in achieving an author's evaluative purposes mentioned by Walsh above.

There are of course other possibilities, and one might mention in passing Kafka's Metamorphosis, a decidedly more allegorical treatment of disaffection. The character who suddenly finds himself turned into non-human vermin, and is thereby irrevocably separated from family and all familiarity, represents the ultimate outsider. To a reader - this reader in particular - the relevant authorial image here is of one who has himself experienced despised otherness, and who wishes to express it in its universal or most dystopian aspect rather than in any realistic particularity. I am not suggesting here that satire and irony are impossible within an allegorical mode - consider Orwell's Animal Farm, for example - but what one does not get is a stylistic of naturalistic or empirical detail, for example the manners or mentalities of social milieux dramatically juxtaposed against one another.

Thus the novel has been formed between two stylistic poles. Perhaps the clearest way of distinguishing the two, is to point in the first case (realism) to the influence historically of biography. When the narrative is constructed through the provision of detail in such a way that it presents a plausible biography of persons who have actually lived, or, who could have lived in a manner recognisable in the experience of a reader, then we have to do with the stylistic pole of realism. The detail supplied is sufficiently naturalistic in the evocation of a world, so that the latter is perceived as no different in kind to the actual world. The fictional aspect to this, as I have mentioned, lies in the provision of impossible knowledge - especially the 'interiors' of subjectivity of fictional or fictionalised characters - which of course does separate it from works of actual biography, history and so on, and which has led to the development of stylistic techniques adequate for this purpose, such as FID.

The second stylistic pole, which I have associated strongly with allegory, may well be described as the evocation of impossible worlds, impossible, that is, from the natural experiences of actual readers. Fantasy, horror and science fiction are generally closer to this pole, but let it not be suggested that this possibility excludes the kinds of evaluation, even social evaluation, mentioned by Walsh above. The example of Metamorphosis suffices here. The details of char- 
acter and plot are presented in such a way that certain value elements emerge in a kind of ethical parallel with the actual world. It is in the very dystopian strangeness of the fictional world that makes its resemblance on this ethical plane as striking as it is. The actual world is defamiliarised in comparison, and is open to an evaluation in which otherness and repulsion are as conceivable as they are in the allegorical fiction. This requires descriptive detail of a different order from the more realistic work.

Naturally a great many works are located between these two extremes, having characteristics of both. But let us focus for the moment on the question of an author's relations with character types and milieux in instances that are closer to the pole of realism.

Fiction very often tends to impart a sense of social milieu. In a novel such as The Ambassadors or The Golden Bowl the speech of James's characters, together with the descriptions of the objects and events that surround them, evokes a milieu of sophisticated manners and refined aestheticism. In other examples, the sense of milieu is created by the naming of actual persons likely to be known to a reader, thereby bringing actual-world associations into the reading. In Bret Easton Ellis's novel Glamorama, there are literally hundreds of famous persons mentioned, interspersed with fictional characters, thereby bringing about in an immediate way the recognition of American celebrity culture.

A milieu provides the ground for plausible characters to emerge and to display agonistic relations with one another. A social tableau is required against which the character/figure is silhouetted, just as a scenic tableau is required against which the coup de theatre is silhouetted (see Brown 1981). Often characters and their agonistic relations with one another represents a milieu problematically, so as to manifest its instabilities or tensions. But more than this, it may be that such characterisation is also likely to be suggestive of an author's own, more or less fraught relationships to the milieu in question. This is an important way in which the agon of literary authorship arises and manifests itself to a reader, as an 'image' of the author posited by the reader.

The struggle of the author in this view is such that one carries one's origins (milieu, background, typicality) around as a problem to be overcome, just as one's fictional characters must do. This is perhaps the agon of fictional authorship in its purest form. Characterisation becomes an act of judgment on a milieu or a social type. Consider the following from F. Scott Fitzgerald's The Beautiful and Damned. 
"You related to Adam ]. Patch?" he inquired of Anthony, emitting two slender strings of smoke from nostrils over-wide.

Anthony admitted it with the ghost of a smile.

"He's a fine man," pronounced Bloeckman profoundly. He's a fine example of an American."

"Yes," agreed Anthony, "he certainly is."

- I detest these underdone men, he thought coldly. Boiled looking! Ought to be shoved back in the oven; just one more minute would do it.

Bloeckman squinted at his watch.

"Time these girls were showing up ..."

- Anthony waited breathlessly; it came -

"...but then," with a widening smile, "you know how women are." (Fitzgerald 1974: 81)

This dialogue between Bloeckman and Anthony Patch is presented from Anthony's perspective - Bloeckman's thoughts are effectively non-existent. But the passage also indicates something of the perspective of the author. Consider the mock description pronounced ... profoundly contrasted with the banality of Bloeckman's expressed sentiments. This intentional irony stereotypes the character and invites the reader to share momentarily the tedium of conversing with someone seemingly incapable of anything other than obtuse platitudes. One imagines the author as someone who has himself been afflicted by the company of the Bloeckman type. Bakhtin offers an important general formulation concerning this: "The author's reaction to what he depicts always enters into the image. The author's relationship is a constitutive aspect of the image" (Bakhtin 1986: 115 [emphasis added]).

The greater the distance that authors wish to put between themselves and a character or milieu, the greater the temptations of caricature and stereotyping. Such a character as a Bloeckman is viewed externally for purposes of expressing distaste. A refusal to present the inner world of the character becomes in this and similar cases a form of judgment. 


\subsection{Revelation and readers' interests}

Reading is as subjective as writing is. No two readings of a work can be exactly alike - interest, attention span, competence and background knowledge all play a role in a subjective reading. Yet the discourse strategy adopted by an author must be based on some apprehension, some calculation, concerning these readership factors.

Much of what constitutes fiction is the directing of a reader's attention towards putative secrets of the actual world. What sorts of unknown things might lie behind the actual objects and events that we know about? Or how might things have turned out in the actual world under certain counterfactual conditions? What sort of alternative history might then be revealed?

If a reader has been drawn into a fictional world, he or she may not only be intent on satisfying something akin to curiosity, but also interested in considering and evaluating the author's perspective on the actual world - an actual milieu, for example. A competent reader of fiction understands the generic convention whereby he or she is invited by an author to share things that are normally private or hidden. The involvement of the reader on this premise is a minimum for comprehension of fiction to take place. But an author does not necessarily write only in order to create faux revelations for a reader's enjoyment, but also to draw the reader into the author's own relationship to the world - a risky endeavour, no doubt, because critical readers will make of this opportunity what they will. The author is answerable for the text in a way that the reader is not, and it is part of an author's task to pique a reader's curiosity about what is to come for fiction to work. Let us bear in mind that fiction is always a movement in time, in this case from the unknown to the known. Often an author will signal to a reader that a mystery or question is being posed that will be answered later. Consider the following from an early short story by Jean Rhys, Illusion: "We had been dining and lunching together, now and then, for two years, yet I only knew the outside of Miss Bruce - the cool sensible, tidy English outside" (Rhys 2017: 4).

It would be an obtuse reader indeed who did not begin to anticipate a revelation concerning the inner life of Miss Bruce. It turns out that she is a secret hoarder of beautiful and glamorous dresses. The whole story is only four pages long, but it illustrates, at a micro level, a principle that plays itself out across many more pages in novels, that of revelation and anticipation thereof. 


\section{Suggestions for further research}

From the perspective of pragmatics, a competent reader of fiction understands him- or herself to be a joint participant in an intentional act. It is only in this way that a text can achieve full coherence for a reader. This coherence as telos is such that we understand the complexities of character, plot, perspective, etc., as authorial purposiveness, whether we know the identity of the author empirically or not. Yet the author can only be posited on the basis of the individual reader's cognitive powers, and the various contents of such positings remain a matter for empirical research.

It is from the point of view of pragmatics that one is in the best position to fully appreciate how the worlds of simulated persons might relate to the actual worlds of authors and readers. I have tried to outline what the agonistic substance of these relations might be, as a basis for further studies. Considering characters in depth leads us to a concern with the world they inhabit, and its relationship to the world that readers and authors inhabit.

Another specific research question concerns how and why it is that readers of literature are interested in companion genres such as interviews with authors, literary biographies and authors' published journals. The intertextuality here would seem to bring together information concerning the empirical author and the author posited in a reading of his or her work. There seems to be a certain fascination in this particular form of blending. In this context, research concerning author's self-staging or self-presentation could be of value.

\section{References}

\section{Corpus}

Ellroy, James (2010): The Cold Six Thousand, London: Windmill.

\section{Other works}

Austin, J. L. (1975): How to do things with words, Oxford: Oxford University Press. Bakhtin, M. M. (1986): Speech genres \& other late essays, Austin: University of Texas Press. 
- (1988): The dialogic imagination, Austin: University of Texas Press.

- (1993): Towards a philosophy of the act, Austin: University of Texas Press.

Barthes, Roland (1977): Image-music-text, New York: Hill and Wang.

Brown, Marshall (1981): "The logic of realism: a Hegelian approach", in: PMLA, 96 (2), 224-241.

Burke, John M. (1989): The death and return of the author: Criticism and subjectivity in Barthes, Foucault and Derrida. PhD thesis, University of Edinburgh.

Culler, Jonathan (2004): "Omniscience", in: Narrative, 12 (1), 22-34.

Eco, Umberto (1981): The role of the reader, London: Hutchinson.

Ellis, Bret Easton (1998): Glamorama, New York: Knopf.

Fitzgerald, F. Scott (1974): The Beautiful and Damned, Harmondsworth: Penguin.

Fludernik, Monika (1995): "The linguistic illusion of alterity: The free indirect as paradigm of discourse representation", in: Diacritics, 25 (4), 89-115.

- (2001): "New wine in old bottles? Voice, focalization, and new writing", in: New Literary History, 32 (3), 619-638.

- (2003): "The diachronization of narratology: Dedicated to F. K. Stanzel on his 8oth birthday", in: Narrative, 11 (3), 331-348.

Foucault, Michel (1980): "What is an author?", in: Josué V. Harari (ed.), Textual strategies: Perspectives in post-structuralist criticism, London: Methuen, 141-160.

Fowles, John (1981): The French Lieutenant's Woman, New York: Signet.

- (1996): A Maggot, London: Vintage.

Gallagher, Catherine (2006): "The rise of fictionality", in: Franco Moretti (ed.), The novel volume 1: History, geography and culture, Princeton: Princeton University Press, 336-363.

- (2011): "What Would Napoleon Do? Historical, Fictional, and Counterfactual Characters", in: New Literary History, 42 (2), 315-336.

James, Henry (1973): The Golden Bowl, London: Penguin.

- (1994): The Ambassadors, London: Penguin.

Kafka, Franz (2000): The Metamorphosis, In the Penal Colony, and Other Stories, New York: Scribner.

Mey, Jacob L. (1998): When voices clash: A study in literary pragmatics, Berlin: Mouton de Gruyter.

Morreall, John (1994): "The myth of the omniscient narrator", in: The Journal of Aesthetics and Art Criticism, 52 (4), 429-435.

Morris, Charles W. (1938): Foundations of the theory of signs, Chicago: Chicago University Press.

Orwell, George (2008): Animal Farm, London: Penguin. 
Rhys, Jean (2017): "Illusion”, in: The Collected Short Stories, UK: Penguin Random House.

Rose, Gillian (1992): The broken middle, Oxford: Blackwell.

Ruthrof, Horst (2004): "The fourth critique", in: New Literary History, 35 (2), 233-258.

Ryan, Marie-Laure (1981): "The pragmatics of personal and impersonal fiction", in: Poetics, 10 (6), 517-539.

- (2011): "Meaning, intent, and the implied author", in: Style, 45 (1), 29-47.

Searle, John. R. (1969): Speech acts: An essay in the philosophy of language, Cambridge: Cambridge University Press.

- (1975): "The logical status of fictional discourse", in: New Literary History, 6 (2), 319-332.

Sternberg, Meir (2007): "Omniscience in narrative construction: Old challenges and new", in: Poetics Today, 28 (4), 683-794.

Walsh, Richard (2003): "Fictionality and mimesis: Between narrativity and fictional worlds", in: Narrative, 11 (1), 110-121.

Wimsatt, William K./Beardsley, Monroe C. (1972): "The intentional fallacy", in: David Lodge (ed.), $20^{\text {th }}$ century literary criticism, London: Longman, 334-344.

Wood, Tahir (2015): Elements of hermeneutic pragmatics: Agency and interpretation, Bern: Peter Lang.

Žižek, Slavoj (2006): How to read Lacan, New York: W. W. Norton.

- (2013): Less than nothing: Hegel and the shadow of dialectical materialism, London: Verso. 



\section{The Relevance of Turning a Page: Monotony and Complexity in $\$ 25$ of David Foster Wallace's The Pale King}

Sixta Quassdorf, University of St. Gallen (Switzerland)

'Irrelevant' Chris Fogle turns a page. Howard Cardwell turns a page. Ken Wax turns a page. Matt Redgate turns a page. 'Groovy' Bruce Channing attaches a form to a file. Ann Williams turns a page. Anand Singh turns two pages at once by mistake and turns one back which makes a slightly different sound. David Cusk turns a page. Sandra Pounder turns a page. Robert Atkins turns two separate pages of two separate files at the same time. Ken Wax turns a page. Lane Dean Jr. turns a page. Olive Borden turns a page. Chris Acquistipace turns a page. David Cusk turns a page. Rosellen Brown turns a page. Matt Redgate turns a page. R. Jarvis Brown turns a page. Ann Williams sniffs slightly and turns a page. Meredith Rand does something to a cuticle. 'Irrelevant' Chris Fogle turns a page. Ken Wax turns a page. Howard Cardwell turns a page. Kenneth 'Type of Thing' Hindle detaches a Memo 402-C(1) from a file. 'Second-Knuckle' Bob McKenzie looks up briefly while turning a page. David Cusk turns a page. A yawn proceeds across one Chalk's row by unconscious influence. Ryne Hobratschk turns a page. Latrice Theakston turns a page. Rotes Group Room 2 hushed and brightly lit, half a football field in length. Howard Cardwell shifts slightly in his chair and turns a page. Lane Dean Jr. traces his jaw's outline with his ring finger. Ed Shackleford turns a page. Elpidia Carter turns a page. Ken Wax attaches a Memo 20 to a file. Anand Singh turns a page. Jay Landauer and Ann Williams turn a page almost precisely in sync although they are in different rows and cannot see each other. Boris Kratz bobs with a slight Hassidic motion as he crosschecks a page with a column of figures. Ken Wax turns a page. Harriet Candelaria turns a page. Matt Redgate turns a page. Ambient room temperature $80^{\circ} \mathrm{F}$. Sandra Pounder makes a minute adjustment to a file so that the page she is looking at is at a slightly different angle to her. 'Irrelevant' Chris Fogle turns a page. David Cusk turns a page. Each Tingle's two-tiered hemisphere of boxes. 'Groovy' Bruce Channing turns a page. Ken Wax turns a page. Six wigglers per Chalk, four 
Chalks per Team, six Teams per group. Latrice Theakston turns a page. Olive Borden turns a page. Plus administration and support. Bob Mc-Kenzie turns a page. Anand Singh turns a page and then almost instantly turns another page. Ken Wax turns a page. Chris 'The Maestro' Acquistipace turns a page. David Cusk turns a page. Harriet Candelaria turns a page. Boris Kratz turns a page. Robert Atkins turns two separate pages. Anand Singh turns a page. R. Jarvis Brown uncrosses his legs and turns a page. Latrice Theakston turns a page. The slow squeak of the cart boy's cart at the back of the room. Ken Wax places a file on top of the stack in the Cart-Out box to his upper right.

(Wallace 2011, 310-311) ${ }^{1}$

Language is able to reveal truths, but also to conceal underlying intentions and purposes. One effective strategy of linguistic concealment, according to David Foster Wallace's posthumous novel The Pale King (TPK), consists in hiding issues of import in irrelevant and hence boringly dull masses of data: "one of the great and terrible PR discoveries in modern democracy [...] is that if sensitive issues of governance can be made sufficiently dull and arcane, [...] no one not directly involved will pay enough attention to cause trouble" (TPK $84, \$ 9)$. Consequently, the power of a literary text may consist in its capacity to explore the facets of such "monumental dullness" (TPK 84, \$9). This essay attempts to show that one chapter $-\$ 25-$ is an exemplary instance of Wallace's "aesthetic of boredom" (Clare 2012: 442): it seems to mimic the "dull and arcane", yet despite superficial monotony and minimalist narrative means, it provokes rich associations that eventually subvert that neoliberal "politics of boredom" mentioned above (see Clare 2012). I thus concur with Clare that \$25 is "an instructive readerly allegory for [...] the theme of boredom [...] in The Pale King" (ibid.: 442). In both content and form, the chapter functions like an exercise against the manipulative threats of numbing monotony, which together with information overload, as discussed in other chapters and exemplified by the whole of the novel, imperil the democratic state at its roots.

Wallace's posthumous novel The Pale King centres on the US Internal Revenue Service (IRS) as "a synecdoche for a wide range of urgent issues" connected to questions of citizenship, economy, government, tax policy, recent history and many other things (Boswell 2014: vii). Wallace's own "Embryonic 
outline" of the novel adds the topics of "paying attention, boredom, ADD, Machines vs. People at performing mindless jobs" (TPK 545, "Notes and Asides") to the list. In short, the novel relates historical, economic and political phenomena to individual and subjective experiences in highly complex ways, and thus acquires an "omnivorous, culture-consuming" dimension (Boswell 2014: vii).

The bureaucracy of the IRS - in Wallace's own description a "parallel world, both connected to and independent of this one" (TPK 85, \$10) - is not only the novel's theme; it also affects its formal aesthetics. The fifty chapters are labelled with the section marks found in official documents; numerous footnotes (seem to) give instructions about how to use and understand the "disjointed, swappable collection of narratives" which form a "labyrinthine layout", reminiscent of "a tax return form" (Wouters 2012: 462). These fifty "disjointed" chapters make use of a broad range of narrative techniques and discourses, including traditional 3rd-person accounts, dialogues and 1st-person narratives, transcribed audio or video tapes, excerpts from encyclopaedias, historical tracts and academic studies, manuals, lists, excerpts from bureaucratic regulations, and not forgetting the interjections "author here" (TPK $66, \$ 9$, and 256 , \$24). These diverse texts then constitute a gigantic set of data waiting to be processed by readers, similar to the data that need to be processed by the fictional IRS employees. Wallace employs this mimetic technique pervasively. The mimetic effect then adds a further dimension to the book: reader here. True to Wallace's understanding of worthwhile (literary) communication, the "disjointed" structure of the novel reminds readers to "put in [their] own share of the linguistic work" (Wallace in McCaffery 1993: 138). Wallace invites reader participation and thus attempts to turn reading into a collaborative act.

In the middle of all these fragmented text data, \$25 sticks out in several ways. For instance, its layout is conspicuous. The chapter is printed in two columns, reminiscent of the aesthetics of many official documents. Granting that official documents tend to be perceived as dry and dull, the impression of an official document is reinforced by a "flood of seemingly irrelevant, repetitious, and boring information" (Clare 2012: 442). Readers are made to observe a group of rote examiners in a large open-floor office who apparently do nothing but turn pages. These observed "wigglers" are explicitly named, e.g., "Ken Wax turns a page. Lane Dean Jr. turns a page. Olive Borden turns a page..." (TPK 310, \$25), yet so far most of them are unknown to the reader. A few observations about the room, e.g., "Exterior temperature/humidity $96^{\circ} / 74 \%$ " 
(TPK 313, \$25), and descriptions of involuntary body movements, e.g. "R. Jarvis Brown uncrosses his legs" (TPK 311, \$25), interrupt the steady flow of pageturning, subtly adding some "skeletal narratives" (see Hayes-Brady 2016) to the text. The careful reader will also detect two "seeming non-sequiturs" (Clare 2012: 443) within the page-turning, such as "Devils are really angels" (TPK 312, $\$ 25)$. Apparently, the devil of boring monotony and irrelevant data overload may turn into an angelos, a messenger of worthy truths. The worthy truths may be revealed, once the diabolos - who according to the word's Greek origin is the one who throws things about in order to cause confusion - can be checked by ordering attention. In keeping with C.S. Lewis's observation that "we must attend even to discover that something is not worth attention" (Lewis 1961: 132), ${ }^{2}$ Wallace explores "paying attention" (TPK 545, "Notes and Asides") as part of the novel's "broad arcs" (TPK 545, "Notes and Asides") as a remedy against the passivising effects of monotony and irrelevant masses of data (see Boswell 2014, Clare 2012, Hayes-Brady 2016). Among many other things, the short interjection "Devils are really angels" (TPK 312, \$25) seems to suggest that \$25 is not only spatially but also conceptually a central chapter.

\section{Relevance Theory and The Pale King}

Perceptions of monotony, boredom, dullness and the effects of information overload are related to Wallace's central question of relevance and irrelevance (see Boswell 2014, Wouters 2012). It seems therefore appropriate to relate his writings to Dan Sperber's and Deirdre Wilson's Relevance Theory (RT). According to RT, a stimulus becomes relevant if it leads to new, strengthened, revised or abandoned available assumptions; that is, if it creates a positive cognitive effect. A positive cognitive effect as "a worthwhile difference to the individual's representation of the world" (Wilson/Sperber 2002: 47) is the precondition for relevance; by generating feelings of pleasure, it is the motor for human cognition. The greater the positive cognitive effect, the more relevant something appears. However, the degree of relevance to an individual is not exclusively determined by the expected cognitive effect. Relevance depends just as much on the expected processing effort, which in turn depends on the

2

Lewis's views on attentiveness seem to have influenced Wallace's own conception that concentrated dedication is of utmost importance to counter the (post)modern fastpaced, ephemeral way of life (see Burn 2012: 379). 
available mental representations at the time of communication. If new data can directly dock on to one's accessible beliefs and assumptions, the expected effort will be small. If, however, those data are difficult to connect to the accessible contexts, the effort will be great. Consequently, the "presumption of relevance" requires that

a) The ostensive stimulus is relevant enough for it to be worth the addressee's effort to process it.

b) The ostensive stimulus is the most relevant one compatible with the communicator's abilities and preferences. (Sperber/Wilson 2007: 270)

In RT, the term "ostension" denotes a "behavior which makes manifest an intention to make something manifest" (ibid.: 49).

The first presumption of relevance recalls, of course, observations by critics like Jonathan Culler who consider the worthiness of one's reading efforts as a precondition for, if not a convention of literature (see Culler 2000: 26). In that sense, the literary discourse, the novel itself and Wallace's renown "as one of the most gifted, important, and influential writers of his generation" (Boswell 2014: viii) provide a priori a strong stimulus to start reading this "long thing" (see Boswell 2014) called The Pale King. Yet, to convince readers to make the effort to read attentively despite seemingly uninformative chapters like $\$ 25$, the text must provide further stimuli that strengthen the presumption of relevance; that is, the renown of the author has to be confirmed by his ability to choose and set ostensive stimuli well.

The steady repetition of "turns a page [...] turns a page [...] turns a page" in $\$ 25$ renders the text semantically boring, which RT explains as a lack of informativeness: (a) the purpose of page-turning is only vaguely inferable; (b) after the initial statement the iteration does not seem to alter anything further in one's cognitive environment; and (c) the indications of the characters' names who turn pages are confusingly unprocessable. Most of these names have not been mentioned before and thus cannot link up with previously established mental representations - they appear to be irrelevant. As if to mock the reader, the first word of $\$ 25$ is, indeed, "irrelevant": "Irrelevant' Chris Fogle turns a page" (TPK 310, \$25). "Irrelevant" is, however, set between single quotation marks, signalling non-literal or citational meaning. It is an instance of Wallace's invitation to accept reading as a collaborative act: the tiny, but undoubtedly ostensive stimulus 'inverted comma' is meant to direct 
away from the boring surface and to overcome the barrier of effort raised by unwieldy linguistic data. It promises a cognitive effect by opening a path to other layers of potential meaning.

The aforementioned "great and terrible PR discovery" (TPK 84, \$9) that "abstruse dullness is actually a much more effective shield" against public interference "than is secrecy", because of the fact that the latter is "interesting" (TPK 83, \$9), reveals an abuse of a general principle in human communication according to RT: "Every act of ostensive communication communicates a presumption of its own optimal relevance" (Sperber/Wilson 2007: 158). Therefore, the narrator of TPK seems to demand of readers, and by analogy of citizens, that they go beyond the level of Sperber/Wilson's "optimal relevance." Optimal relevance is achieved as soon as some plausible interpretation is found through a balanced process of pairing cognitive effort with cognitive effect. In view of the communicative abuse by manipulative and antidemocratic $P R$ strategies, Wallace seems to require that readers accept, a priori, a greater cognitive effort in order to save the relevant from disappearance among distractive irrelevance, and thus to protect the individual's mind from easy manipulation.

\section{Guiding readers' perception of relevance}

To achieve this aim, Wallace often employs a narrative strategy of contrast and multiplicity: the novel's self-declared "shifting p.o.v.s, structural fragmentation, willed incongruities, \& c." (TPK 72, \$9) hamper the integration of newly read information into a larger context and thus the formation of coherent meaning. Even though the often seemingly unrelated data run the risk of not being processed at all if read only in a cursory manner, the "gaps" of meaning (Iser 1972: 346) opened up by such a non-teleological textual enterprise may increase the reader's interest and invite an active participation in the process of meaning generation, as has been observed by reception theorists and (Russian) formalists alike. The simultaneous use of apparent irrelevance and stimulation seems paradoxical; however, the tension generated between readerly resistance and complicity is a rhetorical strategy which can foreground the relationship between world and text, reader and implied author, and thus "enhanc[e] that real-world collaboration toward realising the potential of any text" (Schechet 2005: 30). 
Wallace's "radical realism" (see LeClair 1996) strives for a high degree of mimesis (see Hayes-Brady 2016: 63, 139, 151). Mimesis invites complicity by the representation of the familiar as it is effortlessly processable. At the same time, the familiar can provoke resistance by lacking informativeness. Moreover, resistance is likely against Wallace's apparently unfiltered mimesis of "the noisy, linguistically debased milieu of the turn of the millennium" (ibid.: 63). Unwieldy masses of data require intolerable processing efforts. However, this "logic of juxtaposition" (Burn 2012: 372) itself forms a strong ostensive stimulus. The tension between identification and resistance drives the reader forward, as the contrasts strive for some kind of reconciliation. The novel steadily renews its promise of relevance as an ongoing, never-ending communicative process between "author here" (TPK 66, \$9, and 256, \$24) and 'reader here' - a dialogue which, according to RT, by default presumes its own assumption of relevance. If readers collaborate, follow the lead and do not shirk the cognitive effort, they will be rewarded by the feelings of pleasure that a positive cognitive effect creates. In other words, the assumption of relevance is what stimulates real-world readers, and also what, on the plot level, makes Wallace's characters persist in their work. From their perspective, the relevance certainly lies in the still-dominant belief in the function of the IRS for the well-being of the Nation, which, however, is represented as under threat in a neoliberal economic system.

Thanks to the multiplicity of ostensive stimuli, ranging from tiny, inverted commas to the novel's overall architecture, attentive readers are in many ways well prepared when they approach "the book's more opaque sections" (Wouters 2012: 461) such as \$25. A short interview in \$14 provides a conspicuous preparatory stimulus on the plot level. It anticipates the setting of $\$ 25$ and literally gives instructions about what to make of it. In that interview, employee no. 917229047 recounts a dream about writing "a totally real, true-to-life play" (TPK 106, \$14):

The idea's that a wiggler, a rote examiner, is sitting poring over $1040 \mathrm{~s}$ and attachments and cross-filed W-2s and 1099s and like that. The setting is very bare and minimalistic - there's nothing to look at except this wiggler, who doesn't move except for every so often turning a page or making a note on his pad. (TPK 106, §14)

The employee further imagines that this radically realistic play will make the audience "bored and restless", so that they "finally [...] start leaving, first just a few and then the whole audience, whispering to each other how boring 
and terrible the play is" (TPK 106, \$14). However, the question of whether the reader is supposed to become as bored by $\$ 25$ as the imagined audience in $\$ 14$ is forestalled by the final remark: "once the audience have all left, the real action of the play can start" (TPK 106, \$14). The narrator thus raises questions about representation, the function and effect of art, and the role of the realworld audience. The fictional world can have an impact on the real world as soon as the audience stops merely being spectators consuming art, as soon as fiction is understood as a kind of reality and the barriers between fiction and life start to vanish. As if to prevent the reader from missing the message that art is not just for pleasure but ideally has effects on real-world people, a character in \$19 explicitly observes: “Sometimes what's important is dull. Sometimes it's work. Sometimes the important things aren't works of art for your entertainment" (TPK 138, \$19). The continuous turning of pages in \$25 epitomises Wallace's "aesthetics of boredom" (see Clare 2012), which seems to convey the realism of the quotidian, including experiences of ongoing, neverending work at one's desk or in one's search for meaning. Accordingly, in the "Notes and Asides" section, Wallace declares as the "Central Deal" of his novel "Realism, monotony. Plot a series of set-ups for stuff happening, but nothing actually happens" (TPK 546, "Notes and Asides").

\section{Author-reader collaboration through material stimuli in $\S 25$}

The ostensive stimuli set by the author address not only the rational mind of readers, but also their sensory experience. As mentioned already, $\$ 25$, and only $\$ 25$, is printed in two columns and thus draws attention to its own physical appearance. This visual ostensive stimulus merges readers' real-world experience with their fictional involvement and again draws them into that active author-reader collaboration which seems to be key for Wallace (McCaffery 1993: 138). The layout gives rise to multiple, perhaps contradictory expectations: it may spark interest by its unusualness in a book of fiction, but it also reminds us of the often off-puttingly dry and possibly even boring nature of text types which are typically printed in columns such as terms and conditions, if we remain within the context of the IRS, the explanatory section of a tax form. Columns are generally associated with texts about the factual, not the fictional world. The practice of recurrently disrupting the fictional setting in other chapters by verbal means such as footnotes and "author here" (TPK 66 , \$9, and $256, \$ 24)$ comments has here been translated into form. These 
ruptures again serve as ostensive stimuli to keep readers aware of their realworld situation; the dialogue between text and reader remains active in the reader's mind and steadily renews assumptions of relevance.

When Wallace's thick book lies open at \$25 and one views it from a distance, it recalls another thick book often printed in two columns: The Bible. This association might prime readers towards another sense of what is relevant in factual or fictive discourses: not only what is important and real in the objective sense of general terms, tax declarations and other two-columned official texts, but also what is important and real in the subjective sense of human experiences with the self, the other and the transcendent. Thus, the simple but skilful ostensive stimulus of a two-columned layout raises several expectations which, in the context of the entire book, are equally justifiable and may encourage readers to play with multiplicity and to practice dealing with incoherence in their search for relevance.

Chapter $\$ 25$ provokes multiple effects, some of which drive the readertext dialogue forward while others arrest it. The shorter lines of the printed text allow for reduced eye movements and thus increased reading speed. Despite the former signals of relevance by authorial instruction and the unusual layout, speed increases the danger of superficially skimming the text and, possibly, of skipping altogether the irrelevant-seeming reiterations of "turns a page [...] turns a page [...] turns a page” (TPK \$25). In a radical realistic manner, readers are likely to imitate exactly what the wigglers are supposed to do: they have to skim the tax declarations for signals of promising returns (because the IRS is being restructured from a national service into a neoliberal profit-generating institution). The work of the wigglers and the activity of reading seem to fuse; what happens in the fictional world is likely to be performed by the real-world reader, and thus both worlds are able to influence each other. Once such parallels between fictional characters and real-world readers have been noticed, one starts recognising more and more similarities. The wigglers turning pages in $\$ 25$ seem to mimic the reader's own page turning. This experience has repercussions on the interpretation of both the wigglers' work and the reading process itself. Except for so-called page-turners, skimming is not the conventional way of approaching literature, because sometimes "the important things aren't works of art for your entertainment" (TPK 138, \$19). If readers only skim such texts, they will not detect the hidden gems and be rewarded with the feeling of pleasure that a positive cognitive effect provokes. Rather, they will most likely feel that they have wasted their time. Transferring back from the readers' perspective, it may become ar- 
guable whether merely skimming forms for promising returns is a justifiable approach to the wigglers' work. On the one hand, this may explain the recurrent theme of boredom at work in the novel - the wigglers feel that they are wasting their time. On the other hand, should tax declarations not be checked carefully for their general soundness or faultiness, so that each citizen contributes the right share to the nation's budget? Would such an approach not make more sense and give the wigglers' work more meaning? The perception is that neoliberal ideas of efficiency, here exemplified by skimming, lead to feelings of dissatisfaction. Through a dialogic transfer between the readers' and the characters' worlds, this becomes an implicit critique of the socio-economic transformations discussed on the novel's plot level.

\section{Author-reader collaboration through narrative stimuli in $\S 25$}

However, sensory perception is not only evoked through the physical book and its layout but, naturally, also through the use of language. The peculiar use of the present tense creates what in a comparable narrative context has been described as a "cinematographic flavour" (Senn 1990: 252). It aligns characters and readers in time and place. While the room's features are stated in tenseless phrases as if they were eternal givens, impossible to change, e.g., "Rotes Group Room 2 hushed and brightly lit, half a football field in length" (TPK 310, $\$ 25$ ) or "Ambient room temperature $80^{\circ} \mathrm{F}$ " (TPK 311, \$25), the present tense in "turns a page" transforms readers into observers of the scene. The scene includes a number of details which, even if only half-consciously noticed, will influence readerly perception; the "hushed", rather hot and probably sticky room conveys its own atmosphere. Wallace places the reader in the position of the observer and thus evokes a mimetic experience through his use of language.

If readers take their task of observing people at work seriously, the context may evoke a foreman ticking boxes in a form each time someone "turns a page", an association which fits the motto of the novel: "We fill pre-existing forms and when we fill them we change them and are changed. Frank Bidart, 'Borges and I'." The present tense is then another means of potentially integrating readers into the novel's storyline and the structure of the bureaucratic system depicted. The potential reciprocal effects between text world and readerly world ideally goad readers toward emulating the wigglers' stamina, 
so that they keep playing the active, collaborating role Wallace imagines (McCaffery 1993: 138).

The isomorphic page-turning by both the observed IRS employees and the novel's readers raises further questions about relevance, e.g., what is the relevance of the observable? The essential aspect of reading a novel is obviously not the visible act of page-turning; the essential aspect is what happens in the unseen dialogue between the page and the mind, the implied author and the reader. Likewise, one can question whether page-turning at work can be treated as an activity worthy of observation. Page-turning may indicate a continuing process, but whether the work is done with care or negligence, with or without expertise, whether it is useful at all, escapes observation. In the context of the implied author's critique of neoliberalism, readers are invited to assume a critical stance towards forms of evaluating work efficiency based merely on measurable criteria. Such measurements tend to be reductive, as real things are often more complex than their superficial mechanics suggest. If activities, objects or people are reduced to their surface appearance and their invisible characteristics are dismissed, their linguistic representation threatens to become mere noise, e.g., the noise of 107 instances of "turns a page." This is the kind of noise that Wallace condemns elsewhere as essentially dulling and distracting from the important.

On the other hand, perceptions of the dullness and irrelevance of such noise can be a matter of perspective and choice, a possibility which readers are steadily invited to entertain by Wallace's "radical realism" (see LeClair 1996). Just as an observer's gaze will subconsciously absorb a lot of little details of the entire environment, so it is ultimately a matter of choice and attention whether one focuses on the foregrounded (monotonous) action of page-turning, or other matters like the "Baker-Miller pink" of the walls (TPK 312), the order of the desks, the different sound produced by turning two pages instead of one, or the signs of fatigue and concentration in the posture of the wigglers at their desks. As \$25 transforms readers into observers, it makes them feel that they can (or should) deliberately choose to process different kinds of data according to their preference and expectation of relevance. Through this narrative technique, readers as observers are made aware that the imagined visual overview enables them to choose whether the issues presented as central or as merely incidental are worthy of their attention. They become able to define their own perspective. 


\section{The semantics of sound and silence}

If one chooses to pay attention to the steady reiteration of the dominant phrase "turns a page", one may become aware of a further potentially instructive sensory dimension: rhythm and sound. As suggested earlier, the rhythmic feel could tie in with a foreman calmly ticking boxes in a form. However, this is only one of several possibilities: the rhythm may also recall a ticking clock, while the monotonous, apparently never-ending activity of page-turning seems to make time stand still. Thus, a tension between the subjectively felt and objectively given is expressed and experienced by wiggler and reader alike. It is also easy to imagine that the dominant phrase "turns a page" with its hard plosives ' $t$ ' and ' $p$ ' creates a machine-like ostinato so that readers are even further pushed forward and succumb to speedy superficiality. Alternatively, a calm iteration of the phrase can be reminiscent of ritualistic incantations to induce states of trance. In fact, the novel supports all of these associations, and the interplay between the effects of sound, silent reading and semantics provokes a complex pragmatic effect: readers' cognitive environments are extended not only by the text's verbal propositions but by drawing attention to the full spectrum of language, including its sensory qualities. Thus, readers are guided to search multiple paths in their pursuit of the relevant among the apparently irrelevant.

For example, the association of "turns a page" with a machine-like, driving force aligns with descriptions of neoliberal transformations at the IRS, which reduce the rote examiners to "data processors" (TPK 340, \$27) and which echo Wallace's "Big issue" of "human examiners or machines" (TPK 545, "Notes and Asides"). Paradoxically, in contrast to the rhythmic association with a hammering machine, the inhuman quality of the scene is semantically coded by the absence of noise. The "hushed" atmosphere in the room, where one perceives the "slightly different sound" of "turning two pages by mistake and then back again" (TPK 310, \$25) evokes an inaudible force. The setting in "Rotes Group room 2" (TPK 310, \$25) does not suggest pleasant calm. Nor does the description of the 144 wigglers "plus administration and support" (TPK 311, \$25) who have to sit silently in a large hot room, tied to desks that are orderly arranged according to a bureaucratic rationale, evoke an agreeable workplace. Like manipulative corporate rhetoric, the quietness of the room, and thus Wallace's semantic level of language, demonstrates a widespread euphemistic (ab)use of language. Whether or not the driving hammer is literally audible, whether or not one works in a loud factory or a quiet open-floor office, the 
force of machine logic is there, demanding that one never tire but repeat the same thing over and over again.

While the silent reading of $\$ 25$ feels like an exercise in coping with the dullness of steady repetition, the force of the dominant ostinato becomes especially effective and thus meaningful when the text is read out loud. Semantics alone may prove reductive. Therefore, readers might sense an implicit call to look beyond the typical (silent) way of approaching a text, and instead to draw on the full spectrum of linguistic expression. Readers are thus implicitly enjoined to use all their sensory and cognitive powers in order to appraise the entire picture critically. Searching for the relevant also in the unusual, the hidden, the unsaid, might safeguard them against manipulation. Again, we can observe the effects of Wallace's radical realism that connects the real world with the text world, and vice versa, and thus stimulates readers to develop rather than shirk the necessary processing effort required by the fact that "sometimes what's important is dull, sometimes it's work" (TPK 138, \$19).

Nevertheless, the conventional is also worth heeding as it structures perceptions and makes cognition and communication possible in the first place. When (unconventionally) the text is performed orally, the ostinato of "turns the page" tends to drown out any additional and deviating information scattered across the text, such as descriptions of the room ("One Chalk per row, four rows per column, six columns", TPK 312, \$25), of the wigglers' fatigue ("A yawn proceeds across one Chalk's row by unconscious influence", TKP 310, $\$ 25)$ and of signs of a high degree of concentration ("Boris Kratz bobs with a slight Hassidic motion as he crosschecks a page with a column of figures", TPK 311, \$25), and, of course, the "lyricisms" (see Warren 2012) like "Devils are really angels" (TPK 312, \$25). Conventional silent reading, in contrast, tends to foreground these undercurrents of "skeletal narratives" (see HayesBrady 2016), so typical of Wallace's work. These "skeletal narratives" tend to counteract the speed-reading impulse, as they require readers to embed this scattered information in their accessible mental representations, which takes time. Thanks to their novelty, these deviations from the dominant schema signal a greater presumption of relevance. However, formally, they are presented like asides which usually denote less relevant information. The confusion of what is supposed to be the main message vs. some negligible deviation through Wallace's technique of "skeletal narrative" again serves as an exercise in critical reading: is the information which is foregrounded really the important part? The "skeletal narratives" thus encourage readers to question ostensibly disinterested communicative conventions. As Hayes-Brady observes, 
Wallace thus "bring[s] the reader in as detective [...] so that again they 'put in [their] share of the linguistic work,' just as Wallace intended" (ibid.: 138).

While the ostinato of "turns a page" may recall machine logic, the 'skeletal narratives' recall the human: for instance, when "Meredith Rand does something to a cuticle (TPK 310, \$25), "Howard Cardwell shifts slightly in his chair" (TPK 311, \$25) and "Sandra Pounder [...] swings her head in a neck-stretching arc and leans forward again to examine a page" (TPK 312, \$25). The bored focus on a body part, and the shifting, stretching, yawning etc. communicate the employees' feelings at work. Readers are likely not to read this information as an objective datum, but rather infer the causes of the movements and understand their meaning from their own bodily experience (helped by human mirror neurons). In phenomenological terms, while the observation of the wigglers' work is an object of perception, noticing merely superficial aspects, their individual spontaneous movements are symptoms of the human essence which can thereby be grasped. Such universal human reactions to, for instance, fatigue and boredom have the potential to unite readers with the characters as human beings, constituting another instance of a blurred boundary between the fictional and the real, so that "the real action [...] can start" (TPK 106, \$14).

Still, the sheer number of iterations of the machine-like "turns a page" vs. the occasional attention to the characters turning pages implies the minor role of the individual in a neoliberal economic system. As mentioned earlier, names are listed as mere non-contextualizable data and thus appear irrelevant. As if to prove the irrelevance of such pseudo-personalisations - the attentiveness to names without real interest in the respective human being - other chapters familiarise readers at length with characters whose names are not revealed (or only in a footnote, an aside). The extended context is key to relevance in Sperber/Wilson's theory, not just the linguistic code. Wallace's use or avoidance of names seems to convey a very similar message. The irrelevant listing of names, instead, points out another mechanism by which basic human conceptions of relevance can be abused: in a tradition of nomen est omen, the pseudo-attentiveness of caring for names can easily be mistaken as "optimal relevance" (see Sperber/Wilson 2007) while, in fact, irrelevant names hide the really relevant: the persons behind them. 


\section{To conclude - The reward for seeking relevance}

Regardless of which association one favours, what will render both the work of the wigglers on the plot level and the reading of $\$ 25$ in the real world (and of Wallace in general) worthwhile is careful concentration. Utmost attention in search of the important among or in the dull is explicitly celebrated as modern heroism in \$22. This "hero" must use "care and scrupulosity about each detail" as a weapon to fight "repetition, tedium, monotony," which are to be "fear[ed] ... [f]or they are real" (TPK 231, \$22). \$25 is the attempt to represent this quiet, heroic endeavour which escapes public applause: "Tracing one's jaw's outline with a ring finger" (TPK 311, \$25), "soundlessly moving" lips (TPK 312, \$25) and other absent-minded actions recall states of concentration, which revive readers' own experiences by the mimetic nature of representation. The reward for this heroism on the plot level begins to be explored in the following $\$ 26$, where "concentrated boredom" (TPK 314, \$ 26) results in bliss and transcendence. On the level of the real world, Wallace explicitly envisages an attentive reader experiencing a "second-by-second joy + gratitude at the gift of being alive, conscious" (TPK 546, "Notes and Asides"). Thanks to Wallace's radical realism, the text-world promise turns into a real-world ostensive stimulus for making the effort and reading on.

The entire novel, and \$25 in particular, is an exercise in utmost concentration in order to reach the pleasurable state of discerning the relevant despite the strong cognitive effort required: the novelistic data need to be kept alive in the memory until they can connect to a meaningful context. However, the monotony of "turns a page [...] turns a page [...] turns a page" (TPK \$25) - especially when more than four or five instances are lined up in a row without deviance - also provides relief from that concentrated work. It recalls trance — inducing incantations and thus prepares one - not in an intellectual, but a sensory way - for the wiggler's transcendent experiences to come.

To conclude, \$25 strengthens, questions, rectifies and foreshadows the novel's more specific semantic content and concisely epitomises Wallace's "broad arc" and "central deal" of "Paying attention, boredom, ADD, Machines vs. people at performing mindless jobs" (TPK 545, "Notes and Asides"). Despite its minimalism, the reiterated short phrase "turns a page" in conjunction with its context and immediate co-text of the "skeletal narratives", is able to serve multiple narrative functions on the formal, semantic and pragmatic levels of language. Its mechanical recurrence and peculiar syntax turn into a sensory experience which not only imitates the multiple effects and affects that are 
evoked but also calls for active persistence in the human search for relevance despite discouraging settings. Wallace's mimetic representation transposes the verbally represented into readerly experience so that the author does not just narrate but also demonstrates the complexity of the human condition. The text's power then consists, in part, in making readers question their status as mere spectators, or consumers (of art, among many other things), and in reassuring them that "real action" can, should and will indeed "start" (TPK 106, \$14).

\section{References}

\section{Corpus}

Wallace, David Foster (2011): The Pale King, New York: Little, Brown and Co.

\section{Other works}

Boswell, Marshall (2014): "Preface: David Foster Wallace and 'The Long Thing”, in: Marshall Boswell (ed.), David Foster Wallace and "The Long Thing", New York a. o. p.: Bloomsbury, vi-xii.

Burn, Stephen J. (2012): "A paradigm for the life of consciousness': Closing time in The Pale King", in: Studies in the Novel, 44 (4), 371-388.

Clare, Ralph (2012): "The politics of boredom and the boredom of politics in David Foster Wallace's The Pale King”, in: Studies in the Novel, 44 (4), 428-446.

Culler, Jonathan (2000): Literary theory: A very short introduction, Oxford: Oxford University Press.

Hayes-Brady, Clare (2016): The unspeakable failures of David Foster Wallace: Language, identity, and resistance, New York a.o.p.: Bloomsbury.

Iser, Wolfgang (1972): Der implizite Leser, München: Wilhelm Fink Verlag.

LeClair, Tom (1996): "The prodigious fiction of Richard Powers, William Vollman and David Foster Wallace", in: Critique, 38 (1), 12-37.

Lewis, C. S. (1961): An experiment in criticism, Cambridge: Cambridge University Press.

McCaffery, Larry (1993): "An interview with David Foster Wallace", in: The Review of Contemporary Fiction, 13 (2), 127-151. 
Schechet, Nita (2005): Narrative fissures: Reading and rhetoric, Madison, N.J.: Fairleigh Dickinson University Press.

Senn, Fritz (1990): "Sequential close-ups in Joyce's Ulysses", in: Reingard M. Nischik/Barbara Korte (eds.), Modes of narrative: Approaches to American, Canadian, and British fiction, Würzburg: Königshausen \& Neumann, 252-264.

Sperber, Dan/Wilson, Deirdre (2007 [1995]): Relevance: Communication and cognition, $2^{\text {nd }}$ edition, Malden MA, and Oxford: Wiley-Blackwell.

Warren, Andrew (2012): "Narrative modeling and community organizing in The Pale King and Infinite Jest", in: Studies in the Novel, 44 (4), 389-408.

Wilson, Deirdre/Sperber, Dan (2002): "Relevance theory: A tutorial”, in: Yukio Otsu (ed.), Proceedings of the third Tokyo conference on psycholinguistics, Tokyo: Hituzi Syobo, 45-70.

Wouters, Conley (2012): “What am I, a machine?': Humans, information, and matters of record in David Foster Wallace's The Pale King", in: Studies in the Novel, 44 (4), 447-463. 



\section{The Language of Engagement and the Projection of Storyworld Possible Selves in Roberto Bolaño's The Savage Detectives}

Maria-Angeles Martinez, Universidad de Alcalá - Madrid (Spain)

English version

I think destiny brought me back. This was the fifth session of Álamo's workshop that I'd attended (but it might just as well have been the eighth or the ninth, since lately I've been noticing that time can expand or contract at will), and tension, the alternating current of tragedy, was palpable in the air, although no one could explain why. To begin with, we were all there, all seven apprentice poets who'd originally signed up for the workshop. This hadn't happened at any other session. And we were nervous. Even Álamo wasn't his usual calm self. For a minute I thought something might have happened at the university, that maybe there'd been a campus shooting I hadn't heard about, or a surprise strike, or that the dean had been assassinated, or they'd kidnapped one of the philosophy professors. But nothing like that was true, and there was no reason to be nervous. No objective reason, anyway. But poetry (real poetry) is like that: you can sense it, you can feel it in the air, the way they say certain highly attuned animals (snakes, worms, rats, and some birds) can detect an earthquake. What happened next was a blur, but at the risk of sounding corny, I'd say there was something miraculous about it.

$(\text { Bolaño 2007: 3) })^{1}$

1 In the following, all quotations in English without any reference specified are taken from this literary excerpt. 
Original version

Creo que fue el destino el que me hizo volver. Era mi quinta sesión en el taller de Álamo (pero bien pudo ser la octava o la novena, últimamente he notado que el tiempo se pliega o se estira a su arbitrio) y la tensión, la corriente alterna de la tragedia se mascaba en el aire sin que nadie acertara a explicar a qué era debido. Para empezar, estábamos todos, los siete aprendices de poetas inscritos inicialmente, algo que no había sucedido en las sesiones precedentes. También: estábamos nerviosos. El mismo Álamo, de común tan tranquilo, no las tenía todas consigo. Por un momento pensé que tal vez había ocurrido algo en la universidad, una balacera en el campus de la que yo no me hubiera enterado, una huelga sorpresa, el asesinato del decano de la facultad, el secuestro de algún profesor de Filosofía o algo por el estilo. Pero nada de esto había sucedido y la verdad era que nadie tenía motivos para estar nervioso. Al menos, objetivamente nadie tenía motivos. Pero la poesía (la verdadera poesía) es así: se deja presentir, se anuncia en el aire, como los terremotos que según dicen presienten algunos animales especialmente aptos para tal propósito. (Estos animales son las serpientes, los gusanos, las ratas y algunos pájaros.) Lo que sucedió a continuación fue atropellado pero dotado de algo que a riesgo de ser cursi me atrevería a llamar maravilloso.

(Bolaño 1998: 7)

\section{Introduction}

The present study explores the language of engagement in a short extract from Los Detectives Salvajes (Roberto Bolaño, 1998) and its English translation, The Savage Detectives (2007) within the framework of storyworld possible selves. Storyworld possible selves theory (Martinez 2014, 2018) holds that narrative engagement is strongly connected to the conceptual integration of two mental spaces: the mental representation built for the narrator or focalising character, and the mental representation that readers entertain about themselves. The resulting emergent structure is called a storyworld possible self, or SPS blend. Verbal narratives contain an assortment of linguistic expressions which require such hybrid mental referents, and it is frequent to find clusters of these expressions, or SPS linguistic anchors, at

2 In the following, all quotations in Spanish without any reference specified are taken from this literary excerpt. 
narrative beginnings. My analysis focuses on the first SPS cluster in Bolaño's novel, both in the Spanish original and its English translation, and discusses its bearing on storyworld possible selves projection and narrative construal.

More specifically, the study explores the light that storyworld possible selves theory can shed on one of the riddles posed to readers, namely, the reason why we should be invited to share narrative perspective with the first person narrator that focalises the first part of the novel, when this character, young apprentice poet and university student Juan García Madero, is then barely mentioned again for the major part of the book, to reappear as first person narrator in a flashback closing section that affords global insight on the story. As noted by the stylistician Michael Toolan (2012: 232), narrative beginnings can be expected to exert a significant influence on storyworld projection. Moreover, according to storyworld possible selves theory, narrative beginnings are used to encourage readers to enter the storyworld in the most appropriate SPS format, that is, through the activation of the part of their self-concept with the highest potential to effectively channel the self-relevance (Kuzmicova/Bálint 2019) and self-transformative (Miall/Kuiken 2002) effects of a particular narrative experience.

The analysis suggests that the main narrative function of this first SPS cluster in the novel is to prompt the activation of readers' past selves as young, restless university students as the part of their self-concept networks with a stronger engagement potential in this specific narrative experience. In other words, this early perspectival alignment seems to invite readers to enter the storyworld through their past young selves, thus enhancing the effects of the frantic, kaleidoscopic search for meaning presented in Part II, and of the final moment of blurry revelation about the nature of life, love, death, aging, happiness, and poetry in Part III.

The main aim of the study is to stylistically explore the language of engagement in this extract in the light of storyworld possible selves theory. Clusters of SPS linguistic anchors, or SPS nodes, have been previously discussed and illustrated (Martínez 2018: 83-87), but exclusively in narratives in English. Accordingly, a further aim is to compare the linguistic realisation of the SPS linguistic anchors in the Spanish original with those in its 2007 English translation, thus providing the first contrastive study on the topic. First, a few notes on the plot are presented. These are followed by a brief introduction to storyworld possible selves, with attention to their cognitive linguistic underpinnings in blending theory (Fauconnier/Turner 2002), intersubjective cognitive coordination (Verhagen 2005; 2007), and construal (Langacker 2008). In the 
body of the analysis, the SPS linguistic anchors in this particular extract are described and their function in the novel is discussed.

\section{Notes on the novel}

Roberto Bolaño (Chile, 1953-Spain, 2003) is considered an heir of Gabriel García Márquez's and Jorge Luis Borges's magical realism in Latin American literature (Pollack 2009), marking the shift to a postmodern concern in the line of Pynchon's and Wallace's. Los Detectives Salvajes (1998) received two prestigious awards upon publication - the $16^{\text {th }}$ Herralde Novel Award (1998) and the Rómulo Gallegos Award (1999) - and became a success in the U.S. in its 2007 English translation. The story is a dazzling, quixotic quest in which two young poets, Arturo Belano and Ulises Lima, members of a rebellious poetic movement called 'visceral realism' travel around the world supposedly in search of the movement's founder and icon, the Mexican poet Cesárea Tinarejo. The 641-page-long novel, telling a story that spans twenty years, opens with a 141-page-long Part I which presents the diary entries of a 17-year-old university student and wish-to-be visceral realist poet, young Juan García Madero. These entries display the day-to-day chronicle of the two months (Nov $2^{\text {nd }}$ $1975-$ Dec $31^{\text {st }} 1975$ ) between the day on which Juan was invited to join the visceral realist movement and the day he fled his careless, bohemian student life in Mexico City, to join Belano's and Lima's search of Cesárea Tinarejo.

In the second part of the novel (pp. 147-585) the reader is presented with a postmodernist array of entries, chronologically sequenced from January 1976 to December 1996 — but with the first of them (Amadeo Salvatirerra, January 1976) split up into thirteen parts and interspersed with the others. In these entries, different characters - professors, ex-lovers, real-life literary figures, old school chums, acquaintances - tell what can be envisioned by the reader as an imaginary visitor or interviewer their recollections of having met Arturo Belano or Ulises Lima at different locations (Mexico, Barcelona, Africa) in the course of those twenty years. It is in this puzzle of testimonies, in this Babel of crumpled evidence, where the clues to Belano's and Lima's whereabouts and doings lie for the reader to spot and disentangle. And, as we do so, we may notice that all the characters that are mentioned in the first part, all the visceral realist poets that young Juan García Madero introduces, are in one way or another mentioned in these testimonies. All, except García Madero himself, whom none of those interviewed seems to remember. Finally, the third and 
last part (pp. 586-647) presents García Madero's diary entries again, now covering in flashback the period between his flight from Mexico DC on January ${ }_{1}^{\text {st }} 1976$ - right where Part I stops - to February $15^{\text {th }}$ 1976, the chronological beginning of Part II. This is the time for awareness, when the reader is compellingly and wistfully drawn into dim but inescapable revelations.

The chosen extract occurs very early on in the narrative and anticipates the key moment in which Arturo and Ulises enter young García Madero's life. The reason for its choice is the fact that it contains the first cluster of SPS linguistic anchors in the novel. In other words, this extract is linguistically marked as significant because it is packed with expressions which grammatically invite readers to blend with the focaliser and thus use a storyworld possible self as hybrid mental referent. My study focuses on these linguistic devices and discusses why, from among the many characters with whom the narrative might have prompted early perspectival alignment - for instance, Arturo Belano or Ulises Lima, who feature as main characters in the 438 pages that make up the bulk of the novel - it is Juan García Madero that readers are linguistically encouraged to blend with.

As previously noted, in my analysis I will argue that this particular SPS blend involves the activation of readers' past selves as young restless university students, on the verge of crucial revelations about life, love, and death. Previous research has shown that such SPS clusters are frequently found at narrative beginnings (Martinez 2018: 86), which suggests that they perform the discourse function of activating in readers the self-schema or possible self-desired, undesired, past - most likely to facilitate engagement and the construction of narrative meaning. An initial SPS blend may later shift in varied ways (ibid.: 178), but that initial projection is likely to tinge the whole of the narrative experience (ibid.: 151). The extract is actually packed with what Martinez describes as SPS objectification and subjectification devices - pseudo-deictic you, ambiguous inclusive reference, paratactic accumulation, SENSERless transitivity processes, interactional facework - as if linguistically beguiling readers into close perspectival alignment with the novice visceral realist at this crucial turning point in his life.

\section{Storyworld possible selves}

Storyworld possible selves, or SPSs, are defined as "imagings of the self in storyworlds" (Martinez 2014: 119), and are formally conceived as blends result- 
ing from the conceptual integration (Fauconnier/Turner 2002) of two input spaces: the mental representation built by individual readers for the narrator or character that perspectivises a narrative, and the individual reader's selfconcept network. These two input spaces are conceptual structures and can thus be isomorphically matched: in cognitive approaches to narrative, characters are defined as "text-based mental models of possible individuals, built up in the mind of the reader in the course of textual processing" (Margolin 2012: 76). The self-concept, on its hand, is similarly conceived as a network of mental representations that we entertain about ourselves (Markus 1977; Markus/Nurius 1986; Dunkel/Kerpelman 2006), and consists of two sets of interrelated structures: self-schemas and possible selves. The former are images of the self built on the basis of social experience, such as the self as a sportive person, a cinema-goer, or a good parent. The latter, possible selves, have not been confirmed by social experience, but powerfully influence motivation, emotion, and behaviour, since they are mental structures that contain information about what individuals "might become, what they would like to become, and what they are afraid of becoming" (Markus/Nurius 1986: 954). In social psychology, possible selves can be of three types: desired, undesired, and past. Desired possible selves are images of the self that we would like to become, such as the loved self or the happy self. Undesired possible selves are images of the self that we fear or would loathe to be, such as the lonely self, or the self in danger or sorrow. Finally, past possible selves are images of the self in the past which still condition behaviour and emotion, such as the good student past self or last summer's happy self.

According to storyworld possible selves theory, when a narrative prompts linking matches between a specific reader's self-concept and this reader's narrator or focalising character construct, relevant features in these two inputs are selectively activated and projected into a new space, the emergent SPS blend. Many of the projected features are quite predictable, as mental representations and schemas are strongly grounded on shared background knowledge and cultural experience. However, others are totally unpredictable and idiosyncratic, depending on individual readers' personal experience and even personality (Holland 1975, 2009). Storyworld possible selves can thus serve to account for both idiosyncratic and culturally predictable narrative meaning construction (Martinez/Herman, 2020).

Moreover, using SPS blends in the study of narrative engagement allows the exploration of emotional responses not just as a result of mimetic, empathic attachment to certain narrative entities, but of what narrative psychol- 
ogists call "fresh emotions" (Miall/Kuiken 2001: 224), or emotions which do not mimetically result from sharing fictional entities' feelings, but from personal, idiosyncratic feelings of self-relevance and self-transformation, since, according to self-schema and possible selves theory, approaching a desired possible self produces positive feelings, while negative emotions result from approaching an undesired or feared image of the self (Markus/Nurius 1986; Dunkel/Kerpelman 2006).

Depending on the type of self-concept network activated by a given point in a narrative, five SPS types can be identified (Martínez 2014, 2018: 123-133): (a) self-schema SPSs, resulting from narrative matches between a character construct and a present image of the self, such as the parent self or the warhater self; (b) desired possible self SPSs, as in the case of the smart self engaged in matches with the narrator or focalising character in thrillers, or the loved self in romantic stories; (c) undesired possible self SPSs, such as the haunted self activated by ghost stories, the grieved self, or the threatened self; (d) past possible self SPSs, resulting from the activation by a narrative of a past image of the self, such as the self as a child; and (e) past storyworld possible selves, or past SPSs, derived from a previous narrative experience.

From among these, it is past possible self SPSs that seem most relevant to the extract in the analysis, as explained above. For Bolaño's adult readers, engaging in an early narrative blend with the 17-year-old naive, inexperienced apprentice poet Juan García Madero through the activation of their own young student past selves probably requires the temporary abandonment of all we think we know about life, in order to start afresh, as if the most appropriate cognitive mood for an enhanced narrative experience in this novel involved emptying our overloaded minds of useless weight and returning to the unprejudiced curiosity of those awakening days.

\section{Narrative perspectival alignment and intersubjective cognitive coordination}

Narrative experiencing requires perspectival alignment and intersubjective cognitive coordination between fictional and real minds (Martinez 2018: 44), so that readers can co-conceptualise the storyworld with the focaliser and engage in joint narrative construal. The cognitive grammarian Ronald W. Langacker (2008: 43) defines construal as "our manifest ability to conceive and portray the same situation in alternate ways". As Verhagen (2005: 7) puts it, "the 
point of a linguistic utterance, in broad terms, is that the first conceptualiser invites the second to jointly attend to an object of conceptualisation in some specific way, and to update the common ground by doing so", in a process known as intersubjective cognitive coordination (Verhagen 2005; Verhagen 2007; Langacker 2008; Faeyaerts 2013; Zima 2013). This view of linguistic communication has far reaching effects on the study of narrative, since language users - speaker $(\mathrm{S})$ and hearer $(\mathrm{H})$ - are no longer conceived as just addressor and addressee, but also as co-conceptualisers engaged in the collaborative negotiation of meaning through language.

In other words, a basic intersubjective viewing arrangement (Figure 1) involves a construal operation in which the two subjects of conceptualisation, conceptualisers $\mathrm{C}_{1}$ and $\mathrm{C} 2$, use language to focus their shared attention on an object of attention $\mathrm{O} . \mathrm{C} 1$ and $\mathrm{C}_{2}$ exist in the ground of the construal, which contains the features of the context of situation - participants, setting, aims, tenor, social roles, deictic parameters - in which the utterances occur, and which are shared by speaker $(\mathrm{C} 1)$ and hearer $(\mathrm{C} 2)$. The coordination relationship between these conceptualisers is represented by a vertical line, while a horizontal line represents the relation of joint attention between the conceptualisers and the object. The outer circle around the object, on its part, marks the offstage region of attention, while the square surrounding it indicates the onstage, or explicitly mentioned, region.

Figure 1. Basic intersubjective viewing arrangement

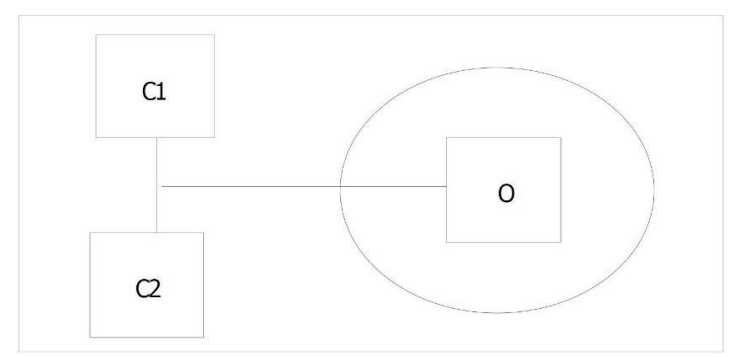

Adapted from Verhagen 2007: 60; Langacker 2008: 466;

Feyaerts 2013: 208.

According to Martínez (2018: 51), narratives similarly require intersubjective cognitive coordination between an intradiegetic perspectiviser, existing within the narrating situation - a narrator and/or focalising character - and 
an extradiegetic one. In the case of written narratives, this is a specific reader. These two conceptualisers, $\mathrm{C}_{1}$ and $\mathrm{C}_{2}$, engage in perspectival alignment and intersubjective cognitive coordination through deictic centre shifting and SPS blending, in order to turn their joint attention to an Object, in this case, the onstage part of the storyworld, as shown in Figure 2.

Figure 2. Basic narrative viewing arrangement in SPS the-

ory

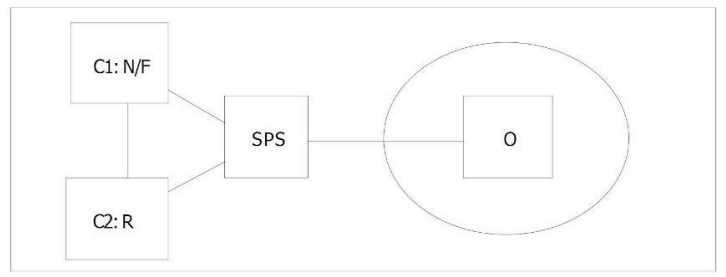

Adapted from Martinez 2018: 50

For instance, in the extract under study, the onstage region is occupied by the explicitly narrated events, such as "[...] we were all there, all seven apprentice poets who'd originally signed up for the workshop", while the offstage region contains the backgrounded part of the storyworld - the fictional participants' private lives before and after the workshop, their previous workshops, the streets of Mexico DC, and so forth - which are not explicitly mentioned, but are however readily available for mental reference.

As pointed out by Martínez (2018: 41-88), narratives contain a number of linguistic expressions, or SPS linguistic anchors, which point to the presence of a hybrid mental referent, inclusive of an intra- and an extradiegetic conceptualiser, in the ground of readers' narrative construal operations. Some of these SPS linguistic anchors intervene in SPS objectification, a construal operation in which "an element of the ground is brought onstage and linguistically coded" (Feyaerts 2013: 210), while others contribute to SPS subjectification, a construal operation in which an element of the ground is moved into peripheral focus or offstage-region through implicit reference. Consider these classic cognitive grammar examples: 
a) Vanessa was sitting across the table from Veronica.

b) Vanessa was sitting across the table from me.

c) Vanessa was sitting across the table. (Zima 2013: 146)

Example (a) illustrates a case of objective construal, in which the subjects of conceptualisation $\mathrm{C}_{1}$ and $\mathrm{C} 2$ are linguistically invisible. Example (b) presents a case of objectification of one of the conceptualisers, moved into the onstage region through explicit linguistic encoding ("me"). Example (c) is a case of subjectification, in which the subject of conceptualisation is moved into the offstage region by means of linguistically prompted inferential processes, but without explicit verbal encoding. Finally, grounding expressions such as deictic determiners - "my," "the," "here" - situate the two co-conceptualisers, C1 and $\mathrm{C} 2$, in the shared common ground of the construal. The rest of my study will focus on the cluster of SPS linguistic anchors in the selected extract from The Savage Detectives, with attention to their function as SPS objectification and subjectification devices in narrative construal operations.

\section{SPS objectification, subjectification, and grounding in Bolaño's extract}

As mentioned above, SPS objectification (Martinez 2018: 60-69) involves the explicit linguistic mention of this hybrid conceptualiser, and is realised through tokens of opaque inclusive reference such as:

a) doubly-deictic you and multiply-deictic one, which drag readers into the intradiegetic deictic centre occupied by narrators and character focalisers;

b) pseudo-deictic one and you, which express generic shared knowledge; and

c) cindefinite pronouns and noun phrases, such as anyone.

In SPS subjectification (ibid.: 69-81) this hybrid conceptualiser is not verbally encoded, but can be inferred from linguistic organisation in constructions which include:

a) SENSERless processes of mental activity - perceptual, emotional, cognitive - expressed through the passive voice, non-finite forms, or nominalisations; 
b) cases of narrated perception, in which sensorial perception - sight, hearing, smell, touch, taste - is presented as narration, suggesting a hybrid sensing entitiy; and

c) the presence of interactional facework in focalisers' inner speech and narratorial voice, which prompts the inference of dialogic interaction simultaneously with the monologuing self and with an overhearing reader.

These subjectification devices weaken the semantic presence of the intradiegetic perspectiviser, and create a semantic gap to be occupied by readers in their SPS format. Additionally, SPS nodes usually contain as well cases of paratactic accumulation, or clusters of clauses and phrases in quick juxtaposition, which serve to facilitate the setting up of common ground between the two conceptualisers (ibid.: 81-83), and thus intervene in SPS grounding.

Nodes containing several of these SPS subjectification, objectification and grounding devices are frequently found at narrative beginnings, as if to favour the early projection and anchoring of an appropriate SPS, that is, the one with the highest immersive potential (ibid.: 83-87). As Toolan remarks, "[i]t is nearly always rewarding to look carefully at the language of a story's opening - texture and expectations are created there that, in a sense, persist and prevail through the remainder of the narrative" (Toolan 2012: 232). These nodes can also be found at other strategic points in a narrative, where the reader seems to be summoned back into the storyworld just before an eventful account or revelation.

\section{Bolaño's extract: the English version}

In the English translation of the novel, the SPS node in the extract contains many of the aforementioned SPS linguistic markers, namely, pseudo-deictic you, indefinite pronominal reference, SENSERless transitivity processes, interactional facework, and paratactic accumulation. Regarding SPS objectification, or explicit linguistic reference to a hybrid conceptualising entity, the text contains two instances of pseudo-deictic you (example 1) and one case of indefinite pronominal reference (example 2). The emphasis in all these examples is mine: 
(1) But poetry (real poetry) is like that: you can sense it, you can feel it in the air $[\ldots]$

(2) [...] although no one could explain why.

The SPS subjectification devices in the extract include three cases of SENSERless transitivity processes: two nominalisations (examples 3 and 4), and a nonfinite verb form of mental state attribution (example 5):

(3) [...] and tension [...] was palpable in the air [...].

(4) What happened next was a blur [...].

(5) [...] there was no reason to be nervous.

Reader SPSs are also subjectified in the frequent cases of interactional facework in the extract. There is epistemic uncertainty, one of the linguistic realisations of negative politeness (Brown/Levinson 1987) and separateness facework (Haugh 2006):

(6) I think destiny brought me back.

(7) (but it might just as well have been the eighth or the ninth [...]).

(8) For a minute I thought something might have happened [...].

(9) [...] that maybe there'd been a campus shooting [...].

(10) No objective reason, anyway.

(11) [...] the way they say certain highly attuned animals [...].

(12) I'd say there was something miraculous about it.

Additionally, there are also cases of positive politeness, or connectedness facework, particularly in the form of contracted forms (I'd attended, I've been noticing, who'd, among others), which imply the presence of a hearer with whom distance has to be shortened. This distance shortening is also evidenced in the presence of two proximity deictics on line 1 , the deictic verb form "brought me back" and exophoric "This." These proximity deictics explicitly provide the parameters of the deictic centre - personal, temporal, spatial - which readers are invited to share with the narrator-focaliser, thus facilitating perspectival alignment just before the battery of SPS linguistic anchors in the node. Finally, the extract contains one case of paratactic accumulation functioning as an SPS grounding device (example 13 below). As can be observed, the common ground here prompted between the reader and the 
current focaliser involves familiarity not only with college life and faculty, but also with the likelihood of such extreme young students' guesses:

(13) For a minute I thought something might have happened at the university, that maybe there'd been a campus shooting I hadn't heard about, or a surprise strike, or that the dean had been assassinated, or they'd kidnapped one of the philosophy professors.

To sum up, the first SPS node in the 2007 English translation of Bolaño's novel contains occurrences of most of the SPS linguistic anchors previously observed in fictional prose in English. Let us now see how these linguistic realisations compare with those in the Spanish original.

\section{Bolaño's extract: the original version}

In the Spanish text, the extract also contains a variety of SPS objectification, subjectification, and grounding devices. However, their explicit linguistic realisations slightly differ from those in the 2007 English translation, some of them in significant ways. In the first place, the two cases of SPS objectifying pseudo-deictic you in the latter (example 1) do not appear in the Spanish original, which at this point presents the SPS subjectifying use of two SENSERless mental processes: ${ }^{3}$

(14) Pero la poesía (la verdadera poesía) es así: se deja presentir, se anuncia en el aire.

[*it lets itself be felt, it announces itself in the air]

But poetry (real poetry) is like that: you can sense it, you can feel it in the air.

SPS objectification through indefinite pronominal reference also differs in the Spanish original: while the English translation contains just one case ("no one"), there are three cases in the original version. Only the first of these (example 15) is preserved in the English text, where the second (16) and third (17) are rendered in ways that do not involve explicit indefinite SPS reference: 
(15) [...] sin que nadie acertara a explicar a qué era debido.

["without anyone managing to explain what it was due to]

[...] although no one could explain why.

(16) [...] nadie tenía motivos para estar nervioso.

[" no one had reasons to be nervous].

[...] there was no reason to be nervous.

(17) Al menos, objetivamente nadie tenía motivos.

["At least, objectively no one had reasons to].

No objective reason, anyway.

Regarding SPS subjectification, while the English text contains three instances of SENSERless mental processes (examples 3-5), there are five in the Spanish original, and only two of them - the nominalisation "tensión" and the non-finite form "estar nervioso" - are preserved in English. Additionally, there are three further occurrences of SENSERless mental process in the Spanish text which do not appear in the English translation. Two of them, realised by pseudo-deictic you in English (example 1), appear in Spanish as the SENSERless mental processes "se deja presentir" and "se anuncia", respectively (example 14). The third is realised in English by the adjective "palpable", which exists in Spanish with exactly the same form and meaning, and is derived from the Latin verb of perception palpare meaning "to touch":

(18) [...] y la tensión, la corriente alterna de la tragedia se mascaba en el aire. [*and tension, the alternating current of tragedy, could be chewed in the air]

[...] and tension, the alternating current of tragedy, was palpable in the air $[\ldots]$.

Despite these different surface realisations, both the Spanish original and the English version resort to the conceptual metaphor TENSION IS AN OBJECT - it can be touched in the original text and chewed in the translation - in the expression of this semantic process of cognition and embodied experientiality without an explicit sensing entity. This suggests that attributive adjectives expressing mental processes deserve further research as potential SPS subjectification devices.

Interactional facework, another SPS subjectification device extensively found in the English text, is also present in the Spanish version. To begin 
with, all the expressions of epistemic uncertainty in the translation (examples 6-12) can be found in the Spanish original, with closely matching linguistic realisations:

(19) Creo que fue el destino lo que me hizo volver

["I think it was destiny that made me come back]

I think destiny brought me back.

(20) [...] (pero bien pudo ser la octava o la novena [...])

[*[...](but just as well it might be the eighth or the ninth [...])]

[...](but it might just as well have been the eighth or the ninth [...])

(21) Por un momento pensé que tal vez había ocurrido algo [...]

["For a moment I thought that maybe something had happened [...]]

For a minute I thought something might have happened [...]

(22) [...] una balacera en el campus de la que yo no me hubiera enterado

[*a shooting in campus of which I had not been aware]

[...] that maybe there'd been a campus shooting I hadn't heard about [...]

(23) Al menos, objetivamente nadie tenía motivos.

[*At least, objectively no one had reasons to]

No objective reason, anyway.

(24) [...] como [...] según dicen presienten ciertos animales [...]

["the way as they say certain [...] animals sense]

[...] the way they say certain highly attuned animals [...]

(25) [...] algo que a riesgo de ser cursi me atrevería a llama maravilloso.

["something that running the risk of being corny I would dare call marvellous]

[...] I'd say there was something miraculous about it.

Additionally, in the Spanish text there are several further cases of epistemic uncertainty not rendered in the translation. Consider example (26). Here, the clause "nadie tenía motivos para estar nervioso" ["no none had reasons to be nervous] is hedged by the epistemic marker "la verdad era que" ["the truth was that] in Spanish, while in the English text the unhedged assertion "and there was no reason to be nervous" is preferred:

(26) [...] y la verdad era que nadie tenía motivos para estar nervioso.

["and the truth was that no one had reasons to be nervous.]

[...] and there was no reason to be nervous. 
It is also in this particular clause that the translator chooses to avoid the SPS objectification device "no one" (example 16). The fact that three of the SPS anchoring devices present in this clause in Spanish ("la verdad era que", "nadie", "estar nervioso") have been reduced to just one ("to be nervous") in the English translation may substantially diminish its potential to prompt readers' perspectival alignment with the narrator's and his fellow-students' state of agitation at this particular moment.

The second instance of epistemic uncertainty which is avoided in the English text occurs at the end of the paratactic sequence, which in the Spanish text ends with the hedge "o algo por el estilo" ["or something like that]. In the English translation, however, this hedge is omitted, and the sequence of juxtaposed clauses ends with the last of the narrator's guesses, "or they'd kidnapped one of the philosophy professors." The third epistemic uncertainty marker absent in the English text involves the substitution of the Spanish indefinite determiner "algún" in "el secuestro de algún profesor de Filosofía" ["the kidnapping of some philosophy professor] by the more determinate "they'd kidnapped one of the philosophy professors" in the English translation.

This example also illustrates a further relevant difference between the two texts, now regarding the language of connectedness. While this is barely found in the Spanish original, its presence is overwhelming in the English translation. In fact, in the original version there are only two cases: one of ellipsis (example 27) and one of emphatic repetition (example 28). Ellipsis is a linguistic phenomenon that presupposes shared background knowledge and thus prompts the inference of in-group solidarity and belonging (Brown/Levinson 1987: 111). This is not present when the extract is translated into English. The emphatic repetition is preserved in the English translation, however, although less redundantly:

(27) También: estábamos nerviosos.

["Also: we were nervous]

And we were nervous.

(28) [...] nadie tenía motivos para estar nervioso. Al menos, objetivamente nadie tenía motivos

["no one had reasons to be nervous. At least, objectively no one had reasons]

[...] there was no reason to be nervous. No objective reason, anyway. 
But, although these two cases of connectedness redress are either omitted or weakened in English, the language of connectedness plays a crucial role in the English rendering of this SPS node. As noted above, in the English translation there are nine contracted forms, which function as markers of informality and in-group solidarity, as if bringing readers closer to García Madero's age group and to the intimacy of his diary entries. It is true that the Spanish language does not have contracted verbal forms, but the fact is that the Spanish extract displays no further occurrences of connectedness language that might make up for the difference. On the contrary, in the Spanish original there are formal constructions which are substituted by more colloquial alternatives in the English translation. A notable example can be found in the paratactic accumulation which functions as an SPS grounding device in the two texts. Here, the Spanish nominalised processes "el asesinato del decano de la facultad" ["the murder of the college dean] and "el secuestro de algún profesor de Filosofia" ["the kidnapping of one of the philosophy professors] are substituted by English finite verb forms, the former in the passive ("the dean had been assassinated") and the latter as the even less formal "they'd kidnapped one of the philosophy professors." It is also worth noticing that, while "Filosofía" is spelt with an initial capital letter in the Spanish original - not a compulsory choice in Spanish - the name of the discipline is decapitalised in the English text, "philosophy", further diminishing formality.

These significant differences regarding the use of the language of separateness and connectedness in SPS subjectification are definitely audienceoriented, that is, aimed at facilitating SPS blending and intersubjective cognitive coordination in the English-speaking readership that the novel is now intended for. It could be hypothesised that these choices have to do with the translator's perception of a culturally less formal, less stiff attitude towards university life and academia in her English-speaking readers than in the Spanish community - both European and Latin-American Spanish for which Bolaño wrote. Undoubtedly, the self-schemas and possible selves on which SPS projection relies are mental representations with strong cultural underpinnings, so this is a hypothesis worth considering in further culturally-oriented SPS research. For the time being, let it suffice to underline this remarkable difference, even more so since all the other SPS objectification, subjectification, and grounding devices in this SPS node are realised in roughly the same ways in the two versions of the extract.

Furthermore, the early explicit deictic orientation which in English involves the use of the deictic verb form "brought...back" and exophoric "This" 
to index spatial deixis, and of the pronouns "I" and "me" for personal deixis, is similarly provided in the Spanish original by the deictic verb "volver" and by the use of first person object pronoun "me" and first person possessive determiner "mi":

(29) Creo que fue el destino el que me hizo volver. Era mi quinta sesión en el taller de Álamo [...].

I think destiny brought me back. This was the fifth session of Alamo's workshop that I'd attended [...].

As the Spanish language allows the unmarked omission of syntactic subjects, these differences should not have a substantial effect on the identification of the intradiegetic deictic centre into which readers should desirably shift in order to share vantage point with young Juan García Madero minutes before the event that would so drastically change his life.

\section{Discussion}

As shown in Table 1, although some of the low-level linguistic choices in the English rendering of the story slightly differ from the Spanish original, the two texts display a similar presence of SPS objectification, subjectification, and grounding devices ( 32 in the English translation versus 31 in the Spanish original). This suggests that both have a similar linguistic potential to prompt readers' perspectival alignment and intersubjective cognitive coordination with the narrator. But, despite these similarities, the analysis reveals a few significant differences. The first involves the use of pseudo-deictic you, an SPS objectification device, in two cases which in the Spanish original are expressed by SENSERless mental processes, markers of SPS subjectification (example 14). Objectification, it should be remembered, moves an entity in the ground of a construal into the onstage focus of attention shared by the co-conceptualisers. This difference is functionally compensated, however, by a higher presence of indefinite pronominal reference, another SPS objectification device, in the Spanish text (examples 15-17) in the form of the negative pronoun "nadie" ["no one], which balances the number of SPS objectification devices in the two texts to five instances each. 
Table 1: SPS objectification, subjectification, and grounding devices in The Savage Detectives and Los Detectives Salvajes.

\begin{tabular}{|c|c|c|}
\hline & English version & Original version \\
\hline \multirow{3}{*}{$\begin{array}{l}\text { SPS } \\
\text { Objectification }\end{array}$} & TOTAL: 3 & TOTAL: 3 \\
\hline & Pseudo-deictic you: $\mathrm{N}=2$ & Pseudo-deictic you: $\mathrm{N}=0$ \\
\hline & $\begin{array}{l}\text { Indefinite pronominal reference: } \\
\mathrm{N}=1 \text { no one }\end{array}$ & $\begin{array}{l}\text { Indefinite pronominal refer- } \\
\text { ence: } \mathrm{N}=3 \\
\text { nadie, nadie, nadie }\end{array}$ \\
\hline \multirow{4}{*}{$\begin{array}{l}\text { SPS } \\
\text { Subjectification }\end{array}$} & TOTAL: 28 & TOTAL: 27 \\
\hline & $\begin{array}{l}\text { SENSERless transitivity process: } \\
\mathrm{N}=4 \\
\text { tension, was palpable, blur, to be ner- } \\
\text { vous }\end{array}$ & $\begin{array}{l}\text { SENSERless transitivity process: } \\
\mathrm{N}=6 \\
\text { tensión, se mascaba, estar nervioso, } \\
\text { se deja presentir, se anuncia }\end{array}$ \\
\hline & $\begin{array}{l}\text { Facework: separateness (epis- } \\
\text { temic uncertainty): } \mathrm{N}=13 \\
\text { I think, it might, just as well, o, I } \\
\text { thought, something, might have } \\
\text { happened, maybe, anyway, they say, } \\
\text { certain, I'd say, something. }\end{array}$ & $\begin{array}{l}\text { Facework: separateness (epis- } \\
\text { temic uncertainty): } \mathrm{N}=18 \\
\text { Creo que, pudo, bien, o, pensé que, } \\
\text { algo, tal vez, hubiera, el secuestro } \\
\text { (nominalisation), some, Filosofía } \\
\text { (capitals), o algo por el estilo, la } \\
\text { verdad era que, al menos, según } \\
\text { dicen, algunos, me atrevería a, } \\
\text { algo. }\end{array}$ \\
\hline & $\begin{array}{l}\text { Facework: connectedness: } \mathrm{N}=11 \\
\text { Contracted forms: } 9 \\
\text { I'd, l've, who'd, hadn't, wasn't, } \\
\text { there'd, hadn't, they'd, I'd. } \\
\text { Ellipsis: } 1 \\
\text { No objective reason } \\
\text { Repetition: } 1 \\
\text { no reason/no objective reason }\end{array}$ & $\begin{array}{l}\text { Facework: connectedness: } \mathrm{N}=3 \\
\text { Contracted forms: } 0 \\
\text { Ellipsis: } 2 \\
\text { También: ; No objective reason } \\
\text { Repetition: } 1 \\
\text { nadie tenía motivos/nadie tenía } \\
\text { motivos }\end{array}$ \\
\hline SPS Grounding & $\begin{array}{l}\text { Paratactic accumulation: } \mathrm{N}=1 \\
\text { (For a minute I thought something } \\
\text { might have happened at the univer- } \\
\text { sity, that maybe there'd been a cam- } \\
\text { pus shooting I hadn't heard about, } \\
\text { or a surprise strike, or that the dean } \\
\text { had been assassinated, or they'd kid- } \\
\text { napped one of the philosophy profes- } \\
\text { sors). }\end{array}$ & $\begin{array}{l}\text { Paratactic accumulation: } \mathrm{N}=1 \\
\text { (Por un momento pensé que tal vez } \\
\text { había ocurrido algo en la universi- } \\
\text { dad, una balacera en el campus de } \\
\text { la que yo no me hubiera enterado, } \\
\text { una huelga sorpresa, el asesinato } \\
\text { del decano de la facultad, el secue- } \\
\text { stro de algún profesor de Filosofía o } \\
\text { algo por el estilo). }\end{array}$ \\
\hline TOTAL & 32 & 31 \\
\hline
\end{tabular}


However, the kind of mental activity which each of these objectifying devices prompts readers to share with the narrator may still entail substantial differences in narrative construal, since in the Spanish text the inclusive indefinite pronoun "nadie" invites readers to share the state of "not-knowing" with the group of young students at Alamo's workshop ("sin que nadie acertara a explicar a qué era debido" ["without anyone managing to explain what it was due to]; "la verdad era que nadie tenía motivos para estar nervioso" ["the truth was that no one had reasons to be nervous]; "objetivamente nadie tenía motivos" ["objectively no one had reasons to]), while the two instances of pseudo-deictic you in the English version objectify the reader's SPS in the act of "sensing" and "feeling." This apparently minor difference may have significant effects on readers' engagement with the novel, since true visceral realist poets - Arturo Belano, Ulises Lima, Juan García Madero himself - seem to be constantly engaged in not-knowing, as if this were a crucial condition for group belonging in this radically subversive poetic movement. And it is as a novice member of this avant-garde community, it must be remembered, that the reader is expected to enter the storyworld by SPS blending with Juan. Consequently, having one's SPS as a "not-knowing" individual objectified may contribute to ensuring early perspectival alignment with the narrator via this key feature of his visceral realist's identity. However, the fact that the translator's choices in the English text objectify readers' SPSs into sharing the sensing and feeling abilities of "certain highly attuned animals" may also indirectly contribute to the emergence of another crucial feature of visceral realists, namely, their reliance on the senses rather than on reason. In other words, the SPS node in this extract, both in Spanish and in English, seems to perform similar communicative functions despite its surface differences regarding SPS objectification: on one hand, to prompt the activation of readers' young university student past selves, with all their features of naïve early explorations of adulthood; on the other, to bring into the onstage region of attention readers' SPSs in cognitive processes of a) "feeling" and "sensing" in the English translation, and b) "not knowing" in the Spanish original. These cues, together with the massive presence of SPS subjectification through epistemic uncertainty in the two texts, provide crucial roadmap indications for readers to navigate the rest of this complex and often disorienting novel.

Another significant difference between the two versions affects the presence of the language of connectedness, another SPS subjectification device. This is overwhelmingly higher in the English translation, with twelve occurrences: nine contracted verbal forms, one case of ellipsis, one of emphatic 
repetition, and a finite verbal form instead of a Spanish nominalisation. In the Spanish original, however, there are just three instances of connectedness: two of ellipsis and one of emphatic repetition. In the analysis it has been argued that this difference may be explained by reference to the communities of readers to which the two texts are, respectively, addressed. Connectedness and in-group membership must certainly be concerns in poetic circles in the Spanish communities of readers - Latin American and Iberian Spanish targeted by Bolaño, but the SPS blending processes with García Madero and his young visceral realist comrades prompted by the Spanish original include a certain interactional formality which is substituted in the English translation by closer comradeship and informality. This suggests that, among the aspects of narrative construal that an SPS analysis can reveal, is the nature of the communities of readers targeted by a given piece of fictional prose and its effects on even minor linguistic choices.

\section{Conclusion}

Chilean writer Roberto Bolaño's awarded novel Los Detectives Salvajes (1998) became a success in the US in its 2007 English translation The Savage Detectives. The present study has looked into the translator's linguistic choices regarding the objectification, subjectification, and grounding of storyworld possible selves (SPSs) in the first SPS node - cluster of SPS linguistic anchors - in the novel, since the presence of SPS nodes at narrative beginnings functions as a powerful prompt for the projection by readers of the most appropriate storyworld possible self, that is, the one with the highest immersive potential.

The analysis shows that most of the SPS anchors found in Bolaño's original - indefinite pronominal reference, SENSERless transitivity processes, interactional facework, paratactic accumulation - are also present in its English translation, thus facilitating readers' blending with the first person narrator, 17-year-old Juan García Madero, at this crucial point in his life. This SPS blend involves the activation in readers of their young, inexperienced student past selves as the most appropriate image of the self through which to enter the narrative experience prompted by the novel.

A few significant differences, however, can be observed across the two versions, particularly regarding the expression of epistemic uncertainty and interactional connectedness. In the analysis, these have been connected both to narrative development and to the nature of the different communities of read- 
ers respectively targeted by the original novel in Spanish and by its English translation. Further research might use longer samples, even whole novels, in order to test this claim. The role of adjectives derived from verbs of cognition as SPS subjectification devices also seems to deserve further attention. And, although generalisations have to be taken with care, the findings broadly suggest that the model of storyworld possible selves can enhance stylistic research into narrative engagement and its associated linguistic features within cognitive linguistics and cognitive narratology paradigms.

\section{References}

\section{Corpus}

Bolaño, Roberto (1998): Los Detectives Salvajes, Barcelona: Anagrama.

- (2007): The Savage Detectives, Farrar, Straus and Giroux/New York: Picador, translated by Natasha Wimmer.

\section{Other works}

Brown, Penelope/Levinson, Stephen C. (1987): Politeness. Some universals in language use, Cambridge: Cambridge University Press.

Burke, Michael (2014): "Rhetoric and poetics: The classical heritage of stylistics", in: Michael Burke (ed.), The Routledge handbook of stylistic, London: Routledge, 11-30.

Dunkel, Curtis/Kerpelman, Jennifer (2006): Possible selves: Theory, research and applications, New York: Nova Science.

Fauconnier, Gilles/Turner, Mark (2002): The way we think: Conceptual blending and the mind's hidden complexities, New York: Basic Books.

Feyaerts, Kurt (2013): "A cognitive grammar of creativity", in: Tony Veale/Kurt Feyaerts/Charles Forceville (eds.), Creativity and the agile mind: A multi-disciplinary study of a multi-faceted phenomenon, Berlin: De Gruyter, 205-227.

Haugh, Michael (2006) "Emic perspectives on the positive/negative politeness distinction", in: Culture, Language and Representation III, 17-26.

Holland, Norman N. (2009): Literature and the brain, Gainesville: The PsyArt Foundation. 
Kuzmicová, Anezka/Bálint, Katalin (2019): "Personal relevance in story reading: A research review", in: Poetics Today, 40 (3), 429-451.

Langacker, Ronald W. (2008): Cognitive grammar: A basic introduction, Oxford: Oxford University Press.

Margolin, Uri (2012): "Character", in: David Herman (ed.), The Cambridge companion to narrative, Cambridge: Cambridge University Press, 66-79.

Markus, Hazel R. (1977): "Self-schemata and processing information about the self", in: Journal of Personality and Social Psychology, 35 (2), 63-78.

Markus, Hazel R./Nurius, Paula (1986): "Possible selves", in: American Psychologist, 41 (9), 954-969.

Martínez, María-Ángeles (2014): "Storyworld possible selves and the phenomenon of narrative immersion: Testing a new theoretical construct", in: Narrative, 22 (1), 110-131.

- (2018): Storyworld possible selves, Berlin: De Gruyter.

Martinez, María-Ángeles/Herman, Luc (2020): "Real readers reading Wasco's 'City': A storyworld possible selves approach”, in: Language and Literature, 29 (2), 147-170.

Miall, David S./Kuiken, Don (2002): "A feeling for fiction: Becoming what we behold", in: Poetics, 30 (4), 221-241.

Pollack, Sarah (2009): "Latin America translated (again): Roberto Bolaño's The Savage Detectives in the United States", in: Comparative Literature, 61(3), 346-365.

Toolan, Michael (2012): "Language", in: David Herman (ed.), The Cambridge companion to narrative, Cambridge: Cambridge University Press, 231-244.

Verhagen, Arie (2005): Constructions of intersubjectivity. Discourse, syntax, and cognition, Oxford: Oxford University Press.

- (2007): "Construal and perspectivization", in: Dirk Geeraerts/Hubert Cuyckens (eds.), The Oxford handbook of cognitive linguistics, Oxford: Oxford University Press, 49-81.

Zima, Elisabeth (2013): "Online semantic creativity in parliamentary debates", in: Tony Veale/Kurt Feyaerts/Charles Forceville (eds.), Creativity and the agile mind: A multi-disciplinary study of a multi-faceted phenomenon, Berlin: De Gruyter, 139-158. 



\section{"Smuggling in Accidental Poetry": Cognitive and Stylistic Strategies of a Stammering Teen in David Mitchell's Black Swan Green}

Constance Robert-Murail, Université Gustave Eiffel - Paris-Est (France)

\section{Extract 1}

Miss Throckmorton'd been playing Hangman on the blackboard one afternoon with sunlight streaming in. On the blackboard was

NIGH-ING- -E

Any duh-brain could work that out, so I put up my hand. Miss Throckmorton said, "Yes, Jason?" and that was when my life divided itself into Before Hangman and After Hangman. The word "nightingale" kaboomed in my skull but it just wouldn't come out. The $n$ got out okay, but the harder I forced the rest, the tighter the noose got. I remember Lucy Sneads whispering to Angela Bullock, stifling giggles. I remember Robin South staring at this bizarre sight. I'd've done the same if it hadn't been me. When a stammerer stammers their eyeballs pop out, they go trembly-red like an evenly matched arm wrestler, and their mouth guppergupperguppers like a fish in a net. It must be quite a funny sight.

It wasn't funny for me, though. Miss Throckmorton was waiting. Every kid in the classroom was waiting. Every crow and every spider in Black Swan Green was waiting. Every cloud, every car on every motorway, even Mrs. Thatcher in the House of Commons'd frozen, listening, watching, thinking, What's wrong with Jason Taylor?

But no matter how shocked, scared, breathless, ashamed I was, no matter how much of a total flid I looked, no matter how much I hated myself for not being able to say a simple word in my own language, I couldn't say "nightingale." In the end I had to say, 'I'm not sure, miss,' and Miss Throckmorton said, 'I see.' She did see, too. She phoned my mum that evening and one week later I was taken to see Mrs. de Roo, the speech therapist at Malvern Link Clinic. That was five years ago. 
It must've been around then (maybe that same afternoon) that my stammer took on the appearance of a hangman. Pink lips, broken nose, rhino cheeks, red eyes 'cause he never sleeps. I imagine him in the baby room at Preston Hospital playing eeny, meeny, miney, mo. I imagine him tapping my koochy lips, murmuring down at me, Mine. But it's his hands, not his face, that I really feel him by. His snaky fingers that sink inside my tongue and squeeze my windpipe so nothing'll work.

(Mitchell 2007 [2006]: 26) ${ }^{1}$

\section{Extract 2}

'Why d'you' - Hangman blocked 'nick,' then 'steal,' so I had to use the naff 'pinch' 'pinch the fags?' [...]

'Plebs smoke "fags." I smoke cigarettes. I don't "pinch." Plebs "pinch." I "liberate."

'Then why did you "liberate" the -' (Now I couldn't say 'cigarettes.')

'Ye-es?' prompted Hugo.

'The Lambert and Butlers.'

'Ifyou mean "Why did you liberate the cigarettes?", it's because smoking is a simple pleasure, with no proven side effects except lung cancer and heart disease. I intend to be long dead by then. If you mean, "Why choose Lambert and Butlers in particular?", it's because I wouldn't be seen homeless smoking anything else, except for Passing Cloud.'

(Mitchell 2007 [2006]: 62-63)

\section{Introduction: the power of a single voice}

When thinking of the words "powerful literary fiction" and "David Mitchell", the first book that comes to mind is his magnum opus, the extremely ambitious and intricate Cloud Atlas (2004), adapted for the screens by the Wachowski sisters and Tom Tykwer in 2012 (Tykwer et al. 2012). The book interweaves six narratives over almost six hundred pages, spanning multiple centuries and continents, each told in a different voice, which has led a New York Times article to review it as "a doggedly expert gloss on various writers and modes"

1 In the following, all quotations without any reference specified are taken from this literary excerpt. 
(Bissell 2004: n. p.). Only two years later, Mitchell published a homely semiautobiographical novel, Black Swan Green (2006), chronicling the life of Jason Taylor, a 13-year-old growing up in the backwater town that gives the novel its title. I was quite intrigued the day I realised that this work of fiction, which in many ways could or should have been Mitchell's debut novel, was written after the dazzling puzzle of a book that is Cloud Atlas. In comparison with the latter's vast project, the book presents a single year divided into 13 chapters, each corresponding to a month between January 1982 and January 1983, and is set in a tiny perimeter of a few kilometres around Jason's house, in the Worcestershire countryside. Each chapter is sufficiently independent that Black Swan Green sometimes reads like a collection of short stories. Throughout the story, Jason navigates problems at school, where he is bullied, and at home, where his parents' marriage is falling apart. The reader witnesses Jason mediating between the various personae of his fragmented identity: Unborn Twin, an alter ego who is allegedly responsible for most of his bad decisions; Eliot Bolivar, the nom-de-plume he uses to anonymously publish poems in the local parish newspaper; and last but not least, Hangman, the evil personification of his stammer.

After having created a world-encompassing sextet in Cloud Atlas, Mitchell bets on the creative power of a single voice, that of a young boy with a sharp wit and a twisted tongue. Using several close readings of the novel and elements pertaining to the cognitive psychology of stuttering, I will explore the powerful tension between communication and cognition in Black Swan Green. Indeed, the novel materialises the relation of psyche and voice in Jason's stutter, creating verbal accidents in the narrative that elicit physical and intellectual empathy in the reader. I will focus mostly on a pivotal moment at the beginning of "hangman", the second chapter of the novel. This scene is a highdefinition rendition of the few seconds during which an eight-year old Jason tries to give the correct answer to his teacher in class, only to find himself smothered by an ominous presence - his newfound speech impediment. In the second extract, taken from the following chapter, thirteen-year old Jason timidly tries to understand what prompted his older, shrewder cousin Hugo to steal cigarettes from the local drugstore. This will illustrate Mitchell's astute treatment of the stutter in dialogue. Even if the written nature of this paper does not allow me to sound Mitchell's prose, I invite you to read the extracts aloud and stumble over it yourself, letting the words challenge your personal voice and physicality. 
I would argue that these extracts present many characteristics that bring about a strong form of empathy in the reader, at once intellectualised and physical. Michael Toolan's study of "high emotional intensity passages" shows that "readers [...] respond not so much in empathy with characters experiencing acute physical pain or pleasure but rather with ones presented experiencing complex revised understandings of their embedded situation" (Toolan 2012: 213). In the first extract, speaking five years after the fact but still enduring the consequences of a key moment in his autobiography, Jason's revised understanding of his experience of stammering is both complex enough to appeal to an adult reader and youthful enough to let us enjoy the voice of a sassy 1980 s teenager. Both texts form a complex cognitive and physical exploration of a specific communicative impairment but also of a young mind in active, dynamic development. Firstly, I will examine the visual and cognitive characterisation of Jason's disorder. The second part of this article will focus on the poetic implications of Jason's (and David Mitchell's) stutter, as well as its role in the physical involvement of the reader.

\section{2. "What's wrong with Jason Taylor?"}

What is so funny about stuttering? Its representation in the arts has mostly been used for comic relief, most notably through theatrical tradition - in the commedia dell'arte, Tartaglia (literally, 'The Stutterer') is a stammering old fool always lost in his poetry. In the past decades, there has been movement towards multidimensional, non-stereotypical depictions of characters with physical or mental disabilities, as highlighted in Jeffrey K. Johnson in his very exhaustive chapter "The Visualization of the Twisted Tongue: Portrayals of Stuttering in Film, Television, and Comic Books" (Johnson 2008). Yet he adds that within this movement, stuttering remains "a crude formulaic storytelling device that adheres to basic misconceptions about the condition" (ibid.: 246). More recently, Judith Maginnis Kuster underlined the main three negative stereotypes around stuttering in films and television, namely: people who stutter can't handle a crisis; stuttering is comical or something to mock; stuttering is a symptom of a psychological flaw or the sign of an evil person (see Kuster 2011). These tropes have been intensely internalised by Black Swan Green's young protagonist, who projects his fear of being either a coward or a monster onto his alter egos Unborn Twin and Hangman. In this extract, 
Mitchell attempts to portray stuttering as both an internal process and an external demonstration, creating a tension between trauma and self-mockery.

\subsection{Visualising cognitive treatment}

Sight is central to the structure of the first extract. It starts off with a seemingly harmless setting, sunlight streaming into a classroom, although the presence of the Hangman is already unsettling. The second part of the first paragraph forms the knot of the scene, reproducing the tight noose that strangles Jason. It shifts the focus from Jason's physical experience to his classmates' reactions to an impersonal, general depiction of what a stammerer looks like. We can see how Jason is swiftly disconnecting from his own body to experience the moment from the outside. In the second paragraph, the repetition of "waiting" (\$2) accompanies a highly cinematographic progression: we're zooming out from the classroom to a bird's eye view of the village to a national scale, only to zoom back in on Margaret Thatcher herself, over a few very long seconds, suspended between silence and speech. In the third paragraph, the few seconds of silence lead to a torrent of words as Jason analyses his own feelings and puts an end to the excruciating scene. To be seen, however, is also to be understood, to be diagnosed, to be treated, as his teacher sees that Jason needs help ("[...] and Miss Throckmorton said, 'I see.' She did see, too." [\$3]) and reaches out to his mother behind his back. Finally, the last paragraph presents the reader with a graphic personification of the teenager's speech impediment, as if to exorcise an unwanted evil presence. The chilling image of Hangman will stick with the reader as it hangs over Jason throughout the book.

By the end of the extract, Jason's teacher has externalised the problem out of the classroom and into a therapist office by treating it as a medical condition, an affection that changes Jason's public persona. Jason, on the other end, has internalised his issue by creating a new private persona, which still enables him to treat the stammer as external, otherly. The stammer sends Jason into the margins, away from what is "normal" in society but also away from his "normal" self.

In this scene, the repetition of the word "sight" "bizarre sight" and "funny sight”, \$1) refers to Jason's teenage obsession with how he is perceived by others. In Black Swan Green, Jason looks at himself speak as much as he hears himself speak. The repeated verb "remember" $(\$ 1)$, far from referring to a personal feeling, portrays the reaction of a third-party and is immediately fol- 
lowed by a description of Jason from an external perspective. Mark Onslow explains that many people who stammer experience social phobia that leads to "observer perspective" memories: "When most people are asked to recall a social encounter, they will relate to their own field of vision - their field perspective - which is of course what is appropriate for them to recall. However, those affected with social anxiety disorder (...) are known to report an observer perspective" (Onslow 2016: 226).

People reporting this explain that their memories of stressful interactions look like they were filmed from behind their shoulder: they see themselves in third-person. It is of course the product of an a posteriori reconstruction, which underlines how anxiety shifts the focus. The observer perspective is often linked to traumatic situations, as it creates some distance between oneself and the event to pretend that it happened to someone else. This detached memory, however, tends to create discontinuity in self-representation. In spite of Jason's attempts to create distance, the extract presents the event as a turning point in his life: "life divided itself into Before Hangman and After Hangman"(\$1). This is consistent with what Mark Onslow has witnessed in young patients: a stammer can appear abruptly in a child's speech, over the course of a day or a week (Onslow 2020: 62). The seemingly factual statement "That was five years ago" $(\$ 3)$ could imply that the narrator has long moved on from this childhood scene, but instead it highlights how vivid the memory, and the shame associated to it, really are.

\subsection{Acting Invisible}

Jason's deadpan sense of humour and taste for hyperbole are another attempt at deflecting the dramatic tension of the extract. Self-mockery allows him to put some distance between himself and the event, but some of his derogatory comments hide something darker. "Total flid" (\$3), as he calls himself, is an extremely offensive way to describe someone mentally or physically handicapped. It is a shortened version of thalidomide, a drug that caused birth defects, and which here expresses the protagonist's own anxiety at being a disappointment to his family. Even if it is never said explicitly, the reader can examine the timeline of the book and deduce that the onset of Jason's speech impediment corresponds to the same year his father started an extramarital affair, which will result in his parents' divorce by the end of Black Swan Green. The source of the stammer was traditionally defined by pathologists, such as 
Wendell Johnson, as a psychological or emotional problem, or a projection of parental anxieties onto the child (Johnson 1959).

Jason links his problems with his speech, with his schoolmates and with his parents together by putting himself into some sort of Venn diagram ${ }^{2}$. He expresses his fear of being seen or stared at as threefold: "Picked-on kids act invisible to reduce the chances of being noticed and picked on. Stammerers act invisible to reduce the chances of being made to say something we can't. Kids whose parents argue act invisible in case we trigger another skirmish. The Triple Invisible Boy, that's Jason Taylor" (233-234).

The emphasis on vision in this extract is not only a way to process trauma through observer perspective memory: it also betrays Jason's fear of standing out.

\subsection{An idiosyncratic disorder}

According to Mark Onslow, "stuttering is an idiosyncratic disorder" (Onslow 2020: 11) in that it forces each individual to create self-management strategies. Speaking rhythmically, for instance, also known as syllable-timed speech (STS), has been known for centuries to be a fluency-inducing condition for people who stutter. Jason is taught this strategy by his speech therapist, and sing-songy rhythms pervade the textual space: "Pink lips, broken nose, rhino cheeks, red eyes "cause he never sleeps" (\$4). This nightmare-like vision of Hangman paradoxically sounds like a nursery rhyme. This familiar rhythm then may evoke in the reader's mind memories of fairy godmothers leaning over baby cradles, granting them powers or cursing them for life. The oral, repetitive and musical dimension of the sentences, small moments of accidental poetry occurring within the prose, elicit empathy from the adult reader, who is at once reminded of the childish innocence of the narrator.

Stammering is not only a matter of not being able to express oneself, it is also a form of physical expression in itself. Onslow notes that what he calls "nonverbal superfluous behaviours" (Onslow 2020: 11) are the most idiosyn-

2 Popularised by English logician John Venn in the 1880s, Venn diagrams are visual diagrams showing the logical relation between sets, usually represented by intersecting circles or ellipses. Here, Jason's invisibility is placed at the intersection of three sets of interpersonal issues: school bullying, instability in the household, and a medical condition impacting self-expression—each of them interacting in a specific way. 
cratic features of a person who stammers, varying from person to person. Onslow's characterisation resembles an accidental choreography:

They include compressed lips, open mouth, breath holding, blinking, nostril dilating, eyebrow raising, grimacing, facial, head and torso movements, inspiratory airflow, runts and other inappropriate noises, and aberrant fluctuations in pitch and loudness. (ibid.)

One of Jason's classmates finds herself "stifling giggles" (\$1): she is able to suppress her laughter, making Jason's lack of control even more striking. This idea of stifling oneself also highlights the importance of air flow in stuttering. Various parts of the body are engaged in this experience. Words "kaboom" in Jason's skull, his eyes pop out as he gasps for air like a fish out of water, and his stammer is like a hand plunging down his windpipe (see \$1). Jason is well aware of the multimodal possibilities of language, as he jokes a few pages later: "At this rate I'm going to have to learn sign language" (32).

People who stutter say on average around one third less than those who do not (Onslow 2016: 15). This rarefied speech also induces idiosyncratic methods of expressing oneself. Behind Jason's reduced verbal output, his mind is going a mile a minute to get himself out of difficult situations. Throughout the book, the reader witnesses him on the lookout for problematic letters and difficult words that might come up in conversation, avoiding them through circumlocutions, restricting his grammar to less elaborate clause constructions, and rarer expressions of modality. My second extract from chapter 3 illustrates quite smoothly Jason's strategies and Mitchell's treatment of dialogue. Here, Jason is facing his older, cooler, stronger cousin Hugo, and struggles to ask him why he felt the need to steal some cigarettes from the local shop:

'Why d'you' - Hangman blocked 'nick,' then 'steal,' so I had to use the naff 'pinch' - 'pinch the fags?' (...)

'Plebs smoke "fags." I smoke cigarettes. I don't "pinch." Plebs "pinch." I "liberate."'

'Then why did you "liberate" the - ' (Now I couldn't say 'cigarettes.')

'Ye-es?' prompted Hugo.

'The Lambert and Butlers.'

'If you mean "Why did you liberate the cigarettes?", it's because smoking is a simple pleasure, with no proven side effects except lung cancer and heart disease. I intend to be long dead by then. If you mean, "Why choose Lambert 
and Butlers in particular?", it's because I wouldn't be seen homeless smoking anything else, except for Passing Cloud.' (Mitchell, 2007 [2006], 62-63)

In this short dialogue, word avoidance leads to constant reconstruction of speech, at first through a play on synonyms and language registers. Jason wants to use the colloquial "nick" to sound cool and detached ('nick' as a noun is also UK slang for prison, adding a rebellious touch to the word). He pivots towards the more neutral "steal", but in the end can only utter "pinch", which sounds very "1980s surfer" (Urban Dictionary 2021), but definitely uncool according to our thirteen year-old hero. The second tactic consists in switching an superordinate for its hyponym, as when he goes for the specific brand Lambert and Butlers because he cannot utter the umbrella term 'cigarettes'. In contrast, Hugo appears to be in total control of his speech, using Jason's choice of words against him and elaborating verbose, uninterrupted explanations. Each of Jason's lexical choices is dissected and disqualified, then re-labelled accordingly to Hugo's vision. He goes as far as providing two different interpretations for Jason's questions. The overanalysis that follows is comically excruciating, as the reader is well-aware that Jason just went with the only words that would come out. His malicious cousin is probably aware of that, too. He's both actor and director of the scene - the verb "prompt" even explicitly states his role as a theatrical prompter, suggesting to Jason his forgotten line.

When they are at work in Jason's negotiation of dialogues, his palliative linguistic devices seep into every aspect of the narrative. They add rhythms and textured sounds to his storytelling. Indeed, in our extract, rephrasing and looking for synonyms are an integral part of how to process emotions: "But no matter how shocked, scared, breathless, ashamed I was, no matter how much of a total flid I looked, no matter how much I hated myself for not being able to say a simple word in my own language, I couldn't say 'nightingale'”(\$3). Jason scours words as if literally running through the pages of a dictionary, each adjective both necessary and insufficient to describe his feelings. The repetition of "no matter" connects three verbs and three levels of understanding the event: Jason's immediate mental state ("I was"), his outward appearance ("I looked") and the inward pull of self-hatred ("I hated myself"). The entire sentence is in itself a delaying tactic, rushing in towards the final utterance of the word that cannot be pronounced: "nightingale" $\left(\$_{3}\right)$. It is the bird of poets, no less: the bird of Cowper, Milton, Coleridge and Wordsworth, the symbol of an eloquence that seems out of reach for our young hero. In Ovid's Metamor- 
phoses, Philomela is raped by Tereus who then cuts out her tongue in punishment for her defiant manner of speech. She nonetheless weaves a tapestry to tell her story and gets her revenge on Tereus. The gods finally turn her into a nightingale so that she can escape Tereus's wrath. The song of a nightingale is therefore also associated with a mournful lament, with Philomela's voicelessness and the speech impediment caused by her injuries. This intertextuality with English Romanticism and Roman narrative poetry points to the extract's emphasis on emotions experienced through the body on the one hand, and on voice and performance on the other.

\section{3. "Accidental poetry"}

\subsection{A voice for the voiceless?}

I chose this extract because it is highly representative of Mitchell's stylistic treatment of a communicative impairment he knows well, as he suffers from stammering himself. He defined Black Swan Green as a way of "outing" himself regarding his speech defect (Mitchell 2011). Mitchell has also been vocal about his son's nonverbal autism. He and his wife have translated The Reason I Jump, a memoir written by Naoki Higashida, then not much older than Jason, about his nonverbal form of autism (Higashida 2013). In a review of the book aptly entitled "Voice for the Voiceless", Sallie Tisdale notes: "Mitchell writes that reading 'The Reason I Jump,' he 'felt as if, for the first time, our own son was talking to us about what was happening inside his head"' (Tisdale 2013: n. p.), which is incidentally (or accidentally) similar to what we are confronted to in this extract from Black Swan Green.

In an interview for The Guardian a few years ago, Mitchell added: "So what are we still getting wrong about autism, and how do we get it right? [...] First up, is that we stop assuming a communicative impairment denotes a cognitive one." (Mitchell 2017: n. p., emphasis added) The book as a whole, and this passage in particular, puts in sharp focus the discrepancy between Jason's communicative difficulties and his extremely articulate, vivid interior monologue. The reader is caught between Jason's frustration at not being able to express himself, and delectation in the many ways he finds to express himself nonetheless.

This passage is powerful in the way it displays a moment of weakness, and challenges the power mechanisms within and through discourse. Ever since the Greek conception of logos, organised speech and rational thought have 
been considered two sides of the same coin. Eloquence is not just a matter of speaking, but of who has the right to speak - the proficient orator has a hold on discursive power, as we have seen in the short dialogue between Jason and Hugo. Books such as Black Swan Green and The Reason I Jump are respectively fictional and non-fictional attempts to counterbalance a lack of positive cultural representations of disorders such as aphasia or stuttering, giving them visibility within the public sphere and, quite literally, a voice. In interviews, Mitchell mentions that he treats his stammer and other people's reactions to it with a form of "militant indifference" (Mitchell 2011: n. p.), which is, in its own way, a political stance.

\subsection{The birth of a novelist}

Jason's voice elicits tenderness and empathy within the reader, and underlines one of the key strengths of Black Swan Green - the youthful creativity and accidental poetry of Jason's language. According to David Mitchell, the power of the novel relies on a delicate balance:

I wanted Jason to be unformed enough to be plausible — I didn't want him to speak like a child genius - but interesting enough to be readable. That's tough, but there's one thing on your side. Kids that age don't have the linguistic formulas in place that adults do - what linguists call collocation the way certain words go with certain other words. That means you can smuggle in accidental poetry, and, with luck, wisdom and insight too. (Mudge 2006, emphasis added)

The Latin root "accidens" can mean occurrence, chance or misfortune. Jason's verbal mishaps are presented in the novel as a form of pharmakôn, both poison and cure, cause of his social anxiety and source of his poetic creativity. An accidental, in music, is also "a note foreign to a key indicated by a signature" (Merriam-Webster online dictionary 2021). Mitchell inoculates prose with the accidental, foreign musicality of stuttering. Accidental poetry also occurs with outbreaks of childish artlessness in the narrative. The novel teems with tongue-in-cheek and somewhat laboured nods to 80s British pop culture. Inside this network of references, another smaller, more intimate network is created with Jason's childlike habit of being extremely precise with proper nouns, e.g. in our extract, "Malvern Link Clinic" (\$3) and "Preston Hospital" (\$4), as well as full names of classmates, hyperlocal details that the reader (just like the adults in Jason's life) most likely does not care about and 
will not remember. This is but one of many features Mitchell has used in his novel to aim at the reader's willing suspension of disbelief and shape an unformed, plausible narrator. As he also notes in an article in The Telegraph entitled "Let me speak": "Children compensate for a lack of lexicon with simile or metaphor" (Mitchell 2006: n. p.). Jason tends to rely on comparisons in moments of crisis, whether they are safely commonplace ("like a fish in a net" [\$1]) or more colourful ("like an evenly matched arm wrestler" [\$1]).

Jason's favourite palliative strategy is poetic writing, as he notes: "Only in my poems, I realised, do I get to say exactly what I want" (156). Mrs. de Crommelynck, a strange old lady who has read his writings in the local parish newspaper, tells him: "The poem is a raid on the inarticulate" (147). This is a direct nod to T.S. Eliot's own take on the failure of speech as standard for poetic creation:

[...] Trying to use words, and every attempt

Is a wholly new start, and a different kind of failure

Because one has only learnt to get the better of words

For the thing one no longer has to say, or the way in which

One is no longer disposed to say it. And so each venture

Is a new beginning, a raid on the inarticulate

With shabby equipment always deteriorating

In the general mess of imprecision of feeling,

Undisciplined squads of emotion. [...] (Eliot 1943, "East Coker", V)

Eliot's "shabby equipment", "general mess of imprecision of feeling" and "undisciplined squads of emotion" unintentionally summarise the adolescent experience of moving around the world in a body that feels increasingly foreign and inadequate, filled with new urges and half-formed thoughts.

Yet, Black Swan Green does not show the reader a single poem Jason has written. This feels very intentional. The only extract that Jason writes diegetically is actually in prose: on page 261 (in the penultimate chapter "disco"), the first two sentences of the chapter that precedes it ("goose fair") are reproduced in what is supposed to be Jason's handwriting, suggesting he has begun to write what will become Black Swan Green. At the end of the book, Jason admits to his sister that he has stopped writing poems. We are made to consider that poetry was, for him, a transitional activity of early adolescence. As he grows up, he starts writing prose. Entering a new phase of his development, leaving childhood behind, the poet becomes a novelist. David Mitchell notes that not all stammerers become writers and not all writers are stam- 
merers (Begley 2010). But in interviews and articles he has repeatedly argued that the type of prose writer that he became owes much to his speech defect and the strategies he implemented to avoid being seen as a stammerer:

Your stammer informs your relationship with language and enriches it, if only because you need more structures and vocabulary at your command. Quite probably, if I could have produced unbroken, effortless sentences like my secretly envied classmates, I would never have felt the need to write them down, nor become a writer. (Mitchell, 2006: n. p.)

The specificities of Mitchell's and Jason's storytelling are underlined by Garan Holcombe:

[Jason] must, if he is to conceal his speech defect, forever seek alternative means of saying the same thing; he must rephrase, search for synonym and close association. He must also think ahead so as to avoid being surprised by words beginning with certain letters (...) It is little surprise, then, that the adult novelist should display such polyphonic narrative virtuosity, or that he should be interested in retelling stories from different perspectives, or that he should display such sensitivity toward the formal necessity of coherence and structure. (Holcombe 2013: n. p., emphasis added)

In a way, Mitchell shows in Black Swan Green what he needed to go through to one day be the author of Cloud Atlas. We can thus read it as an autobiographical Künstlerroman, in which stylistic practices articulate themselves around an articulatory deficiency. The daily work of commutation and permutation, as well as the ceaseless struggle of anticipating and restructuring his discourse, would be in a way the starting point of the author's idiosyncratic writing, the first faltering steps of a stammering writer. This extract illustrates that powerful prose can be achieved by treating language as a permanent process growing organically in all directions at once, which is what Deleuze beautifully states in his text He Stuttered: "Creative stuttering is what makes language grow from the middle, like grass; it is what makes language a rhizome instead of a tree, what puts language in a state of perpetual disequilibrium" (Deleuze 1994: 27). Teetering on the brink of silence, balancing off one sentence with the next, Mitchell's young narrator grasps ten words at a time as he gasps for air. 


\subsection{Multimodality, empathy and somesthetic sensations}

I have shown in our first extract the focus on vision, which goes hand in hand with a depiction of the gestuality, the multimodality of language. I will now conclude on another 'accident' at work here, involving the reader's body. In this very specific sentence the repetitions and muffled sounds force the reader himself/herself to stumble on words: "When a stammerer stammers their eyeballs pop out, they go trembly-red like an evenly matched arm wrestler, and their mouth guppergupperguppers like a fish in a net" ( $\$ 1$, emphasis added). Here, the back and forth of the tongue and mouth between the bilabial nasal $/ \mathrm{m} /$ and the alveolar approximant $/ \mathrm{r} /$ mirrors the movement of a gaping fish mouth. Jason creates his own intimate characterisation of the speech impairment, using markers of the generic aspect: the indefinite article "a" and unanchored simple present tense. For Pierre-Louis Patoine, abstract descriptions (philosophical as well as psychological) tend to create a distance between the work and the reader, stopping the reader from feeling overwhelmed (see Patoine 2015). Here, in spite of the use of the universal aspect of the sentence, this description is very concrete and personal, which is why it elicits a physical reaction within the reader.

This emphasis on physicality in Jason's "complex revised understanding" (Toolan 2012: 213) of the event generates what Patoine has called a "somesthesic" effect on the reader (Patoine 2015: 9). Patoine aims to study the semiotic, cognitive and neurophysiological structures that help build a mimetic relation between the real body of the reader and the bodies represented in fictional situations (ibid.: 9). The latter thus shows that while reading, comprehension and imagination provoke "ghost-like sensations" in readers (ibid.: 86). A literary work could then be conceived as some sort of simulation technology whose intensity is proportional to the empathetic link that binds us to the work. Depending on the topic and the literary devices used, somesthetic effects can be felt through different parts of the body: Patoine takes as an example the short story "Guts" by Chuck Palahniuk (Palahniuk 2005), which is likely to engage the reader's mind, heart and stomach (Patoine 2015: 165-191), and whose public readings frequently provoked nausea and fainting in the audience (ibid.: 9). Patoine's book is a descriptive endeavour as well as a prescriptive one: somesthetic sensations are part of what he calls "empathetic reading", which he defines as a reading technique, that can be worked on to improve the quality and intensity of the reading experience (ibid.: 12). It is 
to be understood as "a set of modes of reading characterised by more or less intense bodily engagement of the reader in literary fiction" (ibid.).

In this present extract, I would locate the somesthetic effects in the place of articulation: the larynx, windpipe, vocal folds, and nasal cavity are all under siege, even when reading the text silently. Indeed, Patoine analyses subvocalisation (the internal speech typically made when reading) as central to empathetic reading, leading to a communion of voices between narrator and reader. Subvocalisation is a phenomenon found mostly in readers that are faced with a word they have never encountered. That is why we are compelled to mark a pause on the words that David Mitchell makes up, such as the verb "gupper", which is duplicated to visually mimic stuttering, therefore transferring Jason's disorder to the reader. Adding to Patoine's argument, I would like to underline that empathetic reading as a technique has much to gain from the powerful practice of performing or hearing fiction, at any age. In this particular instance, whether subvocalising or reading aloud, I find myself stumbling, gasping for air, like a fish caught in a net. This empathetic reading, still according to Patoine, is to be distinguished from more intellectual approaches such as sympathy or identification (ibid.: 99-100). Experiencing first-hand the pressure of stammering on my throat, I empathise with Jason's medical and emotional trouble on a physical level.

\section{Conclusion: 'a raid on the inarticulate'}

Writing Cloud Atlas was something of a power move. But this extract will have shown, I hope, how Black Swan Green is able to move us powerfully during minor yet emotionally engaging 'accidents'. Thanks to a vivid visualisation of the traumatic moment, this text engages the reader in an empathetic and somesthetic response. In the same breath, Mitchell outlines a highly personal characterisation of a misunderstood disorder, presents himself as a smuggler of words, and celebrates his poetics of the accident.

In his conclusion to Dysfluencies: On Speech Disorders in Modern Literature, Chris Eagle addresses the "predominantly metaphorical purpose behind most literary representations of disordered speech," where speech impediments are "glorified" as a way to "disrupt language" (Eagle 2013: 159). By staying true to 
the youthful voice of his narrator, the author allows us to understand and empathise with Jason's condition and social anxiety without glorifying it. The potent yet fallible cognitive treatment of the stammer is weaved into the very fabric of the novel, so that disruptions and dislocations rarely appear contrived or overly literary.

"Words are the part of silence that can be spoken", wrote Jeanette Winterson in Lighthousekeeping (Winterson 2004: 135). At the delight and agony of the reader, this extract creates a sharp contrast between the spoken and the unspoken words. Jason's feelings of powerlessness and anxiety towards certain words are gradually overcome by his powerful storytelling. This tension is directly addressed at the end of the book, when he notes: "Words are what you fight with but what you fight about is whether or not you're afraid of them" (245). Throughout this quest for self-expression, Jason's coming of age is powered by an increasingly fearless approach to language - assertive 'raids on the inarticulate' - as Mitchell reclaims on paper all the words which would not come out. Black Swan Green does not give us a reassuring epilogue in which its young hero becomes a successful novelist like Mitchell grew up to be. What we are left with instead is the potentiality contained in repeated failure - to circle back to T.S. Eliot in his Four Quartets: "For us, there is only the trying. The rest is not our business." (Eliot 1943).

\section{References}

\section{Corpus}

Mitchell, David (2007 [2006]): Black Swan Green, New York: Random House Trade.

\section{Other works}

BBC Radio 4 (2007): "David Mitchell”, in: Bookclub, June 2007.

Begley, Adam/Mitchell, David (2010): "David Mitchell, The Art of Fiction No. 204", in: The Paris Review 193, https:/www.theparisreview.org/ interviews/6034/the-art-of-fiction-no-204-david-mitchell (Last accessed: 15.01.2020). 
Bissel, Tom (2004): "History is a nightmare", in: The New York Times, 29 August 2004, https:/www.nytimes.com/2004/08/29/books/history-is-a-nightma re.html (Last accessed: 02.07.2019).

Deleuze, Gilles (1994): "He stuttered.", in: Constantin V. Boundas/Dorothea Olkowski (eds.), Gilles Deleuze and the theater of philosophy, New York: Routledge.

Eagle, Chris (2013): Dysfluencies: On speech disorders in modern literature, Bloomsbury Publishing USA.

Eliot, Thomas S. (1943): Four quartets, New York: Harcourt.

Freudenberger, Nell (2006): 'Wonder year: 'Black Swan Green,' by David Mitchell", in: The New York Times, April 2006, https:/www.nytimes.com/ 2006/04/16/books/review/wonder-year.html (Last accessed: 15.06.2019).

Higashida, Naoki (2013): The reason I jump: The inner voice of a thirteen-year-old boy with autism, Random House.

Holcombe, Garan (2013): "David Mitchell: Critical perspective", in: British Council, https://iterature.britishcouncil.org/writer/david-mitchell (Last accessed: 16.06.2019).

Johnson, Jeffrey K. (2008): "The visualisation of the twisted tongue: Portrayals of stuttering in films, television, and comic books", in: The Journal of Popular Culture, 41 (2), 245-261.

Johnson, Wendell (1959): The Onset of Stuttering, Minneapolis \& Saint Paul: University of Minnesota Press.

Kuster, Judith Maginnis (2011): "At long last, a positive portrayal of stuttering", in: The ASHA Leader, 16 (2), 13-25, https://leader.pubs.asha.org/doi/10.104 4/leader.FTR2.16022011.13 (Last accessed: 16.01.2020).

Libby, Lisa K. et al. (2005): "Here's looking at me: The effect of memory perspective on assessments of personal change", in: Journal of Personality and Social Psychology, 88 (1), 50-62.

Mitchell, David (2004): Cloud Atlas, New York: Random House Trade.

- (2006): "Let me speak", in: The Telegraph, 30 April 2006, https://www.telegra ph.co.uk/culture/3652013/Let-me-speak.html (Last accessed: 15.06.2019).

- (2011): "Lost for words", in: Prospect Magazine, 23 February 2011, https://ww w.prospectmagazine.co.uk/magazine/david-mitchell-stammering-kings -speech (Last accessed: 12.04.21).

- (2017): "David Mitchell: What my son's autism has taught me", in: The Guardian, 8 July 2017, https://www.theguardian.com/society/2017/jul/o8/ david-mitchell-son-autism-diagnosis-advice (Last accessed: 15.06.2019). 
Mudge, Alden (2006): "David Mitchell: Seconde childhood", in: Bookpage, April 2006, https://bookpage.com/interviews/8342-david-mitchell\%23.W aiAlEpJaDU (Last accessed 12.05.2019).

Onslow, Mark (2016):Stuttering and its treatment: eleven lectures, University of Sydney.

- (2020): Stuttering and its treatment: eleven lectures, University of Sydney, htt ps://www.uts.edu.au/sites/default/files/2020-07/Stuttering\%20and\%20i ts\%20Treatment-Eleven\%20Lectures\%20\%28May\%202020\%29.pdf (Last accessed: 06.03.2021).

Palahniuk, Chuck (2005): "Guts”, in: Chuck Palahniuk, Haunted, New York: Anchor Books, 12-21.

Patoine, Pierre-Louis (2015): Corps/texte: pour une théorie de la lecture empathique. Cooper, Danielewski, Frey, Palahniuk, Lyon: ENS Éditions.

Smith, Ali (2006): "Neither sweet nor as simple", in: The Telegraph, 14 May 2006, https://www.telegraph.co.uk/culture/books/3652162/Neither-sweet -nor-as-simple.html (Last accessed: 02.06.2019).

Tisdale, Sallie (2013): "Voice of the voiceless", in: The New York Times, $23 \mathrm{Au}$ gust 2013, https://www.nytimes.com/2013/08/25/books/review/the-reaso n-i-jump-by-naoki-higashida.html (Last accessed: 13.05.2019).

Toolan, Michael (2012): "Engagement via emotional heightening in 'Passion': On the grammatical texture of emotionally-immersive passages in short fiction", in: The Ohio State University Press, 20 (2), 210-225.

Tykwer, Tom at al. (2012): Cloud Atlas, Warner Bros.

Urban Dictionary (2021): 'pinch', https://www.urbandictionary.com/define.p hp?term=pinch (Last accessed 18.04.2021).

Winterson, Jeanette (2004): Lighthousekeeping, New York: Fourth Estate/Harper Collins Publishers LLC. 


\section{Contributors}

Maryvonne Boisseau is Professor Emerita of the Université de Strasbourg (France) and a member of the research unit Linguistique, Langues, Parole. Her expertise lies in Linguistics, Irish poetry written in English, and Translation Studies. Her research focuses on translation especially by poets-translators (Carson, Mahon among others). She is particularly interested in the complex question of rhythm in language, its perception and translation. She has published numerous articles on Derek Mahon's poetry and translations, enunciative linguistics and translation in various journals and collected works.

Christine Chollier is Professor of American Literature and text semantics at the University of Reims (France). She has published studies in literature and translation. Her literary critical studies include papers on Cormac McCarthy, William Faulkner, Washington Irving, W. S. Merwin, Stephen Crane, Katherine Mansfield, Henry James, Ezra Pound, John Steinbeck, Margaret Atwood, Carson McCullers, Sherwood Anderson, Michael Connelly, Paul Auster, Fredrick Douglass and William Styron, as well as theoretical articles on semiotics, and translations.

Ciarán Kavanagh has recently finished his $\mathrm{PhD}$, "Refiguring ReaderResponse: Theorising Experience in Postmodern Fiction", which he completed under the supervision of Dr Alan Gibbs in University College Cork (Ireland). His research is oriented around reader-response theory, through which he focuses on the variability of reading experiences in contemporary Anglophone literature. His current research project concerns the idea of seriousness in the lay and critical cultures of science fiction, and the effect of this concern on experiences and interpretations of SF texts.

ORCID ID: 0000-0003-1168-0139 
Alice Labourg is professeur agrégée at Rennes-II University (France) where she teaches English to undergraduate and postgraduate students in arts and literature. Her research focuses on the relationships between literature and the visual arts, using a text-image approach which combines the formal analysis of textual poetics, linguistics and stylistics with art history, aesthetics and visual semiotics. She has published various papers on Ann Radcliffe and is currently finalising the publication of her PhD dissertation on the Gothic novelist.

María-Ángeles Martínez is Senior Lecturer in English Linguistics at the Universidad de Alcalá (Spain). Her research interests are in the fields of cognitive literary linguistics and cognitive narratology, and her work has been published in journals such as Language and Literature, Journal of Literary Semantics, Narrative, and Poetics Today. She is the author of Storyworld Possible Selves (2018), a volume that explores narrative engagement within cognitive linguistics and cognitive narratology paradigms. Previously, she lectured on English semantics, pragmatics, and discourse analysis at the Complutense University of Madrid (Spain).

ORCID ID: 0000-0001-6473-1249

Mahlu Mertens (she/her, they/them) is a theatre director, published poet, and literary scholar. Currently she is working at Ghent University (Belgium) as a doctoral candidate, where she explores how literature and theatre can overcome the challenges inherent in representing the multi-faceted and far-reaching phenomenon of climate change. The overall aim is to provide insight into a more diverse arsenal of literary strategies for depicting climate change than those on which most critical energy has been expended so far. Her research interests are contemporary fiction and the environmental humanities in general, and climate change fiction and eco-theatre in particular.

ORCID ID: 0000-0003-2448-0590

Kimberley Pager-McClymont is a PhD researcher in Stylistics at the University of Huddersfield (UK). She is a guest lecturer in Translation Studies and also teaches Academic English Skills for the International Study Centre at the University of Huddersfield. She graduated from the Universite de Cergy (France) with a B. A. in English Language and Literature, her M. A. was obtained from the University of Huddersfield. Her research interests are on figurative language, particularly the impact it has on readers and the process 
of characterisation. Her $\mathrm{PhD}$ aims to provide an updated model of pathetic fallacy using a stylistic approach and Conceptual Metaphor Theory.

ORCID ID: 0000-0002-6214-0995

Sixta Quassdorf got her PhD in English, at the University of Basel (Switzerland) and is currently a post-doc research assistance at the University of St. Gallen (Switzerland). She is author of 'A little more than kin'- Quotations as a linguistic phenomenon: A study based on quotations from Shakespeare's Hamlet (2016). Her present research explores the representation of work, workers and work relationships in contemporary American fiction.

ORCID-ID: 0000-0002-3555-9854

Constance Robert-Murail is writing a PhD thesis in Cultural Studies at Université Gustave Eiffel (France) within the LISAA lab on 21st-century comingof-age narratives. She focuses on the representation of African-American adolescence in contemporary verse novels and films. Her many interests include young adult fiction, spoken word poetry, psychology, sociolinguistics, songwriting, and narrative design in video games.

Elina Valovirta is a senior lecturer at the Department of English, University of Turku (Finland). She is the author of Sexual Feelings. Reading Anglophone Caribbean Women's Writing through Affect (2014) and co-editor of Thinking with the Familiar in Contemporary Literature and Culture 'Out of the Ordinary' (2019). She has published articles in journals such as The Feminist Review, Sexuality and Culture and The Journal of Commonwealth Literature.

ORCID ID: 0000-0002-0792-0876

Peter Wenzel was a professor and chair of English literature at RWTH Aachen University (Germany) until his retirement in 2019. He has published widely in the fields of Shakespeare studies, literary genres and literary theory. In alignment with a new orientation of the Aachen English department, his present research interests focus on reception studies, cognitive narratology and cognitive semantics.

Tahir Wood is an extraordinary professor in the Language Education Department at the University of the Western Cape (South Africa). He is the author of the books Elements of Hermeneutic Pragmatics: Agency and Interpretation (2015) and the forthcoming Philosophy of the Act and the Pragmatics of Fiction (2021). 



\section{Editors}

R. L. Victoria Pöhls is researcher at the Max Planck Institute for Empirical Aesthetics (Frankfurt). Her interest in studying literature with both hermeneutical and empirical methods evolved during graduate studies in Cognitive Science at the University College Dublin (Ireland) and Literature, Linguistics, and Philosophy at the Universität Hamburg (Germany). To foster interdisciplinary work at the frontiers of these disciplines, she co-founded the Powerful Literary Fiction Texts-Network in 2019.

Her research focuses on comparative, empirical, and cognitive approaches to literature and is especially concerned with the literary portrayal of marginalised groups. Additionally, she takes a great interest in developing implicit methods of testing for reader response studies. Publications cover the topics of political emotions elicited by art, transnational literary phenomena, exile literature, and (self-) censorship in Heinrich Heine and contemporary Iranian authors.

ORCID ID: 0000-0001-5464-3245

Mariane Utudji has completed a $\mathrm{PhD}$ thesis in English studies and translatology entitled "Salman Rushdie's Baroque Style and its French Translation: A Stylistic and Translatological Study of Midnight's Children" at the Sorbonne Nouvelle University, a work which investigates Salman Rushdie's highly valued prose style and aims to find out how the reading experience it provides can be retained or recreated in French. Her approach to literary texts thus combines stylistics, applied linguistics and translation studies, and she is getting more and more interested in cognitive linguistics.

As a qualified teacher of English, she has taught many courses in translation and English linguistics at the Sorbonne Nouvelle University, and she also practises literary translation. 


\section{Index}

A

A Lighthouse in Maine, 133, 135, 142 Abbott, H. Porter, 113 actional outcomes, 32,34

adolescence, 69, 242 aesthetic emotion, 28, 29 aestheticization, 87,88 aesthetics of boredom, 196 affect, 28, 29, 32, 55, 57, 78, 79, 191, 203, 226

agon of authorship, 168-170

Alberti, Leon Battista, 149

Amis, Martin, 93

anger, 28

Anthropocene, 64, 68

antidemocratic PR strategies, 194

anxiety, 236, 241, 246

Arasse, Daniel, 155, 157

archival, see archive

archive, 65, 69, 71, 74

archive, geological, 64, 66, 69

arousal, 18, 50, 56-58, 89, 90

Art Notes, 133

attention, 15, 16, 18, 20, 46, 51, $66,68,80,115,130,142$, $174,184,190,192,195$, 196, 199, 200, 202, 203, 209, 214-216, 224, 226, 228
Austin, J. L., 169, 170

authorial intention, see intention

awe, $85,86,88,139,154$

B

Bakhtin, Mikhail, 86, 87, 89, 171-173, 175, 183

Baldick, Chris, 112

Ballard, J.G., 19, 77, 80, 84-88, 90, 91, 93

Barthes, Roland, 149, 174, 175

Baudrillard, Jean, 84, 90

Beardsley, Monroe C., 174

beautiful (the), 146, 147, 152, 154, 155

Benveniste, Émile, 130

Besson, Françoise, 161

biology, 27, 32, 33

Black Swan Green, 21, 233-236, 240-243, 245, 246

blurb, see paratext

Bolaño, Roberto, 20, 21, 207-210, $213,219,223,227$

Booth, Wayne, 80

boredom, 190-192, 198, 202, 203

boring, 20, 90-92, 191, 193, 195, 196

Boswell, Marshall, 190-193

Boulez, Pierre, 142

Brontë, Charlotte, 111, 112, 117, 118 
Brown, Calvin S., 112

Brown, Marshal, 182

bureaucracy, 191

Burgess, Anthony, 93

Burke, Edmund, 39, 152

Burn, Stephen J., 192, 195

C

Canning, Patricia, 78

Carr, Garrett, 133, 135-140, 142

Carroll, Noël, 86

catharsis, 92

Cauquelique, Anne, 149

characterisation, 19, 112-115, 117, $122-124,182,234,238$, 244,245

Charbonnier, Louise, 149

Clare, Ralph, 190-192, 196

cognitive science, 17, 78, 81

coherence, 20, 185, 243

Conceptual Metaphor Theory, 112, 123,124

conceptual reader, $80-82$

Conners, Juliana, 48, 50, 61

consumers, $48,57,58,204$

convention, $48,51,54,56,73,87$, $171,172,184,193,201$

Cord, Florian, 88, 89, 91

Cosette, Claude, 155

counterfactual conditions, 184

Craig, Patricia, 9, 133

Crash, 19, 80, 84-86, 88-93

cross-domain mapping, 123, 124

Culioli, Antoine, 12, 130, 131

Culler, Jonathan, 173, 193

Culpeper, Jonathan, 113, 115, 124

culture, 13, 27, 33, 36, 70, 131, 158, $176,182,191,241$
D

Del Lungo, Andrea, 145, 149

Derrida, Jacques, 71, 148

dialogic, 138, 198, 217

dialogue, 52, 138, 172, 178, 183, 195, 197, 199, 233, 238, 239, 241

Diaz-Vera, Javier E., 123

digital literature, 18, 47, 58

digital reading, 18, 55, 57

discourse presentation, 112, 114, $115,118,122,124$

disgust, 28, 29, 85-90, 92, 101

disorder, 234, 236, 237, 245

distancing effect, 39

dull, 190, 191, 196, 201, 203

dullness, 190, 192, 194, 199, 201

Durant, David, 147

E

easy read, 57

ecological elegy, 64, 73, 74

elegy, 65, 70, 71, 73, 74, 107

Elia, Adriano, 146

ellipsis, 73, 222, 225, 226

Ellis, Bret Easton, 182

Ellroy, James, 168, 169, 177-180

embodied effects, 89, 91-93

embodied experience, $80,85,89$, 155

embodied memory, 71, 73

embodied perception, 31

embodiment, 11, 19, 106, 142

emotion, 13, 18, 26-29, 31, 38, 39, $57,72,79,86,112,113$, $115,116,118,123,124$, 132, 212, 213, 239, 240, 242 
empathetic reading, 244,245

empathy, 20, 21, 130, 233, 234, 237, 241,244

empirical research, 16, 17, 39, 57, 185

enchantment, 57

enjoyment, 57, 58, 91, 171, 173, 184

enunciation, 19, 103, 130, 131, 134, 141,142

Epstein Heller, Lynne, 153

erotic, $36,46,48,50,53-55,57,85$, 86,90

erotic (the), 89

e-book, 48

evolutionary psychology, 27

experience verbs, 31

experientiality, 31, 220

extinction, 19, 65, 67, 70, 72, 73

\section{$\mathbf{F}$}

fascination, $18,29,33,34,50,81$, 101, 185

fear, $28,29,31-35,88,90,154,203$, $212,234,237$

Felski, Rita, 57

fetish, 85,89

Fetterley, Judith, 79, 81

figurative language, 112-114, 122-124

Fish, Stanley, 79, 81

Fitzgerald, F. Scott, 100-102, 106-108, 182, 183

Flaxman, Rhoda, 146

Fludernik, Monika, 176, 177, 180

foregrounding, $15,31,37,58,72$, 114, 115, 117-119, 121, 134, 135, 199, 201

Foucault, Michel, 88, 174, 175
Fowles, John, 171, 172

free indirect discourse, 171, 177

G

Gallagher, Catherine, 168

gap-filling, 18, 54, 68

Garner, Bryan Andrew, 122

gaze, $20,32,34,35,38,84,86,146$, 147, 149-151, 155, 157, 158,199

Genette, Gérard, 148

genre, 15, 17-19, 39, 47, 49, 52, 53, $55,57,83,84,89,129$, $130,156,170,173,175$, 177

George, Anne, 113

Gilbert, Sandra M., 120

Gilpin, William, 147

Gothic (the), 18, 27-29, 33, 34, 39, $146,151,153,155,158,159$

grotesque, $39,85-87,89,90,103$, 104

Groupe $\mu, 157$

Groussier, Marie-Line, 131, 137

$\mathbf{H}$

Haidt, Jonathan, 87, 88

Halliday, Michael A.K., 11, 117

Hamon, Philippe, 149, 151, 155

Harding, Jennifer Riddle, 79

Harkin, Patricia, 79

Harvey, William J., 112

Hayes-Brady, Clare, 192, 195, 201

hearer, 130, 132, 214, 218

Holland, Norman, 79, 212

Hopper, Edward, 133, 134, 140

horror, 18, 27, 29, 30, 32, 34, 36, 38, $39,88,181$ 
humour, $21,85,124,236$
Hussey, Christopher, 154, 155, 158
hypothesis, 11, 14-17, 100, 107, 130, 223

\section{I}

iconic sign, 157

iconicity, 19, 116, 117, 123, 124, 150

iconotext, 146, 156, 157

iconotextual landscape, 146

identification, 20, 31, 104, 107, 139, $142,195,224,245$

idiosyncratic, 16, 171, 212, 213, 237, 238,243

imagery, 87, 112, 115, 116, 118, $122-124,160$

implied reader, 80,100

information overload, 190, 192

informed reader, 80

intention, $20,37,80,81,92,169$, $170,174,193$

interpretation, 11, 13-16, 67, $78-80,83,85,89,91$, 101, 107, 115, 130, 141, 194, 197

interpretive frameworks, 19, 83, 84, 88-91, 93

intersubjective cognitive coordination, 209, 213, 214, 223, 224

intertextuality, 30, 185, 240

irrelevance, 192, 194, 199, 202

irrelevant, 14, 190-193, 197, 200, 202

Iser, Wolfgang, 79, 80, 100, 194
J

Jane Eyre:

An autobiography, 19, 112, 114-117, $119,120,122-124$

Jeffries, Lesley, 112, 114, 116

Johnson, Mark M., 123

K

Kafka, Franz, 181

Keltner, Dacher, 87, 88

Knight, Lionel C., 112

Körtvélyessy, Lívia, 117

Kövecses, Zoltán, 123

Kristeva, Julia, 88

Künstlerroman, 243

L

Lacan, Jacques, 159

Lakoff, George, 123

Lapaire, Jean Rémi, 148

LeClair, Tom, 195, 199

Leech, Geoffrey, 11, 54, 113-120

Lévy, Maurice, 146, 158

Lewis, C. S., 192

Lewis, Matthew Gregory, 26, 29-32, 34, 36-39

limbic system, 28

list, 18, 65, 67-73, 123, 152, 155

Lodge, David, 115

Lorrain, Claude, 152, 153

Los Detectives Salvajes, see The Savage Detectives

Louvel, Liliane, 146-148, 157, 158

M

Mahon, Derek, 130, 133-140, 142

manipulation, 57, 194, 201 
Margolin, Uri, 113, 212

McCaffery, Larry, 191, 196, 199

McIntyre, Daniel, 114

Mellmann, Katja, 27, 28

memory, 67, 70-73, 161, 203, 236,

$$
237
$$

menage romance, see romance

Menninghaus, Winfried, 13, 16, 17, 28,29

metaphor, 33, 35, 85, 113, 123, 132, $149,159,160,220,242$

Mettinger-Schartmann, Elke, 115 Mey, Jacob, 176

milieu, 169, 178-180, 182-184, 195

mimesis, 195

mimetic, 157, 191, 198, 203, 204, 212,244

mimic, 118, 119, 123, 190, 197, 245

Mitchell, David, 21, 232-235, $238-243,245,246$

Mitchell, Thomas W. J., 157

mixed emotions, 18, 29, 101

model reader, 14

monologue, 21, 53, 54, 65, 66, 240

monotony, 20, 190, 192, 196, 203

Morreal, John, 173

moving, 13

Mukařovský, Jan, 114

\section{$\mathbf{N}$}

narrative urgency, 30

narrative viewing arrangement, 215

neural activation, 38

neuropsychology, 27

non-fictional, 65, 100

non-human, 66, 72-74, 181

Nünning, Vera, 129, 130 o

Ontroerend Goed, 18, 64-68, 72 oral performance, 13, 130, 134, 140 Orwell, George, 181

$\mathbf{P}$

parallelism, 16, 37, 114, 115, 117, 118, 159

paratext, 54, 91, 93

pathetic fallacy, 19, 114-116, 118, $122-124$

paying attention, 191, 192, 203

performance, $13,55,65,66,69$, $130,131,134,140,142$, 170,240

persuasion, 130

pictoriality, 20, 156-158

picturesque, $20,146-148,150,152$, 155

plastic sign, 157

pleasure, 11, 18, 29, 47, 50, 55-58, 129, 132, 192, 195-197, 234, 238

poem, 13, 19, 30, 36-38, 130-135, $137,138,140-142,233$, 242

poetic, 12, 16, 104, 134, 136, 138, 141, $142,159,160,210,226$, $227,234,241,242$

poetics, 16, 80, 148, 158, 245

poetry, 13, 19, 21, 117, 132, 134, 141, $146,153,209,218,219$, $234,237,240-242$

points of prosodic condensation, $20,130,132,136,140$

pornography, 46-48, 51, 53, 85, $89-92$

Portner, Paul, 122 
post-structuralism, 174, 176 pragmatics, 168, 169, 173-176, 185 pragmatics of fiction, 20, 169 present tense, 72-74, 119, 198, 244 proleptic, 19, 64, 66, 74, 102, 103, 147

prose, $9,11,13,18,19,130,132-135$, 137, 139-141, 219, 227, 233, 237, 241-243

psychological outcomes, 32,35 psychology, 17, 27, 78, 80, 83, 107, $133,174,212,233$

\section{$\mathbf{R}$}

Radcliffe, Ann, 20, 145-147, 152, $153,155-157,160,161$

reader-performer, 130,138

reader-response, $11,17,19,78-82$, 84,85

reading aloud, 9, 13, 129, 245

reading situation, 15,17

realism, 18, 102, 181, 182, 196, 210

realism, radical, 195, 199, 201, 203

realistic, 30, 181, 182, 195, 197

reality, $72,80,82,122,136,145,148$, 158, 196

reception theory, 81

relevance, 115, 192-195, 197, 199, 201, 202, 204, 209, 213

repertoire, $69,71,73,151$

repetition, $18,37,46-48,55,71,73$, $118,139,156,159,193$, 201, 203, 222, 225, 227, 235, 239

revelation, 102, 184, 209, 217

rhyme, 37, 132, 140, 237

Rhys, Jean, 184 rhythm, 18, 19, 70, 73, 116, 121, 130, 131, 134, 139-142, 160, 200, 237

Riffaterre, Michael, 80, 100

Roger, Alain, 149

Rogers, Deborah, 146, 153, 161

romance, 18, 29, 46-52, 54-58, 61

Rosa, Salvator, 152-154

Rose, Gillian, 168

Rosenblatt, Louise, 79, 81

Rubik, Margarete, 115

Ryan, Marie-Laurie, 170, 171

\section{S}

sadness, 19, 28, 29, 72, 74, 123, 124

Salbayre, Sébastie, 12

Schechet, Nita, 194

Scott, Clive, 130, 131, 142

Searle, John, 169, 170

Self, Will, 93

semantics, 100, 107, 131, 140, 200, 201

Senn, Fritz, 198

sex, 46, 47, 50, 51, 53-56, 61, 84-87, 89,90

sexual fantasy, 46-48, 57

Short, Michael N., 113-120

significance, 11, 13, 27, 28, 39, 92, $117,120,133,134,136$, $138,141,155,176$

silence, 31, 32, 38, 73, 106, 142, 235, 243, 246

Simpson, Paul, 17, 30, 114

skeletal narrative, 192, 201-203

Smith, David Nowell, 132

Smith, Zadie, 93

Sobchak, Vivian, 84

somesthetic effects, 244, 245 
Sorlin, Sandrine, 9, 12-14

sound, 16, 31-33, 37, 66, 117, 118, $123,124,140,155,160$, 174, 199, 200, 233, 237, 239,244

Sparks, Sierra, 48, 50, 61 speech, 21, 31, 103, 112-114, $118-120,122,123,131$, 142, 169-171, 173, 175, $176,178-180,182,217$, $233,235-240,242-245$

speech act, 169, 170, 173, 175, 176 speech act theory, 169, 170, 175, 176 Sperber, Dan, 192-194, 202 SPS grounding, 217, 218, 223 SPS linguistic anchors, 208, 209, 211, 215, 216, 218, 219, 227

SPS node, 217, 219, 223, 226, 227

SPS objectification, 211, 215-217, $219,222-226$

SPS subjectification, 215-218, 220, 223, 224, 226, 228

SPSs (storyworld possible selves), 208, 211-213, 218, 226, 227

Sternberg, Meir, 173

Stoichita, Victor, 149

stutter, see stuttering

stuttering, 233, 234, 237, 238, 241,

$$
243,245
$$

stylistic features, 15, 18-20, 65, 69,

$$
71-73,117,123
$$

stylistics, 12, 16, 78, 114

sublime, 39, 68, 86, 88, 90, 147, 152, 154,156

sublime (the), $85,146,152,154-156$ superreader, 80 suspense, $18,27,30,34,38,39,49$

sympathy, 20, 245

\section{$\mathrm{T}$}

taboo, 29, 36, 49, 58, 88-90

The Cold Six Thousand, 177

The Great Gatsby, 19, 100, 101

The Monk, 18, 29

The Mysteries of Udolpho, 20, 145147, 161

The Pale King (TPK), 190-204

The Rule of the Land, 133

The Savage Detectives, 20, 208, 210, $216,225,227$

threesome, 18, 46-50, 52, 53, 55

Toolan, Michael, 9, 108, 114, 209, $217,234,244$

tragedy, 92, 102, 106, 220

transformation, 85, 88, 101, 107, 109, 213

translation, 21, 130, 208-210, 217, 219-224, 226-228

Two Billionaires for Christmas, 48, 50-54, 61

\section{U}

utterance, 12, 108, 131, 132, 157, 171, 214, 239

\section{W}

Wales, Katie, 114, 116

Wallace, David Foster, 20, 190-204, 210

Walsh, Richard, 180, 181

Warren, Andrew, 201

Whiteley, Sarah, 17, 78

Wilson, Deirdre, 192-194, 202

Wimsatt, William, 174 
Woolf, Virginia, 129, 132

World Without Us, 18, 64, 65, 68, 74

Wouters, Conley, 191, 192, 195

Z

Žižek, Slavoj, 172 


\section{Cultural Studies}

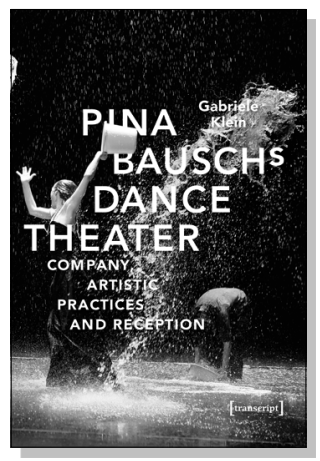

Gabriele Klein

Pina Bausch's Dance Theater

Company, Artistic Practices and Reception

2020, 440 p., pb., col. ill.

29,99€ (DE), 978-3-8376-5055-6

E-Book:

PDF: 29,99 € (DE), ISBN 978-3-8394-5055-0

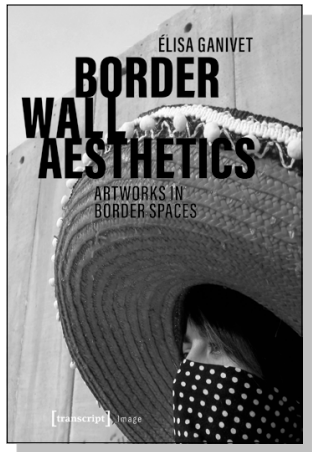

Elisa Ganivet

\section{Border Wall Aesthetics}

Artworks in Border Spaces

2019, 250 p., hardcover, ill.

79,99€ (DE), 978-3-8376-4777-8

E-Book:

PDF: 79,99€ (DE), ISBN 978-3-8394-4777-2

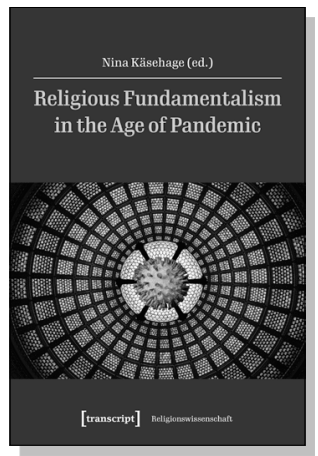

Nina Käsehage (ed.)

\section{Religious Fundamentalism} in the Age of Pandemic

April 2021, 278 p., pb., col. ill. 37,00 € (DE), 978-3-8376-5485-1

E-Book: available as free open access publication PDF: ISBN 978-3-8394-5485-5 


\section{Cultural Studies}
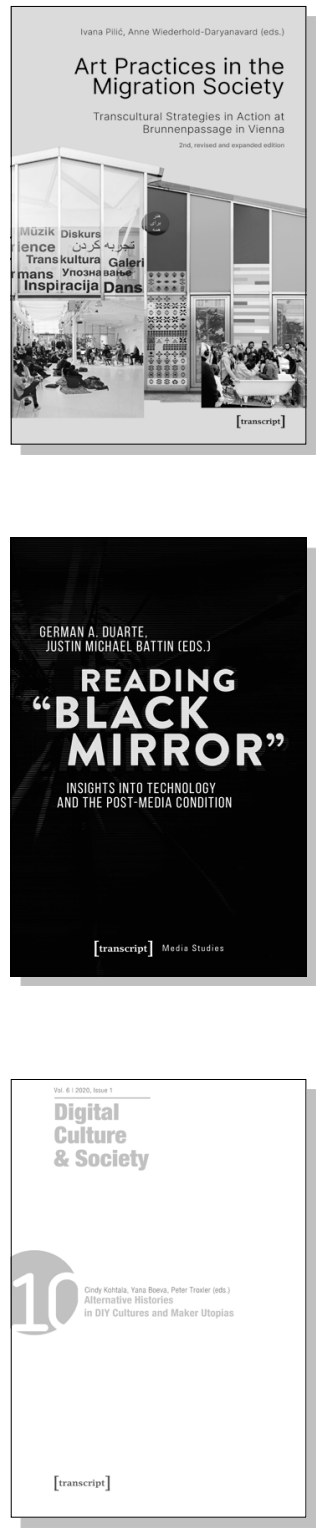

Ivana Pilic, Anne Wiederhold-Daryanavard (eds.) Art Practices in the Migration Society Transcultural Strategies in Action at Brunnenpassage in Vienna

March 2021, 244 p., pb.

29,00€ (DE), 978-3-8376-5620-6

E-Book:

PDF: 25,99€ (DE), ISBN 978-3-8394-5620-0

German A. Duarte, Justin Michael Battin (eds.)

\section{Reading "Black Mirror"}

Insights into Technology and the Post-Media Condition

January 2021, 334 p., pb.

32,00€ (DE), 978-3-8376-5232-1

E-Book:

PDF: 31,99 € (DE), ISBN 978-3-8394-5232-5

Cindy Kohtala, Yana Boeva, Peter Troxler (eds.)

\section{Digital Culture \& Society (DCS)}

Vol. 6, Issue 1/2020 -

Alternative Histories in DIY Cultures and Maker Utopias

February 2021, 214 p., pb., ill.

29,99€ (DE), 978-3-8376-4955-0

E-Book:

PDF: 29,99€ (DE), ISBN 978-3-8394-4955-4 
